\author{
UNIVERSIDADE DE SÃO PAULO \\ ESCOLA DE ENGENHARIA DE SÃO CARLOS
}

\title{
SISTEMAS DE INFORMAÇÕES \\ GEOGRÁFICAS PARA PLANEJAMENTO DE TRANSPORTES
}

ANTÔNIO NÉLSON RODRIGUES DA SILVA

Texto apresentado à Escola de Engenharia de São Carlos da Universidade de São Paulo como parte dos requisitos para obtenção do título de Livre-Docente em concurso realizado pelo Departamento de Transportes.

\author{
SÃO CARLOS \\ 1998
}


Ficha catalográfica preparada pela Seçăo de Tratamento da Informação do Serviço de Biblioteca - EESC-USP

$5586 \mathrm{~s}$

Silva, Antônio Nélson Rodrigues da

Sistemas de Informações Geográficas para planejamento de transportes / Antônio Nélson Rodrigues da Silva. -- São Carlos, 1998.

Texto apresentado à Escola de Engenharia de São Carlos da Universidade de são Paulo como parte dos requisitos para obtenção do título de Livre-Docente em concurso realizado pelo Departamento de Transportes.

1. Sistemas de Informações Geográficas.

2. SIG-T. 3. Planejamento de transportes.

4. Modelos de transportes. 5. Custos urbanos.

6. Acessibilidade. I. Título. 
UNIVERSIDADE DE SÃO PAULO

ESCOLA DE ENGENHARIA DE SÃO CARLOS

\section{SISTEMAS DE INFORMAÇÕES \\ GEOGRÁFICAS PARA PLANEJAMENTO DE TRANSPORTES}

ANTÔNIO NÉLSON RODRIGUES DA SILVA

Texto apresentado à Escola de Engenharia de São Carlos da Universidade de São Paulo como parte dos requisitos para obtenção do título de Livre-Docente em concurso realizado pelo Departamento de Transportes.

SÃO CARLOS

1998 


\section{AGRADECIMENTOS}

- À Léa, uma vez mais, pelo incentivo, paciência, dedicação e pela incrível disposição para enfrentar os desafios ao meu lado;

- Ao David, meu filho, que aprovou este trabalho (pelo menos nunca disse uma palavra contra ele);

- A todos do Urban Planning Group da Universidade de Eindhoven, na Holanda, em especial ao Professor Harry Timmermans e ao amigo Peter van der Waerden, com quem venho trabalhando mais diretamente;

- À amiga Engenheira Eliane Viviani, pela amizade e pelo apoio;

- Aos amigos, e que por acaso também foram, em algum momento, meus orientados, Adriana, Ana Paula, Archimedes, Claúdia, Cléber, Cristina, Elias, Elioth, Gislaine, Henrique, Jônatas, Leni, Luiz Álvaro, Maurício, Nadja, Raphael, Renato, Sandro, Sérgio e Vânia;

- Às agências de fomento à pesquisa CAPES, CNPq e FAPESP, que têm apoiado meu trabalho de diversas maneiras, em diferentes momentos;

- Aos funcionários do Departamento de Transportes da EESC-USP, Sr. Ângelo, Angélica, Carlos, "Fio", Heloísa, Lílian, Magali, Nelson, Sueli Aparecida, Sueli Regina e Vicente, cujo apoio foi crucial para a conclusão deste trabalho no prazo previsto;

- A todos os professores do Departamento de Transportes da EESC-USP, em especial ao Professor Glauco, que me apoiou na Coordenação de Pós Graduação enquanto estive me dedicando a este trabalho; ao Professor Felex, que me incentivou a galgar mais esta etapa da carreira docente; e aos Professores Coca, Edson, Eiji, Setti e Widmer, com quem estou sempre aprendendo algo de novo na área de Planejamento de Transportes;

- A todos aqueles que, direta ou indiretamente, colaboraram para a conclusão deste trabalho. 


\section{SUMÁRIO}

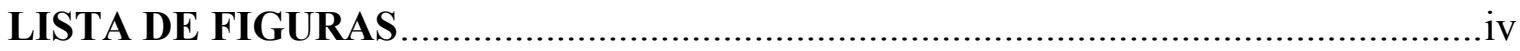

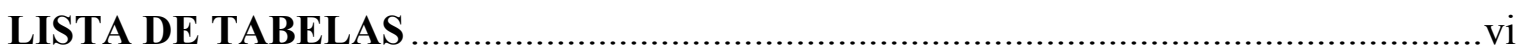

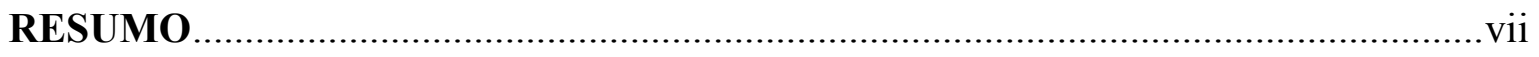

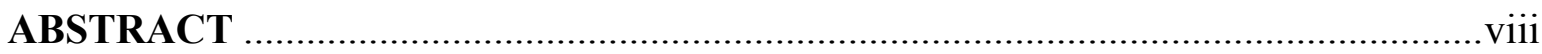

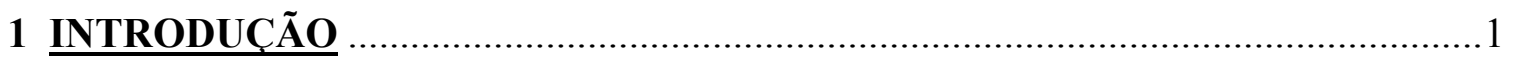

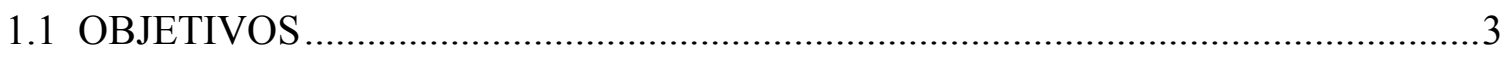

1.2 A INSERÇÃO DO SIG NA LINHA DE PESQUISA ORIGINAL DO AUTOR.........3

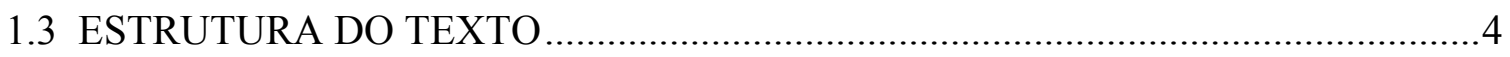

2 OS SISTEMAS DE INFORMACÕES GEOGRÁFICAS

NO PLANEJAMENTO DE TRANSPORTES ................................................

2.1 OS SISTEMAS DE INFORMAÇÕES GEOGRÁFICAS ......................................... 7

2.2 OS SISTEMAS DE INFORMAÇÕES GEOGRÁFICAS E O PLANEJAMENTO DE TRANSPORTES ................................................ 9

2.2.1 A Experiência Brasileira até 1995 ........................................................................... 11

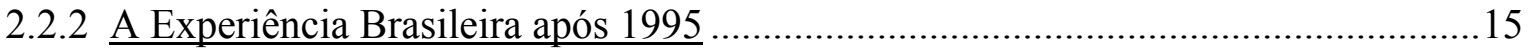

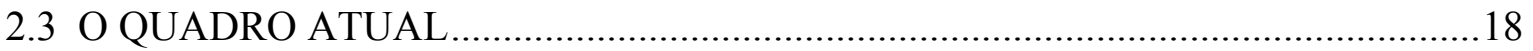

\section{AS PRIMEIRAS APLICACÕES DE SIG NO}

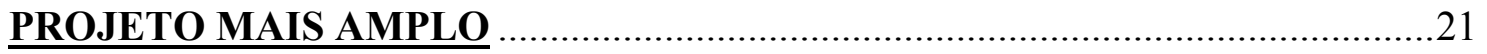

3.1 UM MODELO SIMPLIFICADO DE TRANSPORTE PÚBLICO URBANO............22

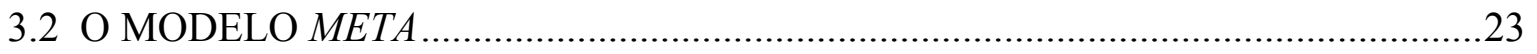

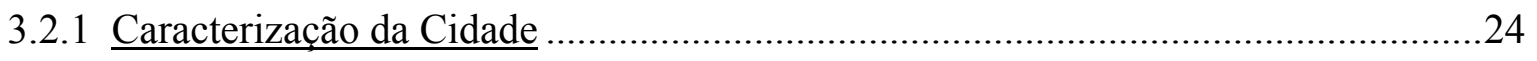

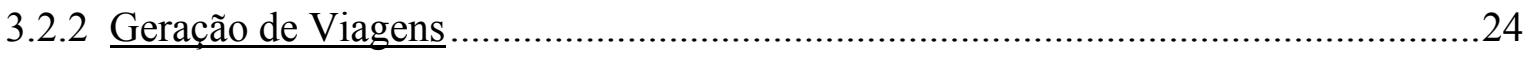

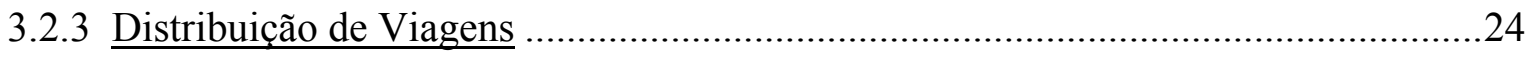

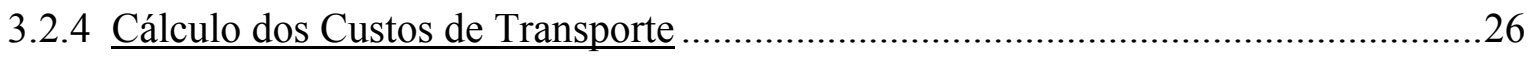

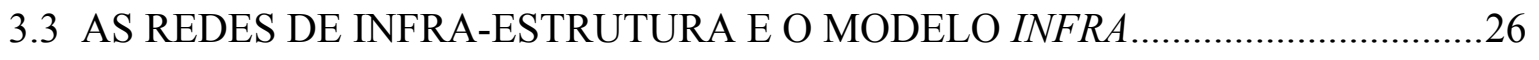

3.4 A ESTRATÉGIA DE TRIBUTAÇÃO DA PROPRIEDADE URBANA......................27 
3.5 UMA AVALIAÇÃO DOS CUSTOS DECORRENTES

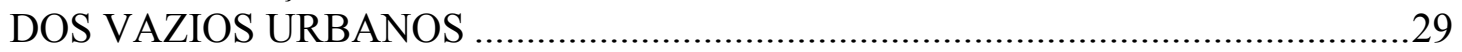

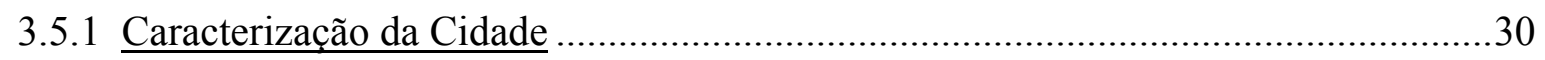

3.5.1.1 Levantamento de Dados Sobre o Adensamento Populacional Urbano .....................31

3.5.1.2 Levantamento de Dados Sobre Níveis de Renda da População ..............................32

3.5.1.3 Caracterização das Zonas de Tráfego....................................................................34

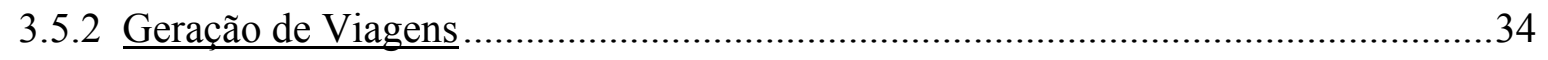

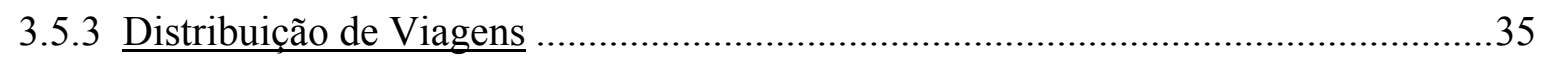

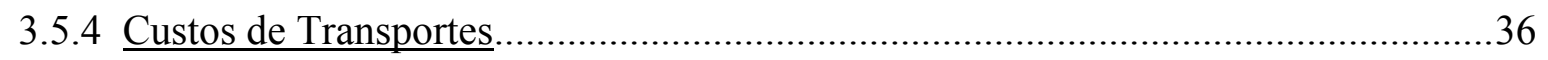

3.5.5 Aplicação do Modelo META para a Cidade de Araraquara ……………………….......37

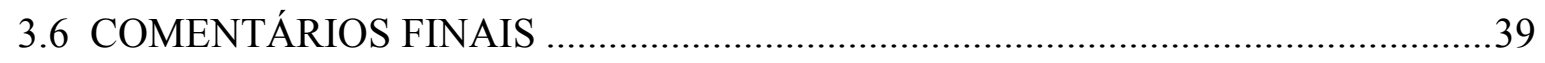

4 COMBINANDO OS MODELOS META E INFRA COM UM SIG …………….......41

4.1 ADAPTAÇÃO DO CONJUNTO ORIGINAL DE DADOS PARA O SIG ................41

4.1.1 Caracterização da Cidade ......................................................................................42

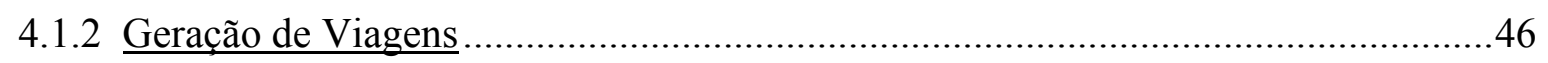

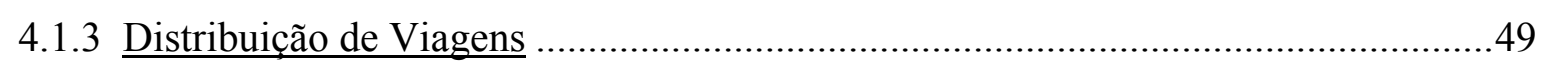

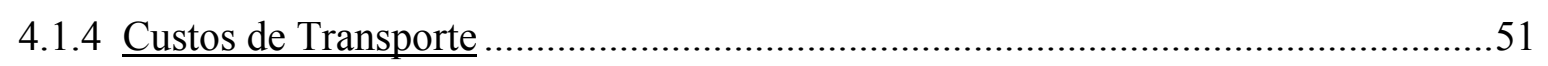

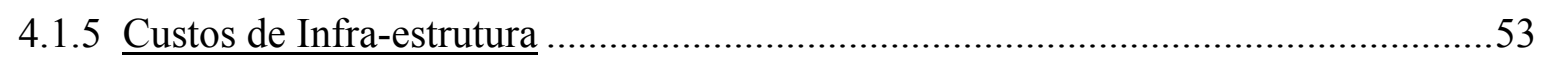

4.2 UTILIZANDO A COMBINAÇÃO SIG-T + META + INFRA ………............................

4.2.1 Cenários Construídos com o Conjunto Original de Dados ……………………….....54

4.2.2 Cenários Construídos com Dados Reais.....................................................................57

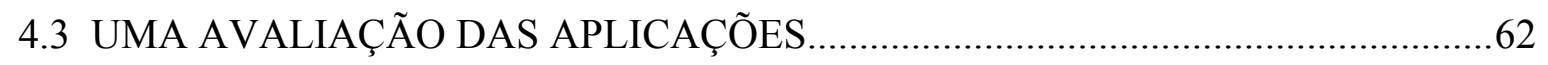

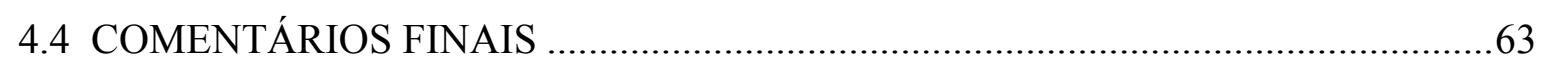

5 AVALIANDO A ACESSIBILIDADE AO TRANSPORTE ……………………......66

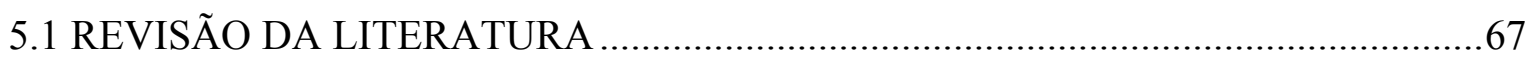

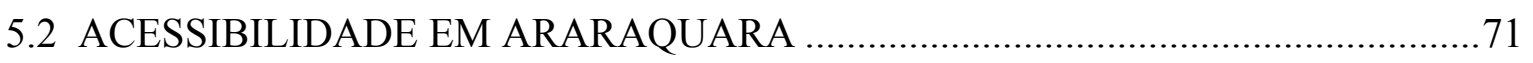

5.2.1 Distância ao Centro da Cidade ................................................................................72

5.2.2 Distância à Rota de Ônibus Mais Próxima …………………………………….........72

5.2.3 Uma Medida de Oferta do Transporte Público..........................................................75

5.2.4 Percentual de Ruas Pavimentadas em Relação à Extensão Total de Ruas..................76

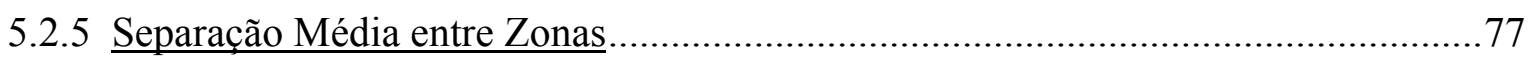

5.2.6 Medida de Acessibilidade do Tipo Gravitacional ....................................................78

5.2 .7 Isolamento 


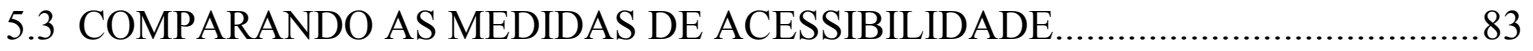

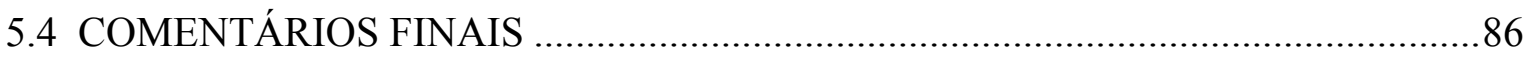

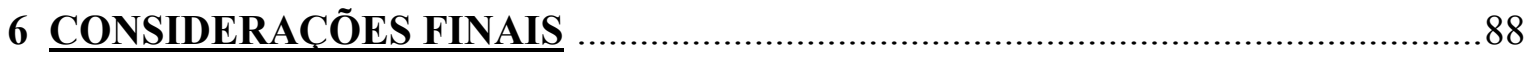

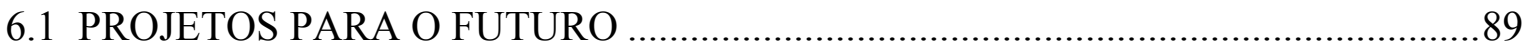

6.1.1 Introdução da Acessibilidade em Modelos de Avaliação de Imóveis........................89

6.1.2 Evolução Urbana e Acessibilidade - O Caso das Cidades Médias Brasileiras .........90

6.1.3 Acessibilidade, Mobilidade e Desigualdade Social ................................................91

6.1.4 Um Estudo Comparativo de Programas de SIG-T …................................................92

6.1.5 Desenvolvimento de Material Didático para a Introdução de um SIG-T em Cursos de Engenharia Civil .........................................................................99

6.1.6 Avaliação de Desempenho de Algoritmos de um Programa Comercial para Roteirização de Veículos ..............................................................................93

6.1.7 Um Sistema de Apoio à Decisão para Implantação e Uso de Infra-estrutura Pontual em Cidades Médias Brasileiras ........................................93

6.1.8 Sistema Informatizado de Consulta para um Sistema de Transporte Público............94

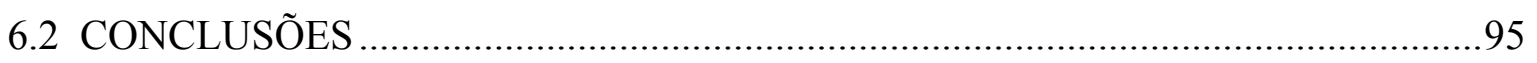

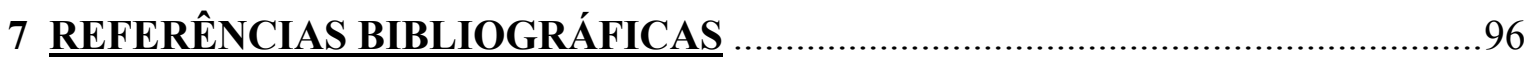




\section{LISTA DE FIGURAS}

Figura 2.1 - Formas de representação de dados espaciais ................................................

Figura 2.2 - Descrição dos módulos de um tutorial para o software TransCAD 3.0...........19

Figura 3.1 - Setores de atendimento e rotas de transporte público urbano ..........................23

Figura 3.2 - Zonas hipotéticas, com os seus centróides e as ligações entre zonas ...............25

Figura 3.3 - Variação do custo de infra-estrutura, por hectare, em função da densidade populacional, para cidades médias brasileiras (Fonte: Mascaró, 1979).........27

Figura 3.4 - Esquema mostrando os contornos das cidades real e de referência .................28

Figura 3.5 - Mapa de níveis de adensamento populacional em Araraquara.........................32

Figura 3.6 - Localização dos transformadores de energia elétrica pesquisados

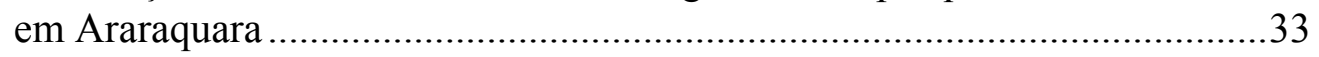

Figura 3.7 - Esquema mostrando as zonas da cidade atual - Configuração Real ................38

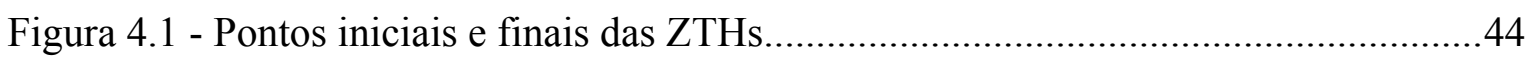

Figura 4.2 - Representação das Zonas de Tráfego Homogêneas de 44

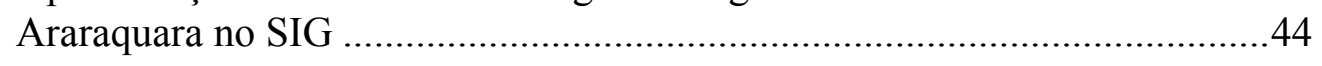

Figura 4.3 - Rede em grelha adaptada do modelo META para o SIG ...................................45

Figura 4.4 - Distribuição de viagens por automóvel resultantes do processo de calibração com as opções disponíveis para o modelo gravitacional no SIG TransCAD

Figura 4.5 - Representação da rede de transporte público criada a partir da rede em grelha e das Zonas de Tráfego Homogêneas adaptadas do modelo META para o SIG.

Figura 4.6 - Distribuição de viagens por ônibus resultantes do processo de calibração com as opções disponíveis para o modelo gravitacional no SIG TransCAD

Figura 4.7 - Cenário da cidade real (38 zonas) e 23 cenários para a cidade de referência construídos para a cidade de Araraquara

Figura 4.8 - Custos diários de viagens por ônibus para o cenário da cidade real

(38 zonas) e para outros 23 cenários da cidade de referência

Figura 4.9 - Custos das redes de infra-estrutura para o cenário da cidade real (38 zonas) e para outros 23 cenários da cidade de referência

Figura 4.10 - Representação das Zonas de Tráfego Homogêneas retangulares e reais de Araraquara

Figura 4.11 - Rede real da cidade de Araraquara digitalizada no SIG a partir de um mapa em papel. 
Figura 4.12 - Representação da rede de transporte público, criada a partir da rede de vias reais e das Zonas de Tráfego Homogêneas, digitalizadas a partir de mapas em papel.

Figura 4.13 - Custos diários de viagens de ônibus para o cenário da cidade real (38 zonas) e para outros 23 cenários da cidade de referência, em dois diferentes tipos de rede

Figura 4.14 - Opções de cenários para a cidade de referência com 31, 26, 21 e 15 zonas, com a real configuração das zonas de tráfego.

Figura 4.15 - Opção de cenário para a cidade de referência vista em conjunto com a rede de trólebus existente

Figura 5.1 - A tipologia dos indicadores de acessibilidade (adaptado de Morris et al., 1979)

Figura 5.2 - Menores caminhos entre as zonas e o centro da cidade de Araraquara............73

Figura 5.3 - Mapa temático mostrando as distâncias das zonas ao centro da cidade...........73

Figura 5.4 - Conjunto de rotas de ônibus na cidade de Araraquara ...................................74

Figura 5.5 - Mapa temático mostrando as distâncias entre os centróides das zonas e a rota de ônibus mais próxima.

Figura 5.6 - Mapa temático mostrando a relação entre CO - Comprimento total das rotas de Ônibus - e CR - Comprimento total das Ruas em cada zona..

Figura 5.7 - Mapa temático mostrando a relação entre o comprimento de ruas não pavimentadas e o comprimento total das ruas....

Figura 5.8 - Mapa temático mostrando a separação média entre centróides de zonas com base na rede completa de ruas

Figura 5.9 - Mapa temático mostrando a separação média entre centróides de zonas com base na rede de ruas servidas por transporte público

Figura 5.10 - Mapa temático mostrando os resultados de medida de acessibilidade do tipo gravitacional com base na rede completa de ruas

Figura 5.11 - Mapa temático mostrando os resultados de medida de acessibilidade do tipo gravitacional com base na rede de ruas servidas por transporte público

Figura 5.12 - Mapa temático mostrando os resultados do índice de isolamento com base na rede completa de ruas

Figura 5.13 - Mapa temático mostrando os resultados do índice de isolamento com base na rede de ruas servidas por transporte público

Figura 5.14 - Mapa temático com os valores da terra em 62 zonas de Araraquara.

Figura 5.15 - Acessibilidade aos transportes e valor do solo em 62 zonas de Araraquara 85

Figura 6.1 - Distribuição de freqüências da acessibilidade em São Carlos. 


\section{LISTA DE TABELAS}

Tabela 3.1 - Níveis de ocupação, número de quadras e população de Araraquara ..............31

Tabela 3.2 - Faixas de consumo de energia elétrica e nível de renda .................................33

Tabela 3.3 - Custos das redes de transporte e infra-estrutura das

Configurações Real, 2, 3, 4 e 5, calculados com os modelos META

e INFRA (Fonte: Raia Jr., 1995)

Tabela 4.1 - Dados usados por Raia Jr. (1995), para a definição das ZTHs nos modelos META e INFRA

Tabela 4.2 - Pontos de controle usados para conversão das coordenadas locais $\mathrm{X}$ e Y para coordenadas geográficas.....

Tabela 4.3 - Taxas de geração de viagens na cidade de Araraquara, coletadas por Raia Jr. (1995).

Tabela 4.4 - Dados de entrada para a fase de geração de viagens........................................48

Tabela 4.5 - Áreas das Zonas de Tráfego Homogêneas (ZTHs) de Araraquara

Tabela 4.6 - Distâncias percorridas por ônibus do centro da cidade a todos os centróides das zonas de tráfego na cidade de Araraquara

Tabela 5.1 - Coeficientes de correlação de rank de Kendall para as classificações de acessibilidade

Tabela 5.2 - Coeficientes de correlação entre valores do solo e acessibilidade aos transportes estimada de dez diferentes maneiras 


\section{RESUMO}

Neste texto são apresentadas, de forma sintética, as características gerais e algumas etapas do processo de introdução de Sistemas de Informações Geográficas para planejamento de transportes (SIG-T) no Brasil. Além de uma retrospectiva sobre o avanço do tema no Brasil, são apresentadas algumas aplicações da ferramenta em um projeto mais amplo e bastante específico. Este último trata da influência de algumas características das cidades (em particular, pequenas e médias) sobre os custos de transportes e infra-estrutura. Neste texto são revistas inicialmente as bases deste projeto, que vem sendo desenvolvido desde 1988, o que inclui desde os primeiros modelos desenvolvidos até uma estratégia de tributação inovadora, proposta para tentar minimizar os efeitos negativos dos vazios urbanos.

São também apresentadas duas etapas do projeto maior, desenvolvidas a partir de 1995, nas quais o SIG-T foi introduzido gradativamente. Na primeira etapa, o SIG foi utilizado apenas de forma acessória na aplicação de modelos para avaliação dos custos de transportes e infraestrutura na cidade de Araraquara. Na fase seguinte, no entanto, o uso da ferramenta já se fez de forma mais intensa, utilizando-se de maneira efetiva várias rotinas de planejamento de transportes disponíveis no software empregado, tudo isso sem descaracterizar os modelos originalmente concebidos para o projeto. O uso do SIG-T, no entanto, apesar de dar mais flexibilidade a algumas etapas da estratégia de tributação proposta, não eliminou todos os seus problemas. Em virtude disso, teve início outra etapa da pesquisa, cujos primeiros passos são aqui também descritos, em que se tenta identificar a influência que características espaciais (no caso específico aqui tratado, a acessibilidade aos transportes) exercem sobre o valor da terra urbana.

Finalmente são apresentados alguns projetos para o futuro, com os quais se busca explorar ainda mais o enorme potencial dos SIG-T, de forma a consolidá-lo como ferramenta de planejamento de transportes no país.

Palavras-chave: Sistemas de Informações Geográficas, SIG-T, planejamento de transportes, modelos de transportes, custos urbanos, acessibilidade. 


\begin{abstract}
This text reviews the general characteristics and some of the stages of the process of introducing Geographic Information Systems in transportation planning (GIS-T) in Brazil. In addition to a summary of the progress of this subject in Brazil, some of the tool's applications are presented in a larger and more specific project. The latter deals with the influence of some urban characteristics (in particular, those of small and medium-size cities) on transportation and infrastructure costs. Initially, a review is made of the basis of this project, which has been under development since 1988, ranging from the earliest models developed up to an innovative taxation strategy, a proposal to reduce the negative effects of empty urban lots.

Also presented here are two additional steps of the main project developed after 1995, in which GIS-T was gradually introduced. GIS was used in the first phase only as an accessory in the application of the models to evaluate transportation and infrastructure costs in the city of Araraquara. The tool was used intensively in the second stage, however, when several transportation planning procedures available in the software were used very effectively. This was done without changing the characteristics of the original models designed for the project. Although the GIS tool has increased the flexibility of some of the proposed taxation strategy steps, it has not eliminated all its problems. This fact has led to another research, whose first steps are also described here, which attempts to evaluate the influence of spatial features on urban land values. Transportation accessibility is the spatial feature of the specific case this paper discusses.

Finally, a brief outline is given of some future projects whose main goal is to further explore the enormous potential of the GIS-T, enhancing its importance and usefulness as a tool for transportation planning in Brazil.
\end{abstract}

Keywords: Geographic Information Systems, GIS-T, transportation planning, transportation models, urban costs, accessibility. 


\section{INTRODUÇÃO}

Este texto procura reunir, de forma organizada, a parte da obra do autor que reflete o seu esforço para introduzir os Sistemas de Informações Geográficas (SIG) para o planejamento de transportes no Brasil. Nesse sentido, não se trata de uma tese original, mas de um texto que sintetiza, sistematiza e apresenta resultados dos principais trabalhos desenvolvidos pelo autor, desde que se envolveu com o projeto acima citado. Este, por sua vez, tem por objetivo fornecer aos profissionais brasileiros uma ferramenta bastante eficiente de planejamento, não só para a área de transportes, mas também para muitas outras que se valem de referências espaciais para o seu funcionamento. É o caso do planejamento urbano como um todo e do planejamento de setores em particular, tais como a localização de escolas, postos de saúde e hospitais, distribuição de produtos e coleta de resíduos, identificação de pontos críticos de acidentes e muitos outros.

Pode parecer para muitos que os Sistemas de Informações Geográficas são um recurso sofisticado demais para um país em desenvolvimento que tem tantas carências, a começar pela quase total ausência de planejamento em muitos casos. Que o país tem carências não se discute, assim como também não se está defendendo que os SIG irão resolver todos os problemas de planejamento de forma imediata e milagrosa. O que se busca com a introdução desta ferramenta é um melhor aparelhamento dos profissionais que têm a difícil tarefa de planejar no país, poupando tempo e garantindo análises mais confiáveis. Não que um SIG vá, por si só, assegurar que as análises serão de melhor qualidade, mas pode permitir um acompanhamento gradual dos passos dessas análises, através de recursos gráficos que facilitam bastante a compreensão, ajudando a manter a correção dos processos. Mais ainda, o autor acredita que os SIG podem fazer, pelo planejamento, o que o astrolábio fez pelos descobrimentos, como descrito em Law (1990 apud Innes \& Simpson, 1993).

Para esclarecer a afirmação acima, vale lembrar que a estória do astrolábio se confunde com a história dos grandes descobrimentos e do sucesso de Portugal nesta área. Ocorre que a Coroa Portuguesa, no século XV, ansiosa por concretizar os seus projetos de descobrir novas terras (ou pelo menos novos caminhos para terras já conhecidas) percebeu que o astrolábio, instrumento já existente, mas usado somente para fins científicos, poderia ser de grande valia para os navegadores. A sua sofisticação até então permitia mais do que identificar a altura do sol sobre a linha do horizonte, trazendo inúmeros recursos que não só não ajudavam aos navegadores, mas que também dificultavam o seu uso sobremaneira. Para torná-lo uma ferramenta eficiente para o fim pretendido, a Coroa ordenou que se eliminasse do instrumento todos os recursos que não tinham benefício direto para a navegação, além de 
estabelecer um amplo processo para a sua divulgação junto aos navegadores, através de um programa de treinamento para o seu uso. A iniciativa se mostrou um grande sucesso, ajudando a fazer dos portugueses os maiores navegadores daquela época.

Traçando um paralelo com o fato histórico acima citado, o autor acredita que os Sistemas de Informações Geográficas podem ser tão importantes para a prática do planejamento de países em desenvolvimento, particularmente do Brasil, quanto foi o astrolábio para a navegação. Isso, no entanto, só será possível quando a sua utilização for acessível a um grupo expressivo de técnicos, capazes de disseminar essa tecnologia para uso imediato e constante. O país já dispõe de amplos recursos de informática, área de suporte que cada vez mais se faz presente para os profissionais que fazem o planejamento de transportes. Esses são, na sua maioria, oriundos de cursos de Engenharia Civil, mas há também profissionais das áreas de Arquitetura, Administração, Economia e muitas outras. No Brasil, as faculdades que formam esses profissionais já se valem amplamente do computador para aprimorar os seus cursos, o que torna a introdução dos Sistemas de Informações Geográficas nos mesmos uma tarefa relativamente simples.

A sua concretização, no entanto, depende, na opinião do autor, da transposição de dois obstáculos principais. Primeiro, a identificação, por parte dos docentes, administradores e dos alunos desses cursos, dos benefícios que a ferramenta pode trazer para o profissional, seja no seu processo de formação, seja nas suas atividades futuras no mercado de trabalho. Em segundo lugar, a implantação de um processo de massificação da ferramenta, com estratégias que tirem da mesma toda a suposta complexidade que a envolve, fazendo com que ela passe efetivamente a estar ao alcance do aluno e, posteriormente, do profissional. Este texto resume os esforços do autor para vencer os dois obstáculos acima citados. Para isto procurou investigar como a divulgação da tecnologia dos SIG vem ocorrendo nos países desenvolvidos.

Nos Estados Unidos, por exemplo, inúmeras agências de pesquisa vêm recebendo o apoio das Universidades para desenvolvimento e implantação de Sistemas de Informação Geográfica, com aplicações diretas em gerência de pavimentos, planejamento de transportes, análise de acidentes, inventário de sinalização viária etc. (Silva, 1992). De forma semelhante, para que a tecnologia possa ser utilizada no Brasil de forma rápida e, acima de tudo, eficiente, é preciso realizar, com o apoio da mão-de-obra altamente especializada existente nas Universidades, estudos preliminares para avaliar quais inovações e em que condições elas são interessantes para cada caso específico. $\mathrm{O}$ autor entende que somente com a visualização de aplicações reais com resultados concretos, associados à realidade que ele experimenta no dia a dia, um profissional pode passar a crer na tecnologia e nos benefícios que podem advir do seu uso. Este foi o primeiro enfoque das atividades do autor, ao começar a trabalhar com os SIG para planejamento de transportes no Brasil, em 1993. Naquela época, somente alguns poucos profissionais pareciam perceber o potencial da ferramenta para o planejamento de transportes no Brasil.

Nos anos seguintes, o autor dedicou grande parte de sua energia tentando construir aplicações que mostrassem as vantagens do uso da ferramenta no planejamento de transportes, divulgando-as, sempre que possível, em congressos e revistas. Essas aplicações, inicialmente isoladas, acabaram por constituir parte de um projeto maior já em andamento, financiado pelo CNPq. O projeto desenvolvido no biênio 1995-97, intitulado Uma aplicação do modelo META para avaliação dos custos adicionais de transportes públicos decorrentes 
dos vazios urbanos, não tinha inicialmente a intenção de incluir recursos de Sistemas de Informações Geográficas no seu desenvolvimento. Ocorre que, em algumas de suas etapas, o SIG já aparecia como um alternativa interessante para a solução de problemas específicos, como será visto mais adiante neste texto. O sucesso dessas pequenas aplicações levou ao desenvolvimento de um projeto de real vinculação com o SIG, desenvolvido a partir de 1997, também financiado pelo CNPq, denominado Combinando os modelos META e INFRA com um SIG-T para avaliação dos custos adicionais de transportes e infra-estrutura decorrentes dos vazios urbanos.

Paralelamente à iniciativa de desenvolver aplicações com a ferramenta, o autor iniciou, em 1995, um esforço para massificar o seu uso, contando para isso com o apoio da ANPET - Associação Nacional de Ensino e Pesquisa em Transportes. No IX Congresso da Associação, realizado em São Carlos, o autor conseguiu trazer para um Workshop sobre o tema SIG em transportes dois dos precursores no uso da tecnologia no Brasil, além de um pesquisador holandês com experiência no ensino de SIG para planejamento urbano e de transportes. Foi com esse último que o autor desenvolveu um material didático no ano seguinte, também divulgado em congresso da ANPET. Este material, transformado mais tarde em livro, deu início a uma série de publicações voltadas para o ensino de SIG, desenvolvidas pelo autor. Cabe mencionar aqui, que tanto o desenvolvimento das aplicações como o trabalho de massificação da ferramenta, não se constituem em uma iniciativa isolada no país. Reuniu, no entanto, em seus primeiros anos, somente uns poucos abnegados, em número que provavelmente se pode contar nos dedos das mãos. Nesse sentido, pode-se dizer que o trabalho do autor, parcialmente descrito neste documento, reveste-se de um certo pioneirismo. Se esta foi (e está sendo) de fato uma iniciativa acertada, no entanto, só o tempo vai dizer.

\subsection{OBJETIVOS}

Todo o trabalho de introdução dos Sistemas de Informações Geográficas (SIG) para planejamento de transportes no Brasil poderia ser resumido em dois objetivos principais, os quais o autor vem perseguindo ao longo dos últimos anos:

- Avaliar a potencialidade do uso dos Sistemas de Informações Geográficas (SIG) para planejamento de transportes no Brasil, através de aplicações práticas;

- Desenvolver técnicas adequadas para transferência e adequação da tecnologia dos SIGs às condições de recursos financeiros e humanos encontradas nas cidades brasileiras.

\subsection{A INSERÇÃO DO SIG NA LINHA DE PESQUISA ORIGINAL DO AUTOR}

Assim, como em outros lugares do mundo, um dos grandes problemas que atinge as cidades brasileiras é o espalhamento urbano causado por inúmeros terrenos vazios, mantidos com fins especulativos. Uma forma de atenuar este problema seria sobretaxar os terrenos ociosos, tomando como referência os custos adicionais de transportes e infraestrutura por eles causados. Para que isto seja factível, no entanto, é necessária uma avaliação 
dos custos produzidos pelo espalhamento das cidades, o que é possível com a utilização de modelos, que reproduzem as condições reais dessas cidades. A criação de modelos com esse objetivo faz parte da linha de pesquisa originalmente conduzida pelo autor, a partir de 1988 .

Após uma série de aperfeiçoamentos nos modelos inicialmente desenvolvidos por Ferraz (1990), e pelo próprio autor (Silva, 1990), foi finalmente proposta uma estratégia de tributação da propriedade urbana (Silva, 1993; Silva \& Ferraz, 1993), com o objetivo de inibir a existência de terrenos ociosos nas cidades médias brasileiras, atendendo ao que preconiza a Constituição de 1988. Nessa estratégia, o valor do tributo é obtido a partir do cálculo, realizado com o auxílio de modelos matemáticos, dos custos adicionais de transportes e infra-estrutura causados por um espalhamento excessivo das cidades.

Uma tentativa de aplicação dessa metodologia, no entanto, apontou algumas falhas como, por exemplo, a não consideração de fatores como a acessibilidade dos lotes aos sistemas de transportes e a oferta real dos serviços de infra-estrutura de rede. Segundo Raia Jr. (1995), apesar de ser um avanço em relação às estratégias de tributação usualmente utilizadas, nela não se discrimina o terreno ocioso localizado na área central da cidade, com grande acessibilidade, do terreno localizado na periferia, onde a acessibilidade é pequena ou mesmo inexistente. Por outro lado percebeu-se, nessa primeira aplicação, que era possível fazer uso de vários recursos dos SIG, tanto para a modelagem em si, como para outros fins, inclusive para o cálculo da acessibilidade aos transportes. $O$ passo seguinte no desenvolvimento da pesquisa foi a inclusão dos modelos propostos em um SIG-T, promovendo a união definitiva da pesquisa original com o esforço do autor para a utilização dessa ferramenta no Brasil.

Uma vez que a etapa de inclusão dos modelos no ambiente do SIG já está praticamente concluída, começa-se a explorar agora alguns dos seus recursos de análise espacial. Encontra-se em fase inicial um projeto para quantificação da valorização a que as propriedades urbanas estão sujeitas, contando com os recursos de redes neurais artificiais e do SIG, uma vez que existem indícios de que o valor dos terrenos urbanos depende diretamente de elementos de natureza espacial. Além das particularidades físicas, como topografia, área, redes de água e esgoto, etc., as propriedades também devem ser avaliadas pela sua vizinhança (proximidade aos pólos de atração como escolas, centros comerciais etc.) e acessibilidade aos meios de transporte, como sugerido por Kirchner (1994) e Duarte \& Gabbay (1995). Adicionalmente outro projeto teve início, no qual se procura explorar o potencial verificado nas medidas de acessibilidade como instrumento de planejamento. $\mathrm{O}$ que se pode observar, em ambos os casos, é que vinculação das pesquisas conduzidas pelo autor com o SIG tornouse praticamente irreversível, face a enorme gama de recursos que a ferramenta oferece para o planejamento urbano e de transportes.

\subsection{ESTRUTURA DO TEXTO}

Este texto é dividido em sete capítulos, incluindo esta introdução. No capítulo 2 são apresentadas as bases deste trabalho, no que diz respeito à fundamentação teórica sobre o uso dos Sistemas de Informações Geográficas no planejamento de transportes. Destaca-se ainda, neste capítulo, como vem se dando o processo de introdução desta ferramenta no Brasil. No capítulo seguinte são apresentados os fundamentos e os resultados principais 
obtidos no projeto Uma aplicação do modelo META para avaliação dos custos adicionais de transportes públicos decorrentes dos vazios urbanos, e destacados os pontos em que o SIG começou a ser ali aplicado. Este projeto tinha por objetivos a coleta dos inúmeros elementos utilizados em modelos propostos anteriormente pelo autor, com uma posterior aplicação dos mesmos a um caso real.

No quarto capítulo, são apresentados detalhes do projeto Combinando os modelos META e INFRA com um SIG-T para avaliação dos custos adicionais de transportes e infra-estrutura decorrentes dos vazios urbanos, em que o SIG foi definitivamente integrado à linha de pesquisa anterior do autor. Diferentemente do projeto anterior, este é um projeto ainda não concluído, em que ainda são feitas, no presente momento, algumas avaliações finais. Os resultados aqui apresentados, todavia, não apresentam lacunas que prejudiquem a sua compreensão. $\mathrm{O}$ que se pôde concluir deste projeto, até o presente momento, é que a estratégia de tributação da propriedade proposta pelo autor e que constitui um ponto importante de sua pesquisa original, ainda carece de refinamentos.

O capítulo 5 traz as primeiras investigações nesse sentido, como uma seqüência dos projetos anteriores que ora se inicia, em que se usa os Sistemas de Informações Geográficas para explorar um elemento de enorme potencial para o planejamento de transportes (e também urbano): as medidas de acessibilidade. Pretende-se, com este e outros elementos, desenvolver uma metodologia para avaliação de imóveis em massa, de forma a complementar a estratégia de tributação original. Os primeiros estudos sobre as medidas de acessibilidade aos transportes, entretanto, permitiram vislumbrar outras aplicações delas derivadas no planejamento urbano e de transportes, que são mencionadas no capítulo 6 . Nele são apresentados alguns trabalhos em andamento, bem como alguns projetos para o futuro, dentre os quais se encontram as iniciativas de cunho didático relativas à aplicação dos Sistemas de Informações Geográficas no planejamento de transportes. Por fim, o último capítulo traz uma lista de referências bibliográficas relativas aos temas tratados neste texto. 


\section{OS SISTEMAS DE INFORMAÇÕES GEOGRÁFICAS NO PLANEJAMENTO DE TRANSPORTES}

Nos países desenvolvidos, o computador é utilizado no planejamento de transportes, há alguns anos, como poderoso auxiliar para a execução de tarefas complexas e/ou que demandam muito tempo quando feitas manualmente. Em passado não muito distante, isso só podia ser feito em computadores de grande porte, o que limitava bastante a sua utilização, uma vez que o equipamento era caro e de uso não muito simples. Com a entrada no mercado dos microcomputadores, o uso desses equipamentos foi estendido a praticamente todas as universidades e institutos de pesquisa, inclusive de países em desenvolvimento, abrindo enormes possibilidades de pesquisa. Os programas aplicativos foram rapidamente adaptados para uso nos microcomputadores, sendo, na maioria dos casos, aperfeiçoados nesse processo de adaptação.

O nível de sofisticação dos programas alcançou tal ponto, que realizam diversas operações bastante complexas ao mesmo tempo. Alguns deles combinam, por exemplo, em um só produto, recursos dos SIG - Sistemas de Informações Geográficas com modelos e técnicas tradicionais de planejamento de transportes. Um Sistema de Informações Geográficas, que é, em essência, a combinação de imagens de mapas com diferentes tipos de informação, tem aplicações não apenas no planejamento de transportes, mas em inúmeras outras áreas, incluindo o planejamento urbano, de forma mais abrangente.

Como o objetivo deste trabalho é voltado para as aplicações de SIG em planejamento de transportes, este será o ponto de maior interesse do capítulo, com destaque para o que vêm ocorrendo no Brasil, embora tentando não perder de vista o que se passa no cenário internacional. No primeiro item deste capítulo se procura, no entanto, fornecer uma breve descrição das características gerais dos Sistemas de Informações Geográficas, apenas para situar o leitor. A concisão se justifica pelo fato de que este é um assunto já bastante explorado, inclusive na literatura nacional. Nos ítens seguintes deste capítulo serão comentados alguns aspectos relativos ao uso de SIG para o planejamento de transportes em outros países para, finalmente, ser abordado o tema no Brasil. O capítulo termina com algumas considerações finais sobre o estágio atual da tecnologia no Brasil, em particular sobre a o problema da formação de recursos humanos. 


\subsection{OS SISTEMAS DE INFORMAÇÕES GEOGRÁFICAS}

Os avanços tecnológicos na área de informática facilitaram o manuseio de grande número de dados através dos computadores. Quando umas das características relevantes do dado é a sua localização (referência espacial), pode-se fazer uso dos Sistemas de Informação Geográfica - SIG ${ }^{1}$, que se baseiam em uma tecnologia de armazenamento, análise e tratamento de dados espaciais, não espaciais e temporais. Esta ferramenta é capaz de gerar informações que permitem obter soluções rápidas e precisas para vários problemas, facilitando o processo de tomada de decisões em diversas áreas, tais como: Geologia, Hidrografia, Agricultura, Engenharia Civil, de Transportes, Urbana, de Minas, etc.

Teixeira et al. (1992) subdividem um SIG em:

- Banco de dados;

- Equipamentos (hardware) e

- Operadores espaciais: conjunto de programas (software) dedicados à execução de operações sobre os dados.

O banco de dados é composto pela base de dados física e por programas que gerenciam esses dados, ou seja, organizam os mesmos, com a finalidade de agilizar a sua procura, manutenção e controle. As estruturas de representação dos dados espaciais em um SIG podem ser classificadas em raster ou vetorial. A estrutura raster (ou matricial) divide o espaço em elementos discretos e é obtida através de uma malha com linhas verticais e horizontais, formando as células (pixel - picture element ou quadrículas). As dimensões dessas células é que definem a precisão do processo (nível de resolução). A estrutura vetorial, por outro lado, considera o espaço de forma contínua, reduzindo os dados espaciais a três formas básicas: pontos, linhas ou áreas (Françoso et al., 1993). Exemplos gráficos destas formas de representação podem ser vistos na Figura 2.1, adaptada de Silva et al. (1997a).

Quanto ao hardware, os SIG podem operar em microcomputadores, estações de trabalho, minicomputadores e computadores de grande porte, tornando a sua utilização possível em praticamente qualquer ambiente e organizações dos mais variados portes. Os operadores espaciais são um conjunto de programas, que atuam sobre a base de dados, produzindo as informações desejadas, dentre as quais se pode listar:

- Localização de uma entidade e/ou listagem de seus atributos;

- Atualização dos dados;

- Cálculos de área, perímetros e distâncias (menor distância entre dois pontos, vizinho mais próximo, rota mais curta ou mais rápida);

- Traçado de redes;

- Operações aritméticas e lógicas entre planos de informações;

\footnotetext{
${ }^{1} \mathrm{O}$ termo SIG é usado, no Brasil, de forma semelhante ao termo original em inglês, GIS, que é a abreviatura de Geographic (ou Geographical) Information System. Em português, entretanto, existem algumas variações deste termo, cada uma delas com uma explicação convincente dada por seus adeptos. Assim pode-se encontrar: Sistema de Informação Geográfica, Sistema de Informações Geográficas e até mesmo Sistema Geográfico de Informações (neste caso, SGI). Como a terminologia definitivamente não interfere nas características da ferramenta, o autor prefere não entrar nessa discussão, adotando todas as formas sem nenhum preconceito.
} 
- Cálculos estatísticos;

- Reagrupamento de dados;

- Cruzamentos dos planos;

- Tratamento de dados altimétricos: declividade, visibilidade entre pontos, perfis do terreno, cálculo de cortes e aterros, modelos digitais de terrenos, etc.;

- Tratamento de imagens através de filtragens, etc.

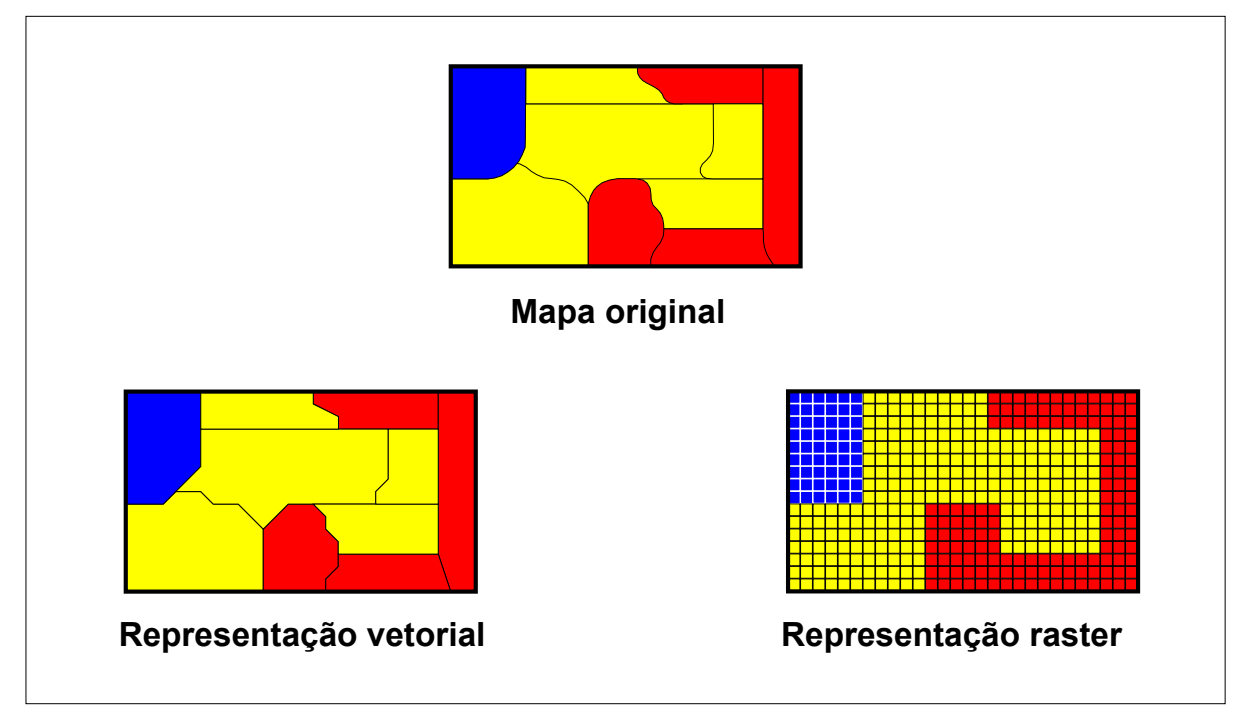

Figura 2.1 - Formas de representação de dados espaciais.

Embora seja amplamente divulgada a idéia de que os SIGs podem ser uma ferramenta fundamental para a solução dos problemas de planejamento urbano e, mais recentemente, de planejamento de transportes, isso não acontece de forma simples e automática. O emprego de Sistemas de Informações Geográficas como ferramenta, depende, além dos três elementos acima citados, de um quarto elemento: os recursos humanos. A aquisição dos programas de computador e dos equipamentos é relativamente simples, pois só depende de recursos financeiros. Os bancos de dados, por outro lado, são elementos que exigem grande atenção em qualquer implantação de SIG. De uma maneira geral, o processo de aquisição de dados é caro e complexo, exigindo que se recorra às mais variadas fontes, sejam elas primárias ou secundárias.

Fontes primárias são aquelas obtidas diretamente, através de levantamentos de campo (topográficos, geodésicos, cadastrais, etc.), recenseamentos, produtos de sensoriamento remoto (fotografias aéreas, imagens orbitais) ou vídeos. As fontes secundárias, como os mapas e as cartas temáticas, são aquelas que foram derivadas de fontes primárias. A entrada desses dados no sistema é também uma fase extremamente importante da implantação de um SIG, pois é através dela que se pode garantir a qualidade, a precisão e a confiabilidade do produto final. De todos os elementos de um SIG, no entanto, os recursos humanos são os mais difíceis de serem obtidos, pois exigem um período de treinamento e adaptação relativamente longo para atingir um nível razoável de capacitação. É justamente na transferência dessa tecnologia para os órgãos locais de administração que as Universidades têm importante papel a desempenhar.

Para mais detalhes sobre os aspectos básicos de um SIG o leitor pode encontrar, em português, os trabalhos de Rodrigues (1990), Alves (1990), Teixeira et al. 
(1992), Calijuri \& Röhm (1994), Câmara et al. (1996), Rosa \& Brito (1996), Paredes (1996), Ferrari (1997) e o primeiro capítulo de Silva et al. (1997). Outra boa referência é o trabalho de Buzai \& Durán (1997), este último em língua espanhola. O maior número de referências bibliográficas, no entanto, está em língua inglesa, inclusive os livros clássicos (o que neste caso não significa antigos) como, por exemplo, Antenucci et al. (1991), Huxhold (1991) e Korte (1997).

Apesar das vantagens do uso dos SIG no planejamento, o seu pleno emprego parece ainda longe de se tornar uma realidade. Mesmo nos Estados Unidos, país onde esses sistemas apresentam avançado estágio de desenvolvimento e onde os recursos de hardware estão dentre os mais avançados do mundo, ainda não são muitos os exemplos de instituições públicas de planejamento que realizaram experiências bem sucedidas de implementação de SIG para planejamento em larga escala (Innes \& Simpson, 1993; Vial, 1991; Mitchel, 1997).

No Brasil, até mesmo a utilização de SIG em planejamento urbano tem sido pouco explorada, em virtude das limitações causadas pela falta de recursos, tanto em termos de equipamentos, quanto, principalmente, em termos de mão-de-obra qualificada. Apesar disso, já no começo desta década, surgiram algumas iniciativas nesse sentido, como, por exemplo, no caso do projeto de avaliação da qualidade de vida urbana proposto por Ceccato et al. (1993), ou do monitoramento do crescimento urbano (Costa \& Silva, 1993).

Nessa época já era também possível encontrar exemplos de aplicação dos SIG em engenharia urbana, como em Françoso et al. (1992), que mesmo utilizando um sistema com limitações e enfrentando todas as dificuldades típicas dos países em desenvolvimento, mostraram que as aplicações podem ser feitas. Esse trabalho, elaborado a partir de um trabalho convencional de planejamento (Silva \& Ferraz, 1991), mostrava de forma inequívoca como o emprego dos SIG poderia agilizar o processo de análise e interpretação de dados. Esse estudo já incorporava algumas análises bastante interessantes sobre os níveis de utilização das redes de infra-estrutura urbana e de transportes, e sobre as áreas que deveriam receber prioridade na implantação de novas redes.

\subsection{OS SISTEMAS DE INFORMAÇÕES GEOGRÁFICAS E O PLANEJAMENTO DE TRANSPORTES}

Segundo Antenucci et al. (1991), um dos primeiros projetos que vinculou os resultados de análises com mapas, de forma a facilitar a sua compreensão (praticamente uma versão preliminar dos atuais SIG), foi justamente um trabalho na área de transportes, desenvolvido em Detroit-USA, em 1955. Naquele projeto foi desenvolvida uma saída gráfica para o programa de computador, através da qual os fluxos resultantes das análises eram representados por linhas de diferentes espessuras.

O planejamento dos transportes urbanos requer, como passo fundamental, a previsão da demanda futura. Os métodos para previsão de demanda no planejamento de transportes mais freqüentemente utilizados em todo o mundo são baseados em quatro diferentes etapas: a de geração de viagens, a de distribuição de viagens, a de escolha modal e a de alocação de viagens às rotas (Morlok, 1978; Dimitriou, 1990). Cada uma dessas etapas emprega modelos matemáticos específicos, que trabalham com uma rede simplificada das 
possíveis ligações de transporte (envolvendo ruas, avenidas, estradas, etc.). A previsão de demanda baseada nesses métodos requer, na maioria das vezes, mesmo em redes de pequenas dimensões (com poucas ligações e nós), a utilização de computadores para agilizar os cálculos e garantir a precisão dos resultados dos diferentes submodelos. Nos países desenvolvidos, onde a maior parte dos modelos de transporte foi criada e aperfeiçoada, o uso dos computadores é bastante comum em qualquer aplicação. A complexidade dos submodelos de transporte, no entanto, limitava o seu uso aos computadores de grande porte (mainframe).

Um dos fatores que tem dificultado a transferência dessa tecnologia para os países em desenvolvimento é exatamente a dependência dos computadores de grande porte, associada à ausência de mão-de-obra qualificada (Dimitriou, 1990). Nos últimos anos, no entanto, o quadro se modificou. Com o expressivo avanço tecnológico dos microcomputadores, que passaram a dispor de elevada capacidade de memória e velocidade de processamento, essas máquinas abriram uma enorme possibilidade de usos, mesmo em países em desenvolvimento, devido ao seu custo relativamente baixo e reduzidas dimensões. Muitos dos programas existentes, que auxiliam no planejamento de transportes, foram convertidos para microcomputadores, ao mesmo tempo em que novos programas foram criados, sendo grande parte deles específica para o planejamento dos transportes urbanos (Ferguson et al., 1992).

Dentre os novos programas, alguns surgiram com uma proposta inovadora: combinar um SIG - Sistema de Informação Geográfica com modelos de transportes. A proposta, no entanto, não pode se limitar a simples junção de programas, pois um SIG para transportes é quase como um novo produto, com características próprias (Simkowitz, 1990). Kagan et al. (1992), ao trabalharem com dois programas independentes (um SIG e um programa específico para planejamento de transportes), enfrentaram alguns problemas na interface entre esses programas, em especial na transferência de dados. Segundo a proposta dos fabricantes dos SIG para planejamento de transportes, em um programa integrado isso não deve ocorrer.

Para Kagan et al. (1992), os Sistemas de Informação Geográfica permitem manusear, atualizar, alterar, ou acrescentar outras informações, ou ainda trabalhar com parte dos dados, em função do problema em questão. Isso parece funcionar muito bem para as informações tipicamente necessárias para alimentar modelos de transportes, que são:

- Dados sócio-econômicos e demográficos de população (habitantes, empregos, renda, produção industrial e agrícola, etc.);

- Dados sobre características de uso e ocupação de solo;

- Dados descrevendo a oferta de transportes;

- Dados sobre a demanda por transporte.

O tipo de programa acima citado, ao reunir os recursos de um SIG e diversas ferramentas de planejamento de transporte (e que se convencionará chamar aqui de SIG-T, a exemplo dos norte-americanos, que adotaram a sigla GIS-T), fornece aos usuários amplo acesso a bases de dados geográficos e de transporte, com a possibilidade de combinar esses elementos de diferentes maneiras. Essa característica faz com que o programa seja útil em várias aplicações: cadastro urbano, gerência de pavimentos, planejamento urbano, análise de impactos ambientais, análise de acidentes, planejamento operacional de qualquer modo de transporte e muitas outras. 
Tanto os modelos tradicionais como os Sistemas de Informação Geográfica conjugados a esses modelos, permitem gerar alternativas para solução de problemas de transportes, simulando o comportamento do tráfego. No entanto, a principal vantagem dos SIGs em relação aos métodos tradicionais é a rapidez e a flexibilidade, pois a utilização de um sistema automatizado oferece ao planejador, administrador público ou engenheiro de transportes, novos conceitos para representação gráfica e manipulação dos dados.

$\mathrm{Na}$ integração dos SIG com o planejamento de transportes, a área de pesquisa ainda está em fase de consolidação inclusive nos países desenvolvidos, onde os primeiros trabalhos tiveram início apenas no final da década de 80 (Simkowitz, 1989; Lewis, 1990). Uma evidência disso são os trabalhos de Spring (1992), Siegfried et al. (1992) e Logie (1992), que apresentavam apenas propostas de utilização dos SIG para resolver problemas de transporte e nenhum trabalho efetivamente concluído. Isso ocorreu nos Estados Unidos, mesmo com os pesquisadores tendo à disposição bases de dados digitais, como os dados do censo, que já podem ser facilmente obtidos nesse formato (Klosterman \& Lew, 1992), e que somente há poucos anos começaram a ser efetivamente utilizados para estudos de transportes (Denno, 1993). Em algumas áreas bem específicas, como no caso de transporte público urbano, ainda hoje são relativamente poucas as aplicações (uma das primeiras pode ser encontrada em Sung, 1992).

Apesar de ainda se encontrar em uma fase de implantação, alguns autores norte-americanos, como Vonderohe et al. (1991) e Stokes \& Marucci (1995), afirmam que os SIG-T são uma tecnologia que veio para ficar. Para estes autores, sua implementação em larga escala é apenas uma questão de tempo. Alguns aspectos operacionais ainda precisam ser melhor resolvidos, como no caso da integração dos modelos tradicionais de transportes com os SIG. Este é um tema ainda explorado por pesquisadores de diferentes partes do mundo (Niemeier \& Beard, 1993; Silva \& Waerden, 1997; McCormack \& Nyerges, 1997; Kaffum \& Taylor, 1998)

Algumas experiências já foram realizadas em países em desenvolvimento para verificar a possibilidade da aplicação dos SIG-T no planejamento de transportes (Abebe \& Holdstock, 1993; Nicolini, 1998), inclusive no Brasil, com resultados interessantes. Nos próximos subitens são comentados os principais trabalhos relacionados com o tema no Brasil, em dois momentos: antes e depois de 1995. Este ano foi tomado como referência, por parecer ser o momento em que se passou do estágio inicial de contato com a nova tecnologia para uma visão mais madura do seu uso.

\subsubsection{A Experiência Brasileira até 1995}

É feita aqui uma retrospectiva dos principais trabalhos sobre SIG-T no país, mostrando a evolução, desde as primeiras sugestões de uso até os projetos em andamento, culminando com as perspectivas para o futuro que se vislumbrava na época. Para captar o desenvolvimento do tema, nada melhor do que analisar os trabalhos publicados nos principais congressos, simpósios, seminários e revistas que abordam a questão dos transportes no Brasil (mesmo que, em alguns casos, se tratem de eventos e publicações internacionais). Um dos fóruns que mais têm contribuído para a divulgação do assunto no país é, indubitavelmente, a ANPET - Associação Nacional de Pesquisa e Ensino em Transportes, principalmente através 
de seus congressos anuais. Assim, para traçar um quadro geral da evolução dos SIG-T no Brasil, foram pesquisados os trabalhos publicados nos Congressos de Ensino e Pesquisa em Transportes, além de alguns dos principais trabalhos extraídos de outras publicações.

Um dos primeiros trabalhos que tratou de SIG-T no Brasil foi o de Kagan et al. (1992), cujo objetivo principal era discutir a potencialidade do uso de um SIG no planejamento de transportes. Os autores afirmam que nas etapas de um modelo de planejamento em transportes - reconhecimento do problema, estabelecimento de metas, objetivos e alternativas para solução do problema, definição de critérios para avaliação das opções, simulação do comportamento do sistema considerando as várias alternativas e escolha da melhor opção - há necessidade de se tratar grandes volumes de informações. Os SIG realizam o armazenamento e processamento dessas informações, além de permitirem a representação espacial, por exemplo, dos resultados alcançados pela aplicação de uma alternativa escolhida para resolução do problema, tornando a análise mais transparente aos usuários. Devido ao bom desempenho e às vantagens dos SIG (facilidade de edição e representação gráfica, tratamento topológico, análises estatísticas, etc.), observados em uma experiência prática de modelagem de transportes associada a um SIG, os autores esperavam uma maior integração dos últimos com os modelos de planejamento na resolução de problemas característicos dos transportes nas cidades.

Já em 1993, o potencial identificado no ano anterior começou a se materializar, ainda que de forma tímida. Dois trabalhos sobre SIG-T foram apresentados no Congresso da ANPET. O primeiro deles mostrava uma aplicação prática de um Sistema de Informações Geográficas em um estudo de transporte (Novaes \& Rosseto, 1993), em que o objetivo era otimizar a distribuição de um certo produto (bebidas) no estado de Santa Catarina, através da locação de depósitos em determinadas cidades do estado, de modo a se conseguir o menor custo total do processo. Seguindo um modelo para resolução do problema de localização de facilidades, estimou-se inicialmente um certo número de depósitos (acima do esperado) e suas respectivas localizações, calculando-se o custo total do processo. Em seguida, retirou-se o depósito de menor movimentação e calculou-se novamente o custo total, repetindo o processo até atingir-se um valor mínimo para o custo total. Em cada uma dessas etapas, o SIG mostrava, desde o contorno da região atendida por cada depósito e os fluxos de distribuição, até a obtenção do número e da localização ideal de depósitos no estado.

O segundo trabalho publicado em 1993 apresentava a iniciativa pioneira de criação de uma base de dados do país, capaz de servir de subsídio para estudos de transportes (Martins \& Iversson, 1993). Era apresentado o trabalho que uma empresa privada, que atua na área de planejamento regional de transporte e logística, vinha desenvolvendo para a conversão das bases cartográficas existentes para $o$ formato digital. Essas eram complementadas por informações alfanuméricas de diversas fontes, formando uma importante base de dados. A conclusão da base geográfica permitiria realizar estudos regionais, não só na área de transportes, mas em outras áreas que requerem planejamento e gerência de recursos econômicos e naturais.

A publicação de trabalhos de cunho mais prático em 1993, somada a divulgação crescente do tema em publicações internacionais, aparentemente estimulou os pesquisadores brasileiros, levando a um aumento no número de trabalhos no Congresso de Ensino e Pesquisa de 1994. O primeiro deles foi um trabalho teórico, em que os autores estavam preocupados com o desempenho dos SIG, de maneira geral. Pimentel \& Salgado 
(1994) observaram que, para o uso adequado de um SIG, é necessário um trabalho conjunto entre os usuários finais e aqueles que desenvolvem os sistemas. A falta de comunicação ou troca de informações entre os envolvidos no processo acarreta geralmente um produto final que não atende plenamente as necessidades dos usuários, ou seja, um sistema ineficiente. $\mathrm{O}$ artigo mostra que, somente com esse trabalho harmônico entre os envolvidos (troca de informações, questionamentos, etc.) será possível a otimização no processo de desenvolvimento e utilização de um SIG.

No segundo artigo, escrito por Ferreira et al. (1994), foram associadas imagens de satélite a modelos matemáticos para o planejamento de transportes, não se podendo, no entanto, identificar claramente a metodologia desenvolvida como um SIG-T. No trabalho, o monitoramento das alterações na estrutura urbana de Teresina-PI se deu através da análise de fotos desde a década de 50 até o estudo de imagens atuais (1991) fornecidas pelo satélite americano LANDSAT e, com a utilização associada de modelos matemáticos, conseguiu-se alocar rotas e freqüência horária ao transporte coletivo, de modo a atender às demandas geradas pelos inúmeros setores existentes com um grau de eficiência preestabelecido.

Dois outros trabalhos apresentaram experiências práticas, mostrando os primeiros passos para a implantação de SIG-T em grandes cidades (Rio de Janeiro e Recife). Em um deles, o de Nassi et al. (1994), o objetivo era gerar imagens para cadastro que auxiliassem no planejamento do transporte público urbano. Para isso, era necessária a representação gráfica de alguns dos principais componentes do sistema, tais como: cadastro das ruas e avenidas do município, itinerários de linhas, perfis de carregamento de linhas e rotas, etc. Com a base cartográfica criada e utilizando-se as ferramentas dos SIG, sugeriam, os autores, que seria possível aos administradores dinamizar o planejamento e operação do transporte público urbano. Na mesma linha, Siqueira \& Cassundé (1994), descreveram a experiência da empresa de transportes coletivos EMTU/Recife na implantação da tecnologia dos SIG. Segundo os autores, através de consultas à base geográfica que se estava criando seria possível obter informações referentes ao sistema de transportes coletivos, que possibilitariam a monitoração do mesmo, com o intuito de obter a eficiência máxima na prestação do serviço à população.

Ainda em 1994, outros cinco trabalhos de pesquisadores brasileiros sobre SIG$\mathrm{T}$ foram publicados em um congresso latino-americano sobre transporte público urbano e em congressos nacionais, um de cadastro técnico multifinalitário e um de geoprocessamento. No congresso de transporte público, foram apresentados dois trabalhos do Brasil sobre SIG em transportes: o primeiro trabalho mostrava as possibilidades de uso dos SIG-T para o planejamento e reestruturação de sistemas de transporte público em cidades de pequeno e médio porte (Silva et al., 1994), enquanto que o segundo tratava da implantação do SIG-T na cidade do Rio de Janeiro (Nassi et al., 1994). Nos congressos de cadastro técnico multifinalitário e de geoprocessamento, uma tentativa de utilização do SIG para gerência de vias não-pavimentadas (Viviani et al., 1994) e duas aplicações práticas dos SIG-T: a primeira na roteirização de veículos (Rosseto \& Cunha, 1994) e a segunda no planejamento de rotas de transporte público urbano, essa última a partir de um sistema desenvolvido especificamente para esse fim (Alencar \& Aquino, 1994).

O ano de 1995 começou promissor para as pesquisas em SIG-T. Em junho foram publicados três trabalhos em um congresso nacional sobre transportes públicos e, no mês seguinte, dois trabalhos em congressos internacionais, um deles sobre o uso de 
computadores em planejamento urbano e o outro sobre pesquisa em transportes. No congresso de transporte público, no primeiro trabalho foi apresentado um Sistema Informatizado para o Planejamento de Transportes no estado de Minas Gerais (Andrade \& Mendes, 1995), no segundo foi abordada a evolução na implantação do SIG-T da cidade do Rio de Janeiro (Nassi et al., 1995), enquanto que no terceiro foi descrita a aplicação de um SIG para o controle operacional de transporte público na cidade de São Paulo (Martins et al., 1995). Nos outros dois congressos foram demonstradas duas aplicações práticas dos SIG-T em cidades médias: a primeira na avaliação dos impactos do crescimento urbano sobre os transportes (Silva et al., 1995), e a segunda na reestruturação de um sistema de transporte público urbano (Silva \& Kawamoto, 1995).

No congresso da ANPET do mesmo ano, mais quatro trabalhos usando a ferramenta foram publicados. No primeiro deles, Viviani \& Sória (1995) apresentaram as bases de um sistema de gerência de vias não-pavimentadas usando um SIG, como projeto de uma tese que se iniciava. Este trabalho é um exemplo claro de uma aplicação prática desenvolvida inicialmente na Universidade, sem o que dificilmente seria implementada no mundo real. $\mathrm{O}$ desenvolvimento dessa pesquisa se deu na Escola de Engenharia de São Carlos, e o autor colaborou com os pesquisadores acima citados ao longo de todo a pesquisa, que se encerrou em 1998, dando suporte nas atividades relacionadas ao SIG. As etapas desse processo foram divulgadas em vários congressos científicos, em que se teve a oportunidade, não só de divulgar a pesquisa, mas de colher sugestões dos profissionais que assistiram às diferentes apresentações entre 1994 e 1998. Este é um exemplo de aplicação de SIG-T em uma área um pouco mais específica, a que envolve diretamente a infra-estrutura de transportes. Nesta, as principais aplicações estão ligadas à atividades de gerência, como se pode verificar em trabalhos de pesquisa concluídos mais recentemente (Oda, 1995; Pantigoso, 1998; e Viviani, 1998).

Em outro artigo publicado no nono congresso da ANPET, Silva \& Mota (1995) apresentaram uma aplicação de um SIG-T na avaliação de aspectos de desempenho de um sistema de transporte público, através de um estudo de caso na cidade de São José do Rio Pardo. O uso do SIG garantiu avaliações rápidas, permitindo verificar o impacto de diferentes alternativas operacionais sobre alguns indicadores de eficiência e eficácia. Novaes (1995), por sua vez, propôs no mesmo evento algumas aproximações em redes logísticas para garantir uma melhor performance dos SIG na busca de rotas ótimas. O último dos trabalhos sobre Sistemas de Informações Geográficas no mesmo congresso foi o artigo de Silva et al. (1995), no qual se propunha o uso de recursos da ferramenta na fase de geração de viagens do modelo de quatro etapas. Foi também no ano de 1995 que se concluíram algumas das primeiras dissertações de mestrado no país, utilizando Sistemas de Informações Geográficas para o planejamento de transportes. Foi o caso de Raia Jr. (1995), da Escola de Engenharia de São Carlos, e de Januário (1995), do Instituto Militar de Engenharia, no Rio de Janeiro.

O que se pôde observar, neste primeiro período de contato dos pesquisadores brasileiros com os Sistemas de Informações Geográficas para planejamento de transportes, foi uma série de intenções de utilização da ferramenta. Poucos foram os trabalhos que se referiam a aplicações práticas efetivamente implementadas. Nesse período, no entanto, alguns grupos começaram a se destacar na área. Nota-se claramente a forte presença de trabalhos da empresa de consultoria em Transportes LOGIT, onde se destacava o Eng. Wagner Colombini Martins; da Universidade Federal do Rio de Janeiro (COPPE-UFRJ); com o Prof. Carlos David Nassi, e da Escola de Engenharia de São Carlos da Universidade de São Paulo (EESC-USP), onde as 
pesquisas com SIG-T eram conduzidas por este autor. A preocupação dominante destes três grupos no início desta fase era a criação de bases de dados, como se pode verificar também em Viviani et al. (1995). De forma menos intensa, mas não menos importante, aparecia também o Prof. Antonio Galvão Novaes, da Universidade Federal de Santa Catarina.

É interessante observar que esse era também o quadro em outros países da América do Sul, como Chile (Bravo \& Cerda, 1995), apesar de sua tradição em desenvolver pesquisas de ponta na área de transportes, e Argentina (Nilda \& Abriani, 1994).

\subsubsection{A Experiência Brasileira após 1995}

O número de trabalhos publicados entre os anos de 1994 e 1995 indicava o crescente interesse pelo assunto na comunidade de transportes e já assumia proporções que permitiam uma retrospectiva sobre o tema no Brasil. Isto foi feito pela primeira vez em 1995, pelo autor, em documento não publicado mas distribuído aos participantes do Workshop SIG em transportes, realizado durante o nono congresso da ANPET, em São Carlos. No ano seguinte foi publicado, no décimo congresso da ANPET, o artigo de Dantas et al. (1996), apresentando o estado da arte sobre o tema, acrescentado ainda outros elementos à retrospectiva do ano anterior. Este artigo mostrava também o interesse de mais um grupo de pesquisa em reforçar essa área de pesquisa no Brasil: o programa de Mestrado em Transportes Urbanos da Universidade de Brasília. Isso ficou claro em outros dois artigos publicados no mesmo evento, do mesmo grupo. No primeiro, Taco et al. (1996) combinaram os recursos de um SIG-T com dados de sensoriamento remoto na definição de zonas de tráfego. No segundo, Bartoli et al. (1996) também usaram as mesmas tecnologias, mas para avaliar a acessibilidade locacional de paradas de ônibus.

Ainda no décimo congresso da ANPET, mais um grupo de pesquisa começou a despontar, o da Universidade Federal do Ceará, com um trabalho em que o SIG foi usado como plataforma para análise de redes de transportes (Loureiro \& Ralston, 1996). Diversas propostas de pesquisa foram também apresentadas como projetos para dissertações e teses como, por exemplo, Deluqui \& Aguiar (1996), Geleski \& Aguiar (1996) e Santos \& Aguiar (1998a e 1998b), dentre outros.

No oitavo congresso latino-americano sobre transporte público e urbano foram apresentados três trabalhos na seção específica sobre SIG em transportes, todos do Brasil: dois deles relacionados a questão da acessibilidade aos transportes (Raia Jr. \& Silva, 1996 e Campos \& Januário, 1996) e o último descrevendo a experiência no uso de Sistemas de Informação Geográfica aplicados ao sistema de transporte público urbano no município do Rio de Janeiro (Nassi et al., 1996).

Como nos anos anteriores, trabalhos envolvendo o uso de SIG em planejamento de transportes foram também publicados em congressos mais específicos de SIG e geoprocessamento. É curioso observar, entretanto, uma certa mudança no status das aplicações de SIG em transportes. Enquanto que na edição de 1994 do Congresso GIS BRASIL, os trabalhos de SIG em transportes foram classificados no módulo Usos não convencionais de SIG, em 1996 foi criado um módulo próprio para abrigá-los, denominado 
Roteamento, Distribuição e Marketing. Além disso, o número de contribuições também aumentou. No GIS BRASIL 96 podem ser encontrados os trabalhos a seguir:

- Apresentação de sistemas em que o SIG foi usado na roteirização para distribuição de jornais (Silva \& Grubman, 1996 e Rocha, 1996);

- Perspectivas de uso do geoprocessamento no sistema de transporte e trânsito de Belo Horizonte (Zuppo et al., 1996),

- Apresentação de algoritmo para auxiliar na criação de grafos a partir de mapas viários (para fins de roteamento) (Caliari et al., 1996);

- O uso do SIG como auxiliar na obtenção de alguns dados fundamentais para o planejamento de transportes (Silva et al., 1996);

- Localização de pontos de parada de ônibus com o auxílio de um SIG (Tesima \& Lapolli, 1996).

No XI Congresso da ANPET, uma só seção técnica já não comportaria todos os trabalhos de SIG-T, uma vez que o seu uso parece finalmente ter se consolidado como meio, e não como fim, no processo de planejamento de transportes. Assim, foram publicados trabalhos sobre os seguintes temas:

- Análise do problema de roteirização de veículos para o processo de coleta e descarga de resíduos sólidos de serviços de saúde (Graciolli et al., 1997);

- Avaliação dos custos de deslocamento de estudantes antes e depois de uma reforma escolar promovida no estado de São Paulo (Dutra \& Silva, 1997);

- Definição de zonas de tráfego, a partir de setores censitários (Sanches, 1997);

- Aplicações de SIG em coordenação semafórica (Oliveira \& Ribeiro, 1997);

- Elaboração de cadastros de linhas de ônibus, combinando SIG e GPS (Sistema Global de Posicionamento) (Pinto \& Lindau, 1997);

- Construção de sistemas de informações para usuários de transporte público urbano (Marques \& Silva, 1997);

- A elaboração de uma estrutura de decisão para planejamento de transportes baseada no Método da Análise Hierárquica e SIG (Dantas et al., 1997);

- Modelos de geração de viagens (Taco et al., 1997);

- Avaliação da acessibilidade aos transportes (Salles Filho, 1997; Raia Jr. et al., 1997a);

- Introdução de SIG no ensino de engenharia de transporte (Silva et al., 1997).

Assim como nos eventos anteriores, projetos para dissertações e teses sobre o tema foram também apresentados como, por exemplo, Almeida \& Sanches (1997) e Barra \& Kawamoto (1997), para citar apenas dois. Além disso, mais um grupo de pesquisa em transportes no Brasil parece ter se envolvido de forma mais direta com o tema. A Universidade Federal de São Carlos, que já contava com trabalhos do Prof Archimedes Raia Jr. desde 1995, passou a ter nesse evento a presença de trabalhos da Professora Suely Sanches, consolidando mais este grupo no Brasil.

No Congresso Nacional de Transportes Públicos, realizado em Belo Horizonte, os artigos utilizando os recursos dos SIG-T foram: 
- Apresentação de um sistema básico de informação para órgãos gestores de transporte público urbano, inteiramente apoiado no uso de Sistema de Informações Geográficas e recursos gráficos (Rosseto et al., 1997);

- Desenvolvimento de uma metodologia para otimização de frota e redução de custos operacionais para serviços de ônibus fretados para transporte de funcionários (Martins et al., 1997);

- Utilização de um modelo para avaliar a influência do adensamento das cidades nos custos do transporte público urbano (Raia Jr. \& Silva, 1997);

- Apresentaçãodas aplicações de SIG destinadas aos sistemas de transporte coletivo e trânsito já utilizadas ou em desenvolvimento na cidade de Belo Horizonte (Meirelles, 1997).

Trabalhos ligados a SIG aplicados aos transportes foram também apresentados em outros eventos nacionais em 1997. O IV Simpósio Brasileiro de Geoprocessamento contou com os trabalhos de Paiva (1997), na determinação de itinerários para ônibus escolares; de Dantas et al. (1997), mostrando, em um só trabalho, uma aplicação para a fase de geração de viagens e um estudo de atendimento de usuários de transporte coletivo; e de Raia Jr. et al. (1997b), que utilizaram um SIG como ferramenta auxiliar no processo de determinação dos custos adicionais de transportes e infra-estrutura causados pelo espalhamento urbano. O GIS BRASIL 97 teve os trabalhos de Davis Jr. (1997), que apresentou a implementação de um algoritmo para aumentar a eficiência na busca de caminhos mínimos em um SIG; o de Silva et al. (1997d) cujo objetivo era mostrar a experiência da implantação de um SIG para o planejamento do transporte integrado ao metrô de São Paulo; e o de Silva \&Waerden (1997b), em que foi apresentada um ferramenta de auto-instrução para o ensino de planejamento de transportes, baseada em um SIG-T.

Mais recentemente, alguns autores brasileiros voltaram a divulgar trabalhos em eventos internacionais, empregando a tecnologia dos SIG aplicada aos transportes. Na quinta conferência internacional sobre o uso de computadores em gerência e planejamento urbano (International Conference on Computers in Urban Planning and Urban Management), por exemplo, Silva \& Waerden (1997c) apresentaram um trabalho em que foi mostrada a possibilidade de se combinar modelos simplificados (inclusive de transportes) com SIG para estimar custos urbanos em países em desenvolvimento. No IX Congresso Latino-americano de Transporte Público e Urbano aparecem trabalhos sobre:

- A experiência de implantação de SIG-T no Rio de Janeiro e em Caracas (Ortiz \& Nassi, 1998);

- O potencial dos SIG para a quantificação de impactos ambientais decorrentes de projetos de transporte público (Sinay \& Lima Jr., 1998);

- Um sistema de informações para usuários de transporte coletivo baseado em um SIG-T (Silva \& Marques, 1998).

$\mathrm{Na}$ Oitava Conferência Mundial de Pesquisa em Transportes (World Conference on Transport Research) foram apresentados os trabalhos de Salles Filho (1998), Silva et al. (1998) e Viviani et al. (1998). Os dois primeiros artigos tratam de aspectos ligados à acessibilidade em transportes, enquanto que o último se refere a um projeto de uso de SIG na manutenção de estradas rurais no Brasil. 


\subsection{O QUADRO ATUAL}

A retrospectiva dos trabalhos publicados a respeito dos SIG em transportes não deixa dúvidas que esta é uma área emergente no Brasil. O crescente número de artigos publicados já despertou o interesse dos profissionais de transportes, sejam eles do meio acadêmico ou técnicos que vivem o dia a dia dos problemas nas cidades. Pode-se afirmar que a fase inicial de assimilação da tecnologia já está bem encaminhada. Ainda existe, no entanto, um grande obstáculo para a sua efetiva implementação no Brasil, que é a formação de recursos humanos.

A combinação de Planejamento de Transportes e Sistemas de Informações Geográficas (SIG) requer profissionais bem preparados e treinados. No caso de planejamento de transportes, muitas vezes instrutores e estudantes encontram dificuldades ao lidarem com pacotes de software que não são projetados para iniciantes, o que ocorre com freqüência no caso de estudantes de planejamento de transportes. Os manuais contêm, geralmente, uma grande quantidade de informações sobre conceitos geográficos contidos no pacote e suas ferramentas. Para contornar estes problemas é preciso desenvolver ferramentas de treinamento a serem usadas em situações onde os estudantes não têm um conhecimento geográfico geral, quando começam a usar conceitos de um software SIG-T.

O desenvolvimento de ferramentas didáticas vêm sendo o principal enfoque do trabalho do autor no momento, para utilização com alunos de graduação, pós-graduação (stricto e lato sensu) e até mesmo para profissionais não envolvidos nos cursos formais mencionados acima. Calcado na experiência do curso Os Sistemas de Informações Geográficas e a Engenharia de Transportes, oferecido na Área de Pós-Graduação em Transportes da EESC-USP desde 1994, foram desenvolvidas algumas ferramentas para o ensino de SIG-T. A primeira delas foi uma adaptação do tutorial que acompanhava a versão 2.1 do software TransCAD (Caliper, 1990 e 1992). Nessa adaptação, os elementos originais que acompanhavam o tutorial, relativos a uma região nos Estados Unidos, foram substituídos por dados referentes à realidade brasileira. Os tópicos abordados na versão em português do tuturial eram:

1) Comandos básicos;

2) Mudanças de escala;

3) Seleção de dados;

4) Exibição de dados através de mapas;

5) Condições;

6) Criação de mapas;

7) Edição de dados;

8) Comandos avançados de edição;

9) Gráficos;

10) Edição de dados Geográficos.

A segunda ferramenta foi também um tutorial, inteiramente desenvolvido por Silva e Waerden (1997a) para o software TransCAD 3.0 (Caliper, 1996a e 1996b) e cuja aplicação foi comentada em Silva e Waerden (1997b) e Waerden \& Silva (1997). Finalmente, a última opção didática foi outro tutorial, semelhante ao anterior, mas desenvolvido, em 
português, para o software UfosNet 2.1. A grande vantagem desta última opção é o fato desse software estar disponível na Internet, sem custo, o que pode permitir a sua introdução em larga escala no ensino de graduação. Por este motivo ele vem sendo aplicado desde 1997 no curso de Engenharia de Transportes, oferecido para alunos de Engenharia Civil da EESCUSP.

Três questões básicas guiaram o desenvolvimento dos conteúdos e a estrutura desses dois últimos tutoriais:

- Quais são os tópicos básicos de SIG-T que os estudantes têm que conhecer?

- Em que ordem aprender esses tópicos?

- Qual deve ser o nível de detalhamento exigido num primeiro contato com um SIG-T?

Os tópicos básicos que os estudantes de planejamento de transportes precisam para a utilização de um SIG-T foram trabalhados em 10 módulos (Figura 2.2). Os módulos são ordenados de modo que os estudantes aprendam primeiro os tópicos que eles realmente precisam para começar uma aplicação. Assim, esse conhecimento é usado em exercícios mais avançados. Isto significa que o tutorial começa com tópicos simples e baixo nível de detalhamento, terminando com tópicos mais sofisticados e detalhados. O início trata da criação de bases de dados para uma aplicação. Nos módulos seguintes as informação que são armazenadas nessas bases de dados são utilizadas em manipulações simples e diferentes análises. Os últimos dois módulos dispensam maior atenção a assuntos específicos relacionados a planejamento de transportes, como matrizes e análises de rede.

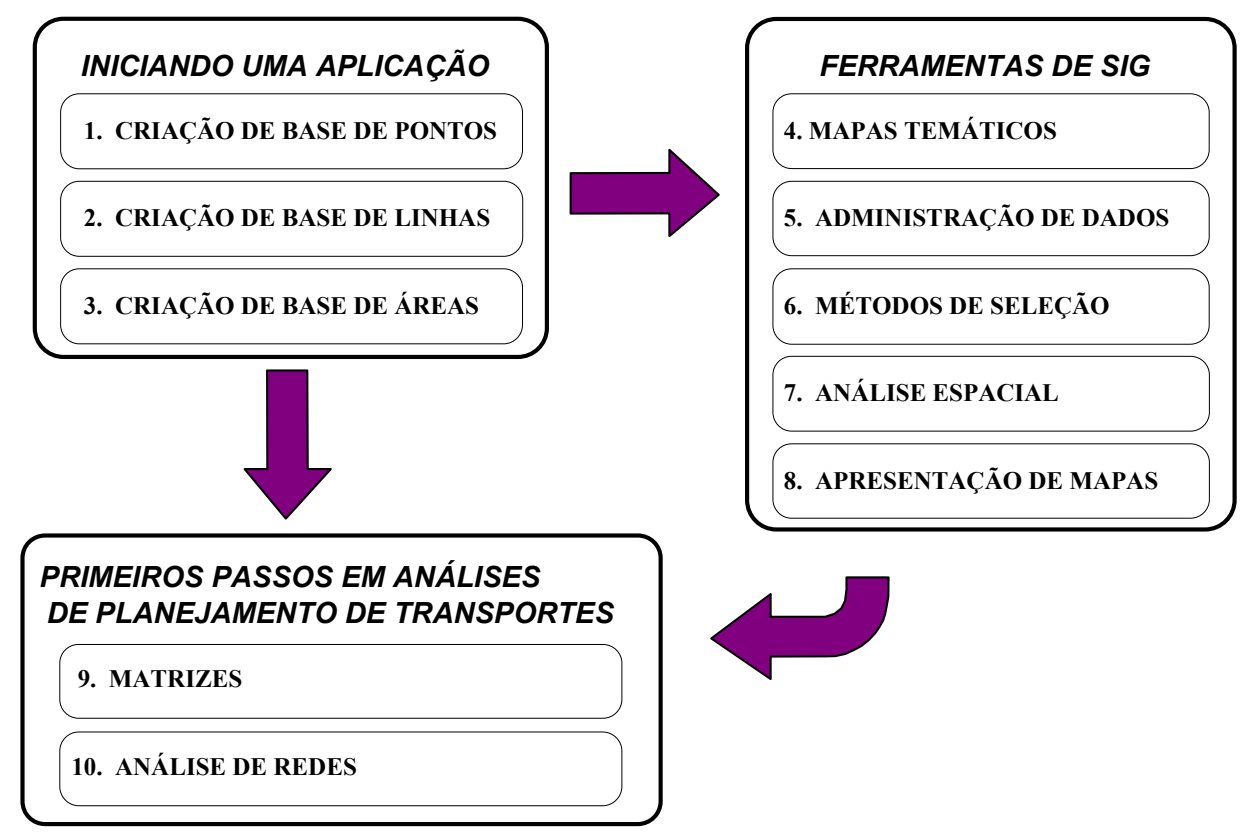

Figura 2.2 - Descrição dos módulos de um tutorial para o software TransCAD 3.0.

Essa tendência de melhorar as condições de ensino para acelerar e aprimorar a formação de recursos vem sendo observada também nos principais centros de pesquisa que se dedicam ao SIG-T no Brasil, como é o caso da Programa de Engenharia de Transportes da Universidade Federal do Rio de Janeiro, que recentemente disponibilizou uma página 
(http://146.164.26.6/TCW/) na rede mundial de computadores (Internet) para a divulgação de um curso e de bases de dados.

Talvez seja um pouco cedo para tal otimismo, mas a julgar pelos fatos aqui comentados, talvez já possamos afirmar, como Vonderohe et al. (1991) e Stokes \& Marucci (1995), citados anteriormente, que os SIG-T são uma tecnologia que veio para ficar também no Brasil. É preciso, no entanto, que não cometamos o erro de criar problemas para a ferramenta. Temos sim, que usar a ferramenta, da forma correta, para solucionar os problemas existentes, tirando o máximo de proveito do seu potencial para otimizar os nossos escassos recursos. Isso é o que o autor vem tentando fazer nos casos em que vem aplicando o SIG, como nos projetos de pesquisa que serão apresentados nos próximos capítulos. 


\section{AS PRIMEIRAS APLICAÇÕES DE SIG NO PROJETO MAIS AMPLO}

Este capítulo contém uma breve revisão das primeiras atividades de pesquisa desenvolvidas pelo autor, que tiveram início com a elaboração de modelos matemáticos simplificados para avaliação dos custos urbanos decorrentes, inicialmente, dos transportes e, posteriormente, das demais redes de infra-estrutura. Estes modelos permitiram identificar o impacto de baixas densidades populacionais nos custos de transportes e de infra-estrutura, o que conduziu, mais tarde, a uma proposta de tributação diferenciada da propriedade urbana. Nesta proposta, também resumida neste capítulo, os terrenos vazios, que geram baixas densidades globais, são sobretaxados.

A última parte desse capítulo é um resumo dos resultados do projeto de pesquisa intitulado Uma aplicação do modelo META para avaliação dos custos adicionais de transportes públicos decorrentes dos vazios urbanos, financiado pelo CNPq a partir de 1995, em que se tentou aplicar um dos modelos desenvolvidos anteriormente à cidade de Araraquara. Foi exatamente neste projeto que o autor começou a utilizar as ferramentas de um Sistema de Informações Geográficas, ainda que de forma incipiente. Apesar disso, o que se pôde constatar, já nesse projeto, é que em vários momentos da pesquisa o SIG foi usado em procedimentos de análise, embora essa não tivesse sido uma proposta do projeto inicial, mas uma alternativa que surgiu naturalmente para poupar tempo e facilitar alguns procedimentos.

Este trabalho, que constou da coleta dos inúmeros elementos utilizados na modelagem desenvolvida, com uma posterior aplicação dos modelos propostos a um caso real, se insere em uma ampla linha de pesquisa. Nesta, conduzida pelo Departamento de Transportes da Escola de Engenharia de São Carlos, da Universidade de São Paulo, são estudados problemas de transportes específicos das cidades médias brasileiras, razão pela qual a aplicação aqui proposta foi desenvolvida em uma cidade desse porte - Araraquara - no estado de São Paulo. Na realização deste projeto contou-se com a colaboração do Eng. Archimedes Azevedo Raia Jr., a quem o autor orientou em programa de Mestrado concluído em 1995, e dos bolsistas de Iniciação Científica Ana Paula Rodrigues Alves Carrinho, Maurício Olbrick Rodrigues e Renato da Silva Lima, esses últimos, alunos do curso de Engenharia Civil da EESC-USP. 


\subsection{UM MODELO SIMPLIFICADO DE TRANSPORTE PÚBLICO URBANO}

Sabe-se que as densidades populacionais urbanas devem ser um ponto de interesse no processo de planejamento, uma vez que podem representar uma economia substancial para as cidades. Tanto assim, que diversos trabalhos foram elaborados com o objetivo de determinar essa densidade econômica de forma mais precisa. A influência do custo dos transportes na avaliação de uma densidade econômica não foi, no entanto, muito explorada nesses estudos. Alguns trabalhos sobre esse tema foram conduzidos em países desenvolvidos (Regional Plan Association, 1976; Newman \& Kenwhorty, 1989; Newman et al. 1995; Næss, 1996; Fouchier, 1997), mas não podem ser aplicados diretamente no Brasil, uma vez que refletem condições urbanas bastante diferentes daquelas encontradas em países em desenvolvimento.

Em virtude da complexidade das cidades, a análise da influência das densidades populacionais sobre os custos de transporte coletivo pode ser feita a partir de modelos matemáticos, que nesse caso específico, simulam as condições de uso do solo e transportes típicas das cidades médias (descritas em Silva, 1990). Algumas hipóteses foram previamente estabelecidas neste primeiro modelo utilizado, de forma a assegurar um bom nível de serviço para os usuários do transporte público urbano. Essas condições constam do estudo desenvolvido, para cidades médias, por Ferraz (1989) e são as seguintes: nenhum usuário do transporte público deverá caminhar mais do que 400 metros para chegar da origem ao ponto de embarque, ou do ponto de desembarque ao destino final, e o intervalo entre dois ônibus consecutivos será de, no máximo, 30 minutos.

As cidades consideradas eram sempre circulares e a sua ocupação residencial imaginada como totalmente homogênea (sempre com a mesma densidade). Essas características são bastante próximas daquelas adotadas por Ferraz \& Felex (1988), no modelo para avaliação da influência do porte da cidade no custo do transporte coletivo, uma vez que a metodologia aqui apresentada originou-se daquela. As viagens eram todas consideradas com destino ao centro da cidade, operando o transporte coletivo com rotas radiais. Cada uma das linhas atendia a uma área específica e o sistema operava com ônibus padronizados. As freqüências de atendimento podiam variar, desde que não fossem inferiores a 2 veículos por hora (intervalo máximo de 30 minutos).

Como o usuário não deve caminhar mais de 400 metros, a pé, para alcançar um ônibus, somente quando a cidade ultrapassasse esse raio é que deveria ser atendida por transporte coletivo, cada rota servindo a um setor, como mostrado na Figura 3.1. Cada setor de atendimento teria, então, sempre a largura máxima (junto à circunferência que delimita a zona urbana) inferior a 800 metros.

Se fosse considerada uma população urbana total constante, o raio da cidade iria variar de acordo com a densidade de ocupação. Para o caso de uma cidade com ocupação homogênea, como a que aqui estava sendo considerada, o raio dessa podia ser calculado. Uma vez definido o raio da cidade, era possível determinar o comprimento de sua circunferência externa. Sabendo-se, ainda, que cada setor de atendimento do transporte coletivo tinha largura de 800 metros, junto a esta circunferência, era possível determinar o número de setores de 
atendimento. Com o número de setores de atendimento, podia-se definir a área de cada um deles e em seguida calcular a freqüência de atendimento por transporte coletivo em cada rota. Para este cálculo eram considerados ainda: a capacidade dos ônibus, a densidade populacional e o fator de geração de viagens. A freqüência obtida devia ser, no mínimo, de 2 viagens por hora. Caso isto não ocorresse, essa era a freqüência adotada. A freqüência, o raio da cidade e o número de setores de atendimento permitiam determinar a quilometragem total percorrida em uma hora, com a qual era possível avaliar o custo do serviço por habitante.

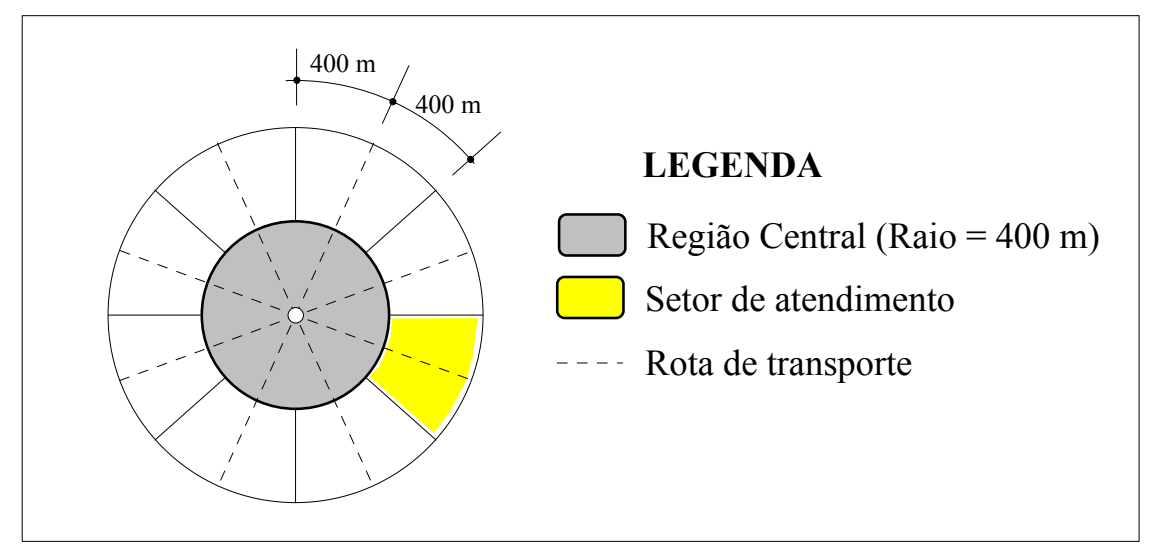

Figura 3.1 - Setores de atendimento e rotas de transporte público urbano.

Este modelo, no entanto, apresentava uma série de limitações e simplificações, que podem afastá-lo da realidade. Para avaliar essa possibilidade, foi feita uma comparação com dados de uma cidade real, apresentados por Silva \& Ferraz (1991). A diferença significativa entre os valores encontrados com o modelo simplificado e os de uma situação real indica que o modelo simplificado pode ser útil para análises gerais, apenas para observar tendências (como a de que a elevação das densidades até valores próximos de 300 habitantes/hectare traria uma redução significativa no custo dos transportes públicos), e não para avaliar valores isolados. Em virtude disso, o modelo simplificado assumiu características mais sofisticadas, passou a ser chamado de META e, tendo muitas das considerações anteriores refinadas, permitiu uma representação mais fiel das variações encontradas em diferentes cenários urbanos (ver também Barros Jr., 1994), como se poderá verificar na seqüência.

\subsection{O MODELO META}

O modelo META (Modelo para Estimativa de custos de Transportes EM ÁREAS URBANAS) foi desenvolvido com o objetivo de avaliar os custos de transportes (ônibus e automóvel) em cidades com diferentes características (formato, tamanho, densidade etc.). Tal como no modelo simplificado, foram adotadas características específicas das cidades brasileiras de pequeno e médio porte na sua formulação, o que faz com que o seu uso seja, a princípio, restrito a este grupo de cidades (Silva, 1993; Silva \& Ferraz, 1993). O modelo apresenta quatro etapas distintas (duas das quais coincidem com as etapas do conhecido modelo de transportes de quatro etapas): caracterização da cidade, geração de viagens, distribuição de viagens e cálculo dos custos de transportes. 


\subsubsection{Caracterização da Cidade}

Para aplicação do modelo META, a cidade deve ser inicialmente dividida em zonas. Estas zonas devem se caracterizar basicamente pela homogeneidade de dois elementos: a densidade populacional e o nível de renda da população residente. Devem ser identificadas ainda as zonas que são ou que contém pólos significativos de geração de viagens: zonas industriais e comerciais, grandes escolas e universidades, além de terminais de ônibus urbanos e interurbanos. A divisão da cidade em zonas deixa de ser regular, e passa a acompanhar as barreiras naturais ou artificiais já existentes, tais como rios, morros, rodovias, ferrovias etc, que naturalmente se constituem em elementos de separação de áreas urbanas.

\subsubsection{Geração de Viagens}

A quantidade de fatores que pode influenciar a geração de viagens é muito grande, incluindo o nível de motorização, nível de renda, tamanho da família, disponibilidade de transporte público, densidade populacional, bem como a qualidade dos sistemas de transportes (Sosslau et al., 1978). Enquanto que países industrializados, como os Estados Unidos por exemplo, possuem muitas informações sobre viagens atraídas e produzidas por diferentes tipos de uso do solo, no Brasil, esses dados são poucos e precários. $\mathrm{O}$ fato destes dados serem escassos no Brasil é que levou o modelo proposto a ser extremamente simples, mas com alguns avanços, em relação ao modelo simplificado.

$\mathrm{Na}$ fase de geração de viagens são calculados os totais de viagens produzidas e viagens atraídas em cada zona. Para a avaliação das viagens produzidas, três níveis de renda passaram a ser considerados (baixo, médio e alto), para obtenção das taxas de produção de viagens com início ou fim na residência. Era considerada ainda a presença de um pólo especial de geração de viagens: o Terminal Rodoviário, bastante significativo em cidades de porte médio. No que concerne à atração de viagens, o modelo trabalha com cinco taxas relacionadas a diferentes tipos de uso do solo: comercial, industrial, educacional, residencial e, de novo, a Estação Rodoviária.

\subsubsection{Distribuiç̃o de Viagens}

A distribuição de viagens é baseada no modelo gravitacional - "uma das técnicas mais amplamente usadas no planejamento de transportes" (Wright \& Ashford, 1989). A expressão do modelo gravitacional usada no modelo para calcular as viagens entre zonas inclui $A_{i}$ e $B_{j}$, que são fatores de balanceamento (como mostrado por Putman, 1983), que garantem que o total de origens e destinos para cada zona será mantido.

Existem outros dois fatores da expressão ainda não conhecidos, que são o expoente $\alpha$ e o custo $\mathrm{C}_{\mathrm{ij}}$. Na realidade, algumas formas do modelo gravitacional substituem 
$\mathrm{C}_{\mathrm{ij}}$ por $\mathrm{F}\left(\mathrm{C}_{\mathrm{ij}}\right)$, que se convencionou chamar de fator de fricção. $\mathrm{O}$ fator de fricção pode ser descrito por inúmeras funções matemáticas, tais como: exponencial, potência e geométrica. Tanto Sanches (1988), para quem não se justifica a utilização de funções complexas no caso das cidades médias, quanto Di Pierro (1982), utilizaram funções exponenciais para suas análises das cidades médias brasileiras.

$\mathrm{O}$ custo $\mathrm{C}_{\mathrm{ij}}$ da viagem aqui considerado é apenas a distância percorrida. Neste caso, o expoente $\alpha$ reflete a importância da distância (poderia ser também do custo generalizado) na distribuição das viagens. As distâncias podem ser introduzidas no modelo de diferentes formas. Uma opção é aquela em que as distâncias entre centróides são informadas uma a uma, com o seu valor real, acompanhando a rede viária da cidade. Neste caso, podem (e devem) ser considerados os obstáculos existentes na cidade em estudo. Uma segunda opção pode ser a introdução de distâncias que correspondam a trechos ortogonais, sem vinculação com a rede viária, o que pode ser calculado automaticamente pelo computador, mesmo sem dados da rede viária.

No sistema de transporte público considerado supõe-se que qualquer pessoa possa ir a qualquer ponto da cidade realizando, no máximo, uma transferência. Isto é possível com a passagem de todas as linhas pela zona central da cidade, o que normalmente acontece em cidades médias e pequenas, onde a região central é o maior pólo de atração de viagens. Assim, uma vez conhecido o local por onde passam todas as linhas (terminal central de integração, quando houver), é possível calcular também as distâncias entre centróides de duas zonas quaisquer, para viagens de ônibus. Neste caso, o cálculo deve considerar que o passageiro vai primeiro até o centro, onde toma um novo ônibus para ir até outra zona, a não ser que esteja indo para a mesma zona na qual se localiza o ponto central. Pode-se usar o exemplo da Figura 3.2, assumindo-se que o ponto central esteja localizado no centróide da zona 2, apenas para simplificação. Assim, da zona 3 para a zona 1, a distância total de ônibus seria a distância entre os centróides 3 e 2 (através do ponto B), mais a distância entre os centróides 1 e 2 , também seguindo um padrão em grelha.

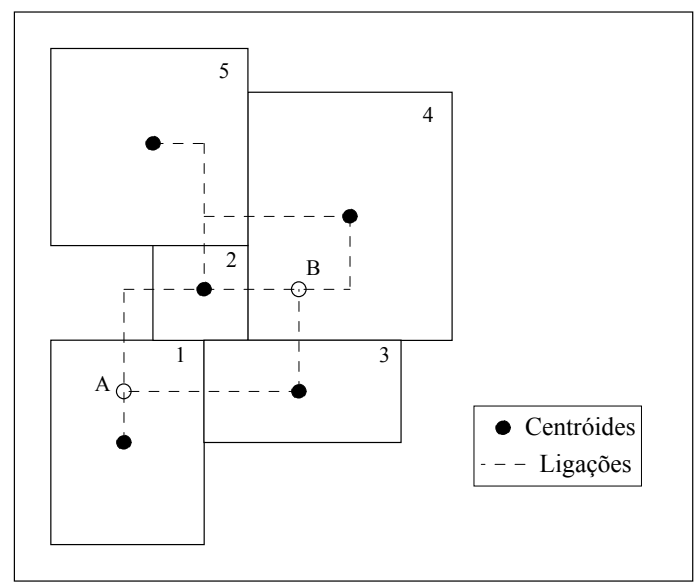

Figura 3.2 - Zonas hipotéticas, com os seus centróides e as ligações entre zonas.

Outro caso específico é aquele das viagens internas às zonas. O modelo assume que as distâncias das viagens seguirão a formulação de Smeed (1967). O valor do expoente $\alpha$ é o último elemento que o modelo necessita para que a matriz de distribuição de viagens possa ser determinada. 


\subsubsection{Cálculo dos Custos de Transporte}

Os custos de transporte são calculados de forma simples, sendo utilizadas apenas duas informações adicionais: o custo por quilômetro e o número de passageiros por veículo. No caso do transporte público, os números totais de viagens atraídas e produzidas em cada zona $i$ devem ser comparados, sendo selecionado o maior valor. Este valor representa a demanda crítica (sentido de maior movimento) que a linha de transporte público deve suportar naquela ligação entre a zona $i$ e o ponto central, supondo viagens redondas (ida e retorno). Se o sistema é projetado para atender ao maior fluxo, significa que o menor fluxo, feito no sentido inverso, será certamente atendido.

O número de viagens redondas efetivas dos ônibus pode ser obtido através da divisão da demanda crítica pelo número médio de passageiros em cada veículo, multiplicado por 2 para se considerar as viagens nos processo de ida e de volta. $\mathrm{O}$ número de viagens por trecho é multiplicado pela distância de ida e volta entre cada zona e o ponto central (viagem redonda) para se obter a distância total percorrida pelo modo ônibus. Os subtotais são então somados para obtenção da distância total viajada na cidade. $O$ valor encontrado, multiplicado pelo custo médio por quilômetro percorrido, dá o custo total de uso do transporte público.

Os resultados encontrados em aplicações teóricas com os dois modelos aqui apresentados comprovaram que, para o caso do transporte público urbano, densidades populacionais mais altas conduzem, seguramente, a um aumento de eficiência, podendo produzir até mesmo melhores resultados do que algumas estratégias estritamente operacionais. O que ficou comprovado em todos os estudos sobre o tema no Brasil é que as cidades devem ser mais adensadas. Se não é possível se obter o máximo de economia, é também inadmissível que a média das densidades urbanas esteja hoje em torno de 40 habitantes/hectare, quando a menor densidade econômica está, seguramente, acima de 100 habitantes/hectare. Isso representa desperdício de recursos e provoca desvios de investimentos, os quais, em um quadro diferente, poderiam ser alocados para outros setores de maior relevância social. Estas conclusões levaram o autor a propor uma estratégia de tributação da propriedade urbana que fosse capaz de penalizar os proprietários de terrenos ociosos. Esta estratégia, no entanto, deveria considerar ainda os custos de redes de infraestrutura, o que levou à criação de modelos para o seu cálculo, da forma apresentada no próximo item.

\subsection{AS REDES DE INFRA-ESTRUTURA E O MODELO INFRA}

O modelo INFRA leva em consideração os estudos feitos por Mascaró (1979), que foram desenvolvidos exclusivamente para as cidades médias brasileiras. Uma das suas conclusões foi a de que os custos de infra-estrutura por hectare, em função do adensamento urbano, crescem muito pouco, conforme mostra a Figura 3.3. Com exceção dos custos para as redes de energia elétrica e pavimentação, que têm uma elevação maior, os custos das demais 
redes (água pluvial, água potável, esgoto e gás canalizado) permanecem quase que constantes, com a elevação da densidade urbana. Quando se considera os custos de infra-estrutura por domicílio, eles diminuem quando se promove um maior adensamento populacional.

Silva (1993) construiu, a partir dos valores obtidos por Mascaró (1979), uma série de equações que vieram a compor o modelo INFRA, o qual pode ser utilizado para o cálculo dos custos de infra-estrutura de cidades médias brasileiras. As curvas da Figura 3.3 mostram os custos de infra-estrutura para adensamentos do intervalo entre 75 e 600 habitantes por hectare. De zero a 75 hab/ha, Silva (1993) considera que o custo é constante e igual ao custo levantado para a densidade de $75 \mathrm{hab} / \mathrm{ha}$. Para adensamentos acima de $600 \mathrm{hab} / \mathrm{ha}$, os custos não são conhecidos.

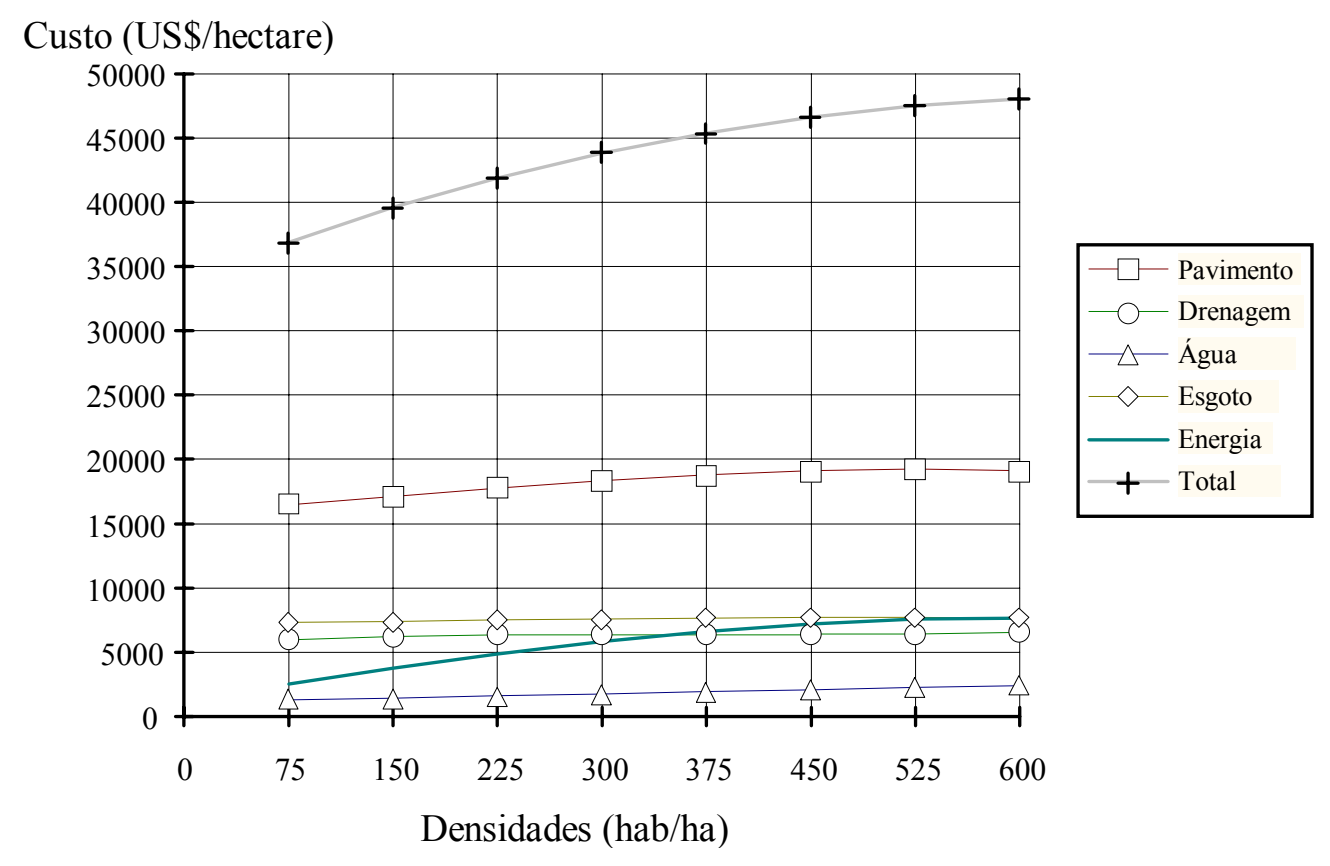

Figura 3.3 - Variação do custo de infra-estrutura, por hectare, em função da densidade populacional, para cidades médias brasileiras (Fonte: Mascaró, 1979).

O modelo INFRA, que considera todas as redes em conjunto, adotou para todas elas uma vida útil de 30 anos e um valor residual nulo. Dessa forma, conhecidos os custos para a densidade a ser estudada, através das equações do modelo, o valor correspondente anual de cada uma das redes pode ser calculado. Todas estas considerações sobre o modelo INFRA, estão inseridas em um programa de computador desenvolvido por Silva (1993), com o qual os custos de transportes (através do modelo META) e de infra-estrutura (através do modelo INFRA), podem ser calculados para qualquer cidade. Estes dois últimos modelos são a base da estratégia de tributação também proposta pelo autor e resumida a seguir.

\subsection{A ESTRATÉGIA DE TRIBUTAÇÃO DA PROPRIEDADE URBANA}

Em linhas gerais, a sistemática consiste nos seguintes passos: os custos de capital e de operação (incluindo manutenção) de cada uma das redes de infra-estrutura e de 
transporte público devem ser avaliados para duas diferentes situações (para este propósito foram desenvolvidos os modelos META e INFRA, já apresentados). A primeira situação corresponde à realidade vigente, ou seja, é um retrato dos custos da cidade real. Em seguida, ainda fazendo uso das mesmas ferramentas, deve ser avaliado o custo de uma cidade hipotética, obtida a partir da cidade real, com a eliminação de áreas e lotes desocupados. Esta seria uma cidade de referência ("ideal"), do ponto de vista dos custos das redes de infraestrutura e do transporte público. Estas duas cidades são mostradas esquematicamente na Figura 3.4.

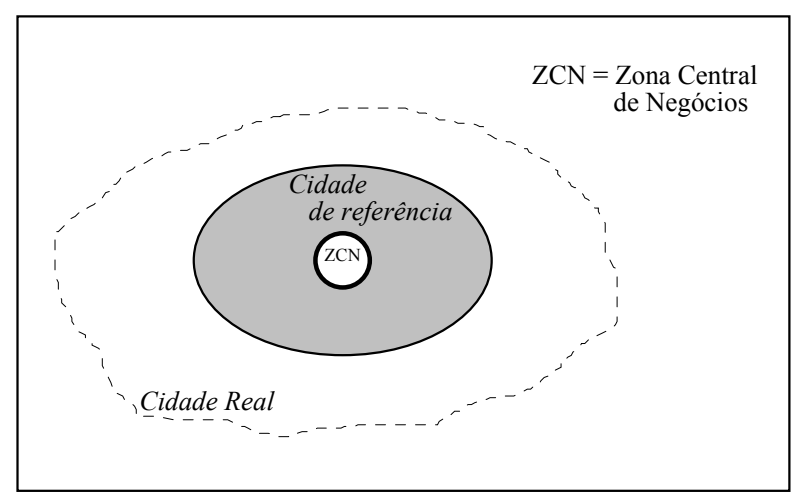

Figura 3.4 - Esquema mostrando os contornos das cidades real e de referência.

Uma vez calculados os custos da cidade real e da cidade de referência, deve ser levantada ainda a área dos terrenos (parcelados ou não) existentes na cidade, com a identificação daqueles que não estão sendo utilizados. A primeira parcela dos custos, correspondente aos custos de capital da infra-estrutura e do transporte público na cidade de referência, deve ser cobrada de todos os proprietários de terrenos que têm o serviço à disposição, proporcionalmente à área dos lotes. No caso de edifícios, o uso mais intenso do lote será compensado pela consideração do número de pavimentos, pelo qual a área do terreno deve ser multiplicada.

$$
I^{t}=\frac{C C_{i}}{\sum A_{r}^{t}} \times A_{r}^{t} \times N P
$$

Onde:

$\mathrm{I}^{\mathrm{t}}=$ imposto a ser pago pelos proprietários de todos os terrenos;

$A_{r}^{t}=$ área de terreno qualquer da cidade real;

$\mathrm{CCi}=$ custos de capital na cidade de referência;

$\mathrm{NP}=$ número de pavimentos da edificação, quando houver.

O custo de operação correspondente à cidade de referência deve ser cobrado, sob a forma de taxa, proporcionalmente ao consumo. No caso do transporte público, esta taxa pode ser cobrada diretamente nos ônibus.

$$
T=\frac{C O_{i}}{C o T} \times C o U
$$


Onde:

$\mathrm{T}=$ taxa a ser paga pelos proprietários de todos os terrenos que utilizam os serviços urbanos;

$\mathrm{CO}_{\mathrm{i}}=$ custos totais de operação da cidade de referência;

$\mathrm{CoT}=$ consumo total de qualquer dos serviços públicos (pode ser a área total de terrenos atendidos pelo serviço, no caso de serviço cuja medição de consumo não é possível transporte público (se for o caso), pavimentação, águas pluviais etc.);

$\mathrm{CoU}=$ consumo unitário (por terreno) de qualquer dos serviços públicos (ou área de terreno atendido pelo serviço, se não se pode medir o consumo).

A diferença entre os custos totais (de capital e de operação) da cidade de referência e da cidade real deve ser também rateada, mas somente entre os proprietários dos terrenos ociosos, uma vez que estes são os únicos responsáveis pelo acréscimo dos custos.

$$
I^{t o}=\frac{\left(C C_{r}-C C_{i}\right)+\left(C O_{r}-C O_{i}\right)}{\sum A_{r}^{t o}} \times A_{r}^{t o}
$$

Onde:

$\mathrm{I}^{\text {to }}=$ imposto a ser pago pelos proprietários de todos os terrenos ociosos;

$\mathrm{CC}_{\mathrm{r}}=$ custos totais de capital da cidade real;

$\mathrm{CC}_{\mathrm{i}}=$ custos totais de capital da cidade de referência;

$\mathrm{CO}_{\mathrm{r}}=$ custos totais de operação da cidade real;

$\mathrm{CO}_{\mathrm{i}}=$ custos totais de operação da cidade de referência;

$A_{r}^{t o}=$ área de terreno ocioso qualquer da cidade real.

Na expressão (1) foi inserido o número de pavimentos para fazer com que os proprietários de edifícios paguem de forma proporcional à parcela dos serviços que utilizam. $\mathrm{O}$ uso do número de pavimentos elimina a necessidade de qualquer cadastro mais detalhado da edificação. Se estes cadastros fossem de fácil execução, poderia ser utilizado o índice de aproveitamento (área construída dividida pela área do lote), se maior que 1, em lugar do número de pavimentos.

\subsection{UMA AVALIAÇÃO DOS CUSTOS DECORRENTES DOS VAZIOS URBANOS}

A pesquisa relatada neste item, intitulada Uma aplicação do modelo META para avaliação dos custos adicionais de transportes públicos decorrentes dos vazios urbanos, foi um prosseguimento dos estudos sobre o impacto das densidades populacionais urbanas nos custos de transportes (Silva, 1990), bem como sobre a possibilidade de se tributar a propriedade urbana a partir dos custos de transportes que ela impõe ao conjunto da sociedade (Silva, 1993). Em ambos os trabalhos foram construídos modelos com o objetivo de avaliar os custos de transportes das cidades estudadas. Uma aplicação real e detalhada desses modelos, no entanto, exigia a coleta de inúmeros dados de campo, o que não havia sido feito nas pesquisas realizadas até então. 
Para que se tenha, a priori, uma noção mais clara das diversas abordagens, pesquisas e levantamentos que foram conduzidas neste projeto, são listadas a seguir todas as tarefas e dados que o modelo META requer para o cálculo dos custos de transportes, tanto para viagens de automóvel como para viagens de ônibus:

\section{ETAPA DE CARACTERIZAÇÃo DA CIDADE}

- Divisão da cidade em zonas de tráfego;

- Coordenadas dos vértices das áreas retangularizadas;

- Nível de renda de cada zona de tráfego;

- Zonas de tráfego homogêneas de mesma densidade e nível de renda;

- Densidade populacional de cada zona de tráfego.

\section{ETAPA DE GERAÇÃo DE VIAGENS}

○ Produção de viagens

- Taxas de produção de viagens, por ônibus e automóveis, para os três níveis de renda e para o terminal rodoviário.

- Atração de viagens

- Taxas de atração de viagens para as atividades comerciais/de serviços/industriais, educacionais, residenciais e do terminal rodoviário, para automóveis e ônibus, separadamente;

- Número de empregos existentes em cada zona de tráfego;

- Número de vagas escolares ocupadas em cada zona de tráfego.

\section{ETAPA DE DISTRIBUIÇÃO DE VIAGENS}

- Escolha da função fator de fricção (custo generalizado da viagem) que melhor se adapta ao estudo de caso (potência ou exponencial);

- Calibração do modelo gravitacional, obtendo-se o valor do expoente $\alpha$, que reflete o impacto das distâncias nas viagens;

\section{CÁlCULO dOS CUSTOS DE TRANSPORTES}

- Custo por quilômetro para ônibus e automóvel;

- Número médio de passageiros por automóvel e ônibus.

\subsubsection{Caracterização da Cidade}

A Prefeitura de Araraquara, a exemplo do que acontece na maioria das cidades brasileiras, não dispunha de dados necessários para a caracterização da cidade. Estes dados, quando não disponíveis, exigem um esforço considerável para o seu levantamento. A caracterização da cidade, segundo o modelo META, deve apresentar, sempre que possível, zonas de tráfego com características de homogeneidade quanto ao adensamento populacional e nível de renda familiar. A caracterização da cidade constou de quatro etapas, nas quais se fez uso dos recursos de um SIG pela primeira vez. 
A primeira etapa consistiu na elaboração de uma base de dados de adensamento populacional urbano. Na segunda etapa, além de se criar uma base de dados com os níveis de renda, foi proposta uma metodologia para a sua determinação, a partir de dados de consumo de energia elétrica. Essa foi uma das atividades em que se fez uso de um Sistema de Informações Geográficas de forma intensa. A terceira etapa consistiu na obtenção das zonas de tráfego e, finalmente, foram levantados os demais dados necessários para a caracterização da cidade.

\subsubsection{Levantamento de Dados Sobre o Adensamento Populacional Urbano}

Essa etapa constou na digitalização, com o auxílio de uma mesa digitalizadora e utilizando o software TransCAD versão 2.1, do mapa do sistema viário urbano de Araraquara, seguida da criação de uma base de dados contendo os registros relativos ao adensamento populacional. Para a determinação dos níveis de adensamento populacional urbano foi adotado um método simplificado, prático e rápido, com um custo muito baixo, a partir da utilização de fotografias aéreas de pequeno formato, técnica já utilizada por Silva (1993), Silva et al. (1994) e Raia Jr. (1995).

Através da análise de um mosaico confeccionado a partir de fotografias aéreas tiradas a bordo de um avião tipo Piper, a uma altitude de aproximadamente 1.500 metros, pôde-se representar, em um mapa em escala 1:10.000, o adensamento populacional. Esse adensamento foi traduzido por seis padrões: áreas não habitáveis, áreas com raro adensamento, áreas pouco adensadas, áreas medianamente adensadas, áreas relativamente adensadas, e áreas totalmente adensadas. Cada área está associada a um determinado número de quadras, e a uma população que nela habita, conforme apresentado na Tabela 3.1. A partir destas informações, alimentou-se o banco de dados do SIG, com o qual se gerou o mapa temático de adensamento populacional por áreas da Figura 3.5.

\begin{tabular}{ccc}
\hline OCUPAÇÃO (\%) & QUADRAS & POPULAÇÃO \\
\hline $0-5$ & 442 & 1.050 \\
$5-25$ & 460 & 6.556 \\
$25-50$ & 180 & 6.414 \\
$50-75$ & 243 & 14.431 \\
$75-100$ & 1.582 & 131.536 \\
\hline
\end{tabular}

Tabela 3.1 - Níveis de ocupação, número de quadras e população de Araraquara. 


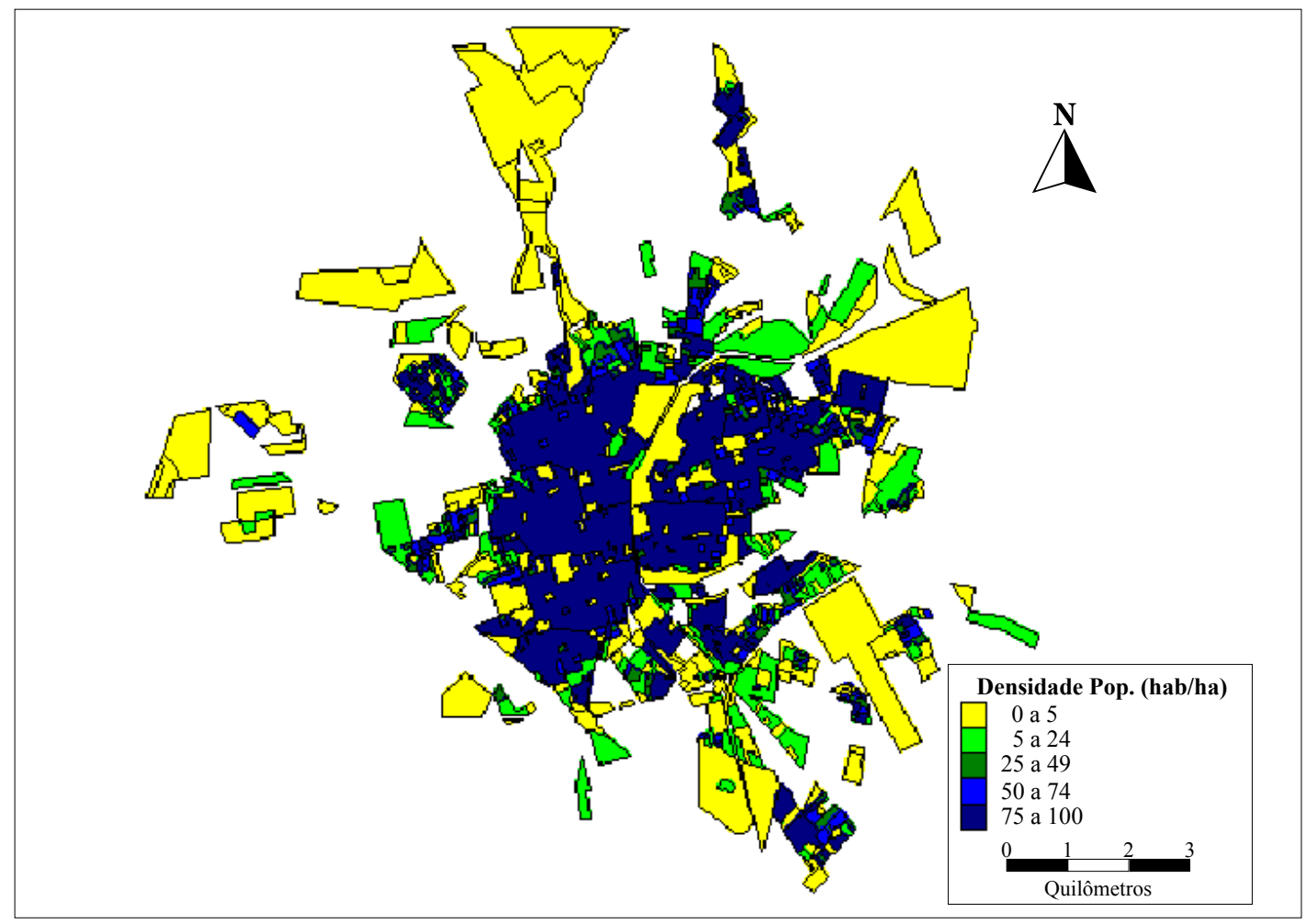

Figura 3.5 - Mapa de níveis de adensamento populacional em Araraquara.

\subsubsection{Levantamento de Dados Sobre Níveis de Renda da População}

Embora estivesse disponível no Departamento de Planejamento da Prefeitura de Araraquara um mapa contendo as regiões de diferentes níveis de renda, essas apresentavam uma grande agregação. Por outro lado, os dados sobre níveis de renda levantados pela primeira vez no censo demográfico brasileiro de 1991 ainda não estavam disponíveis para uso neste projeto, apesar de decorridos mais de quatro anos após a realização da pesquisa. Em vista disso, optou-se pelo desenvolvimento de uma nova alternativa para a determinação de níveis de renda, que viesse atender às necessidades deste estudo e que também pudesse servir de ferramenta para outros estudos. Neste caso, o uso do SIG foi extremamente importante para esta atividade. No novo método proposto, um mapa de nível de renda familiar podia ser obtido a partir de dados de consumo de energia elétrica residencial.

A obtenção do nível de renda familiar a partir de consumo de energia elétrica residencial não chega a representar uma novidade. GEIPOT (1980 e 1985) já haviam usado o consumo de energia elétrica, obtido através de pesquisa domiciliar, como indicador de renda familiar. Como a realização de pesquisas domiciliares requer uma grande quantidade de recursos, tanto humanos quanto financeiros, que não se dispunha para o projeto, procurou-se uma forma alternativa de se obter os dados de consumo médio de energia elétrica residencial, sem a necessidade de realização das onerosas pesquisas domiciliares. O caminho encontrado foi o levantamento de dados de consumo residencial mensal de energia elétrica, junto aos arquivos da Companhia Paulista de Força e Luz (CPFL). A Companhia elabora levantamentos periódicos de consumo de energia elétrica, tanto residencial quanto não-residencial, por 
transformadores de energia elétrica instalados em toda a cidade, mantendo esses dados arquivados em microfilmes.

Do registro de cada um dos transformadores consta o consumo médio das residências a ele ligadas. Em média, vinte e quatro residências estão ligadas a um determinado transformador. De um total de 1.564 transformadores residenciais instalados na zona urbana de Araraquara, foi pesquisada uma amostra aleatória correspondente a 54\% do total (845 transformadores). Os transformadores pesquisados foram alocados no mapa do sistema viário de Araraquara anteriormente digitalizado e, associados a cada transformador os valores de consumo médio por residência correspondente (ver Figura 3.6). Confrontando, com o SIG, o mapa com os valores médios de cada transformador com o mapa de níveis de renda elaborado pelo Departamento de Planejamento da Prefeitura, foram obtidas faixas de consumo, correspondentes aos níveis de renda (para mais detalhes ver Silva et al., 1996). Os níveis de renda e suas faixas de consumos, estão mostrados na Tabela 3.2.

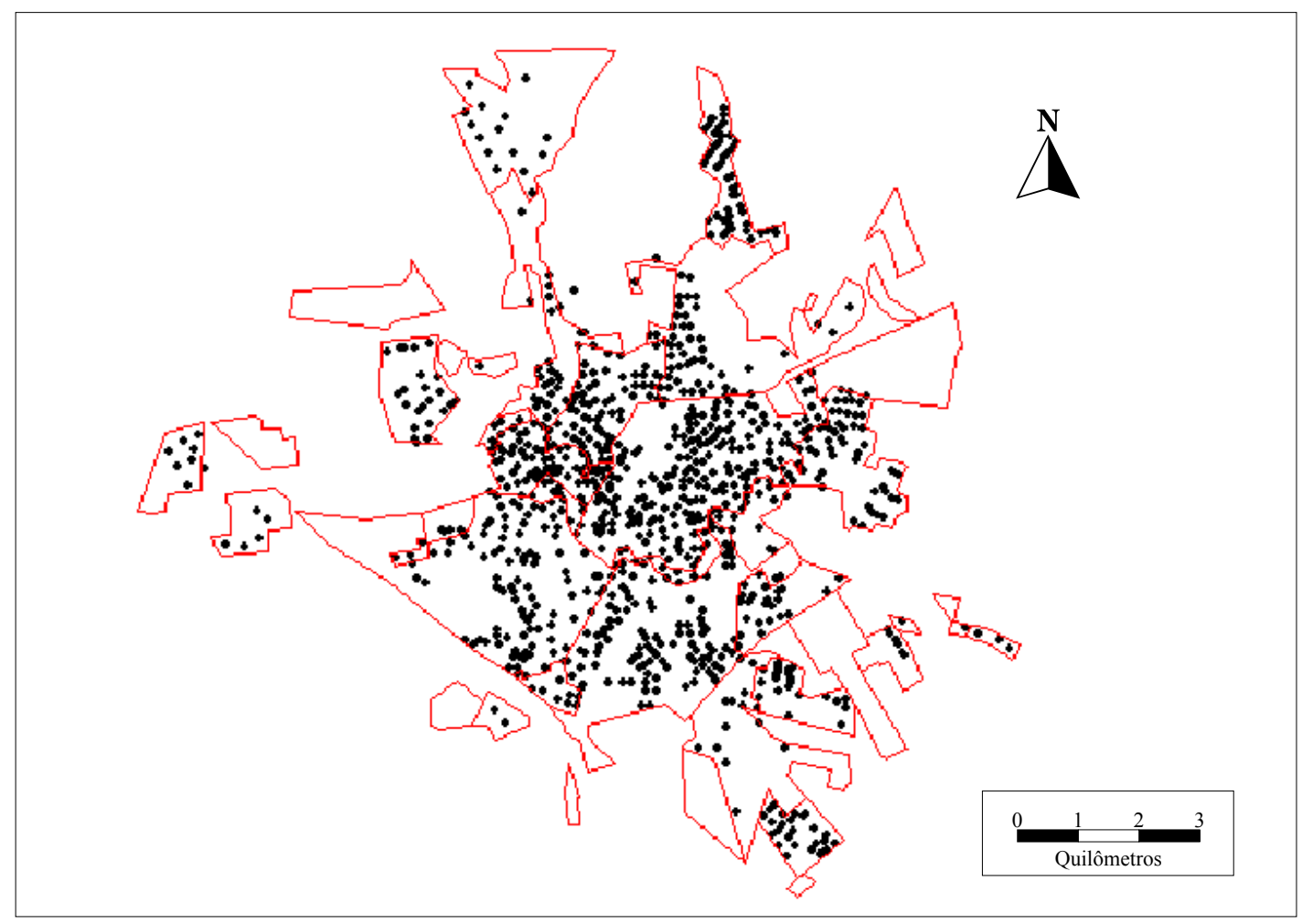

Figura 3.6 - Localização dos transformadores de energia elétrica pesquisados em Araraquara.

\begin{tabular}{cc}
\hline $\begin{array}{c}\text { CONSUMO MENSAL } \\
\text { KWH/MÊS }\end{array}$ & NÍVEL DE RENDA \\
\hline até 165 & baixo \\
de 165 a 240 & médio \\
acima de 240 & alto \\
\hline
\end{tabular}

Tabela 3.2 - Faixas de consumo de energia elétrica e nível de renda.

Esta classificação de consumo relacionada com o nível de renda pode ser considerada aceitável, para o grau de agregação utilizado, uma vez que $86,8 \%$ dos 
transformadores localizados nas zonas de renda baixa registraram consumo acima de 165 $\mathrm{kWh} ; 74,2 \%$ dos transformadores localizados nas zonas de renda média apresentaram consumo entre 165 a $240 \mathrm{kWh}$; e $89,7 \%$ dos transformadores localizados nas zonas de alta renda registraram consumo acima de $240 \mathrm{kWh}$. É conveniente utilizar esta classificação com certa cautela, uma vez que, em residências com consumos próximos aos limites das faixas, a definição dos níveis de renda não é muito clara. A metodologia, no entanto, permite que se trabalhe com diferentes níveis de agregação das zonas, dependendo da precisão desejada e dos recursos humanos e de informática disponíveis.

\subsubsection{Caracterização das Zonas de Tráfego}

Esta é uma das etapas que se beneficiou do SIG de forma bastante significativa, como ocorreu em trabalhos de outros autores (Sanches, 1996; Taco et al., 1996). No caso aqui considerado, foi feita a combinação de elementos de diferentes camadas (layers), mesmo quando os seus contornos não eram coincidentes. Foi possível, por exemplo, calcular a população contida em cada uma das áreas com diferentes níveis de renda, a partir dos dados constantes na camada de densidade populacional.

Além disso, pôde ser comprovada a afirmação feita em Silva (1993), de que a simplificação das zonas de tráfego (áreas retangulares e obtidas através de processo manual) não comprometeria os resultados. Comparando-se as áreas das zonas de tráfego obtidas com a utilização do método simplificado com as áreas reais em que a cidade havia sido dividida, estas últimas estimadas pelo SIG a partir do mapa digitalizado da cidade, verificou-se uma variação de apenas 1,15\%. Considerando individualmente cada uma das 38 zonas de tráfego, o valor das áreas variou de $0,18 \%$ a $6,02 \%$, sendo que as maiores distorções ocorreram nas menores áreas, onde a própria espessura do traço do grafite $(0,5 \mathrm{~mm})$ que delimitava as áreas desenhadas em papel milimetrado, era suficiente para gerar alguma distorção. Ainda assim, $0,5 \mathrm{~mm}$ é um valor geralmente aceito para erros planimétricos sobre mapas (D'Alge \& Goodchild, 1993).

Recorreu-se ainda a um teste para se avaliar a precisão no valor das áreas obtidas com o uso do SIG, utilizando-se um planímetro, instrumento destinado a medição de áreas de figuras planas. Dadas as pequenas diferenças encontradas e considerando-se que o planímetro é um instrumento adequado para este teste, pois para o caso de aplicação em pequenas superfícies (como é o caso de medições em mapas em escala de 1:10.000), a sua precisão é de 1\% (Davis et al., 1972), constatou-se a viabilidade do uso do SIG para o cálculo das áreas (visto que a variação de medições obtidas pelo software e aquelas obtidas pelo planímetro foi muito pequena).

\subsubsection{Geração de Viagens}

A etapa de geração de viagens está intimamente relacionada com o levantamento dos tipos de viagens de pessoas e veículos em zonas de tráfego. Como parte da pesquisa de geração de viagens, levantou-se o número de viagens que se origina em cada zona 
de tráfego (produção de viagens) e o número de viagens destinadas a cada zona (atração de viagens). Apesar do software de SIG disponível possuir ferramentas para esta fase, em nenhum momento dessa primeira aplicação elas chegaram a ser utilizadas.

Procurou-se, nesta fase, obter taxas de produção de viagens a partir de pesquisas de campo, utilizando a técnica de contagem de tráfego (veículos e passageiros) através de uma seção. Devido ao reduzido número de pesquisadores disponíveis (quatro) para a contagem de tráfego, foi necessário selecionar bairros que apresentassem características de acesso com relativo controle, ou seja, no máximo duas vias de acesso. Em virtude da grande dificuldade de se obter dados nas duas regiões de renda alta de Araraquara através da pesquisa domiciliar, optou-se por realizar a pesquisa no Parque Sabará, em São Carlos, uma vez que este bairro, além de conter uma população de alta renda, possui a forma de condomínio fechado, com um só local de entrada e saída de moradores e funcionários.

A etapa de atração de viagens consistiu, basicamente, de dois passos: o levantamento do número de empregos existentes no comércio/indústria/serviços, o número de vagas nas escolas e, posteriormente, a determinação das taxas de atração de viagens. Para a obtenção do número de empregos oferecidos pelas indústrias, comércio e serviços, bem como a localização dos mesmos, procedeu-se um levantamento das empresas (individuais e coletivas) cadastradas junto ao Departamento de Finanças da Prefeitura e à pesquisa publicada por SEADE (1993). O número de vagas oferecidas nas escolas de Araraquara (todos os níveis, menos pré-escola) foi obtido através de levantamentos junto às Secretarias Municipal e Estadual de Educação, universidades e escolas de ensino superior da cidade. SEADE (1993) apontou o número de matrículas em 1991, para o ensino de primeiro e segundo graus, muito próximo dos dados pesquisados neste estudo.

As taxas de atração de viagens pelos motivos estudo e trabalho, para modos automóvel e ônibus foram obtidos de GEIPOT (1985), em pesquisa elaborada na cidade tipo Bauru. Extrapolando as taxas de atração de viagens de Bauru para as atividades de trabalho e estudo, Raia Jr. (1995) obteve taxas de atração de viagens para Araraquara, que incluiu também as taxas para atividades residencial e terminal rodoviário. As taxas de atração de viagens para atividades residenciais foram obtidas por meio de pesquisas em seções de controle nos acessos de alguns bairros. A taxa de atração para o terminal rodoviário resulta do estudo feito por FIPAI (1987), adaptado para os valores vigentes de demanda de viagens.

\subsubsection{Distribuiç̃o de Viagens}

Para a utilização do modelo gravitacional de distribuição de viagens proposto por Silva (1993), é necessária a calibração do mesmo, com a escolha da função do fator de fricção (custo generalizado) e da determinação do expoente $\alpha$, tanto para o ônibus quanto para o automóvel. Para efeito deste estudo, considerou-se que o fator de fricção representa, tão somente, a distância. A calibração do modelo gravitacional foi feita para as curvas das funções potência e exponencial, sendo que os pontos da curva construída através de dados reais de viagens foram obtidos através de pesquisa de campo, realizadas em vários locais da cidade: área central, campus universitário, bairros. Aos entrevistados perguntou-se os seus endereços de origem e destino e o modo de transporte utilizado (ônibus ou automóvel). As 
respostas que não se enquadravam em um dos dois modos foram desprezadas. A partir dos endereços fornecidos, as viagens realizadas foram consideradas como sendo iniciadas e terminadas nos centróides das zonas de tráfego que contêm os respectivos endereços de origem e destino.

As distâncias percorridas em cada viagem por automóvel correspondem às distâncias entre centróides, calculadas pelo SIG e procurando-se obedecer o método do caminho mínimo entre os centróides. As viagens por ônibus, de acordo com a hipótese prevista no modelo META, foram consideradas como passando sempre pela área central (em Araraquara, zona 38) ou se dirigindo a esta ou dela partindo. Esses caminhos foram identificados visualmente na tela do computador, utilizando-se o mapa do sistema viário anteriormente digitalizado no SIG e percorrendo-se com o cursor da mesa digitalizadora as vias que compunham o trajeto hipoteticamente mínimo. $\mathrm{Na}$ ocasião tentou-se utilizar as rotinas do próprio software para o cálculo do caminho mínimo de forma automática, mas uma série de inconsistências na rede de vias digitalizadas inviabilizou o processo. Ainda assim, a identificação dos menores caminhos diretamente na tela do computador agilizou, de certa forma, os cálculos das distâncias. Essa foi, no entanto, a única aplicação do SIG nesta etapa do projeto.

\subsubsection{Custos de Transportes}

A verificação do item custos de transportes constou de duas partes: a primeira consistiu no levantamento do número médio de passageiros por automóvel e ônibus. Na segunda parte foram pesquisados os custos médios por quilômetro para ônibus e automóvel.

Para o levantamento no número médio de passageiros em automóveis, foram utilizados os dados obtidos nas pesquisas de contagem de veículos e passageiros, realizadas na fase de geração de viagens. Foram pesquisados 3.032 veículos (2480 automóveis, 399 motos e 153 caminhões), que transportaram um total de 5.658 passageiros, apresentando uma média de 1,87 passageiros por veículo. A contagem levou em consideração tanto os veículos que entraram nos bairros, quanto os que deles saíram. O número médio obtido, de 1,87 passageiros por veículo, é relativamente alto comparando com os dados normalmente adotados nos estudos de transportes, próximos de 1,4 passageiros/veículo. Ferraz (1990) utilizou o valor 1,5 passageiros/veículo e Silva (1993) adotou 1,2 passageiros/veículo. Os números relativos à operação do sistema de transporte coletivo por ônibus foram obtidos através de um levantamento realizado junto aos arquivos da Companhia Trólebus Araraquara, que apontou uma quantidade transportada, em 1994, de 18.075.038 passageiros, o que corresponde a 1.506.253 passageiros transportados por mês.

O custo médio por quilômetro, para automóveis, é um dado praticamente inexistente, a não ser em determinadas empresas que operam com frotas de automóveis, mas que não têm interesse em torná-los públicos. Para se obter um consumo médio mensal que fosse significativo foram considerados os custos (fixos e variáveis) de seis levantamentos mensais no ano de 1994, da revista especializada Custos \& Fretes (1994), que considera o veículo Gol CL 1.6, a álcool, como veículo padrão. Chegou-se a valor total do custo por quilômetro, para automóvel, de US\$ 4,2544. O custo médio por quilômetro, para o transporte 
coletivo, foi obtido a partir do Boletim Estatístico da ANTP (1994). Foram utilizados os dados mensais de 33 cidades médias (18,9\% das cidades de porte médio existentes no país, de acordo com FIBGE, 1992), durante 5 meses, representando um total de 144 valores de custo por quilômetro levantados. O valor médio obtido foi de $1,1338 \mathrm{US} \$ / \mathrm{km}$.

\subsubsection{Aplicação do Modelo META para a Cidade de Araraquara}

Após a conclusão da fase de levantamento de dados, aplicou-se o modelo META em Araraquara, com o que foi possível avaliar os custos adicionais de transportes provocados pelos vazios urbanos na cidade. Para isso, foram avaliados os custos de transportes para diferentes cenários (o real e quatro outros hipotéticos) de ocupação e uso do solo da cidade mencionada. Além dos cálculos dos custos das redes de transportes, foram feitas estimativas de custos relativos às redes de infra-estrutura (pavimentação e drenagem, água potável, esgoto sanitário, energia elétrica) existentes na cidade de Araraquara, utilizando os recursos do modelo INFRA.

A primeira configuração analisada corresponde à situação real da cidade, levando-se em conta as barreiras geográficas e terrenos vazios, nos locais onde hoje eles existem. As Configurações 2 e 4 são variações da primeira (Real), assumindo que as áreas próximas à Zona Central de Negócios $(\mathrm{ZCN})$ teriam densidades mais altas, produzindo uma densidade global maior que a da primeira situação. Nestes casos, as localizações das zonas originais próximas ao centro foram mantidas e os tamanhos ajustados ao novo adensamento. Nas Configurações 3 e 5, cidades praticamente quadradas foram construídas totalmente compactas sem, no entanto, preservar as condições das zonas iniciais da Configuração Real. Através da comparação dos custos totais da primeira configuração e das outras configurações mais compactas, foi possível fazer uma avaliação dos custos resultantes do espalhamento da cidade.

A Figura 3.7 mostra um esquema da cidade de Araraquara, usado para a confecção da Configuração Real, que foi dividida em 38 zonas para a aplicação dos modelos. As zonas 1, 10, 16, 17, 19, 20 e 22, na Figura 3.7, são apresentadas com destaque, para indicar que são áreas com características de maiores geradoras de viagens. As zonas 26 a 36 são áreas institucionais e a zona 27 representa o campus universitário (UNESP). A ZCN está localizada em 3 diferentes zonas: 16, 17 e 38, sendo que nesta última ocorre teoricamente a interseção das linhas de ônibus na área central. O Terminal Interurbano de Passageiros encontra-se na zona 17. 


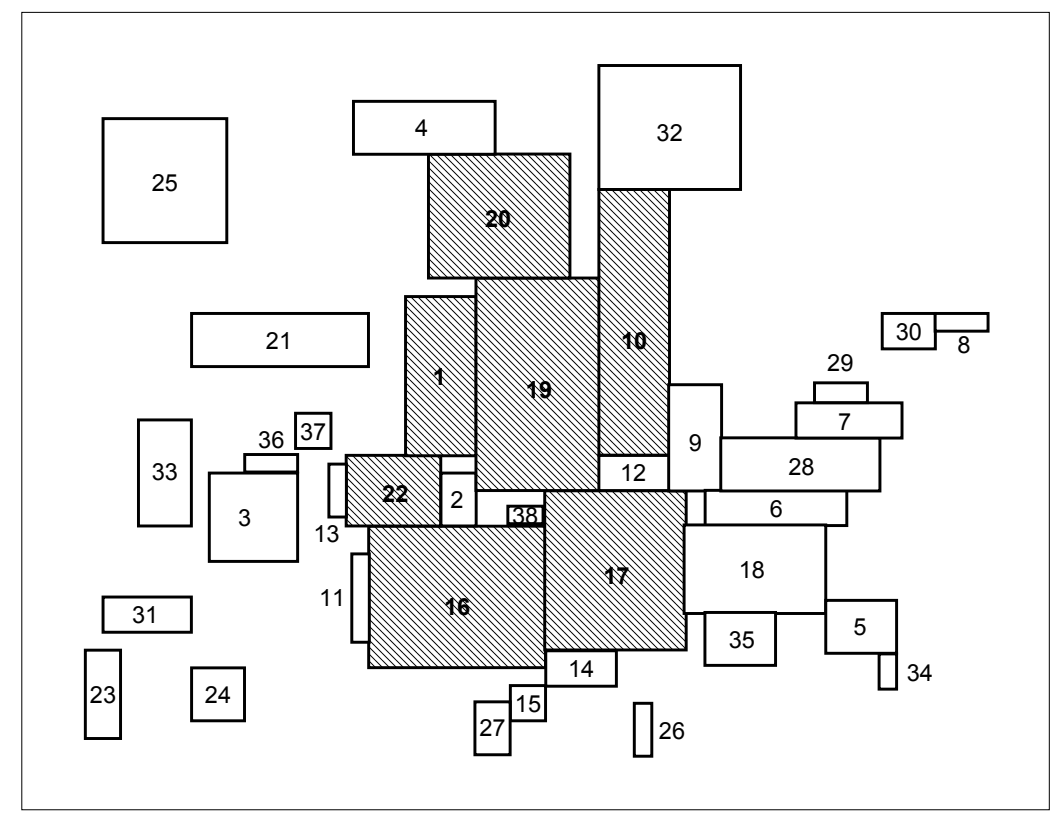

Figura 3.7 - Esquema mostrando as zonas da cidade atual - Configuração Real.

Os níveis de renda e as densidades populacionais de cada zona foram identificadas, bem como as áreas institucionais. A cidade de Araraquara apresenta uma densidade bruta baixa, de 25 hab/ha, que se deve, em parte, à grande quantidade de áreas institucionais (campus universitário, parque ecológico, cemitérios, pátios ferroviários, etc.) existentes na cidade, totalizando 916 ha ( $14 \%$ da área da cidade). A maior causa para a baixa densidade global, no entanto, são os vazios urbanos. As duas zonas mais adensadas (1 e 2), ambas de renda alta, apresentam densidades de 84 e 47 hab/ha, respectivamente. As zonas de baixa renda são aquelas que apresentam as menores densidades e são, na sua maioria, justamente aquelas mais distantes da área central.

$\mathrm{Na}$ Configuração 2, as zonas que estavam mais próximas da área central da cidade tiveram suas densidades elevadas até atingir o nível de 100 habitantes por hectare, que é um valor acima do maior valor encontrado na cidade, mas ainda é menor que o valor de 118 habitantes por hectare proposto pelo autor para esta configuração. Como conseqüência deste adensamento, algumas zonas periféricas foram eliminadas. Este procedimento foi adotado para cada um dos três níveis de renda de forma isolada. Ainda com a densidade de 100 habitantes por hectare, foi construída uma nova configuração (3), agora uma cidade totalmente regular, de formato aproximadamente quadrado. Nesta configuração, as zonas de mesma atividade foram agrupadas em blocos. Seguindo com a simulação de novas configurações, duas novas são propostas. Nestas novas configurações, as densidades das zonas não institucionais foram elevadas até o nível de 150 habitantes por hectare, tal como proposto por Silva (1993).

Os resultados finais da aplicação em Araraquara apontam para uma queda nos custos, tanto para automóvel quanto para ônibus, quando se eleva o nível de adensamento e se promove uma compactação da cidade. Comparando a Configuração $5 \mathrm{com}$ a Configuração Real, os custos da primeira, em geral, diminuíram em aproximadamente $50 \%$ em relação à segunda. Uma vez estimados os custos de transportes para as várias configurações simuladas, foram calculados ainda os custos de infra-estrutura para os mesmos cenários. Um resumo dos 
resultados é apresentado na Tabela 3.3. Fazendo-se uma comparação entre os custos de transporte e infra-estrutura, por exemplo, o custo de infra-estrutura diário por habitante é apenas $30,7 \%$ do custo de transportes, para a Configuração Real. No caso extremo, de cidade totalmente compactada e com adensamento de 150 hab/ha nas zonas residenciais, os custos diários de infra-estrutura chegam a ser somente $11,2 \%$ em relação aos custos de transportes.

\begin{tabular}{ccccccc}
\hline Configuração & $\begin{array}{c}\text { Área } \\
\left(\mathrm{km}^{2}\right)\end{array}$ & $\begin{array}{c}\text { População } \\
\text { (habitantes) }\end{array}$ & $\begin{array}{c}\text { Densidade } \\
\text { total bruta } \\
(\mathrm{hab} / \mathrm{ha})\end{array}$ & $\begin{array}{c}\text { Custo infra- } \\
\text { estrutura } \\
\text { (US\$/hab/dia) }\end{array}$ & $\begin{array}{c}\text { Custo } \\
\text { transporte } \\
\text { (US\$/hab/dia) }\end{array}$ & $\begin{array}{c}\text { Custo total } \\
\text { habitante } \\
\text { (US\$/dia) }\end{array}$ \\
\hline $\mathrm{R}$ & 63,81 & 156465 & 25 & 0,427 & 1,389 & 1,816 \\
2 & 24,50 & 156462 & 63 & 0,119 & 1,136 & 1,255 \\
3 & 25,83 & 156462 & 61 & 0,119 & 0,862 & 0,981 \\
4 & 19,38 & 156462 & 81 & 0,081 & 0,972 & 1,053 \\
5 & 18,90 & 156463 & 83 & 0,081 & 0,723 & 0,804 \\
\hline
\end{tabular}

Tabela 3.3 - Custos das redes de transporte e infra-estrutura das Configurações Real, 2, 3, 4 e 5, calculados com os modelos META e INFRA (Fonte: Raia Jr., 1995)

A obtenção dos custos de transportes e infra-estrutura para vários cenários permitiu, finalmente, avaliar os custos adicionais de transportes provocados pelos vazios urbanos na cidade estudada. O objetivo desses modelos, no entanto, vai além da simples determinação desses custos, servindo de base para uma tributação dos terrenos vazios, cuja discussão não é aqui pertinente.

\subsection{COMENTÁRIOS FINAIS}

Os objetivos do projeto de pesquisa, cujos resultados estão resumidos no item 3.5 desse capítulo, foram atingidos. A coleta, em uma cidade de porte médio, dos dados utilizados pelo modelo META, foi feita com sucesso, dentro do prazo previsto. Em seguida foi feita uma aplicação dos modelos META e INFRA a um caso real, com cujos resultados se pôde avaliar os custos adicionais de transportes provocados pelos vazios urbanos na cidade de Araraquara. Nesta aplicação, no entanto, foi possível identificar alguns problemas do modelo META e extrair daí algumas sugestões para o seu aprimoramento, bem como da estratégia de tributação.

Embora do ponto de vista acadêmico o modelo META seja extremamente simples, houve ainda uma certa dificuldade para a sua aplicação, decorrente, dentre outras coisas, do processo da obtenção de dados. Os dados, quando existentes, geralmente não estavam organizados e, na maioria das vezes, encontravam-se totalmente desatualizados. Neste ponto começou-se a especular que os Sistemas de Informações Geográficas poderiam ser extremamente úteis no processo de implantação de cadastros municipais, armazenando dados alfanuméricos e espaciais. Para fins de tributação da propriedade, se esses cadastros fossem realizados com o uso de um SIG seria possível delimitar-se a área de um imóvel, assim como conhecer-se sua localização e outras características de natureza espacial desejadas. O seu dinamismo permite que modificações (tais como agregações, desmembramentos, aumento de área construída, dentre outros) sejam facilmente atualizadas 
(Kirchner, 1994). Um mapeamento produzido por este tipo de software, portanto, é uma ferramenta poderosa no cadastro urbano que, por sua vez, pode servir de base para o sistema de taxação (Schneider, 1994; Silva et al., 1994).

Neste projeto, a importância do SIG se fez notar, principalmente, na fase de caracterização da cidade. Foi desenvolvido um método para o levantamento de níveis agregados de renda familiar, a partir de dados de consumo de energia elétrica, coletados diretamente na concessionária local. As faixas que definiram os níveis de renda representaram satisfatoriamente a realidade da cidade de Araraquara e, é possível que possam, inclusive, ser utilizadas em outras cidades de porte médio. Para outras categorias de cidades, essas faixas de consumo talvez devam ser ajustadas.

Segundo Raia Jr. (1995), uma alteração que poderia ser introduzida seria a utilização de planilhas eletrônicas, tanto para a calibração dos modelos, quanto para seu uso como banco de dados. Isso poderia conduzir a um expressivo avanço na interface com o usuário, do programa de computador disponível para o uso dos modelos META e INFRA, que se mostrou pouco flexível. Sugeria ainda o uso de Sistemas de Informação Geográfica para Transportes na própria modelagem, através de uma interface com os modelos aqui apresentados.

Estas constatações estimularam o autor a elaborar um novo projeto, em que os modelos propostos trabalhassem efetivamente dentro de um SIG-T. Desta forma, seria possível fazer uso dos recursos já disponíveis no programa escolhido, além de permitir o desenvolvimento de aprimoramentos na estratégia de tributação, tais como considerações relativas a localização de cada lote a ser taxado. O novo projeto, também financiado pelo CNPq, teve início em 1997, e um resumo do seu desenvolvimento é apresentado no próximo capítulo. 


\section{COMBINANDO OS MODELOS META E INFRA COM UM SIG}

O desenvolvimento das atividades de pesquisa do autor até o ano de 1997, descritas nos capítulos anteriores, o levaram naturalmente a pensar em aplicar os recursos dos SIG em seu principal projeto, que consiste em investigar estratégias para reduzir os custos urbanos decorrentes do espalhamento das cidades. O primeiro contato com o SIG para este fim, no entanto, havia sido muito superficial, como se pôde acompanhar no capítulo 3. Aquela primeira tentativa, no entanto, levou o autor a elaborar novo projeto, que se iniciou em 1997, intitulado Combinando os modelos META e INFRA com um SIG-T para avaliação dos custos adicionais de transportes e infra-estrutura decorrentes dos vazios urbanos, a exemplo do anterior, também financiado pelo CNPq.

O principal objetivo do projeto, cujos resultados são resumidos neste capítulo, é realizar uma ligação efetiva entre os modelos externos propostos e um software de Sistema de Informações Geográficas. O SIG utilizado, denominado comercialmente como TransCAD, foi criado para aplicações em transportes e os modelos aqui considerados são aqueles desenvolvidos por Silva (1993), como parte de sua estratégia de tributação da propriedade urbana, denominados META e INFRA, e que foram apresentados no capítulo anterior.

As ferramentas disponíveis na versão 3.0 do software TransCAD, em sua versão para plataforma Windows, tornaram possível reconstruir os modelos diretamente dentro do software, de forma bastante simplificada, ao invés de exigir a importação de dados pré-processados em outro programa de computador. Essa última opção iria demandar mudanças no programa original concebido para execução dos modelos META e INFRA, como o objetivo de melhorar a sua interface de saída, uma vez que ele não considerava a possibilidade de exportar os resultados. A construção dos modelos diretamente dentro do ambiente do SIG traz, por outro lado, algumas desvantagens, como a necessidade de reavaliar os modelos passo a passo, para garantir que suas estimativas são corretas. Apesar disto, esta desvantagem parece ser um problema menor, se for considerada a vasta gama de benefícios que podem advir do uso de Sistemas de Informações Geográficas para inúmeras outras aplicações.

\subsection{ADAPTAÇÃO DO CONJUNTO ORIGINAL DE DADOS PARA O SIG}

Para assegurar que os resultados obtidos dentro do SIG eram semelhantes aqueles obtidos com os modelos no programa original, foram implementados os mesmos 
dados coletados por Raia Jr. (1995) e utilizados na aplicação dos modelos META e INFRA para a cidade de Araraquara, descrita no capítulo 3. Devido a este fato, o primeiro passo no processo de reconstrução dos modelos no SIG foi a adaptação dos dados originais para o software TransCAD. É importante lembrar que os modelos originais trabalhavam com poucos dados de fácil obtenção, como parte de uma filosofia de modelos simplificados para atender a países em desenvolvimento, abordagem que não se alterou neste projeto.

\subsubsection{Caracterização da Cidade}

Uma das etapas mais importantes para a operação dos modelos originais era a definição de Zonas de Tráfego Homogêneas (ZTH). Essas ZTHs foram definidas inicialmente como retângulos, cada um deles limitado por dois pontos (canto superior esquerdo e canto inferior direito), como no programa original. O programa de computador utilizava as coordenadas desses dois pontos para calcular as coordenadas do centróide de cada retângulo (ou ZTH) e as distâncias entre os centróides de todas as ZTHs. Os pontos usados em Araquarara, que eram baseados em um sistema local de coordenadas, foram adaptados para uso no Trans $C A D$, de maneira a assegurar que ambos os mapas teriam a mesma escala, embora o mapa gerado no SIG passasse a ter coordenadas geográficas. Isso é importante, pois a comparação das ZTHs reais (obtidas através de digitalização de mapas em papel) e das ZTHs simplificadas, que será descrita mais adiante, somente será possível se os dois mapas estiverem na mesma escala. A cidade de Araraquara foi dividida em 38 ZTHs, definidas pelas coordenadas apresentadas na Tabela 4.1.

Não foi difícil adaptar os pontos que definem as ZTHs para o software TransCAD, a partir de alguns procedimentos específicos. Inicialmente, o arquivo com as coordenadas foi salvo como um arquivo $d B$ ase. Ao ler este tipo de arquivo, o SIG identifica a existência de coordenadas e pergunta ao usuário se ele deseja criar arquivos geográficos. Usando esta opção, dois arquivos geográficos foram criados a partir do mesmo arquivo dBase: um com os pontos superiores e outro com os pontos inferiores dos retângulos. Em seguida, os dois arquivos geográficos foram reunidos em um mesmo mapa, com os pontos superiores e inferiores identificados com símbolos diferentes e rotulados com os seus números de identificação, como se pode verificar na Figura 4.1.

Na Figura 4.1 pode-se também observar uma das ZTHs, representada por um retângulo preenchido na cor cinza. Essa é a zona de tráfego número 24, como se pode verificar pelos números de seus pontos extremos (ver também Figura 3.7). Com esses pontos de referência é possível desenhar todas as ZTHs. Embora esse processo não seja muito preciso, ele seria razoável se o propósito não fosse comparar os resultados dos modelos em seu programa original com os resultados destes mesmos modelos rodando em um SIG. Neste caso, seria recomendável maior precisão. 


\begin{tabular}{|c|c|c|c|c|c|}
\hline \multirow{3}{*}{$\begin{array}{c}\text { Número } \\
\text { da Zona } \\
\text { (ID) }\end{array}$} & \multicolumn{4}{|c|}{ Coordenadas } & \multirow{3}{*}{$\begin{array}{c}\text { Densidade } \\
\text { populaciona } \\
\text { l } \\
\text { (hab/ha) }\end{array}$} \\
\hline & \multicolumn{2}{|c|}{ Ponto Inicial } & \multicolumn{2}{|c|}{ Ponto Final } & \\
\hline & $\mathbf{X}$ & $\mathbf{Y}$ & $\mathbf{X}$ & $\mathbf{Y}$ & \\
\hline 1 & 5,13 & 5,49 & 6,20 & 7,61 & 47,00 \\
\hline 2 & 5,75 & 4,43 & 6,20 & 5,13 & 84,00 \\
\hline 3 & 2,39 & 3,98 & 3,63 & 5,31 & 19,00 \\
\hline 4 & 4,43 & 10,09 & 6,64 & 10,71 & 23,00 \\
\hline 5 & 11,77 & 2,21 & 12,92 & 3,10 & 40,00 \\
\hline 6 & 10,09 & 4,25 & 11,95 & 4,87 & 9,00 \\
\hline 7 & 11,06 & 5,75 & 12,39 & 6,20 & 15,00 \\
\hline 8 & 12,48 & 6,90 & 13,28 & 7,17 & 11,00 \\
\hline 9 & 9,38 & 4,87 & 10,27 & 6,46 & 24,00 \\
\hline 10 & 8,41 & 5,31 & 9,38 & 9,20 & 29,00 \\
\hline 11 & 4,25 & 2,21 & 4,60 & 3,72 & 17,00 \\
\hline 12 & 8,41 & 4,87 & 9,38 & 5,31 & 54,00 \\
\hline 13 & 4,16 & 4,43 & 4,43 & 5,31 & 18,00 \\
\hline 14 & 7,52 & 1,33 & 8,41 & 1,86 & 58,00 \\
\hline 15 & 6,90 & 0,89 & 7,52 & 1,50 & 5,00 \\
\hline 16 & 4,60 & 1,77 & 7,52 & 4,34 & 38,00 \\
\hline 17 & 7,52 & 1,86 & 9,74 & 4,87 & 32,00 \\
\hline 18 & 9,74 & 2,74 & 11,77 & 4,25 & 4,00 \\
\hline 19 & 6,20 & 4,87 & 8,41 & 7,97 & 52,00 \\
\hline 20 & 5,31 & 7,97 & 7,70 & 10,09 & 13,00 \\
\hline 21 & 2,21 & 6,64 & 4,87 & 7,52 & 13,00 \\
\hline 22 & 4,43 & 4,34 & 5,75 & 5,49 & 67,00 \\
\hline 23 & 0,44 & 0,44 & 1,06 & 1,95 & 1,00 \\
\hline 24 & 1,77 & 0,80 & 2,66 & 1,86 & 4,00 \\
\hline 25 & 0,89 & 8,32 & 2,66 & 10,44 & 1,00 \\
\hline 26 & 8,94 & 0,44 & 9,20 & 1,06 & 11,00 \\
\hline 27 & 6,37 & 0,44 & 6,90 & 1,33 & 0,00 \\
\hline 28 & 10,27 & 4,87 & 12,12 & 5,75 & 0,00 \\
\hline 29 & 11,42 & 6,20 & 11,86 & 6,37 & 10,00 \\
\hline 30 & 12,04 & 6,81 & 12,48 & 7,17 & 4,00 \\
\hline 31 & 0,89 & 2,21 & 2,21 & 2,74 & 6,00 \\
\hline 32 & 8,41 & 9,20 & 10,18 & 10,97 & 0,00 \\
\hline 33 & 1,33 & 4,33 & 2,21 & 6,02 & 2,00 \\
\hline 34 & 12,74 & 1,77 & 12,92 & 2,21 & 0,00 \\
\hline 35 & 10,18 & 1,68 & 11,06 & 2,74 & 1,00 \\
\hline 36 & 2,92 & 5,31 & 3,54 & 5,58 & 0,00 \\
\hline 37 & 3,54 & 5,49 & 3,98 & 5,93 & 3,00 \\
\hline 38 & 7,17 & 4,34 & 7,52 & 4,60 & 83,00 \\
\hline
\end{tabular}

Tabela 4.1 - Dados usados por Raia Jr. (1995), para a definição das ZTHs nos modelos META e INFRA.

Para melhorar a precisão, o arquivo geográfico contendo as zonas de tráfego foi exportado em formato de texto (para o TransCAD, tipo Text/Geography) e as coordenadas nele registradas foram corrigidas uma a uma, com o auxílio de um editor de texto. O arquivo corrigido foi então novamente carregado no SIG, desta vez convertendo-se as coordenadas locais X e Y para o sistema global de coordenadas, com a ajuda dos pontos de controle apresentados na Tabela 4.2. O resultado final foi um arquivo geográfico de áreas contendo as 38 zonas de tráfego criadas por Raia Jr. em Araraquara, como se pode verificar na Figura 4.2. 


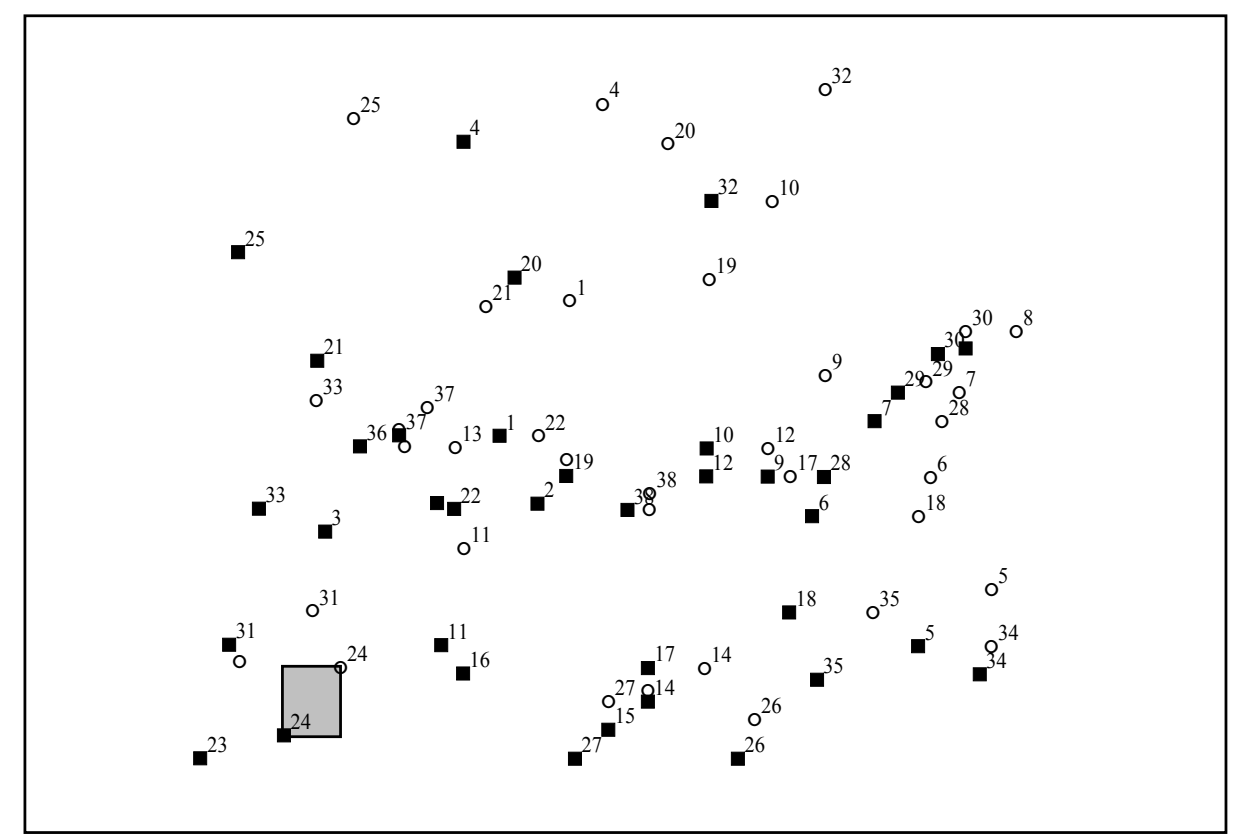

Figura 4.1 - Pontos iniciais e finais das ZTHs.

\begin{tabular}{ccccc}
\hline $\begin{array}{c}\text { NÚMERO DA ZONA } \\
\text { (ID) }\end{array}$ & LOCAL $\mathbf{X}$ & LOCAL $Y$ & LONGITUDE & LATITUDE \\
\hline 4 & 5.535 & 10.400 & -48.153696 & -21.736693 \\
23 & 0.750 & 1.195 & -48.242080 & -21.779165 \\
34 & 12.830 & 1.990 & -48.142639 & -21.841158 \\
\hline
\end{tabular}

Tabela 4.2 - Pontos de controle usados para conversão das coordenadas locais X e Y para coordenadas geográficas.

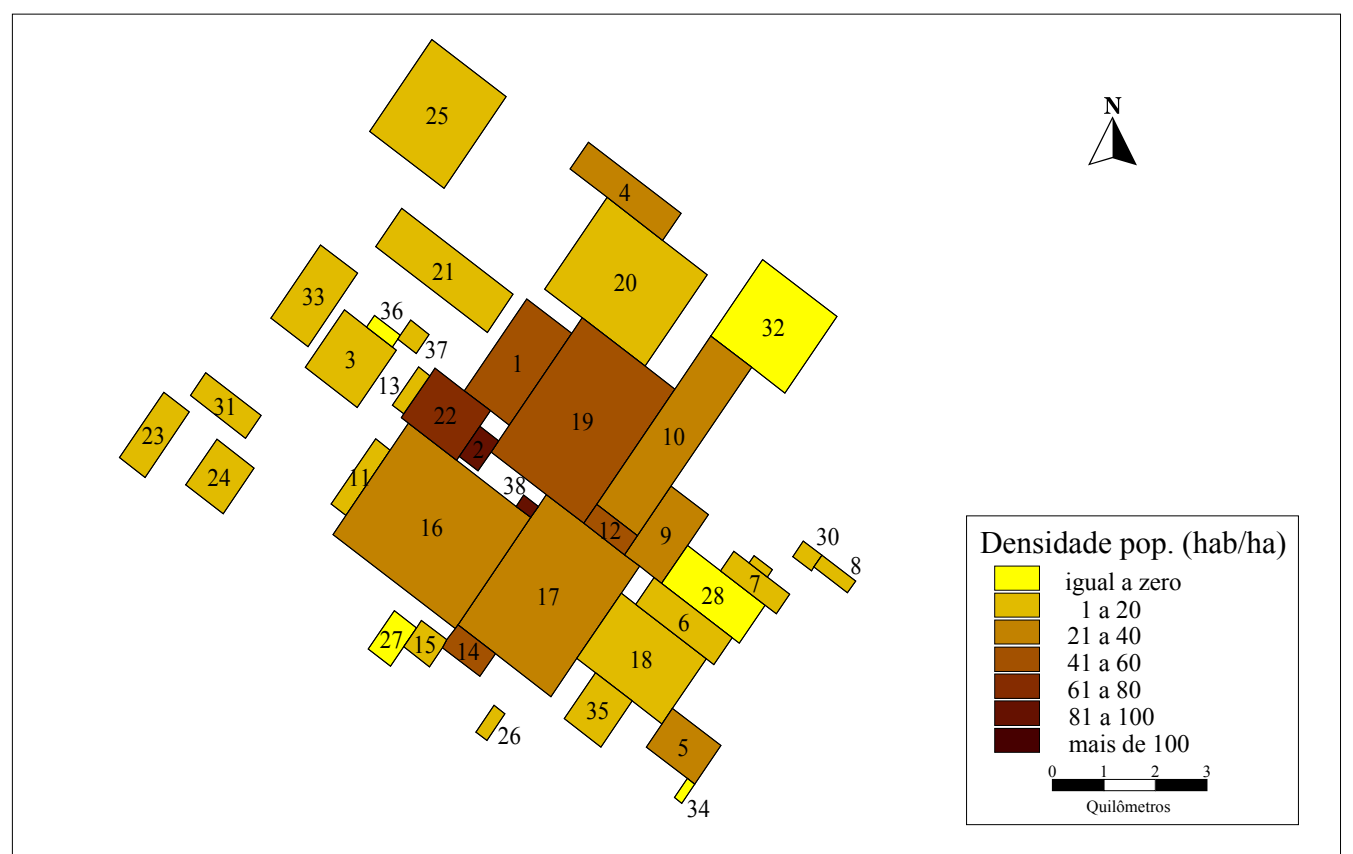

Figura 4.2 - Representação das Zonas de Tráfego Homogêneas de Araraquara no SIG.

Como o programa original calculava as distâncias entre zonas seguindo uma malha ortogonal que conectava os centróides, as coordenadas de cada centróide tiveram que 
ser calculadas. Elas foram obtidas em uma planilha eletrônica, a partir do mesmo arquivo dBase com as coordenadas extremas das ZTHs. Um arquivo geográfico de linhas contendo todas as ligações entre centróides através de uma malha ortogonal foi criado a partir de um arquivo texto e os resultados podem ser vistos na Figura 4.3.

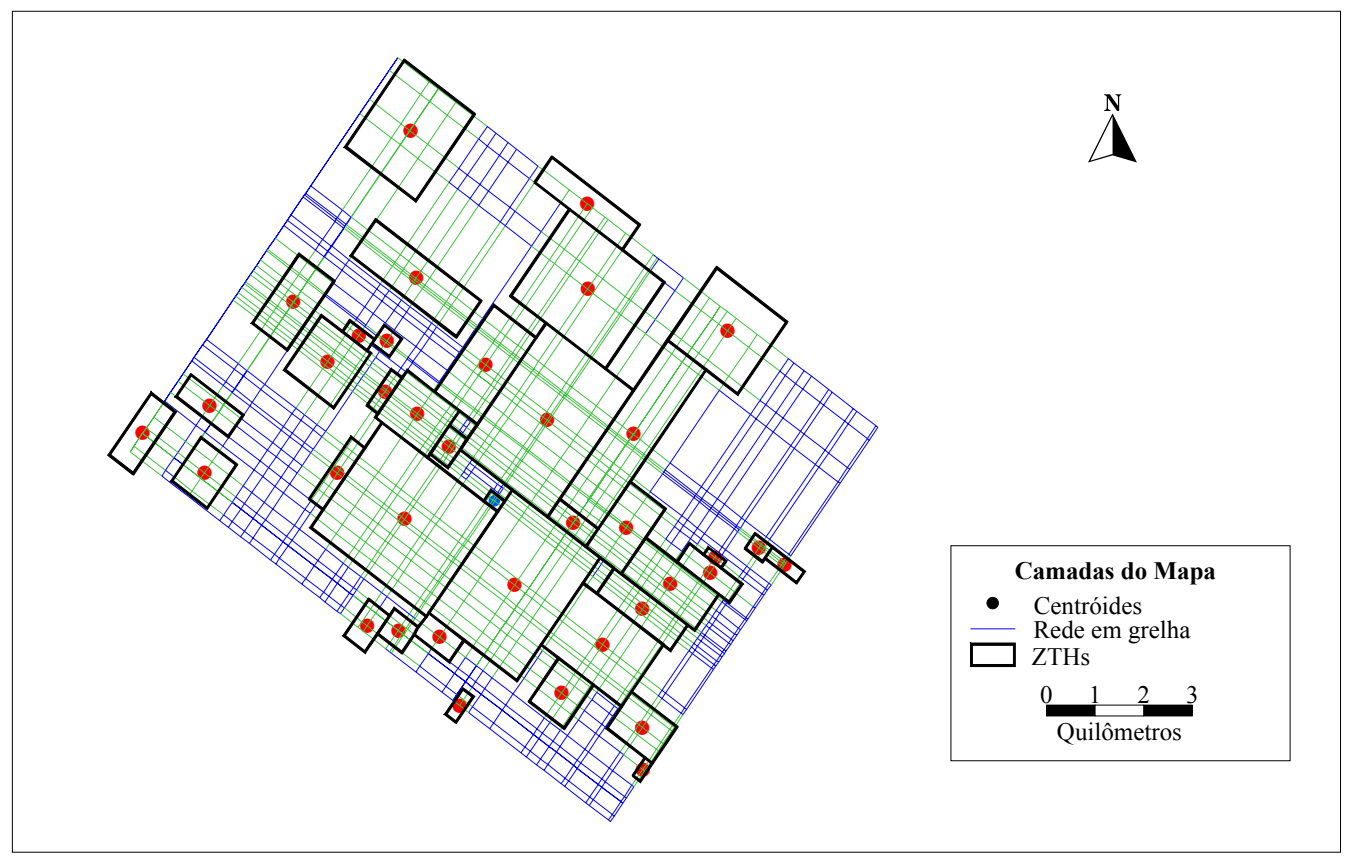

Figura 4.3 - Rede em grelha adaptada do modelo META para o SIG.

A nova base de dados de linhas foi usada para criar uma rede, ou seja, o elemento através do qual se pode efetivamente realizar análises de transportes (Silva e Waerden, 1997). Os menores caminhos conectando os centróides foram então calculados sobre esta rede, e os resultados armazenados em um arquivo para matrizes. Neste mesmo arquivo foram adicionadas duas outras matrizes: uma com as distâncias calculadas pelo programa original do modelo META e outra usada para comparar os valores das duas matrizes anteriores.

A matriz com os menores caminhos teve que ser modificada, uma vez que o SIG não calculava automaticamente as distâncias intrazonais. Devido a isto, estas distâncias tiveram que ser calculadas com a introdução de uma fórmula em uma nova coluna (formula field) de um arquivo anexado à base de dados original (joined view). A fórmula usada foi a mesma do programa original (Silva, 1993), segundo a qual distâncias intrazonais podem ser assim obtidas:

$$
d_{i z}=0,87 \cdot \sqrt{A_{i}}
$$

Onde $d_{i}$ é a distância intrazonal e $A_{i}$ é a área de uma zona qualquer $i$.

As áreas consideradas na fórmula acima são as mesmas calculadas pelo SIG para as Zonas de Tráfego Homogêneas. Elas foram transferidas para um arquivo de matrizes, a partir da identificação dos identificadores de colunas e linhas de uma matriz escrita em um arquivo dBase. A ferramenta para juntar matrizes foi então utilizada para transferir os resultados de distâncias intrazonais para a matriz completa, preenchendo a diagonal anteriormente vazia. 
A segunda matriz do arquivo de matrizes foi preenchida com as distâncias calculadas no programa original, para permitir uma comparação com os resultados obtidos pelo SIG. Os valores foram importados de um arquivo dBase, através de rotinas disponíveis no próprio SIG. Na seqüência, a terceira matriz do arquivo de matrizes foi preenchida com o resultado da divisão da primeira (distâncias calculadas no SIG) pela segunda (distâncias calculadas no programa original) matriz. Quanto mais os valores dessa terceira matriz se aproximassem de um, melhor seria a representação da rede criada por Raia Jr. para Araraquara pelo SIG. A média dos valores de todas as células dessa matriz foi igual a 1,02, que pode ser considerada boa. Observando os valores máximos encontrados na matriz, apenas quatro deles $(1,034,1,034,1,038,1,042)$ excederam $3 \%$ de diferença.

A melhor maneira de reduzir ainda mais as diferenças entre as distâncias calculadas pelo TransCAD e as distâncias calculadas pelo modelo original seria carregar novamente o arquivo texto, utilizando novos pontos de controle. Todavia, o processo de localização de melhores pontos de controle exige bastante tempo, uma vez que não se pode identificar a priori quais os melhores pontos para este propósito. Como a introdução dos dados originais de Araraquara no SIG servia apenas para proceder a uma verificação dos resultados dos modelos a serem empregados a seguir, e essas diferenças são muito pequenas para alterar os resultados de forma significativa, essa etapa foi considerada concluída. As próximas etapas consistiram na implementação dos submodelos de transportes no SIG, começando pela fase de geração de viagens.

\subsubsection{Geraç̃o de Viagens}

A fase de produção de viagens do modelo era baseada em taxas de geração de viagens para três níveis de renda: alta, média e baixa. A razão para esta divisão em três classes apenas era a dificuldade de obtenção de dados sócio-econômicos, como é o caso dos níveis de renda, à época que o modelo foi concebido. Para lidar com esta dificuldade, Silva et al. (1996) chegaram a propor um método, já com o auxílio de um SIG, para obtenção destes dados a partir do consumo de energia elétrica, como se viu no capítulo anterior. As viagens atraídas foram calculadas tomando por base o número de empregos e estudantes em cada zona de tráfego, assim como a população residente em cada uma delas. Todas as taxas de produção e atração de viagens, aqui resumidas na Tabela 4.3, foram obtidas por Raia Jr. (1995) através de entrevistas e medição de fluxos nas cidades de Araraquara, São Carlos e Bauru, conforme citado no capítulo 3 .

O software de SIG empregado, por ter sido desenvolvido especificamente para planejamento de transportes, oferece mais do que uma possibilidade para a fase de geração de viagens. Três tipos de modelos estão disponíveis na versão 3.0 do TransCAD: classificação cruzada, modelos de regressão e discrete choice models. O software também oferece um Método de Resposta Rápida (Quick Response Method) e uma base de dados com taxas de viagens calculadas pelo Instituto Americano de Engenheiros de Transportes para os Estados Unidos da América.

Como o Método de Resposta Rápida tem características bastante semelhantes ao modelo META, poderia perfeitamente substituí-lo na fase de geração de viagens. Entretanto, o software oferece uma outra alternativa que parece ser ainda mais adequada à forma como o modelo foi concebido para ser usado. Como um dos objetivos do modelo é permitir a criação 
de cenários para as cidades analisadas, a possibilidade de se ter fórmulas diretamente armazenadas na base de dados parece ser bastante interessante. Com as taxas de geração de viagens armazenadas em fórmulas dinâmicas, que são atualizadas cada vez que os dados de entrada são alterados, é muito simples obter as viagens geradas em tantos cenários quanto se desejar, bastando para isso introduzir novos dados de entrada para cada novo cenário.

\begin{tabular}{lccc}
\hline \multicolumn{3}{c}{ TAXAS DE PRODUÇÃO DE VIAGENS } & \\
\hline \multicolumn{1}{c}{ Característica da zona } & Auto & Ônibus & Total \\
\hline Baixo (viagens/pessoa/dia) & 0,796 & 1,809 & 2,605 \\
Médio (viagens/pessoa/dia) & 1,692 & 0,895 & 2,587 \\
Alto (viagens/pessoa/dia) & 2,806 & 0,100 & 2,906 \\
Terminal de ônibus (viagens/habitante/dia) & 0,005 & 0,023 & 0,028 \\
\hline
\end{tabular}

TAXAS DE ATRAÇÃO DE VIAGENS

\begin{tabular}{lcc}
\hline \multicolumn{1}{c}{ Característica da zona } & Viag. Auto & Viag. Ônibus \\
\hline Comércio/Indústria/Serviços (viagens/emprego/dia) & 1,7858 & 1,2668 \\
Educação (viagens/estudante/dia) & 1,0456 & 0,7418 \\
Residencial (viagens/pessoa/dia) & 1,5590 & 0,3000 \\
Terminal de ônibus (viagens/habitante/dia) & 0,0054 & 0,0230 \\
\hline
\end{tabular}

Tabela 4.3 - Taxas de geração de viagens na cidade de Araraquara, coletadas por Raia Jr. (1995).

O modelo original também incluía um pólo especial de geração de viagens: o terminal de ônibus interurbanos. Isto também foi considerado na modelagem com o SIG, através do mesmo recurso da introdução de uma fórmula na base de dados. Essa abordagem é que garante a atualização dos resultados a cada alteração dos dados de entrada. As fórmulas são usadas aqui para criar novas colunas da base de dados, a partir de operações matemáticas com dados armazenados em outros campos e dependendo permanentemente desses dados, o que garante a sua atualização. Os dados de entrada para os modelos de geração de viagens foram armazenados em quatro colunas da base de dados, como se pode ver na Tabela 4.4.

A informação sobre Nivel de Renda é usada em uma expressão lógica, do tipo "se o nível de renda é $X$, então multiplique a população pela taxa $Y$ ". O campo População é usado tanto para estimar viagens atraídas como viagens produzidas, enquanto que os campos Número de empregos e Número de alunos são ambos usados para estimar viagens atraídas.

Existem ainda quatro colunas adicionais na base de dados, contendo informações relativas ao pólo especial de geração de viagens (neste caso, o terminal de ônibus interurbano). Essas colunas, com apenas um registro cada, sempre relativo à zona onde se encontra o terminal, contêm informações a respeito do número de viagens produzidas e atraídas, tanto para carros como para ônibus. 


\begin{tabular}{|c|c|c|c|c|}
\hline ZONA & $\begin{array}{l}\text { NÍVEL DE } \\
\text { RENDA }\end{array}$ & POPULAÇÃO & $\begin{array}{l}\text { NÚMERO DE } \\
\text { EMPREGOS }\end{array}$ & $\begin{array}{c}\text { NÚMERO DE } \\
\text { ESTUDANTES }\end{array}$ \\
\hline 1 & Alto & 10661 & 442 & 1123 \\
\hline 2 & Alto & 2729 & 76 & 4169 \\
\hline 3 & Baixo & 3133 & 23 & 0 \\
\hline 4 & Baixo & 3151 & 152 & 1856 \\
\hline 5 & Baixo & 4094 & 70 & 1774 \\
\hline 6 & Baixo & 1038 & 3 & 0 \\
\hline 7 & Baixo & 898 & 0 & 0 \\
\hline 8 & Baixo & 238 & 0 & 0 \\
\hline 9 & Baixo & 3396 & 48 & 1197 \\
\hline 10 & Baixo & 10943 & 6600 & 1084 \\
\hline 11 & Baixo & 898 & 51 & 820 \\
\hline 12 & Baixo & 2305 & 23 & 0 \\
\hline 13 & Baixo & 428 & 0 & 0 \\
\hline 14 & Baixo & 2736 & 910 & 0 \\
\hline 15 & Médio & 189 & 42 & 0 \\
\hline 16 & Médio & 28517 & 9863 & 15303 \\
\hline 17 & Médio & 21383 & 4454 & 4659 \\
\hline 18 & Médio & 1226 & 3685 & 0 \\
\hline 19 & Médio & 35622 & 7015 & 7330 \\
\hline 20 & Médio & 6587 & 183 & 271 \\
\hline 21 & Médio & 3043 & 116 & 1291 \\
\hline 22 & Médio & 10171 & 1882 & 1205 \\
\hline 23 & Médio & 94 & 0 & 0 \\
\hline 24 & Médio & 377 & 2679 & 0 \\
\hline 25 & Médio & 375 & 39 & 0 \\
\hline 26 & Baixo & 177 & 0 & 0 \\
\hline 27 & -- & 0 & 99 & 0 \\
\hline 28 & -- & 0 & 0 & 0 \\
\hline 29 & Baixo & 75 & 0 & 0 \\
\hline 30 & Baixo & 63 & 0 & 0 \\
\hline 31 & Baixo & 420 & 0 & 0 \\
\hline 32 & -- & 0 & 155 & 0 \\
\hline 33 & Baixo & 297 & 0 & 0 \\
\hline 34 & -- & 0 & 0 & 0 \\
\hline 35 & Baixo & 93 & 31 & 0 \\
\hline 36 & -- & 0 & 0 & 0 \\
\hline 37 & Baixo & 58 & 268 & 0 \\
\hline 38 & Médio & 1047 & 648 & 773 \\
\hline
\end{tabular}

Tabela 4.4 - Dados de entrada para a fase de geração de viagens.

Os métodos de balanceamento utilizados no SIG para igualar o número de viagens atraídas por uma área e o número de viagens produzidas em uma área são semelhantes aos métodos usados no programa original. O SIG possui uma rotina interna que pode armazenar os resultados em arquivos binários, os quais podem ser facilmente anexados às bases de dados das ZTHs. 


\subsubsection{Distribuição de Viagens}

O programa original com o modelo META tem a fase de distribuição de viagens baseada no modelo gravitacional, duplamente restringido para viagens produzidas e viagens atraídas. A medida de impedância usada no modelo de distribuição de viagens era a distância percorrida, de forma a facilitar o processo de aquisição de dados. O programa original trazia ainda duas alternativas para as funções de impedância: exponencial e potência.

O SIG aqui empregado pode trabalhar com modelos com restrição simples ou dupla, oferecendo como função de impedância as mesmas opções do programa original, além da função gama. Dispõe ainda de uma outra alternativa, bastante interessante, que é a de trabalhar com funções discretas, a partir de uma tabela de fatores de fricção. É possível considerar também, no TransCAD, os parâmetros das ligações zonais denominados fatores $\mathrm{K}$. Com todas essas possibilidades, o SIG não só é capaz de reproduzir o modelo META, mas pode certamente melhorar os resultados obtidos anteriormente sem muito esforço adicional.

O primeiro passo na fase de distribuição de viagens aqui conduzida foi a calibração do modelo gravitacional. Todas as opções disponíveis no SIG foram testadas, com base em fluxos reais observados na cidade de Araraquara em 1994, tanto para carros como para ônibus (Raia Jr., 1995). Usando este conjunto de dados, com exceção da função gama, todas as funções disponíveis no software convergiram ao se proceder a calibração de viagens de automóveis.

Os resultados do processo de calibração para as viagens por automóvel podem ser vistos na Figura 4.4, na qual se pode ver a distribuição dos comprimentos das viagens com os dados reais e com os resultados de todos os modelos empregados. Os resultados obtidos com as funções exponencial e potência não diferem muito entre si, mas os resultados encontrados com a tabela de fatores de fricção diferem bastante dos demais. $\mathrm{O}$ fator $\mathrm{K}$ foi também testado, tanto para a função potência como para a tabela de fatores de fricção. Todos os modelos testados deram uma boa representação da distribuição original dos dados usados para a calibração. Não se procedeu aqui a um processo de validação dos modelos, o que seria desejável em uma aplicação real. Em todos os casos, o modelo reproduziu razoavelmente bem a elevada concentração de viagens com comprimento entre 2,5 e $5,5 \mathrm{~km}$, que é um padrão esperado nas cidades médias brasileiras.

É importante observar que as distâncias de viagem consideradas como impedância não são as mesmas para viagens de automóvel e de ônibus. Da mesma forma que no modelo original, as viagens de carro são consideradas como percorrendo os menores caminhos conectando os centróides das zonas, sempre através da rede de vias ortogonais já descrita no início deste capítulo. As viagens de ônibus, por outro lado, não seguem este mesmo padrão, devido a forma como os sistemas de transporte público são operados em muitas cidades médias brasileiras, com um terminal central servindo como ponto de transferência entre viagens. 


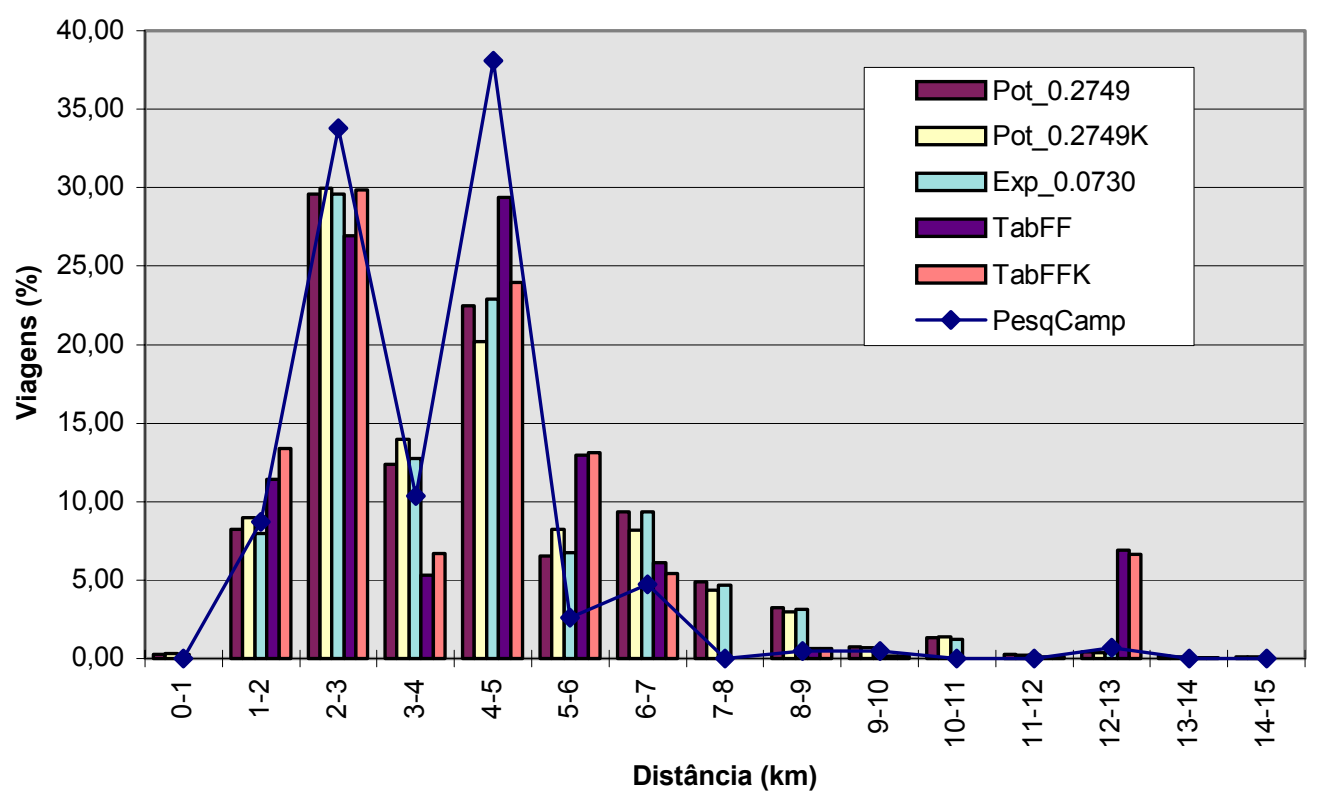

Figura 4.4 - Distribuição de viagens por automóvel resultantes do processo de calibração com as opções disponíveis para o modelo gravitacional no SIG TransCAD.

A exceção para esse padrão de viagens de ônibus se dá para viagens conectando centróides de zonas que estejam situadas ao longo de uma rota. Neste caso, as viagens só passarão pelo terminal central se as zonas conectadas estiverem em lados opostos do terminal. Este padrão de viagens era construído no modelo META original através da comparação das coordenadas dos centróides das ZTHs com as coordenadas do terminal central de ônibus urbanos.

No ambiente do SIG, a simulação das viagens de ônibus é muito mais simples do que no modelo original, porque é possível criar uma rede que representa somente as conexões feitas pelas rotas de ônibus, algo que poderia ser considerado como uma rede de transporte público. Isto é possível mesmo em uma rede totalmente artificial, como a rede em grelha aqui criada para reproduzir, de forma simplificada, o padrão ortogonal encontrado nas vias da maioria das cidades médias brasileiras. A rede de transporte público construída para o estudo de caso em desenvolvimento é mostrada na Figura 4.5.

Os resultados do processo de calibração para as viagens de ônibus são representados graficamente na Figura 4.6, na qual se pode observar os valores da pesquisa de campo e os valores encontrados com os modelos calibrados. Uma vez mais se pode observar que os modelos produziram uma boa aproximação dos dados originais, sendo que a tabela de fatores de fricção combinada com os fatores $\mathrm{K}$ forneceu as melhores estimativas. 


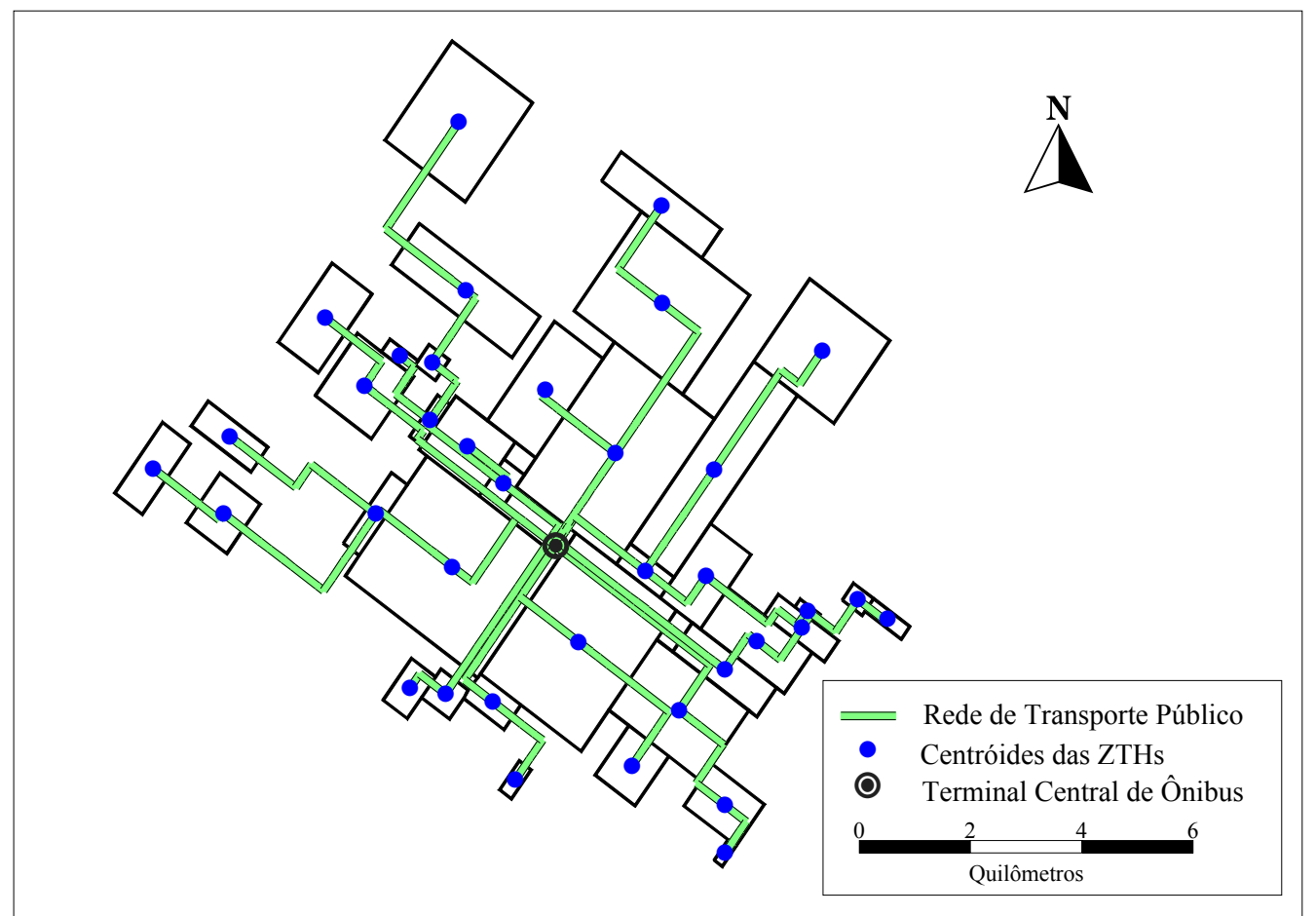

Figura 4.5 - Representação da rede de transporte público criada a partir da rede em grelha e das Zonas de Tráfego Homogêneas adaptadas do modelo META para o SIG.

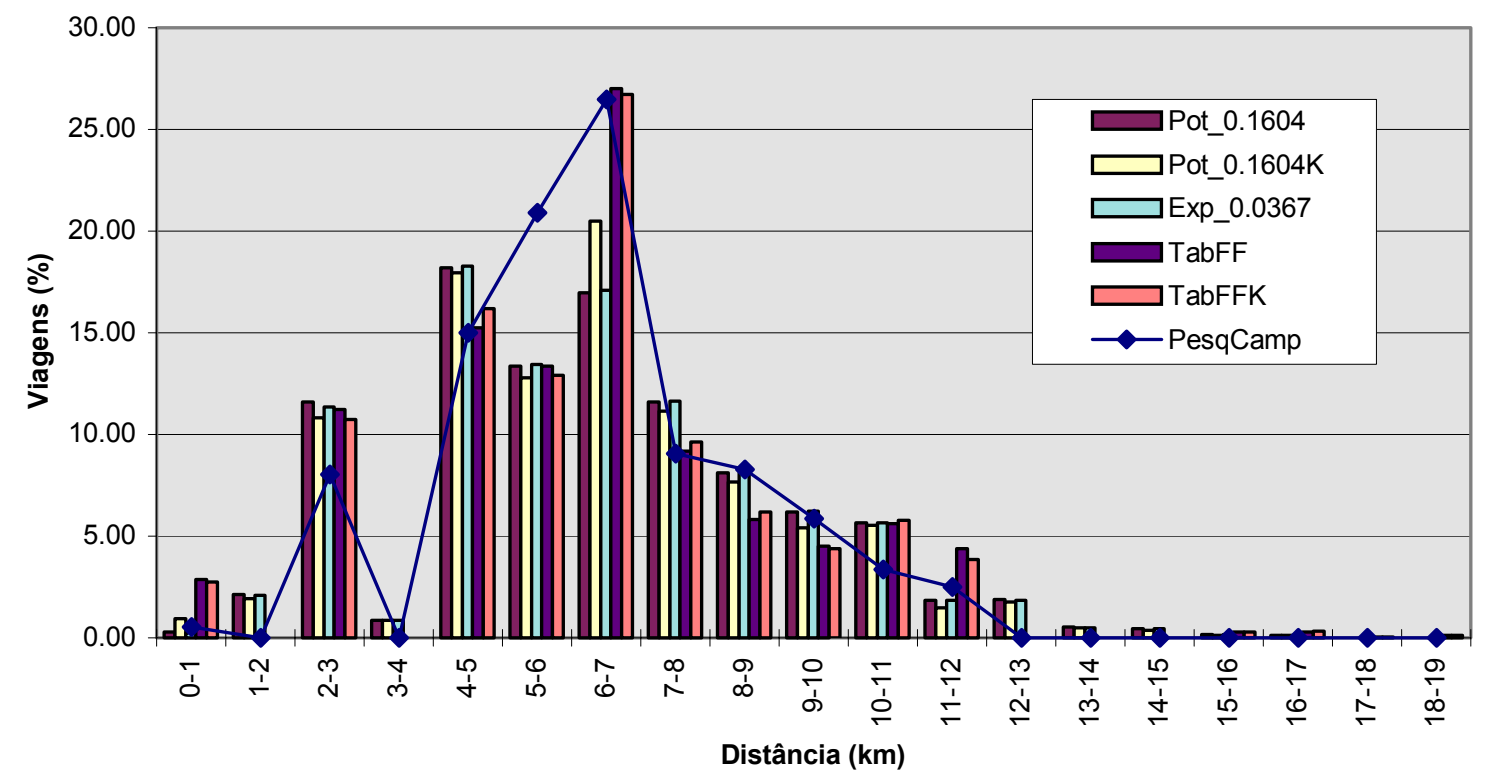

Figura 4.6 - Distribuição de viagens por ônibus resultantes do processo de calibração com as opções disponíveis para o modelo gravitacional no SIG TransCAD.

\subsubsection{Custos de Transportes}

O cálculo dos custos de transportes foi o último passo para a implementação do modelo META no SIG. Não se trata de um procedimento complexo, exigindo apenas duas 
informações adicionais: o custo variável por quilômetro e o número médio de passageiros por veículo. Os custos de transportes podem ser calculados para viagens de carro e de ônibus no modelo META, embora somente viagens de ônibus tenham sido consideradas na estratégia de tributação da propriedade urbana que empregava o modelo, proposta por Silva (1993). Os custos totais em ambos os casos eram calculados em duas etapas, sendo a primeira delas para obtenção da distância total percorrida. Para detalhar um pouco mais o que já foi mencionado no capítulo anterior, para viagens de carro, esta distância podia ser obtida de seguinte forma:

$$
D_{T A}=\sum_{i} \sum_{j} \frac{\left(2 . V_{A_{i j}}\right)}{\operatorname{Pass}_{A}} \cdot D_{i j}
$$

Onde:

$\mathrm{D}_{\mathrm{TA}}=$ distância total percorrida por automóveis, em km;

$\mathrm{VA}_{\mathrm{ij}}=$ número de viagens de automóvel da zona $i$ para a zona $j$, em viagens/dia;

Pass $_{\mathrm{A}}=$ número médio de passageiros por automóvel;

$\mathrm{D}_{\mathrm{ij}}=$ distância entre as zonas $i \mathrm{e} j$, em $\mathrm{km}$.

por:

No caso das viagens de ônibus, a distância total percorrida por ônibus é dada

$$
D_{T O}=\sum_{i} \frac{\left(2 \cdot V o_{i c}\right)}{\operatorname{Pass}_{O}} \cdot\left(2 \cdot D_{i c}\right)
$$

Onde:

$\mathrm{D}_{\mathrm{TO}}=$ distância total percorrida por ônibus, em km;

$\mathrm{Vo}_{\mathrm{ic}}=$ número de viagens de ônibus da zona $i$ para a zona em que o terminal central está localizado, em viagens/dia;

Pass $=$ número médio de passageiros por ônibus;

$\mathrm{D}_{\mathrm{ij}}=$ distância entre a zona $i$ e a zona em que o terminal central está localizado, em $\mathrm{km}$.

As distâncias totais percorridas resultantes das equações acima devem ser então multiplicadas pelos custos médios por quilômetro, de forma a fornecer os custos totais das viagens de automóveis e de ônibus. A inserção dessas equações no ambiente do SIG exige procedimentos específicos para cada caso. O cálculo das viagens de automóvel pode ser feito através de operações com matrizes, não exigindo nenhum outro cálculo adicional. Isto é possível porque a operação de preenchimento de matrizes com resultados de fórmulas é bastante simples no software empregado. O caso das viagens de ônibus, por outro lado, requer alguns passos adicionais, a começar pelo cálculo dos menores caminhos entre o terminal central de ônibus e os centróides das zonas de tráfego. A utilização da rede de transporte público, associada à rotina para cálculo de múltiplos menores caminhos, torna este procedimento bastante simples. O resultado dessa operação pode ser um sistema de rotas conectando os pontos desejados, ou uma matriz contendo as distâncias percorridas nestas ligações. Em ambos os casos é possível exportar os valores das distâncias para um novo arquivo e posteriormente anexá-lo à base de dados das zonas de tráfego. 
$\mathrm{O}$ número de viagens de ônibus da zona $i$ para a zona em que se situa o terminal central pode ser obtido no SIG em um campo contendo fórmula, que seleciona os maiores valores entre as viagens produzidas na zona $i$ e atraídas para esta mesma zona. Todos os demais passos mencionados acima para o cálculo dos custos foram também introduzidos em campos de fórmulas, cuja atualização é feita de forma automática a cada mudança nos dados de entrada, de forma a facilitar a análise de custos para todo novo cenário criado.

\subsubsection{Custos de Infra-estrutura}

Como já mencionada no capítulo 3, o outro modelo usado para a estratégia de tributação proposta por Silva (1993), denominado INFRA, foi construído com o propósito de estimar os custos de redes fixas de infra-estrutura urbana (pavimentação e drenagem, energia elétrica, esgoto sanitário e água potável). Este modelo, desenvolvido especificamente para as cidades médias brasileiras, é basicamente um conjunto de equações representando as curvas obtidas por Mascaró (1979), as quais podem ser escritas diretamente em colunas contendo fórmulas no SIG. Desta maneira, elas são atualizadas sempre que um novo cenário é construído, permitindo uma rápida avaliação de custos de novos cenários.

Como as curvas de Mascaró (Figura 3.3) representam somente os custos de infra-estrutura no intervalo entre 75 e 600 habitantes por hectare, para valores abaixo da menor densidade estudada, estes custos são considerados constantes. Esta hipótese parece razoável, uma vez que não se pode reduzir o diâmetro de várias das redes de infra-estrutura (como é o caso do esgoto, por exemplo), abaixo de determinado limite. Assim sendo, os custos totais permanecem os mesmos, independendo se a rede é usada por uma única pessoa ou por 75 indivíduos em uma área de um hectare. Além disso, valores acima do limite superior também não são considerados no modelo INFRA, uma vez que densidades tão elevadas não são comuns nas cidades médias brasileiras.

\subsection{UTILIZANDO A COMBINAÇÃO SIG-T +META + INFRA}

Diversos aspectos podem influenciar as características de transporte e infraestrutura em áreas urbanas, afetando os seus custos de forma significativa. O tamanho e o formato das cidades, bem como suas densidades populacionais, são alguns desses aspectos, uma vez que alterações dessas características podem reduzir ou aumentar os custos urbanos. Esta é a principal razão pela qual a estratégia de tributação proposta considera dois diferentes cenários. O primeiro deles é uma representação da cidade como ela realmente é - chamada de cidade real. O segundo cenário é uma condição hipotética, derivada da cidade real, mas sem os seus espaços ociosos - denominada de cidade de referência. Estes cenários, como já foi comentado no capítulo 3, formam a base da estratégia de tributação proposta, pois somente os proprietários de terrenos ociosos é que são onerados com a diferença entre os custos totais da cidade real e da cidade de referência.

É importante destacar que, enquanto a construção do cenário da cidade real é apenas um problema técnico, a definição da cidade de referência é essencialmente um problema político. No programa original com os modelos META e INFRA, a construção de 
novos cenários era sempre uma tarefa que demandava bastante tempo. Na aplicação original na cidade de Araraquara, por exemplo, foram construídos somente 4 cenários para a cidade de referência, além do cenário com a cidade real. Um dos grandes benefícios da introdução dos modelos simplificados no ambiente de um Sistema de Informações Geográficas é exatamente a possibilidade de se construir diversos cenários para a cidade de referência em um curto período de tempo.

Uma vez que os modelos META e INFRA tenham sido totalmente implantados no software de SIG, o seu desempenho pode ser avaliado. Eles podem ser usados na construção de diferentes cenários, o que se constitui um importante passo na procura do cenário de referência para a estratégia de tributação proposta. Isto será feito agora, inicialmente com os mesmos dados utilizados no capítulo anterior e, em seguida, com um outro conjunto de dados. Estes últimos são representações mais fiéis da realidade, em que os elementos geográficos não são tão esquemáticos quanto eles eram no primeiro caso. A comparação dos resultados obtidos com os dois conjuntos de dados torna possível uma verificação do impacto, sobre esses resultados, de algumas hipóteses simplificadoras feitas no modelo original (zonas de tráfego retangulares, vias ortogonais, etc.).

\subsubsection{Cenários Construídos com o Conjunto Original de Dados}

A combinação de modelos simplificados e SIG tornou a criação de cenários fácil e rápida. Usando os mesmos dados de Raia Jr. (1995), 24 cenários foram construídos no SIG para a cidade de Araraquara, incluindo a cidade real. O primeiro cenário para a cidade de referência era similar ao cenário da cidade real, exceto pelo fato de que a zona mais distante do centro da cidade foi eliminada. A população desta zona foi realocada para a zona mais próxima com o mesmo nível de renda e com densidade populacional menor que a média da cidade. A criação do segundo cenário para a cidade de referência seguiu o mesmo método, desta vez baseado no primeiro cenário para a cidade de referência. O processo foi repetido de forma semelhante até que os 24 cenários, que podem ser vistos na Figura 4.7, tivessem sido criados.

A estimativa dos custos da cidade tornou-se então um processo simples, que no caso dos custos provenientes de viagens de ônibus pode ser resumido nos passos a seguir, para cada novo cenário: 


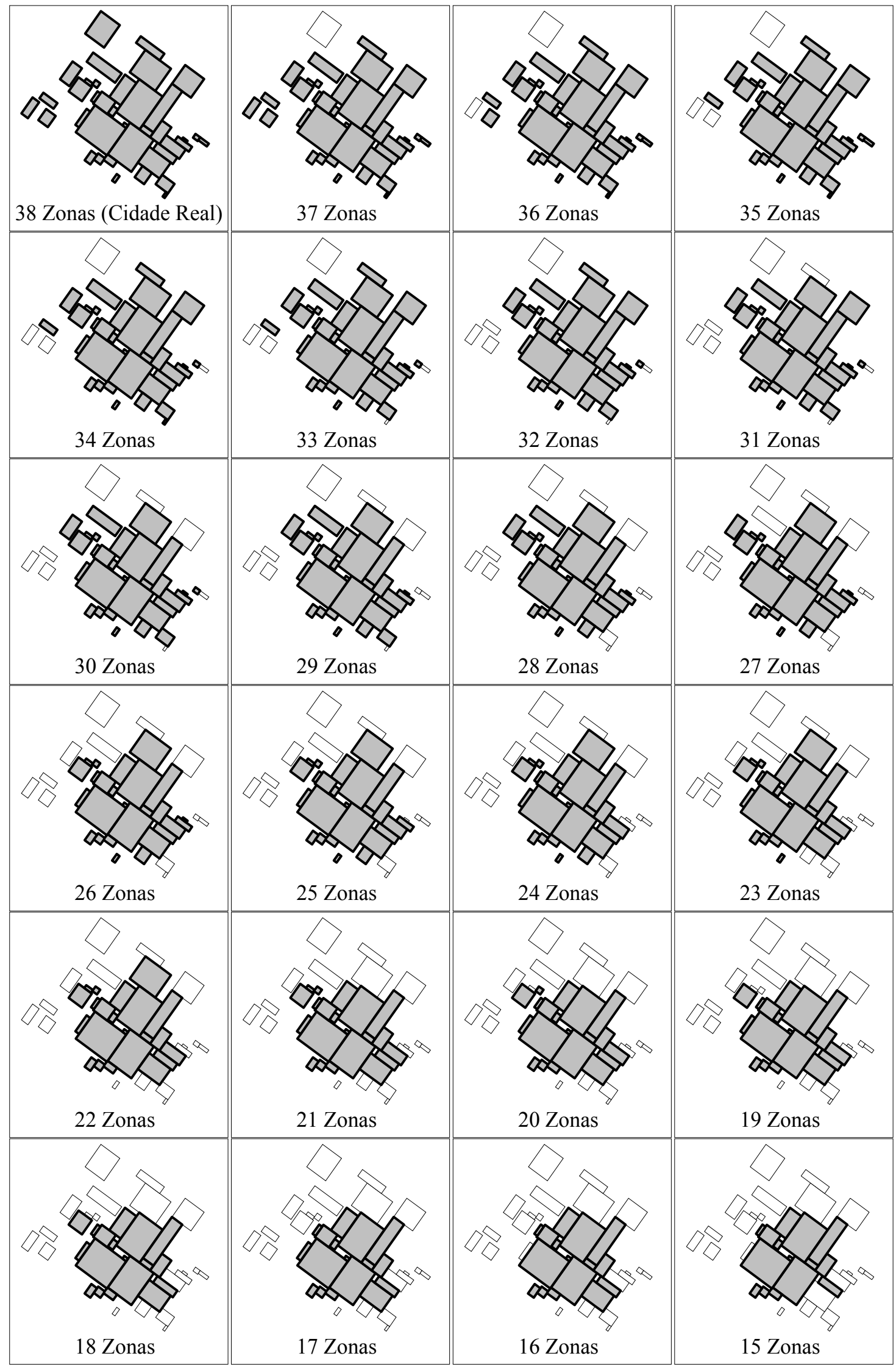

Figura 4.7 - Cenário da cidade real (38 zonas) e 23 cenários para a cidade de referência construídos para a cidade de Araraquara. 
- O arquivo contendo as fórmulas de geração de viagens pode ser usado para estimar as viagens produzidas e atraídas nas zonas de cada cenário. Isso é possível através de uma simples alteração dos valores constantes nas colunas que contêm os dados de entrada para a fase de geração de viagens (ver Tabela 4.4). Os resultados devem ser salvos em arquivos $d$ Base (aqui denominados $X$ zones.dbf, em que $X$ é o número de zonas de cada cenário em particular);

- O arquivo contendo as fórmulas para o cálculo dos custos das viagens de ônibus (aqui denominado cstmtb38.dvw) deve ser anexado ao arquivo mencionado acima;

- Os campos Viagens Produzidas e Viagens Atraídas do arquivo devem ser preenchidos com os valores de cada novo cenário. A opção Statistics pode ser usada em seguida para verificar se os totais de viagens estão corretos. Em caso afirmativo, a conexão entre os arquivos pode ser desfeita;

- As Viagens Produzidas e Viagens Atraídas devem ser balanceadas na própria coluna;

- O comando Statistics pode ser utilizado novamente para verificar se os totais de viagens foram mantidos. Este comando pode ser também usado para calcular a soma dos custos obtidos nas colunas de fórmulas;

- A janela resultante do comando Statistics deve ser salva em um arquivo de base de dados ou em um arquivo binário (aqui denominado $\operatorname{costb} X$.bin, onde $X$ corresponde ao número de zonas da cada cenário específico). seguintes passos:

A estimativa de custos de infra-estrutura para cada novo cenário segue os

- O arquivo contendo as fórmulas para o cálculo de custos de infra-estrutura (aqui denominado infrmt $38 . d v w$ ) deve ser anexado aos arquivos criados no primeiro passo da estimativa de custos de viagens;

- O campo Densidade Populacional deve ser preenchido com os valores do novo cenário;

- A opção Statistics pode ser usada para verificar se a população total da cidade está correta. Em caso afirmativo, a janela Statistics deve ser salva em um arquivo de base de dados ou em um arquivo binário (aqui denominado costin $X$.bin, onde $X$ corresponde ao número de zonas de cada cenário específico).

Os custos totais de transporte público e de infra-estrutura para os 24 cenários foram calculados como descrito acima, sempre utilizando os modelos no SIG. Os resultados estão resumidos nos gráficos das Figuras 4.8 e 4.9. A comparação dos custos da cidade real com os custos dos demais cenários deixa claro o impacto do espalhamento urbano sobre os custos urbanos. 


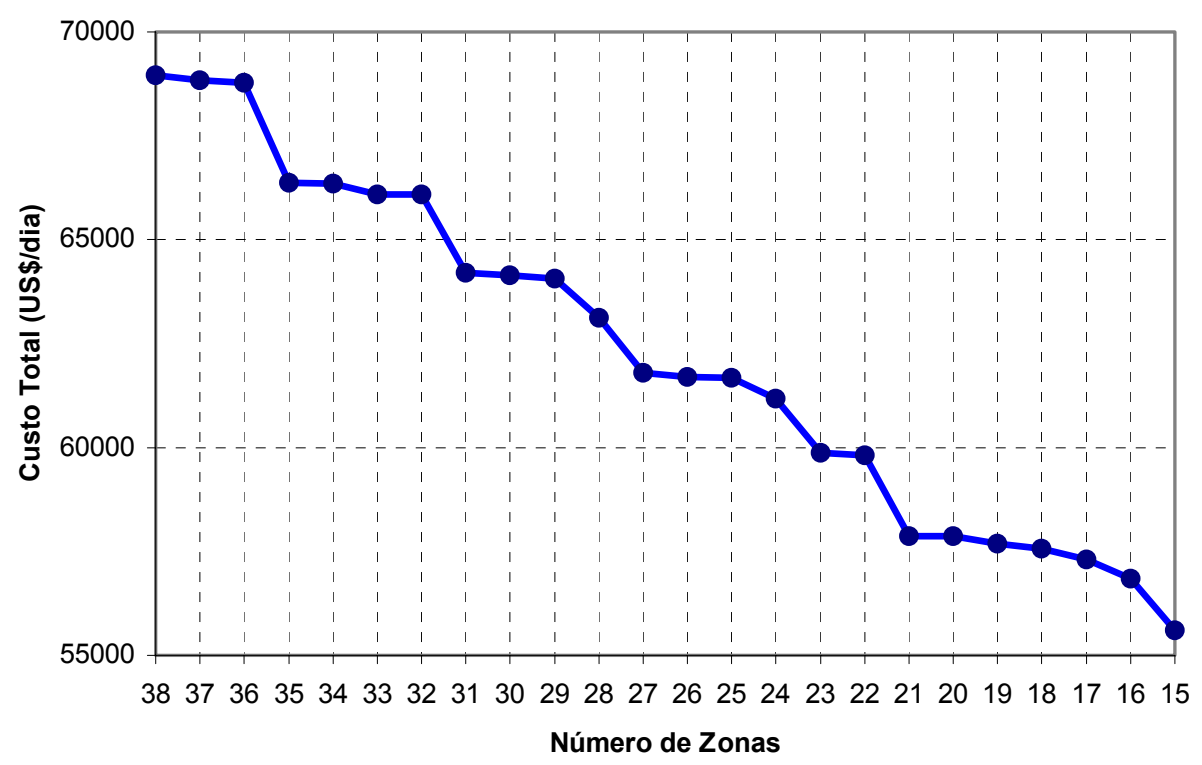

Figura 4.8 - Custos diários de viagens por ônibus para o cenário da cidade real (38 zonas) e para outros 23 cenários da cidade de referência.

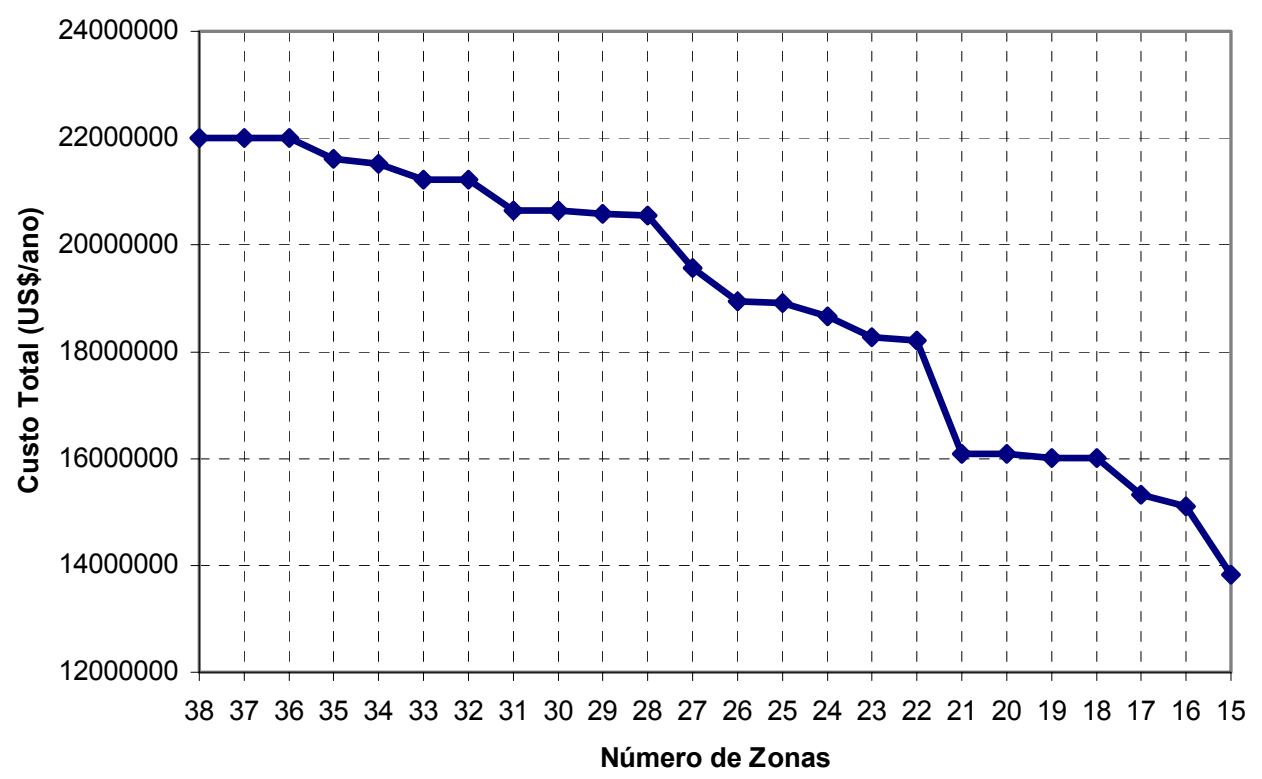

Figura 4.9 - Custos das redes de infra-estrutura para o cenário da cidade real (38 zonas) e para outros 23 cenários da cidade de referência.

\subsubsection{Cenários Construídos com Dados Reais}

A primeira mudança a ser introduzida neste novo conjunto de dados foi a representação das zonas de tráfego (ZTHs). Essas zonas, que nos modelos originais eram definidas como retângulos, passaram a ter aqui feições mais próximas da sua real configuração. A hipótese adotada na construção das ZTHs nos modelos originais tinha por objetivo simplificar a entrada de dados, uma vez que eles foram registrados via teclado do 
computador. A principal conseqüência da alteração do formato das zonas está na locação dos centróides, como pode ser visto na Figura 4.10. A comparação entre os mapas, que não mostra grandes variações na posição dos centróides das zonas, é possível somente graças ao trabalho de ajuste de escala descrito no item 4.1.1.

Outra conseqüência da adoção de zonas de formato irregular é a variação de suas áreas, uma vez que elas são usadas no cálculo dos custos de infra-estrutura com o modelo INFRA. Embora a área total da cidade tenha apresentado uma variação muito pequena nos dois casos considerados, em zonas específicas ela chegou a ter uma diferença de mais de $40 \%$, como pode ser visto na Figura 4.10 e na Tabela 4.5.

Outra característica geográfica que pode produzir alterações nos custos de transportes é a configuração da rede. $\mathrm{O}$ modelo original calculava as distâncias entre zonas seguindo um padrão em grelha para conectar os centróides das zonas (Figura 4.3), mas esta não é a configuração real da rede. Em um ambiente de SIG, é possível obter uma representação da rede mais próxima da realidade de forma simples, através da digitalização de mapas já existentes em papel. O resultado deste processo para o caso de Araraquara pode ser visto na Figura 4.11.

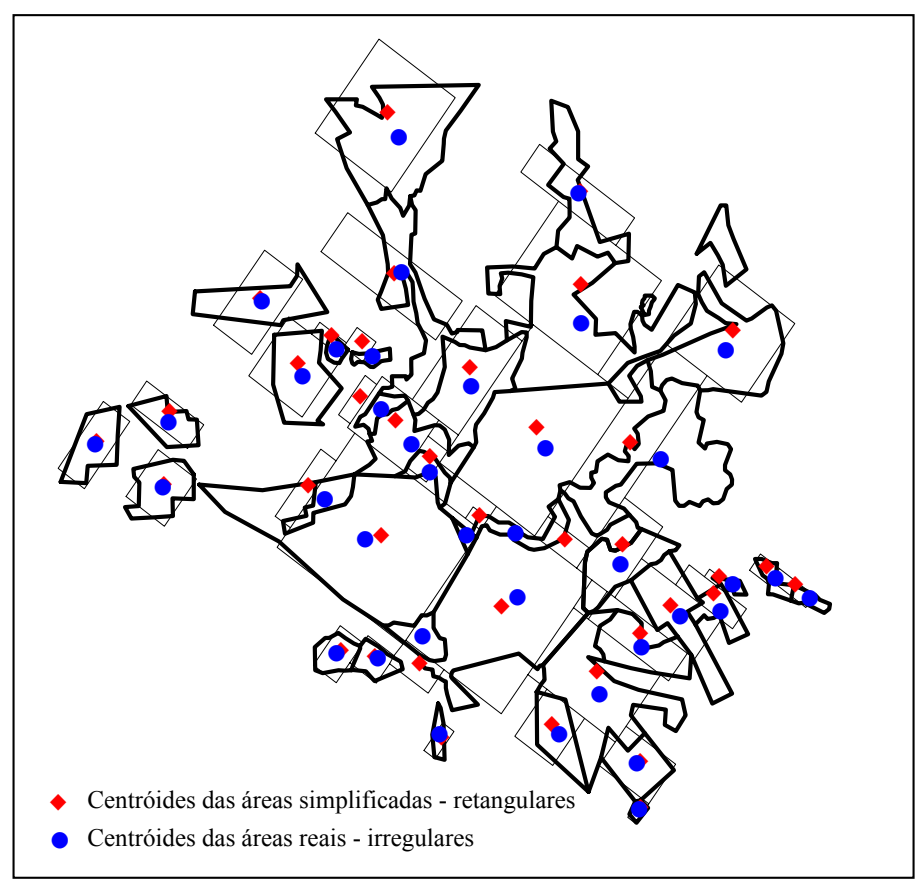

Figura 4.10 -Representação das Zonas de Tráfego Homogêneas retangulares e reais de Araraquara.

Um novo arquivo de rede foi criado, usando a base de dados de linhas contendo a real configuração das vias como referência. A rede contendo todas as vias pode ser usada para a modelagem das viagens de automóveis, mas não pode ser usada para representar as viagens de ônibus, que são o ponto de maior interesse para a estratégia de tributação proposta pelo autor. Para a montagem desta rede, informações reais sobre o sistema de transporte público da cidade foram obtidas (Silva et al., 1995) e em seguida digitalizadas, tendo como referência a camada de ruas da cidade. O resultado é mostrado na Figura 4.12. Os menores caminhos conectando os centróides das ZTHs foram calculados em ambas as redes, e os demais passos da modelagem foram conduzidos a seguir, da mesma forma que no item 4.1. 


\begin{tabular}{|c|c|c|c|}
\hline Zona & Área retangular $\left(\mathbf{k m}^{2}\right)$ & Área irregular $\left(\mathrm{km}^{2}\right)$ & Variação (\%) \\
\hline 1 & 2,27 & 2,30 & 1,32 \\
\hline 2 & 0,32 & 0,37 & 15,63 \\
\hline 3 & 1,65 & 1,64 & $-0,61$ \\
\hline 4 & 1,37 & 1,58 & 15,33 \\
\hline 5 & 1,02 & 1,00 & $-1,96$ \\
\hline 6 & 1,15 & 1,26 & 9,57 \\
\hline 7 & 0,60 & 0,52 & $-13,33$ \\
\hline 8 & 0,22 & 0,17 & $-22,73$ \\
\hline 9 & 1,42 & 1,28 & $-9,86$ \\
\hline 10 & 3,77 & 3,49 & $-7,43$ \\
\hline 11 & 0,53 & 0,53 & 0,00 \\
\hline 12 & 0,43 & 0,53 & 23,26 \\
\hline 13 & 0,24 & 0,29 & 20,83 \\
\hline 14 & 0,47 & 0,53 & 12,77 \\
\hline 15 & 0,38 & 0,41 & 7,89 \\
\hline 16 & 7,50 & 7,69 & 2,53 \\
\hline 17 & 6,68 & 6,59 & $-1,35$ \\
\hline 18 & 3,07 & 3,19 & 3,91 \\
\hline 19 & 6,85 & 7,10 & 3,65 \\
\hline 20 & 5,07 & 4,92 & $-2,96$ \\
\hline 21 & 2,34 & 2,44 & 4,27 \\
\hline 22 & 1,52 & 1,50 & $-1,32$ \\
\hline 23 & 0,94 & 0,93 & $-1,06$ \\
\hline 24 & 0,94 & 0,97 & 3,19 \\
\hline 25 & 3,75 & 3,82 & 1,87 \\
\hline 26 & 0,16 & 0,17 & 6,25 \\
\hline 27 & 0,47 & 0,47 & 0,00 \\
\hline 28 & 1,63 & 1,70 & 4,29 \\
\hline 29 & 0,07 & 0,10 & 42,86 \\
\hline 30 & 0,16 & 0,23 & 43,75 \\
\hline 31 & 0,70 & 0,70 & 0,00 \\
\hline 32 & 3,13 & 3,38 & 7,99 \\
\hline 33 & 1,49 & 1,44 & $-3,36$ \\
\hline 34 & 0,08 & 0,08 & 0,00 \\
\hline 35 & 0,93 & 0,92 & $-1,08$ \\
\hline 36 & 0,17 & 0,14 & $-17,65$ \\
\hline 37 & 0,19 & 0,15 & $-21,05$ \\
\hline 38 & 0,09 & 0,10 & 11,11 \\
\hline Total & 63,77 & 64,63 & 1,35 \\
\hline
\end{tabular}

Tabela 4.5 - Áreas das Zonas de Tráfego Homogêneas (ZTHs) de Araraquara. 


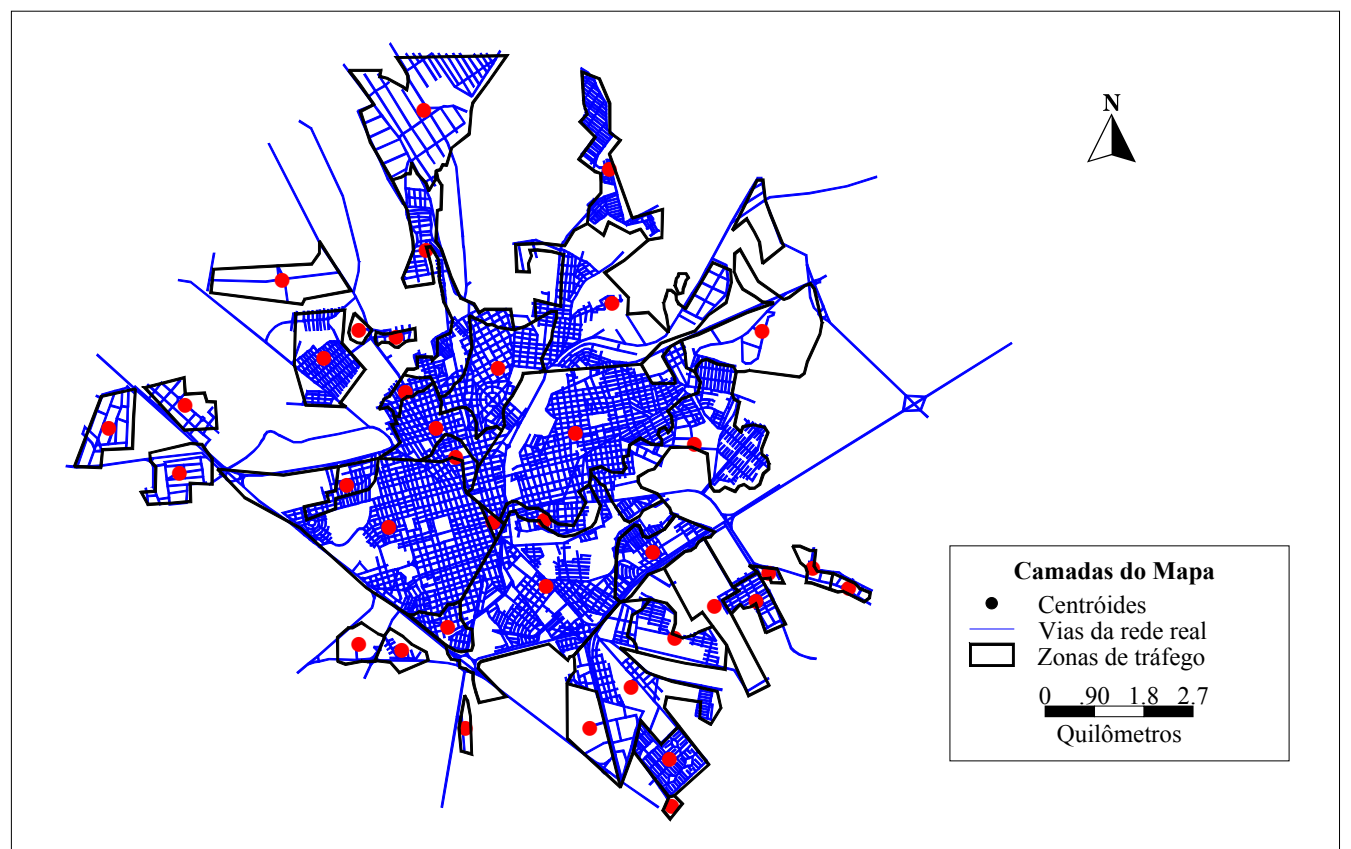

Figura 4.11 -Rede real da cidade de Araraquara digitalizada no SIG a partir de um mapa em papel.

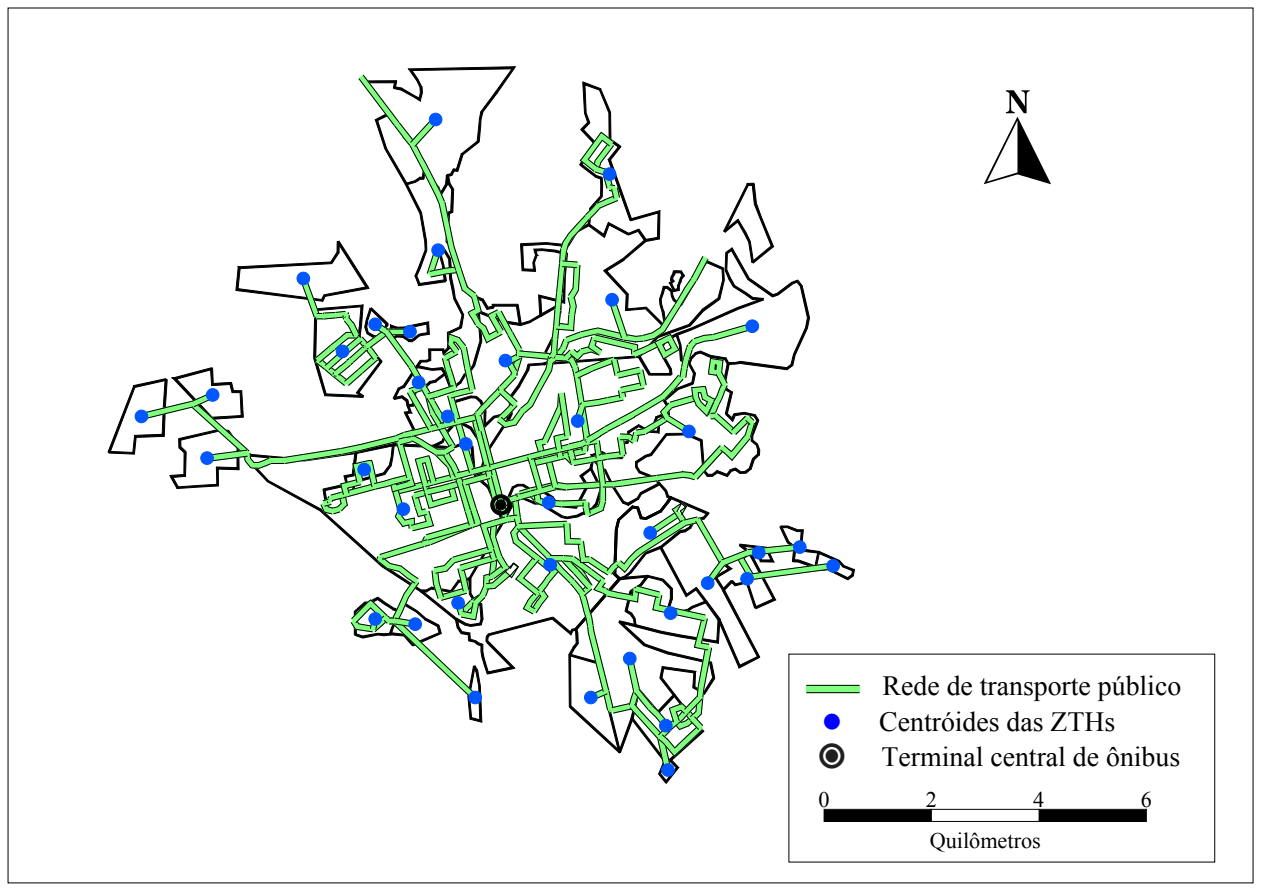

Figura 4.12 -Representação da rede de transporte público, criada a partir da rede de vias reais e das Zonas de Tráfego Homogêneas, digitalizadas a partir de mapas em papel.

As distâncias da zona central, na qual todas as linhas de ônibus se concentram, para todas as outras zonas, são apresentadas na Tabela 4.6. Nesta tabela se pode examinar a diferença do comprimento das viagens de ônibus feitas na rede em grelha e aquelas feitas na rede real. Os valores da tabela não permitem predizer, no entanto, o impacto dessas diferenças sobre os custos totais de transporte público. Em alguns casos o sistema real apresentou distâncias maiores que o sistema hipotético, mas em outros casos ocorreu justamente o oposto. 


\begin{tabular}{|c|c|c|c|c|}
\hline $\begin{array}{l}\text { Zona de } \\
\text { Origem }\end{array}$ & $\begin{array}{l}\text { Zona de } \\
\text { Destino }\end{array}$ & $\begin{array}{l}\text { Menores caminhos na } \\
\text { rede em grelha }\end{array}$ & $\begin{array}{c}\text { Menores caminhos na } \\
\text { rede real }\end{array}$ & $\begin{array}{l}\text { Variação } \\
(\%)\end{array}$ \\
\hline 38 & 1 & 3.83 & 3.31 & -13.58 \\
\hline 38 & 2 & 1.72 & 1.76 & 2.33 \\
\hline 38 & 3 & 4.63 & 5.50 & 18.79 \\
\hline 38 & 4 & 7.87 & 8.32 & 5.72 \\
\hline 38 & 5 & 6.96 & 6.56 & -5.75 \\
\hline 38 & 6 & 3.85 & 5.01 & 30.13 \\
\hline 38 & 7 & 6.02 & 7.81 & 29.73 \\
\hline 38 & 8 & 8.27 & 9.32 & 12.70 \\
\hline 38 & 9 & 3.76 & 6.53 & 73.67 \\
\hline 38 & 10 & 4.42 & 5.18 & 17.19 \\
\hline 38 & 11 & 4.51 & 5.10 & 13.08 \\
\hline 38 & 12 & 2.22 & 1.18 & -46.85 \\
\hline 38 & 13 & 3.53 & 3.20 & -9.35 \\
\hline 38 & 14 & 3.54 & 3.22 & -9.04 \\
\hline 38 & 15 & 3.46 & 6.38 & 84.39 \\
\hline 38 & 16 & 2.75 & 3.17 & 15.27 \\
\hline 38 & 17 & 2.43 & 1.75 & -27.98 \\
\hline 38 & 18 & 4.48 & 6.32 & 41.07 \\
\hline 38 & 19 & 2.02 & 3.67 & 81.68 \\
\hline 38 & 20 & 5.48 & 6.47 & 18.07 \\
\hline 38 & 21 & 6.55 & 7.90 & 20.61 \\
\hline 38 & 22 & 2.77 & 2.61 & -5.78 \\
\hline 38 & 23 & 10.08 & 9.10 & -9.72 \\
\hline 38 & 24 & 8.44 & 7.44 & -11.85 \\
\hline 38 & 25 & 10.69 & 10.12 & -5.33 \\
\hline 38 & 26 & 5.53 & 8.14 & 47.20 \\
\hline 38 & 27 & 4.36 & 6.69 & 53.44 \\
\hline 38 & 28 & 4.80 & 7.00 & 45.83 \\
\hline 38 & 29 & 6.24 & 7.29 & 16.83 \\
\hline 38 & 30 & 7.59 & 8.10 & 6.72 \\
\hline 38 & 31 & 7.96 & 8.50 & 6.78 \\
\hline 38 & 32 & 7.69 & 6.92 & -10.01 \\
\hline 38 & 33 & 6.44 & 8.88 & 37.89 \\
\hline 38 & 34 & 8.13 & 6.85 & -15.74 \\
\hline 38 & 35 & 5.64 & 4.84 & -14.18 \\
\hline 38 & 36 & 5.22 & 4.64 & -11.11 \\
\hline 38 & 37 & 4.94 & 4.83 & -2.23 \\
\hline
\end{tabular}

Tabela 4.6 - Distâncias percorridas por ônibus do centro da cidade a todos os centróides das zonas de tráfego na cidade de Araraquara.

Os custos totais de transporte público e de infra-estrutura foram novamente calculados para os 24 cenários criados anteriormente, agora com as versões reais das zonas de tráfego e da rede de transporte. Os custos de transporte público aumentaram claramente com a configuração agora adotada, em relação aos valores calculados anteriormente, como se pode verificar na Figura 4.13. Os custos de infra-estrutura, por outro lado, tiveram um incremento relativamente pequeno, da ordem de $1 \%$. 


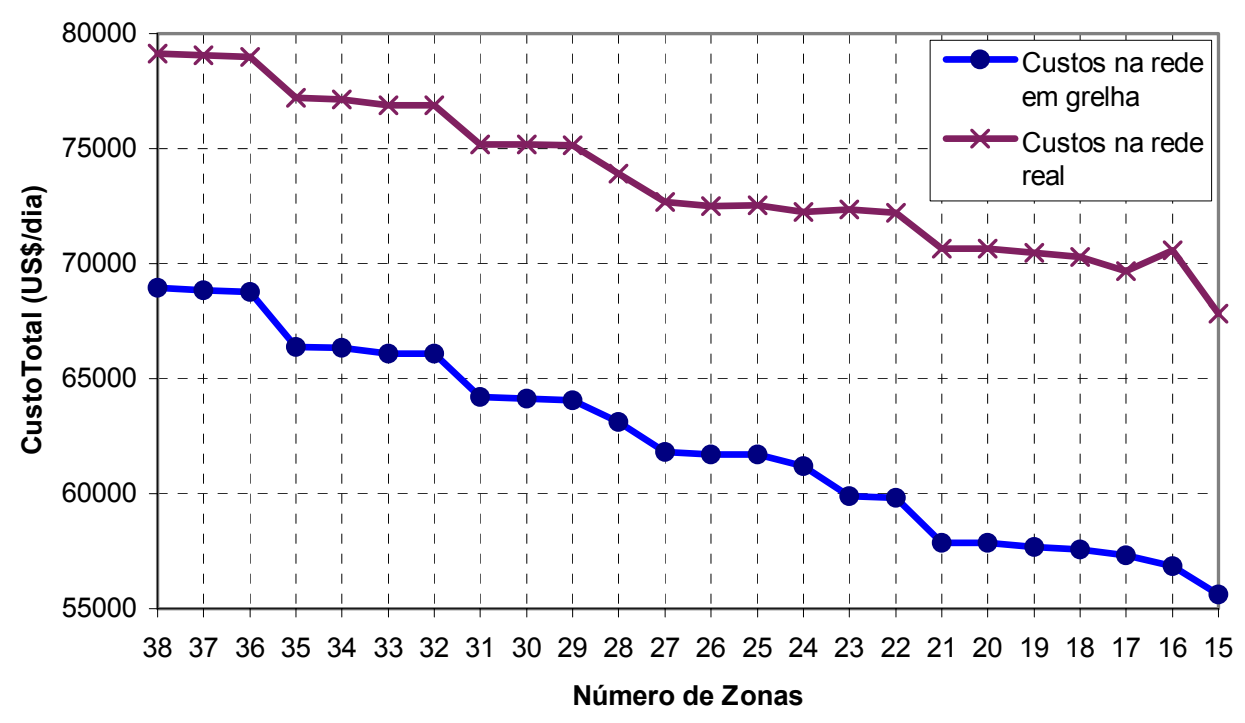

Figura 4.13 -Custos diários de viagens de ônibus para o cenário da cidade real (38 zonas) e para outros 23 cenários da cidade de referência, em dois diferentes tipos de rede.

\subsection{UMA AVALIAÇÃO DAS APLICAÇÕES}

Os modelos META e INFRA trabalharam de forma bastante eficiente no ambiente do SIG. A geração de cenários se tornou rápida e simples, permitindo a criação de tantas alternativas quanto se desejar. A comparação direta do número de cenários gerados aqui e aqueles criados no capítulo 3 com os modelos no programa original mostra claramente como o processo foi simplificado no SIG. A geração de vários cenários auxilia, inclusive, no processo de identificação daqueles que produzem importantes mudanças nos patamares de custo. Este é o caso, por exemplo, dos cenários com 31, 26, 21 e 15 zonas, novamente mostrados na Figura 4.14, desta vez com sua real configuração.

As aplicações também mostram que a adoção da configuração real da rede de transporte é importante para a estimativa dos custos de transporte público urbano. A variação encontrada oscilou entre 15\% (no cenário 38) e 4\% (no cenário 16). Quanto às zonas de tráfego, mesmo considerando que alterações nos seus formatos não produziram grande diferença em termos de custos, é sempre interessante apresentar as reais feições da cidade a administradores e tomadores de decisões.

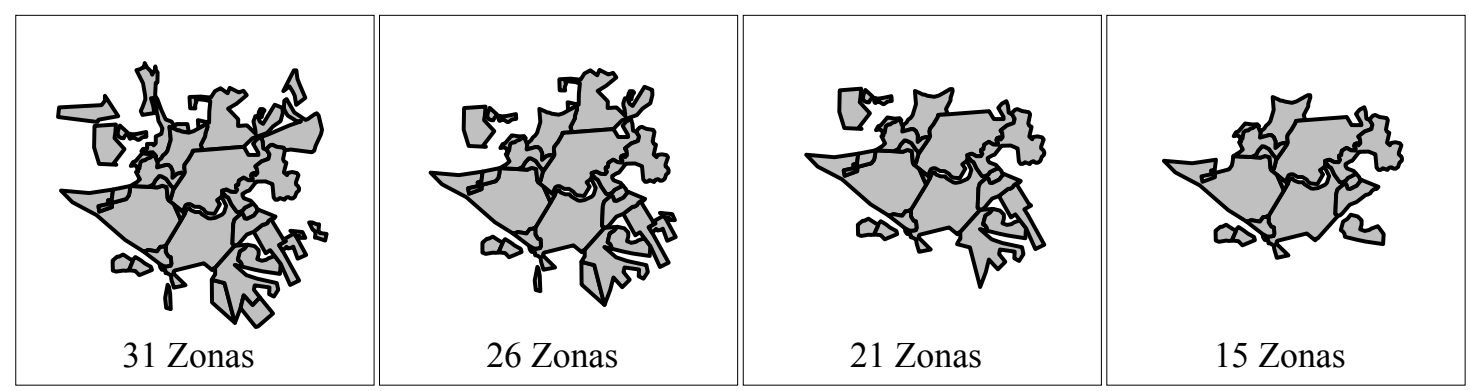

Figura 4.14 -Opções de cenários para a cidade de referência com 31, 26, 21 e 15 zonas, com a real configuração das zonas de tráfego. 
Além disso, o processo de criação de cenários pode ser aprimorado, através do uso de outros recursos do SIG. Nos exemplos aqui conduzidos, os cenários foram construídos através da realocação de população de uma zona para outra, de acordo com a localização das zonas e suas densidades populacionais. Outras alternativas, tais como a "idade" das zonas ou a ausência (ou presença) de alguma infra-estrutura podem ser facilmente utilizadas para selecionar zonas a serem removidas das cidades de referência, ou para a escolha do cenário definitivo para a estratégia de tributação. Os dados necessários para essas duas alternativas não são de difícil obtenção, como mostrado em Silva et al. (1995). Este seria o caso, por exemplo, da rede de trólebus, que serve apenas parte da cidade de Araraquara. Analisando este elemento em particular, o melhor cenário dentre os quatro selecionados na Figura 4.14 seria aquele com 21 zonas, como se pode verificar na Figura 4.15.

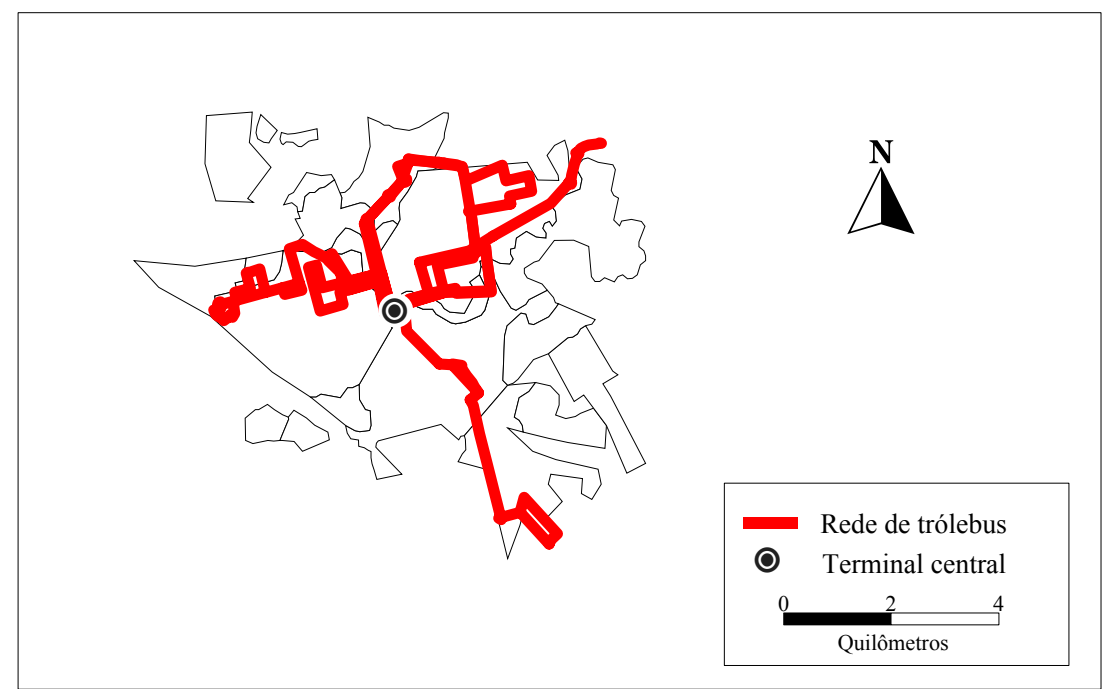

Figura 4.15 -Opção de cenário para a cidade de referência vista em conjunto com a rede de trólebus existente.

O motivo para levar em consideração a rede de trólebus na escolha do cenário para a cidade de referência é bastante simples. A rede de trólebus pode dar uma clara indicação de que a cidade se expandiu além de limites razoáveis sem antes preencher os seus espaços vazios. Sabe-se que este tipo de transporte público está vinculado a uma rede elétrica fixa, que não pode ser expandida sem altos investimentos. Desta forma, devem ser evitadas baixas densidades ao longo de rotas de trólebus. Se a cidade tivesse a configuração mostrada na Figura 4.15, ao invés do contorno atual, o uso da rede de trólebus certamente seria mais intenso. De forma diferente, o cenário com 15 zonas teria a parte sul da rede de trólebus fora do contorno das zonas.

\subsection{COMENTÁRIOS FINAIS}

Neste capítulo foi feita uma descrição de todos os passos seguidos para introdução dos modelos META e INFRA em um Sistema de Informações Geográficas (ver também Silva \& Waerden, 1997c). O conjunto de dados da cidade de Araraquara, reunidos ao se empregar os modelos originais, foi aqui utilizado com o objetivo de testar se os resultados encontrados em ambas as circunstâncias (nos modelos originais e no SIG) eram semelhantes. A comparação dos resultados mostrou que os modelos produziram resultados satisfatórios ao 
serem utilizados no novo ambiente, reproduzindo os valores encontrados com os modelos originais.

Em seguida, os modelos foram usados para construir o cenário da cidade real e vários outros possíveis cenários para a cidade de referência. Dois diferentes conjuntos de dados foram utilizados para alimentá-los: um conjunto de dados simplificados, semelhante aquele usado com o programa original; e um conjunto de dados em que os elementos geográficos foram representados com maior fidelidade à sua condição real. Desta forma, foi possível verificar o impacto que as simplificações desses elementos podia trazer para o cálculo dos custos urbanos. Com base na aplicação aqui conduzida, os custos de transporte público parecem ser subestimados com o uso da rede simplificada.

A principal vantagem de se introduzir os modelos simplificados no ambiente do SIG foi, como se supunha a priori, a possibilidade de se construir, com rapidez, diversos cenários para a cidade de referência. Dos 48 cenários aqui construídos, um foi selecionado como aquele que deveria ser a cidade de referência para ser usada na estratégia de taxação proposta. A escolha do cenário de 21 zonas, do conjunto de dados reais apresentado na seção 4.3, foi baseada principalmente no impacto que esta configuração produzia sobre os custos urbanos, mas também levou em conta outros aspectos, tal como a configuração da rede de trólebus.

Mas o uso dos Sistemas de Informações Geográficas permite fazer muito mais do que foi aqui apresentado. Os dados originais empregados na aplicação original em Araraquara foram na sua maioria obtidos com técnicas bastante simples, como o uso de fotografias aéreas de pequeno formato para estimar a distribuição de população na cidade, usando pequenas aeronaves, praticamente sem controle sobre a escala das fotos. Outro exemplo diz respeito à identificação das características de nível de renda da população, obtidas a partir de dados do consumo de energia elétrica. Existe hoje uma fonte de dados que pode fornecer essas mesmas informações e que se ajusta ao SIG de forma perfeita: são os dados dos recenseamentos gerais do país, realizados a cada 10 anos pelo Instituto Brasileiro de Geografia e Estatística.

Estes dados, que até recentemente só podiam ser obtidos sob a forma impressa, hoje já se encontram disponíveis também na forma de arquivos digitais. Embora esses arquivos digitais não sejam ainda diretamente associados com mapas, como acontece com os arquivos denominados TIGER nos Estados Unidos, essa associação pode ser feita de forma relativamente simples no ambiente do SIG (Silva et al., 1996b). Um problema ainda persiste, no entanto, que é a demora na divulgação desses dados. Os arquivos digitais do censo de 1991, por exemplo, só foram disponibilizados para o público em 1995.

Essa base de dados do censo geral poderia ajudar bastante nas aplicações aqui conduzidas ao fornecer, por exemplo, um quadro mais fiel da distribuição da população e da sua renda. Além disso, a digitalização de dados de recenseamentos anteriores pode permitir a modelagem de tendências das cidades nos Sistemas de Informações Geográficas. Essas bases de dados têm, sem dúvida, ainda muito mais a ser explorado. Em 1991, por exemplo, os arquivos do IBGE para Araraquara continham mais de 290 campos, com informações sobre distribuição da população, níveis de renda, tamanho dos domicílios, infra-estrutura básica disponível (água, esgoto, coleta de lixo, etc.) e muito mais. Alguns desses dados podem ser usados diretamente para melhorar os modelos aqui descritos. Muitos outros podem ser usados 
para estimar o valor da terra nas cidades, o que pode ser bastante útil para fins de tributação da propriedade.

De fato, alguma forma de estimar o valor da propriedade urbana deveria estar contida na estratégia de tributação proposta pelo autor. Como já mencionado neste trabalho, na sua concepção original, a estratégia de tributação não leva em conta o valor de mercado de cada propriedade. Uma forma de resolver este problema seria estimar os valores de mercado dos terrenos urbanos com base nos dados do censo, como foi sugerido no parágrafo acima. Além disso, inúmeras outras possibilidades são oferecidas pelas ferramentas de análise espacial disponíveis nos SIG. Usando estas ferramentas, a estimativa dos valores das propriedades urbanas pode ser baseada em aspectos que os influenciam de forma decisiva, como é o caso de algumas características dos sistemas de transportes (a acessibilidade, por exemplo). Isto deve, ser dúvida, ser investigado com maior atenção.

Este é justamente o ponto de partida para o próximo projeto do autor, que já começa a se materializar, e cujos primeiros resultados são mostrados no próximo capítulo. Considerando que a acessibilidade aos transportes parece exercer forte influência sobre o valor dos imóveis urbanos, o próximo projeto tentará identificar se isto se verifica de fato nas cidades médias brasileiras. Neste ponto, as ferramentas do SIG passam a ser muito importantes para o desenvolvimento do projeto, uma vez que a acessibilidade é um elemento de natureza claramente espacial. Uma vez identificada a influência da acessibilidade no valor dos terrenos urbanos, pretende-se, em seguida, desenvolver uma metodologia para avaliação de imóveis em massa, considerando essa e outras variáveis, fazendo uso de redes neurais artificiais. 


\title{
5 AVALIANDO A ACESSIBILIDADE AO TRANSPORTE
}

Mesmo que existam divergências quanto a definição exata do que é acessibilidade, parece haver um consenso de que qualquer região com alto nível de acessibilidade é mais atrativa do que qualquer outra com baixo nível. Como conseqüência, o valor da terra deve refletir, de alguma forma, os níveis de acessibilidade de uma região. Isto não significa que a acessibilidade aos transportes seja o único fator influenciando os preços das propriedades, mas não se pode negar que exerce forte influência sobre os mesmos. Podese afirmar ainda mais sobre a acessibilidade, de acordo com Wachs, 1978 (apud Morris et al., 1978):

\begin{abstract}
"Os indicadores de acessibilidade são provavelmente o modo mais apropriado e útil de resumir um grande conjunto de informações sobre a distribuição dos domicílios em relação a distribuição de atividades urbanas e ao sistema de transporte que as conecta." (tradução livre do autor)
\end{abstract}

No Brasil existe uma clara necessidade de pesquisas a este respeito, uma vez que os trabalhos de Borges (1975) e Nigriello (1977) são alguns dos raros exemplos em que a relação entre aspectos de transportes e valor da terra foi investigada em cidades brasileiras. A definição de quais aspectos do transporte devem ser considerados é o primeiro passo para se trabalhar nessa relação. Considerando que a acessibilidade é uma característica de transporte que é capaz de influenciar no valor da terra urbana, uma ampla pesquisa sobre as medidas de acessibilidade foi conduzida na literatura internacional e os principais aspectos desta revisão são apresentados na próxima seção deste capítulo. Em seguida, medidas que podem ser adequadas para as condições brasileiras foram selecionadas e aplicadas na cidade de Araraquara, juntamente com algumas medidas simples aqui propostas, sempre com o auxílio de um Sistema de Informações Geográficas. Os resultados desses passos são também mostrados nesse capítulo.

Finalmente procura-se identificar quais das medidas de acessibilidade empregadas parecem ter maior influência sobre o valor da terra urbana no caso estudado. A sua identificação, não só neste caso, mas de maneira mais ampla, é fundamental para a construção de modelos de avaliação de imóveis em massa que incorporem essa característica. 


\subsection{REVISÃO DA LITERATURA}

Quando se inicia a busca por artigos com o termo ACESSIBILIDADE em uma base de dados de qualquer boa biblioteca, a resposta é surpreendente. A consulta retorna artigos de diferentes áreas de conhecimento, tão distintas quanto biologia, sociologia, informática, ciências da comunicação, engenharia mecânica, química, medicina, psicologia, ciências políticas e física, só para citar algumas. Dentre estas está, como se poderia esperar, a área de transportes, na qual se encontra o conceito de acessibilidade que se está aqui buscando.

Mesmo no campo de transportes, no entanto, as definições e os usos de acessibilidade variam consideravelmente. Isto não chega a ser uma surpresa, considerando que o tema tem estado presente na literatura de transportes há bastante tempo, como mostra o trabalho de Hoggart (1973), no qual são citados artigos sobre o tema escritos em 1826, 1903 e 1909. Apesar da variedade de usos que o conceito permite, a autora também oferece, nesse trabalho, uma espécie de definição geral para a acessibilidade:

"A aplicação do termo tem em comum a interpretação, implícita
ou explícita, da facilidade de contato com oportunidades de
alguma forma distribuídas no espaço. Assim sendo, a
acessibilidade parece depender não somente da localização das
oportunidades, mas também da facilidade com que se
ultrapassa a separação espacial entre o indivíduo e locais
especificos." (tradução livre do autor)

O trabalho de Hoggart (1973) é interessante não só por trazer a definição geral de acessibilidade já apresentada, mas porque traz uma revisão bastante ampla sobre o tema até 1973. Muitos dos artigos ali apresentados já destacam a importância da acessibilidade sobre o valor da terra.

Após a revisão de Hoggart em 1973, o assunto permaneceu vivo na literatura científica praticamente com a mesma intensidade do período anterior. Alguns outros artigos de revisão são destacados aqui, por trazerem medidas, definições e aplicações de acessibilidade ao transporte. Este é o caso dos artigos escritos por Vickerman (1974); Dalvi \& Martin (1976); Davidson (1977); Black \& Conroy (1977); Ben-Akiva \& Lerman (1978); Dalvi (1978); Wachs \& Koenig (1978); Morris et al. (1979); Pirie (1979); Weibull (1980); Koenig (1980); Jones (1981); Richardson \& Young (1982) e Hanson \& Schwab (1987).

Do início dos anos setenta é também o trabalho de Ingram (1971), cuja definição de acessibilidade é certamente uma das mais citadas nas últimas duas décadas. Segundo este autor, acessibilidade pode ser definida "como a característica (ou vantagem) inerente de um local no que diz respeito a vencer alguma forma de resistência de natureza espacial ao movimento (por exemplo, tempo elou distância)" (tradução livre do autor). Ingram (1971) também estabeleceu a seguinte divisão para o conceito de acessibilidade:

- Acessibilidade Relativa é o grau com que dois pontos na mesma superfície são conectados e 
- Acessibilidade Integral ou Total é o grau de interconexão de um ponto com todos os demais pontos da mesma superfície.

Outra classificação interessante para os indicadores de acessibilidade foi feita por Morris et al. (1979), que estendeu os conceitos de acessibilidade relativa e integral para indicadores de processo e de efeito:

- Indicadores de processo são medidas das características de oferta do sistema;

- Indicadores de efeito estão relacionados com o nível corrente de uso e de satisfação.

Várias medidas e as duas formas de classificação aqui comentadas aparecem resumidas na Figura 5.1, adaptada de Morris et al. (1979).

Nos anos 90, após um curto período de atividade menos intensa ligada ao tema, vários autores o retomaram. Alguns desses autores são: Miller (1991); Handy (1992 e 1993); Linneker \& Spence (1992); Martin \& Williams (1992); Allen et al. (1993); Ihlanfeldt (1993); Arentze et al. (1994a e 1994b); Gerrard \& Church (1994); Oppong \& Hodgson (1994); Geertman \& Van Eck (1995); Davidson (1995); Love \& Lindquist (1995); Tagore \& Sikdar (1995); Roehl et al. (1995); Mackiewicz \& Ratajczak (1996) e Akinyemi (1998).

No Brasil, os estudos relacionados com a acessibilidade aos transportes são, na sua maioria, poucos e recentes, como algumas medidas bastante simples aplicadas por Raia Jr. et al. (1996) e Raia Jr. \& Silva (1996a e 1996b); e os trabalhos de Arruda (1995); Januario (1995 e 1996); Sanches (1996); Salles Filho (1996, 1997 e 1998); Raia Jr et al. (1997) e Silva et al. (1998a e 1998b)

Embora eles tenham diferentes abordagens, um dos principais pontos de todos esses estudos é a forma como a acessibilidade foi medida, pois ela varia bastante. Alguns estudos adotaram medidas bem simples, como aquelas usadas por Love \& Lindquist (1995). Após apresentar uma breve revisão sobre medidas de acessibilidade, eles escolheram trabalhar com duas medidas conceitualmente simples para avaliar a acessibilidade de idosos a hospitais: o número de hospitais dentro de uma distância de $y$ milhas a partir de uma quadra $i$ e distância mínima. Nesta última medida, foram consideradas as distâncias Euclidianas ou em linha reta e não através de uma rede.

Medidas simples de acessibilidade são freqüentes na literatura sobre geografia médica e podem ser também encontradas no trabalho de Oppong \& Hodgson (1994). Eles avaliaram a acessibilidade espacial a instalações de saúde no distrito de Suhum, em Gana, trabalhando com dois indicadores de acessibilidade: distâncias médias percorridas (de pólos populacionais a instalações de saúde) e distância de cobertura (proporção de pessoas dentro de uma distância específica das instalações de saúde). Eles usaram um algoritmo simples para calcular distâncias Euclidianas entre pontos, justificando o uso dessas distâncias pelo fato de que o modo a pé é predominante na área de estudo. Embora as medidas de acessibilidade comentadas acima fossem simples, em ambos os casos elas produziram resultados interessantes. 


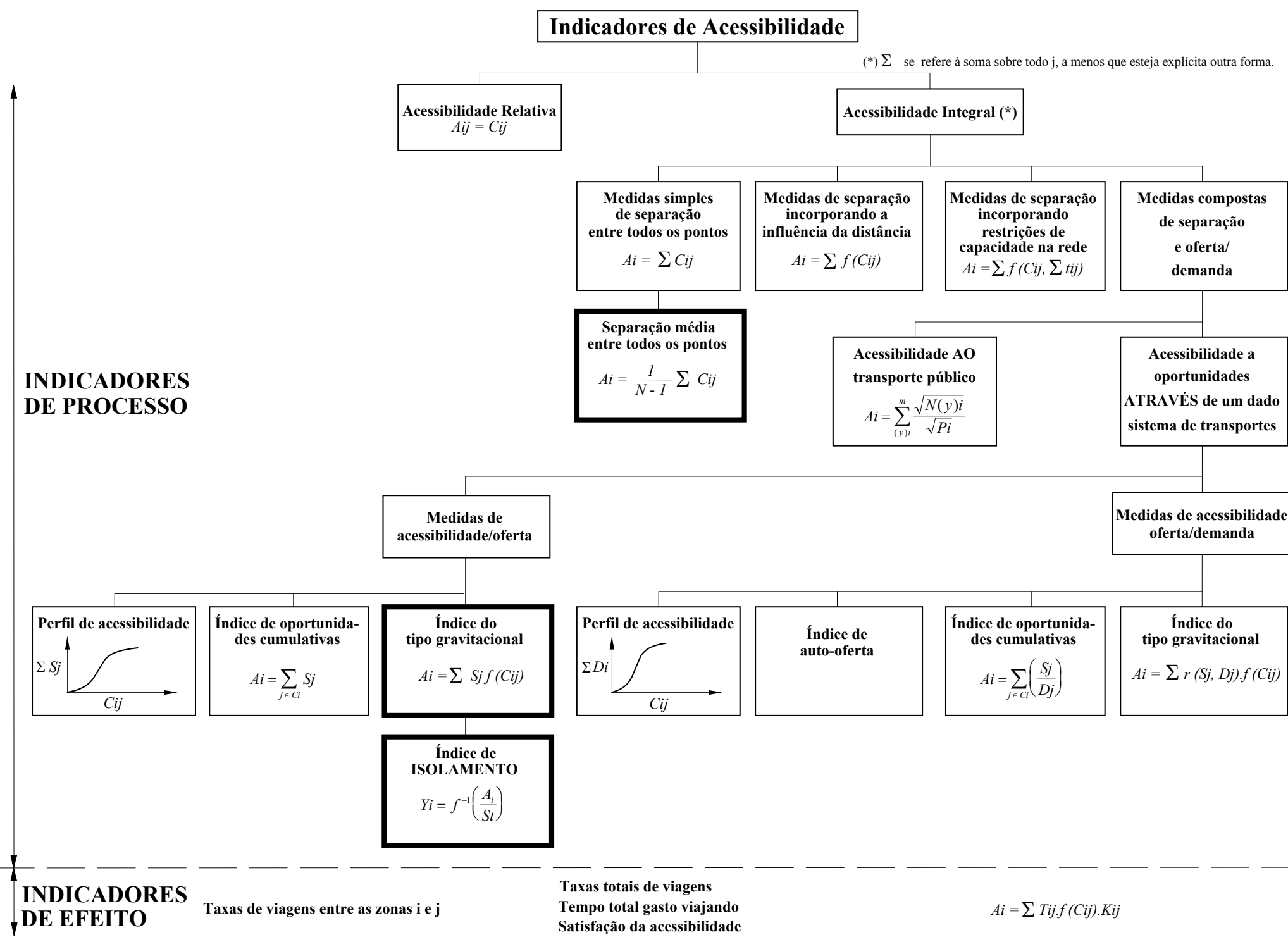

Figura 5.1 - A tipologia dos indicadores de acessibilidade (adaptado de Morris et al., 1979).

\section{LEGENDA:}

$\mathrm{i}, \mathrm{j}=$ zonas, $1, \ldots, \mathrm{n}$

Aij $=$ acessibilidade da zona i relativa a zona $\mathrm{j}$

Ai $=$ acessibilidade total da zona $\mathrm{i}$

Cij $=$ separação espacial entre as zonas $i$ e j (tempo, distância, custo, etc.)

eumero de zonas

$(\mathrm{Cij})=$ função de impedância entre as zonas i e $\mathrm{j}$, em que a forma precisa é definida empiricamente para refletir o efeito amplo da área na separação espacial sobre as mudanças entre zonas (potência, exponencial, etc.)

$\mathrm{f}(\mathrm{Cij}, \Sigma$ tij $)=$ função do efeito

combinado da separação espacial

sobre os padrões de viagens e desses (congestionamento) na separação espacial

$\mathrm{Cij}=$ intercâmbio de viagens entre as zonas i e j

$N(y) i=$ freqüência de serviços de transporte, $\mathrm{y}$, servindo a zona $\mathrm{i}$

$\mathrm{m}$ = numero de serviços de transporte,

$$
y \text {, servindo a zona i }
$$

$\mathrm{Pi}$ = área física da zona i (metros quadrados, etc.)

$\mathrm{Sj}=$ atratividade de oportunidades na zona j (número de empregos, etc.)

$\mathrm{Yi}=$ isolamento na zona

St $=$ total de atividades na área de estudo

$\mathrm{j} \in \mathrm{Ci}=$ conjuntos de zonas, $\mathrm{j}$, dentro do limite de viagens em torno da zona $\mathrm{i}$, tal que

$0 \leq \mathrm{Cij} \leq \mathrm{Cmax}$

$\mathrm{Dj}=$ nível de demanda na zona (número de pessoas, etc.)

$\mathrm{r}(\mathrm{Sj}, \mathrm{Dj})=$ função da influência combinada das oportunidades atratoras e da demanda competindo na zona $\mathrm{j}$

Tij = número de viagens atraídas pela zona $\mathrm{j}$

Kij = fator de ajuste específico zona-azona que leva em conta, nos padrões de viagens, o efeito de aspectos sociais ou econômicos não contemplados na fórmula do modelo gravitacional 
Alguns autores trabalharam com conceitos mais sofisticados, reconstruindo idéias antigas, tais como Geertman and Van Eck (1995) e Allen et al. (1993), que basearam o seu trabalho em Ingram (1971). Este é também o caso de Davidson (1995), que adaptou a sua própria medida de acessibilidade (semelhante a de Hansen, 1959) para uma forma particular, denominada Isolamento.

Como nem a acessibilidade relativa nem a acessibilidade integral são capazes de capturar o nível de acesso de uma área inteira ou permitem comparações entre áreas, Allen et al. (1993) propuseram uma extensão do trabalho de Ingram. O índice $E$ por eles proposto pode ser definido como um "índice global de acessibilidade para uma área". A particularidade, tanto do índice de Ingram como da nova medida proposta por Allen et al. (1993) é que, em ambos os casos, a acessibilidade é definida somente como uma medida de esforço para transpor a separação espacial entre pontos dentro de uma área. Eles não consideram em seus modelos nem características de oferta e demanda, nem aspectos comportamentais. Desta forma, trata-se de uma medida bastante simples de acessibilidade, uma vez que não exige muitos dados para o seu cálculo.

Com modelos teóricos e testes empíricos, Allen et al. demonstraram que o seu índice converge rapidamente para um valor estável quando o número de pontos usados para o cálculo do índice aumenta. Outra vantagem deste índice é que ele pode ser usado para medir a acessibilidade global de uma área, tornando possível não apenas a comparação dos níveis de acesso de diferentes pontos de uma região, mas também comparações entre regiões.

Pooler (1995), no entanto, criticou o trabalho de Allen et al. (1993), inicialmente descrevendo os índices mais comuns de acessibilidade encontrados na literatura, nos quais algum tipo de medida de tamanho das áreas estudadas (população, por exemplo) é comum. Em seguida, ele afirma que o índice proposto por Allen et al. não era nada além do tempo médio de viagem, o que não se constituía em nenhuma novidade. Ele também enfatizou que a revisão da literatura conduzida por Allen et al. foi muito limitada, uma vez que os autores não procuraram as reais raízes do índice no qual basearam a sua medida de acessibilidade. Eles procuraram trabalhos apenas em um intervalo de 30 anos, quando deveriam ter retornado 50 ou 60 anos para encontrar o trabalho de Shimble (1953) sobre a teoria dos grafos, que parece ser a real base do seu índice. Mais ainda, este índice é comumente empregado em análises espaciais quantitativas, mas mesmo nesses casos é muitas vezes ponderado por variáveis de oferta ou demanda.

Usando uma abordagem diferente, Geertman \&Van Eck (1995) propuseram o uso de um modelo potencial para estimar a acessibilidade. O seu modelo é um quociente de duas fórmulas de potencial clássicas, baseadas em um padrão de interação do tipo gravitacional. A dimensão do "modelo potencial modificado" é a mesma do tempo de viagem (os resultados são também medidos em minutos), tornando fácil a sua interpretação. A aplicação do modelo em uma região da Holanda (Randstad Holland) mostrou que a integração de modelos externos com o Sistema de Informações Geográficas funcionou bem, ampliando a capacidade de análise espacial do SIG e melhorando a forma como ele lida com o problema da acessibilidade.

Apesar de algumas diferenças necessárias para se ajustar às aplicações para as quais foram projetadas, as medidas de acessibilidade dos últimos anos não trouxeram grandes inovações para o planejamento de transportes. Alguns trabalhos, no entanto, podem ser de interesse particular para os pesquisadores da área, por lidarem com problemas bastante 
específicos. Este é o caso das medidas de acessibilidade no contexto das viagens com múltiplos propósitos (Arentze et al., 1994a e 1994b), da inclusão do conceito de mobilidade como parte da medida de acessibilidade (Tagore \& Sikdar, 1995) e do uso do isolamento ao invés da acessibilidade para avaliar uma rede de transportes (Davidson, 1995).

O isolamento irá receber atenção especial aqui porque, embora tenha um certo nível de sofisticação, os dados necessários para o seu cálculo não são de difícil obtenção. $\mathrm{Na}$ realidade, os dados para implementação desta medida já foram utilizados na aplicação do modelo META. Isolamento e acessibilidade são ambas características de um lugar, definidas pelo sistema de transporte e pela distribuição de atividades mas, de acordo com Davidson (1995), isolamento é a função inversa da acessibilidade e a sua expressão em termos de utilidade. Ambos os índices de Davidson (acessibilidade e isolamento) são considerados para uso aqui porque atendem aos requisitos gerais identificados por Morris et al. (1979) para auxiliar na escolha de um índice de acessibilidade:

- Deve incorporar um elemento de separação espacial (como por exemplo as distâncias medidas na rede de vias);

- Deve ter bases comportamentais (segundo Davidson, o isolamento é a expressão da acessibilidade em termos de utilidade);

- Devem ser tecnicamente factíveis e operacionalmente simples (neste caso, todos os elementos considerados na equação já tinham sido empregados no modelo META);

- Os resultados devem ser de fácil interpretação.

\subsection{ACESSIBILIDADE EM ARARAQUARA}

A acessibilidade pode ser medida de várias formas, como já foi descrito anteriormente. $\mathrm{Na}$ aplicação aqui conduzida ela será medida dez vezes, através da aplicação de sete diferentes índices. A aplicação tem início com os indicadores simples listados abaixo, sugeridos em trabalhos anteriores (Raia Jr. et al., 1996; Raia Jr. \& Silva, $1996 a$ e $b$ ):

- Distância ao centro da cidade;

- Distância à rota de transporte público mais próxima;

- Uma medida de oferta do transporte público; e

- Percentual de ruas pavimentadas em relação a extensão total de ruas em cada zona.

Em seguida, três índices extraídos da revisão da literatura foram aplicados, cada um deles em duas situações diferentes. O primeiro deles é a medida proposta por Allen et al. (1993), que é basicamente uma medida espacial (distância média de viagem). Finalmente, o isolamento de Davidson é calculado para a cidade de Araraquara, juntamente com sua medida original de acessibilidade, como as medidas que atendem aos requisitos propostos por Morris et al. (1978) para a seleção de índices de acessibilidade. Para melhor identificar as características dessas medidas, elas estão também incluídas na Figura 5.1, onde aparecem marcadas com uma moldura em destaque. Estes três indicadores (incluindo a acessibilidade de Davidson) serão inicialmente aplicados usando a rede completa de ruas e, 
em seguida, usando uma rede que representa apenas as possíveis conexões através das rotas de transporte público.

Os índices aplicados serão brevemente descritos na seqüência, acompanhados de mapas temáticos que resumem os resultados encontrados com cada um deles na cidade de Araraquara. É importante observar que a divisão de zonas empregada agora não é a mesma que foi usada nos capítulos anteriores. A cidade foi agora dividida em 200 zonas, que de maneira geral coincidem com os loteamentos da cidade. A explicação para se trabalhar aqui com uma divisão diferente é bastante simples: os preços de terrenos que serão considerados na comparação com os resultados aqui obtidos foram coletados tendo por base os loteamentos. Como o SIG pode efetuar os cálculos com este número de zonas sem nenhum problema, não havia razão para não se adotar esta nova divisão nesta aplicação. Além disso, um número maior de zonas permite uma melhor visualização dos valores de acessibilidade nos mapas temáticos.

\subsubsection{Distância ao Centro da Cidade}

Esta é uma das mais simples medidas de acessibilidade utilizadas em estudos de planejamento de transportes. O seu uso é perfeitamente justificado nas cidades brasileiras pequenas e médias porque, de maneira geral, a maior parte das funções comerciais, financeiras e administrativas se encontra nos centros dessas cidades. Na cidade de São Carlos, que é semelhante a Araraquara em muitos aspectos, o centro da cidade é responsável por 50\% dos empregos, em cerca de 5\% da área urbana total (Sanches, 1988).

No estudo de caso aqui conduzido, as distâncias foram consideradas como as ligações dos centróides das zonas a um ponto na área central da cidade, onde todas as rotas de ônibus se concentram. As distâncias foram sempre medidas através da rede de ruas, da mesma forma que as viagens de automóvel no modelo META, mas desta vez considerando a nova divisão de zonas. Os caminhos e as distâncias para cada zona são mostradas nas Figuras 5.2 e 5.3, respectivamente. O SIG foi usado tanto para calcular as distâncias, como para produzir os mapas temáticos com os resultados do procedimento. A distância média de todas as zonas para o centro da cidade é de $3,5 \mathrm{~km}$, com mais de $50 \%$ destas distâncias entre 2,0 e 4,0 km, conforme se pode constatar na Figura 5.3.

\subsubsection{Distância à Rota de Ônibus Mais Próxima}

De acordo com Nigriello (1977), a distância que as pessoas têm que caminhar para utilizar o sistema de transporte público urbano é um importante indicador de acessibilidade nas cidades brasileiras. Esta distância é normalmente medida do local de origem até o ponto em que o indivíduo pode tomar o ônibus. Elas foram aqui consideradas como as distâncias Euclidianas entre o centróide de cada zona e a rota de ônibus mais próxima, de forma a simplificar o processo de cálculo. Esta medida provavelmente não tem o mesmo significado em todas as zonas, sendo mais importante em zonas de baixa renda, nas 
quais a maioria dos habitantes é constituída de usuários cativos do sistema de transporte público.

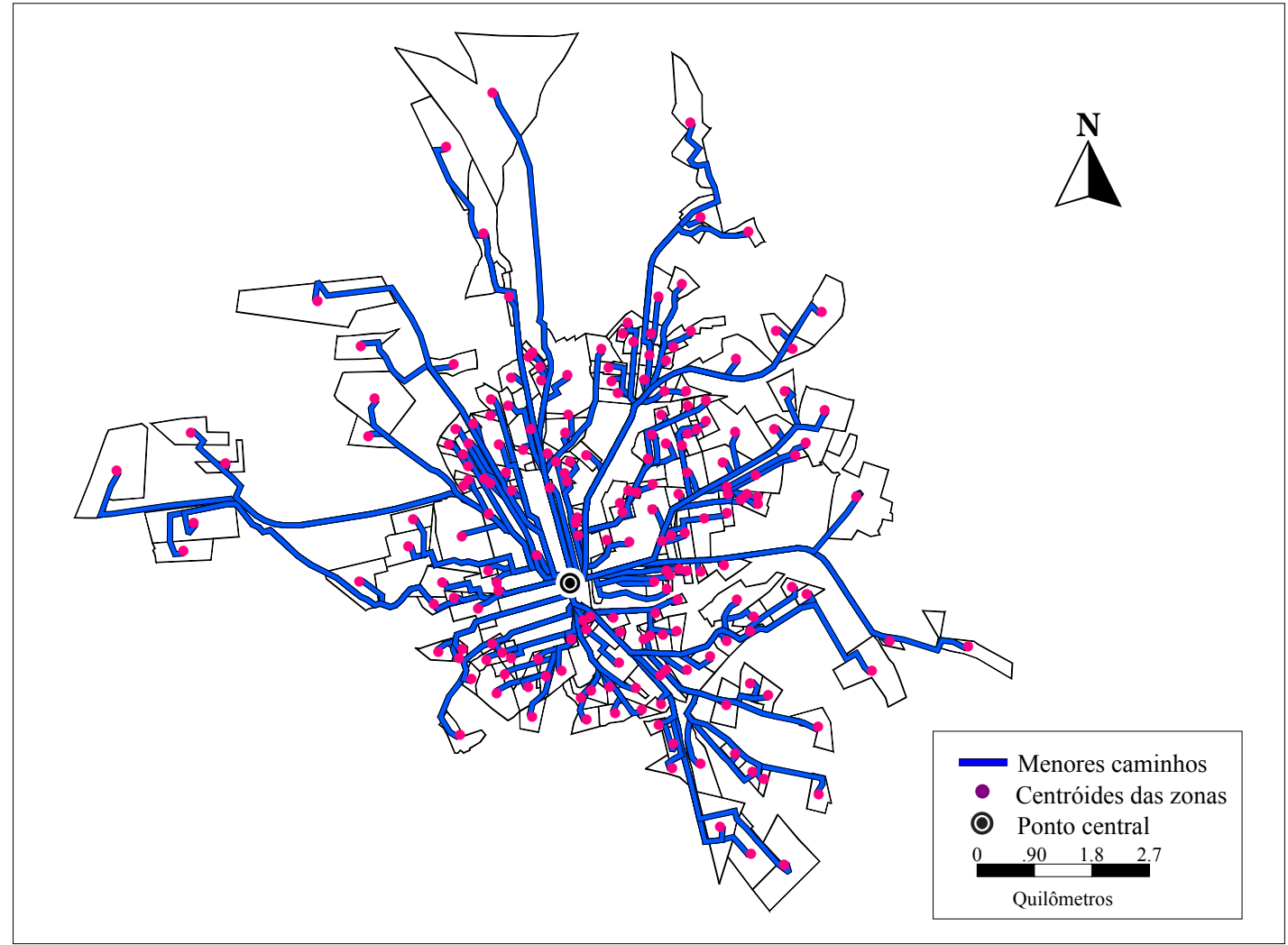

Figura 5.2 - Menores caminhos entre as zonas e o centro da cidade de Araraquara

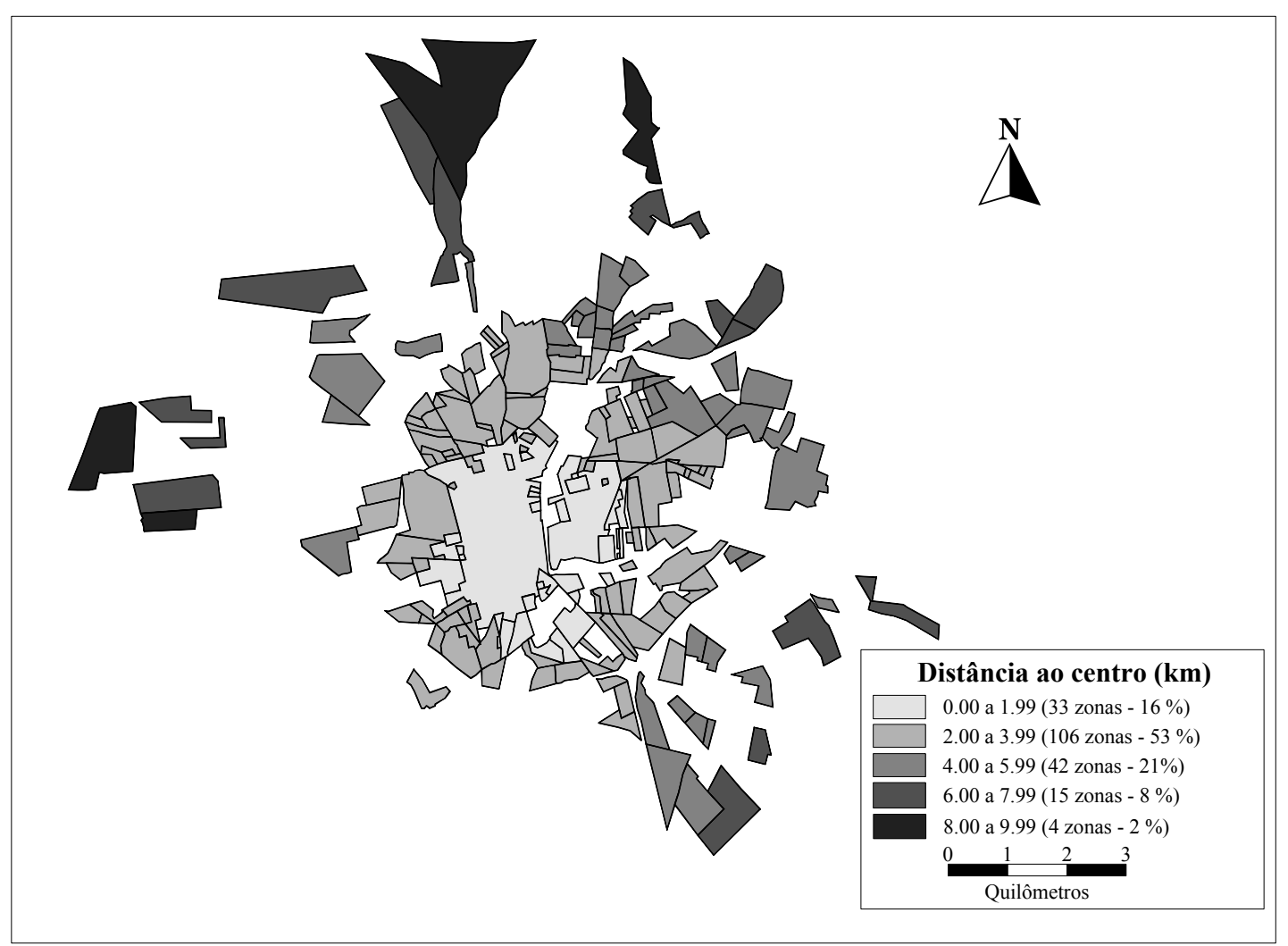

Figura 5.3 - Mapa temático mostrando as distâncias das zonas ao centro da cidade. 
As rotas de ônibus aqui consideradas seguem os traçados reais, digitalizadas a partir de mapas em papel e apresentadas na Figura 5.4. Embora as rotas que seguem em uma mesma rua sejam, para esta medida, consideradas como uma só entidade, elas estão na realidade armazenadas, na base de dados, de forma independente umas das outras. Este aspecto é bastante importante para a próxima medida de acessibilidade, que leva em consideração a extensão total das rotas de ônibus em cada zona.

O software pode combinar as camadas de Centróides das Zonas e Rotas de Onibus, através do preenchimento de um campo de informação da base de dados da segunda com o comando Distance to Feature (após a seqüência Edit-Fill-Tag). Mais de $80 \%$ das zonas têm os seus centróides mais próximos do que $0,18 \mathrm{~km}$ de uma rota de ônibus. A distância média neste caso é de $0,12 \mathrm{~km}$ e o número de zonas em cada classe é mostrado na Figura 5.5. Considerando que $0,40 \mathrm{~km}$ é a distância máxima a que todo usuário deve estar do sistema de transporte público para ser considerado bem atendido, o sistema de Araraquara pode ser considerado muito bom (84,5 \% das zonas estão dentro deste limite). É evidente que a forma como esta medida foi considerada fornece apenas uma distância média, mas mesmo assim esta parece ser uma medida de acessibilidade simples e interessante.

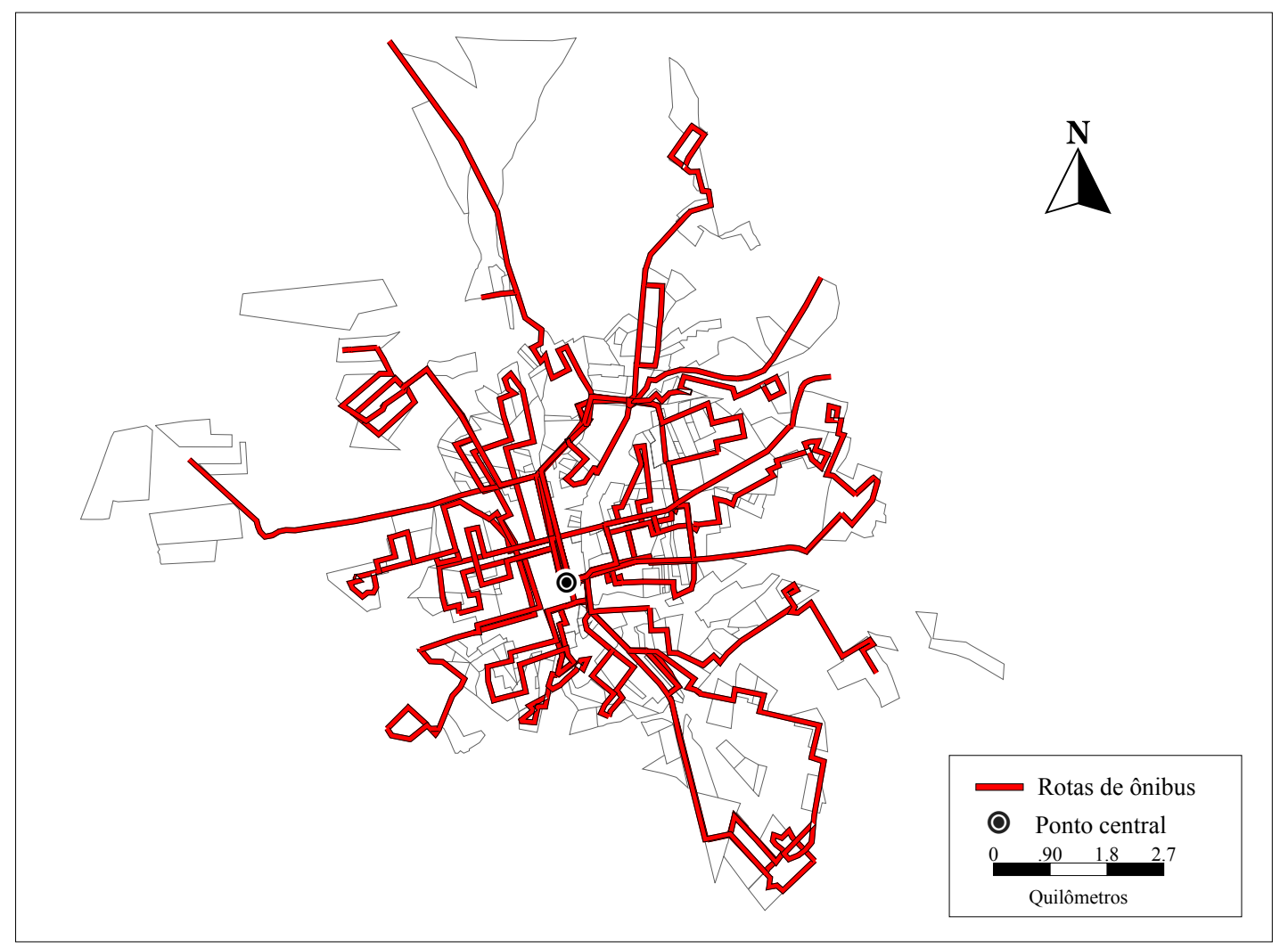

Figura 5.4 - Conjunto de rotas de ônibus na cidade de Araraquara. 


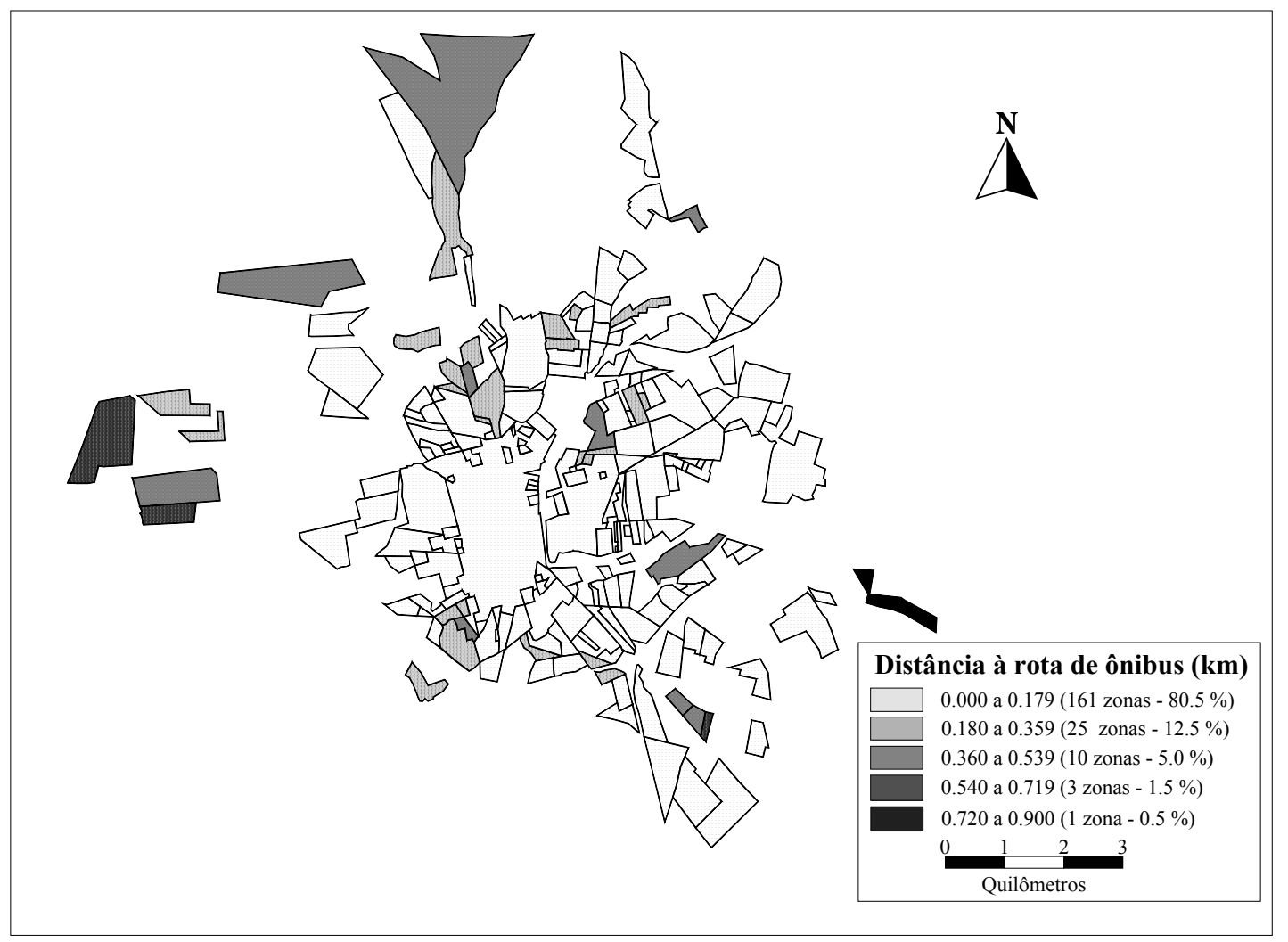

Figura 5.5 - Mapa temático mostrando as distâncias entre os centróides das zonas e a rota de ônibus mais próxima.

\subsubsection{Uma Medida de Oferta do Transporte Público}

Outra abordagem aqui proposta para se medir a acessibilidade ao transporte público urbano é a relação entre a soma de todos os segmentos de rota em uma zona (CO, ou Comprimento total das rotas de Ônibus) e o comprimento total das vias na mesma zona (CR, ou Comprimento total das Ruas). Quanto maior este indicador, melhor a oferta de transporte público da zona considerada. Como já mencionado, embora o conjunto de rotas seja mostrado no mapa como uma única linha, os comprimentos de cada rota são considerados de forma independente nesta medida. Desta maneira, as zonas centrais podem ter valores até mesmo superiores a 1,0, como uma conseqüência do elevado número de rotas de transporte público que servem a região.

Este não foi o caso observado aqui, uma vez que o maior valor encontrado foi 0,96 - correspondente a zona central (Figura 5.6). Como se poderia esperar, as zonas com os maiores valores estão todas em torno do centro da cidade. $\mathrm{O}$ valor médio, excluídas as zonas não servidas por transporte público, é de 0,23 , com um desvio padrão de 0,22 . 


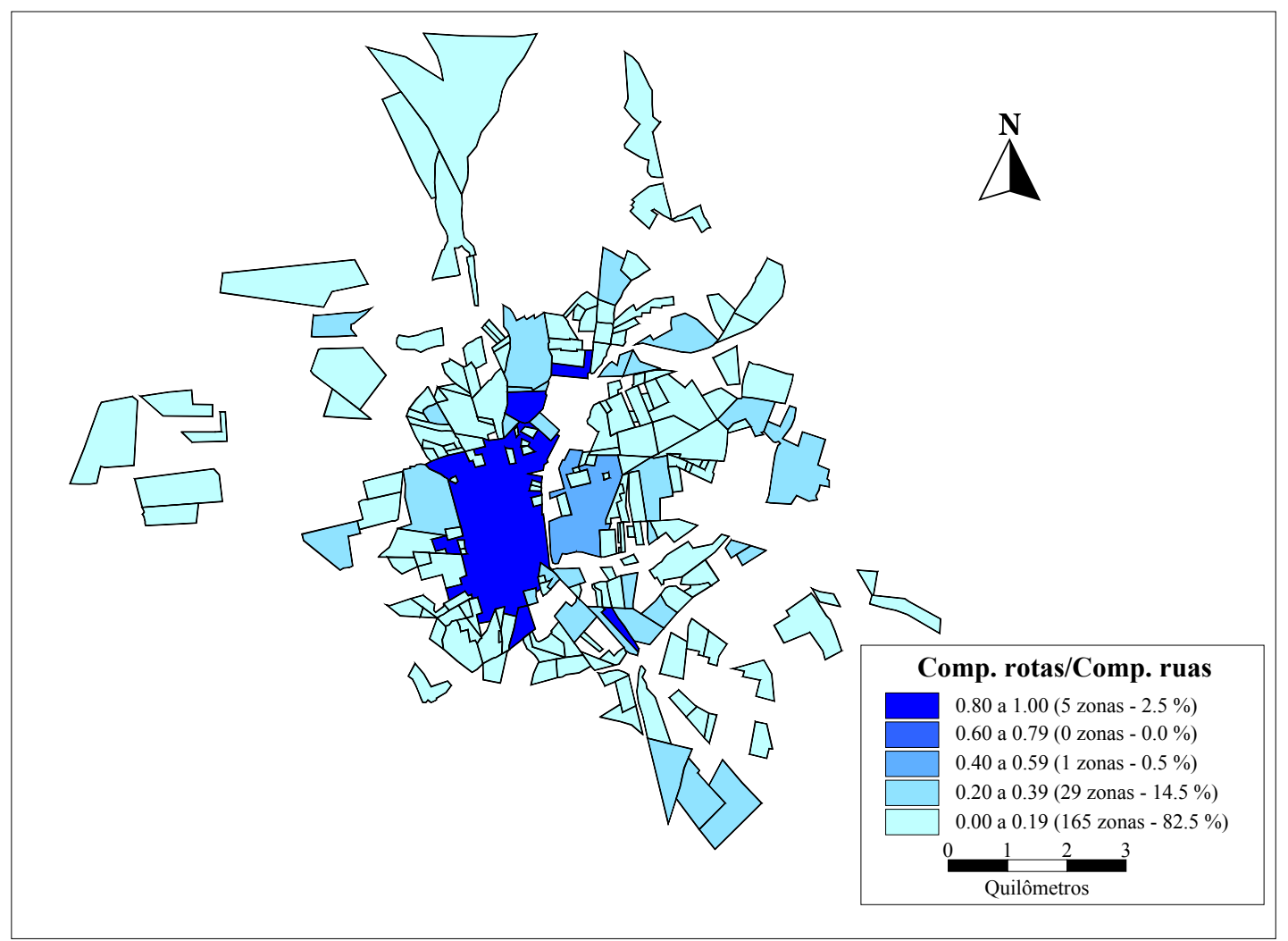

Figura 5.6 - Mapa temático mostrando a relação entre CO - Comprimento total das rotas de Ônibus - e CR - Comprimento total das Ruas em cada zona.

\subsubsection{Percentual de Ruas Pavimentadas em Relação à Extensão Total de Ruas}

Esta medida provavelmente soaria sem sentido em um país desenvolvido, mas a situação é bastante diferente nos países em desenvolvimento, nos quais existem inúmeras vias nas áreas urbanas sem pavimentação, normalmente localizadas na periferia das cidades. O pavimento oferece uma superfície uniforme, que permite maiores volumes de tráfego com maior velocidade. Além disso, todas as viagens, inclusive as de transporte público, se tornam mais confortáveis. Esta combinação de fatores se traduz de alguma forma em um melhor nível de acessibilidade para a área. Esta é a justificativa para o indicador aqui proposto, que pode ser obtido pela divisão do comprimento total das vias não pavimentadas pelo comprimento total da vias em cada zona.

Os índices de acessibilidade são mostrados na Figura 5.7. A maioria das zonas tem uma parcela significativa (em termos de comprimento) de vias pavimentadas, mas mais de $10 \%$ do total de zonas têm entre 80 e $100 \%$ de ruas não pavimentadas. Como já se havia comentado anteriormente, essas são, em geral, as zonas pobres da periferia da cidade. 


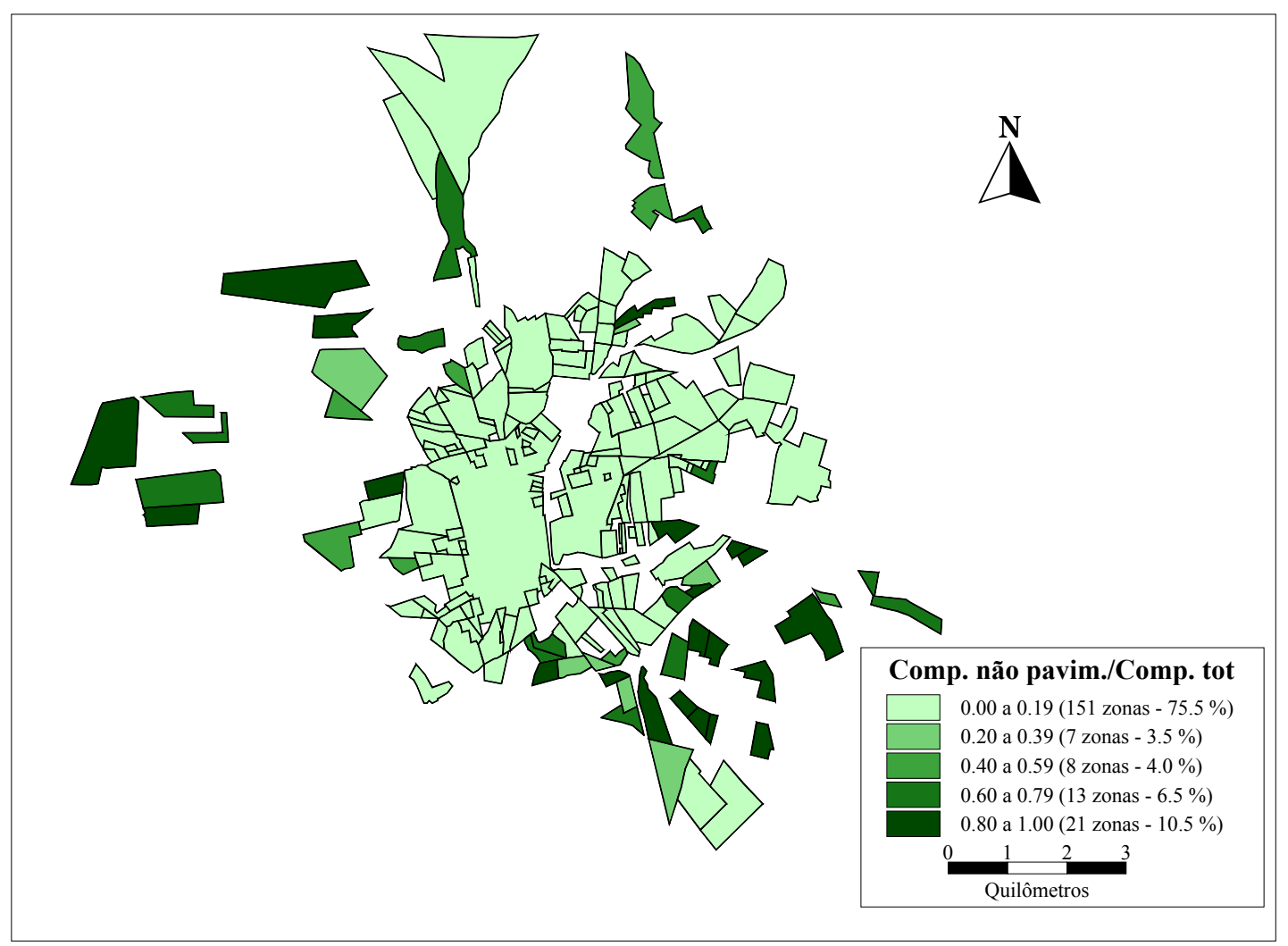

Figura 5.7 - Mapa temático mostrando a relação entre o comprimento de ruas não pavimentadas e o comprimento total das ruas.

\subsubsection{Separação Média entre Zonas}

Este índice, proposto por Allen et al. (1993), é somente uma medida do esforço para vencer a separação espacial entre os centróides das zonas. Isto significa que ele não tem bases comportamentais. Por outro lado, ele é operacionalmente simples e os seus resultados são de fácil interpretação. Estes últimos dois aspectos são as principais razões para a inclusão deste indicador nessa aplicação. Esse índice pode ser matematicamente expresso da seguinte forma:

$$
A_{i}=\frac{1}{N-1} \sum C_{i j}
$$

Onde:

$\mathrm{A}_{i}=$ acessibilidade da zona $i$

$\mathrm{N}$ = número de locações (zonas) usadas no cálculo;

$\mathrm{C}_{i j}=$ custo percebido pelo usuário entre as zonas $i \mathrm{e} j$.

Allen et al. sugeriram, em seu trabalho, que o custo percebido pelo usuário fosse dado pelo tempo de viagem, mas adotou-se aqui a distância de viagem. Isto não deve chegar a se constituir em um problema, considerando-se que Araraquara é uma cidade média. É que nestas cidades ainda não são verificados elevados níveis de congestionamento, capazes 
de fazer com que o tempo de viagem difira muito das distâncias para os fins aqui pretendidos. Em outras palavras, se as velocidades de deslocamento não variam em demasia dentro da área de estudo, as distâncias e os tempos de viagem conduzem a resultados semelhantes em termos de classificação da acessibilidade.

Este índice foi aplicado em duas condições diferentes na cidade de Araraquara: a primeira considerando os menores caminhos através da rede composta por todas as vias da cidade, enquanto que a segunda rede foi construída apenas com as vias servidas por pelo menos uma linha de transporte público. Os resultados de ambos os casos são apresentados, respectivamente, nas Figuras 5.8 e 5.9, nas quais se pode ver que os mesmos apresentam de fato alguma variação, justificando o uso das duas abordagens.

\subsubsection{Medida de Acessibilidade do Tipo Gravitacional}

De acordo com Davidson (1977 e 1995), acessibilidade pode ser matematicamente expressa como:

$$
A_{i}=\sum_{j} S_{j} \times f\left(C_{i j}\right)
$$

Onde:

$\mathrm{A}_{i}=$ acessibilidade da zona $i$

$\mathrm{S}_{j}=$ uma medida de atividade na zona $j$;

$\mathrm{C}_{i j}=$ custo percebido pelo usuário entre as zonas $i$ e $j$;

$\mathrm{f}$ = função de impedância do tipo usado em modelos gravitacionais como, por exemplo, potência ou exponencial.

Considerou-se aqui a densidade populacional como a medida de atividade das zonas, a distância através da rede como custo percebido pelo usuário, e uma função de impedância semelhante àquela adotada ao se trabalhar com o modelo META. Adaptando-se a expressão acima para os dados disponíveis, tem-se:

$$
A_{i}=\sum_{j} \operatorname{Dens}_{j} \times\left(\text { Dist }_{i j}\right)^{-\alpha}
$$

Onde:

$\mathrm{A}_{i}=$ acessibilidade da zona $i$

Dens $_{j}=$ densidade populacional na zona $j$;

Dist $_{i j}=$ distância entre as zonas $i$ e $j$.

$\alpha=$ expoente da função potência.

Este indicador foi também usado com dois tipos de redes, tal como o índice anterior. Os resultados com a rede total de vias são resumidos na Figura 5.10, enquanto que aqueles da rede de transporte público são mostrados na Figura 5.11. 


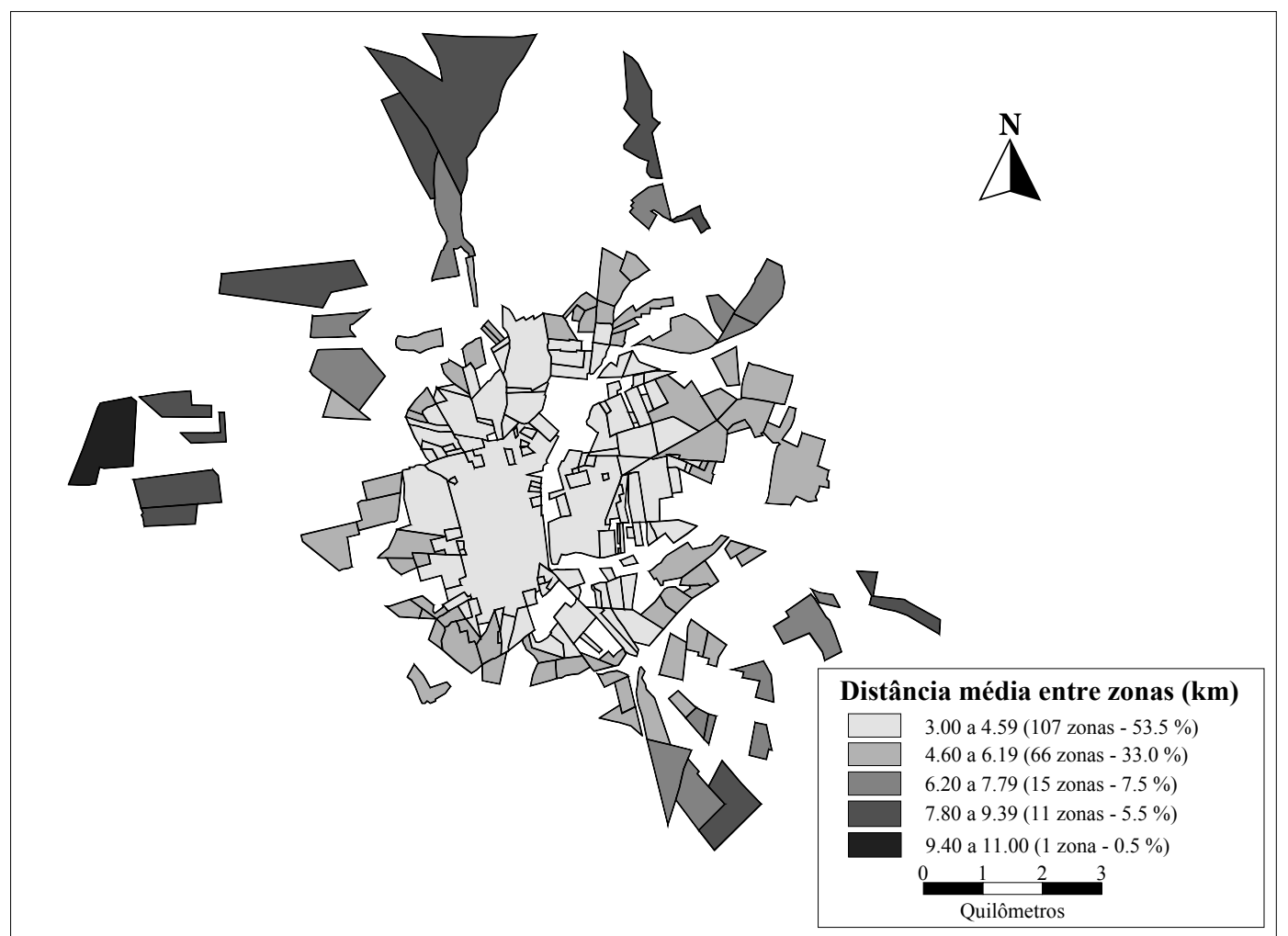

Figura 5.8 - Mapa temático mostrando a separação média entre centróides de zonas com base na rede completa de ruas.

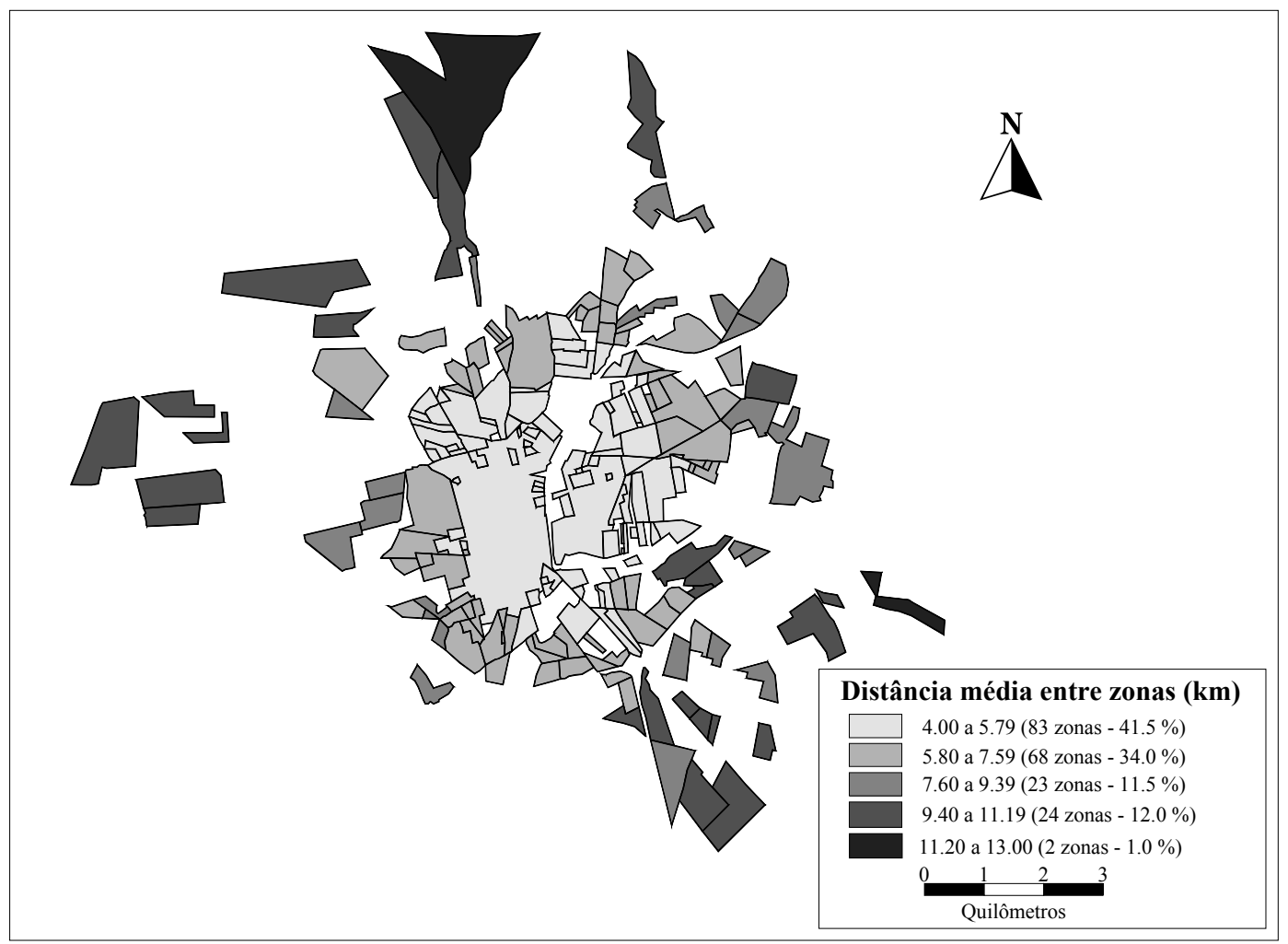

Figura 5.9 - Mapa temático mostrando a separação média entre centróides de zonas com base na rede de ruas servidas por transporte público. 


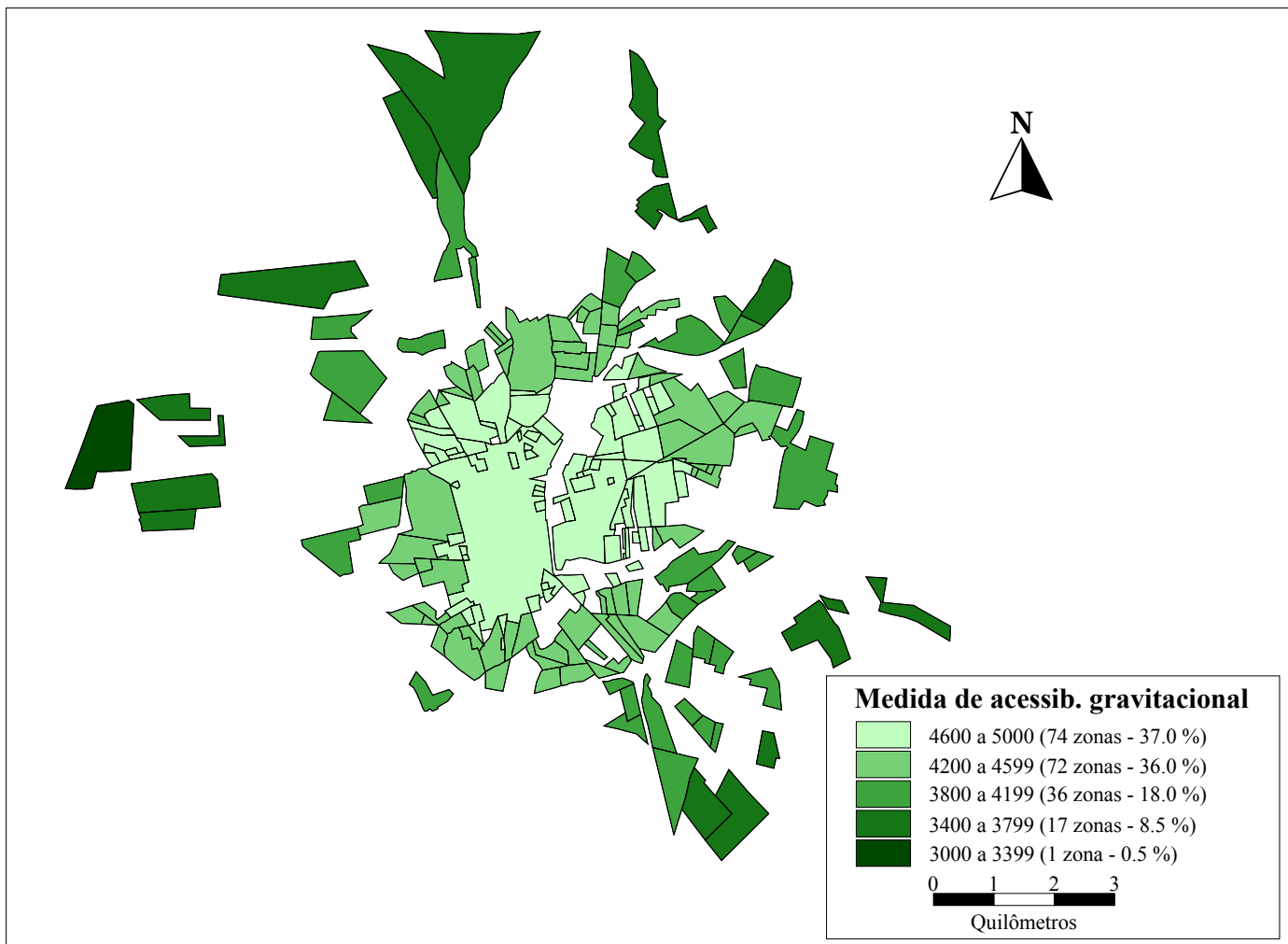

Figura 5.10 - Mapa temático mostrando os resultados de medida de acessibilidade do tipo gravitacional com base na rede completa de ruas.

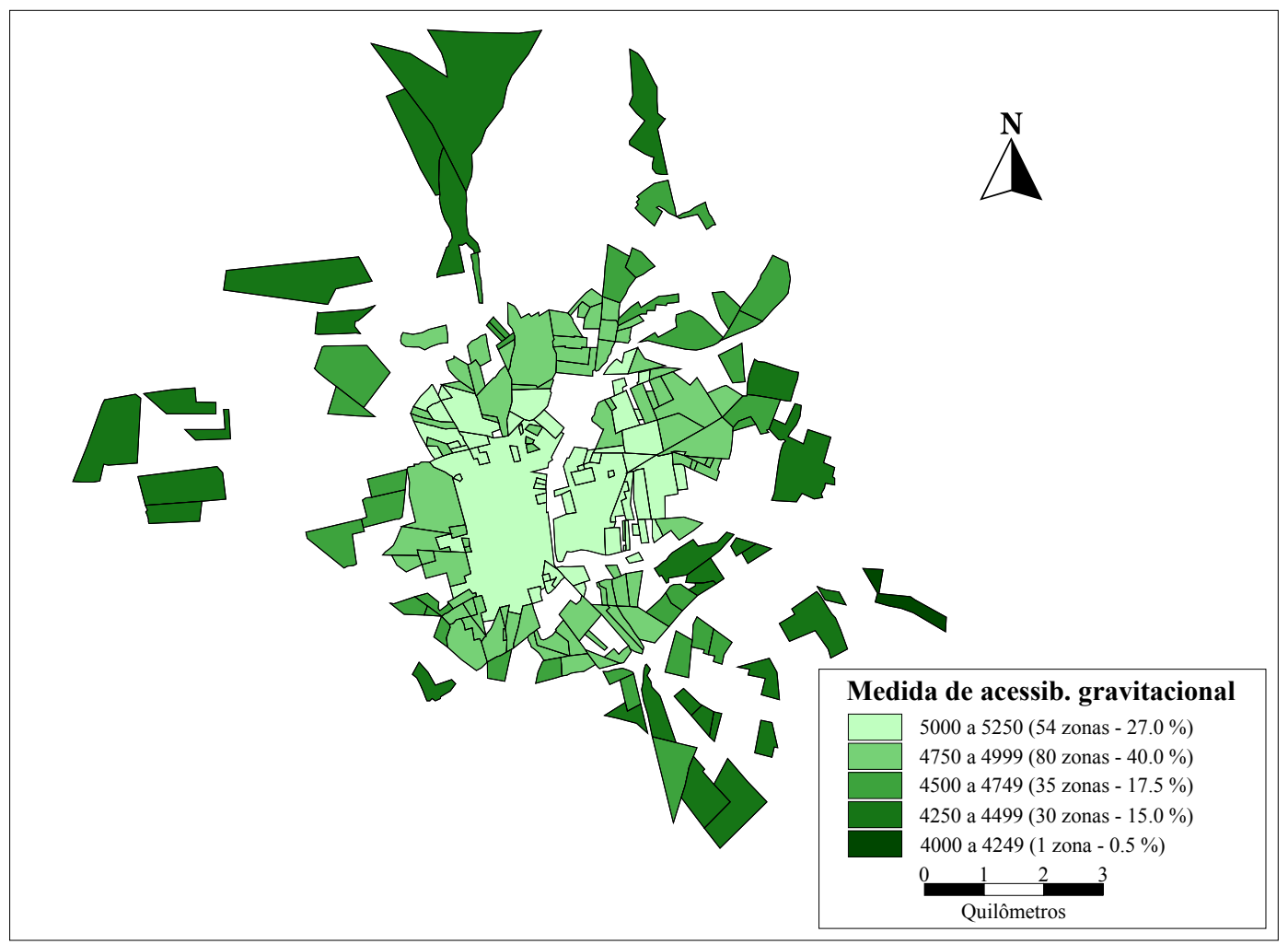

Figura 5.11 - Mapa temático mostrando os resultados de medida de acessibilidade do tipo gravitacional com base na rede de ruas servidas por transporte público. 


\subsubsection{Isolamento}

Como já foi mencionado, isolamento e acessibilidade são ambas características de um lugar definidas pelo sistema de transportes e pela distribuição de atividades, mas o isolamento é, segundo o seu criador, uma expressão da acessibilidade em termos de utilidade. O isolamento é uma transformação particular da definição de acessibilidade descrita no item anterior (Davidson, 1995):

$$
Y_{i}=f^{-1}\left(\frac{A_{i}}{S_{T}}\right)
$$

Onde:

$\mathrm{A}_{i}=$ acessibilidade da zona $i$

$\mathrm{Y}_{i}=$ isolamento da zona $i$;

$\mathrm{S}_{T}=$ total de atividades na área de estudo.

Adaptando-se a expressão acima para os dados disponíveis, de forma semelhante ao item anterior, tem-se:

$$
Y_{i}=\left(\frac{A_{i}}{\operatorname{Dens}_{T}}\right)^{-1 / \alpha}
$$

Onde:

$\operatorname{Dens}_{T}=$ densidade populacional de Araraquara;

$\alpha=$ expoente da função potência.

Os resultados da rede completa estão resumidos na Figura 5.12, enquanto que aqueles da rede de transporte público são mostrados na Figura 5.13. 


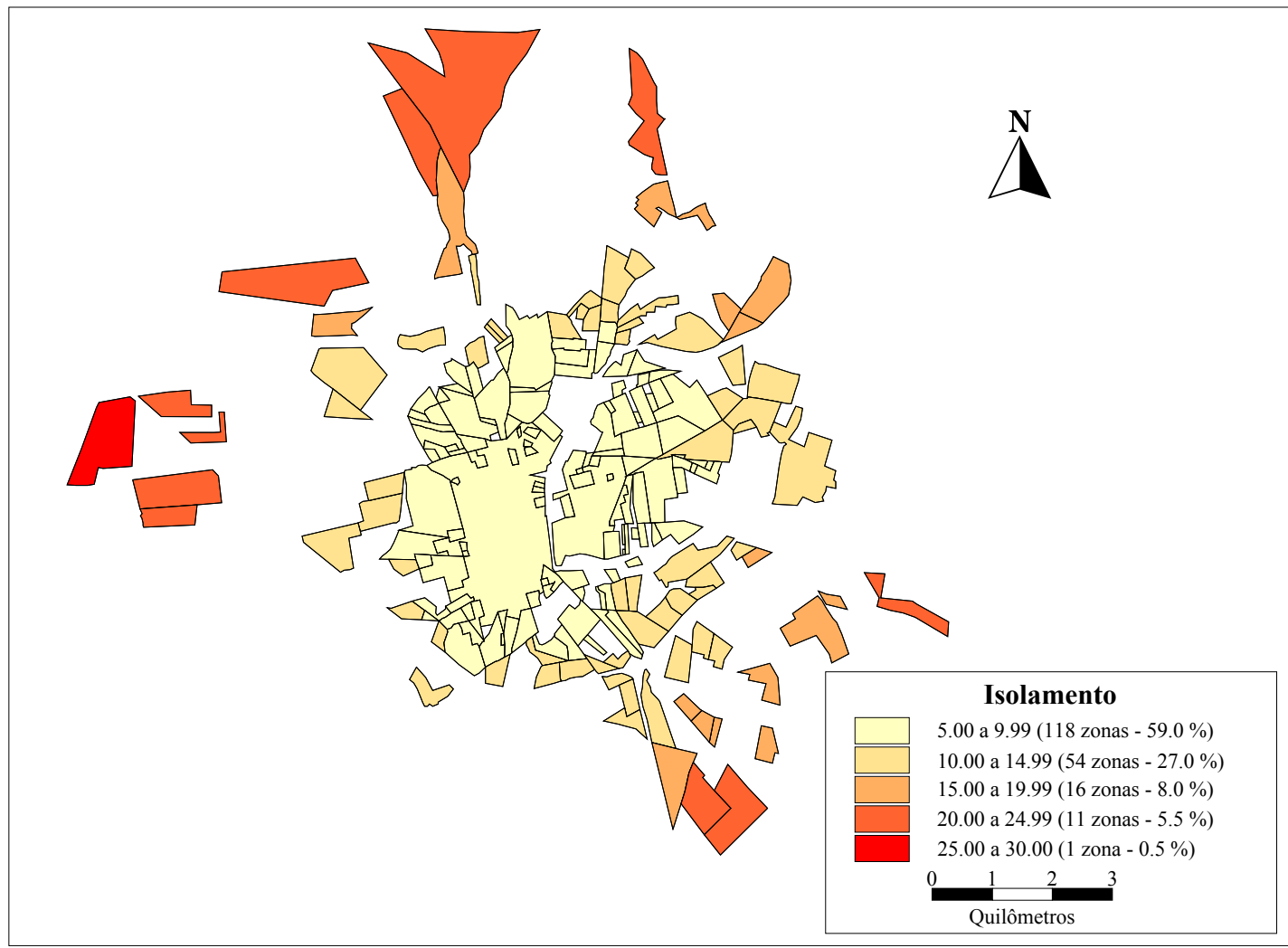

Figura 5.12 - Mapa temático mostrando os resultados do índice de isolamento com base na rede completa de ruas.

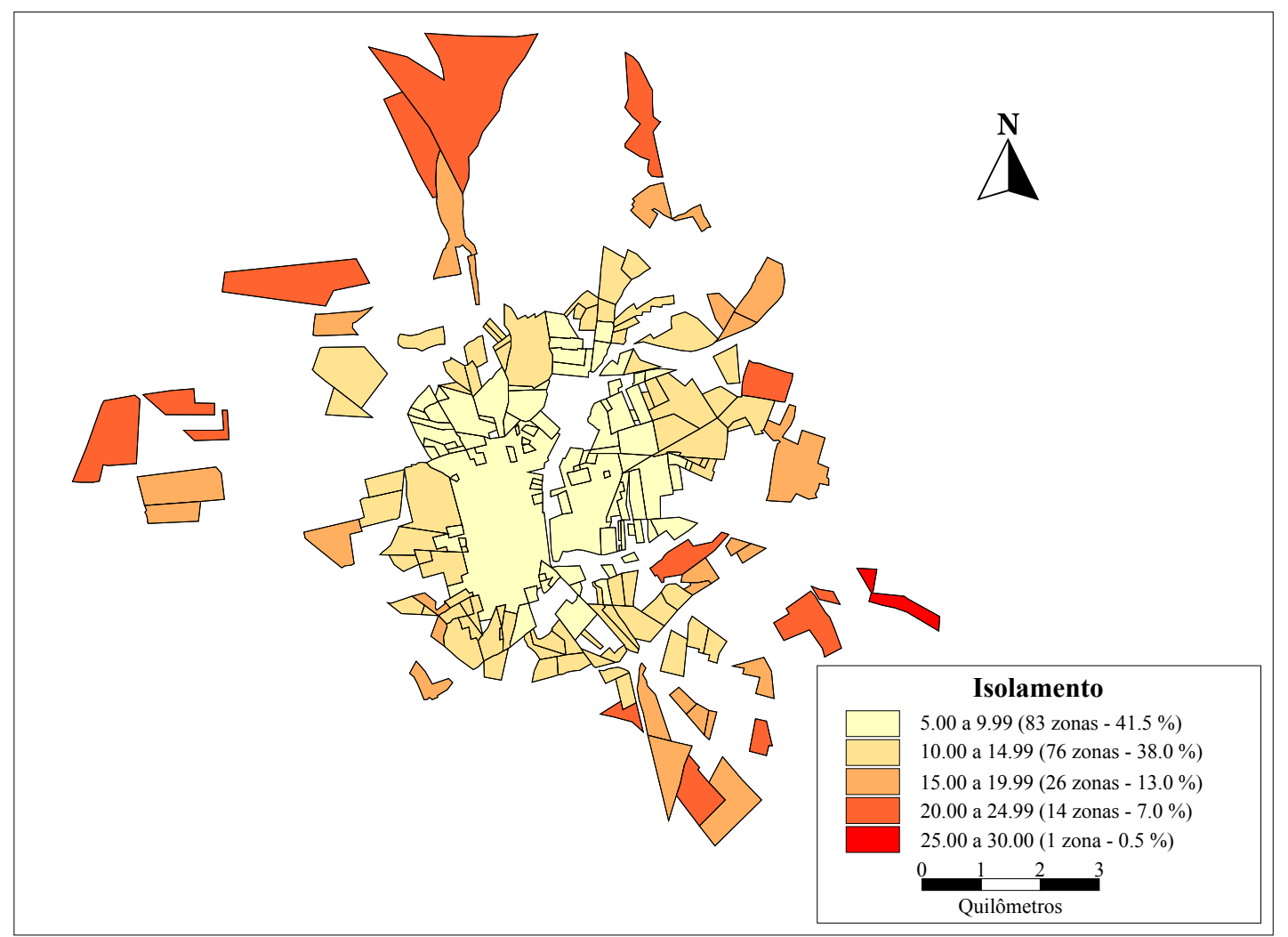

Figura 5.13 - Mapa temático mostrando os resultados do índice de isolamento com base na rede de ruas servidas por transporte público. 


\subsection{COMPARANDO AS MEDIDAS DE ACESSIBILIDADE}

A aplicação das diferentes medidas de acessibilidade em Araraquara, que se acabou de apresentar na última seção, produziu resultados bastante diversos. $\mathrm{O}$ desafio agora é identificar qual dessas medidas melhor representa os níveis de acessibilidade da cidade para fins de avaliação de imóveis. Provavelmente não existe uma resposta definitiva para esse problema, e ele foi tratado aqui de duas diferentes formas. A primeira abordagem consistiu simplesmente em se comparar as classificações produzidas pelas dez medidas, usando-se, para este fim, o índice de correlação de rank de Kendall. Em seguida, os resultados das dez medidas foram comparados com os preços de mercado dos terrenos em toda a cidade, para identificar se alguma das medidas de acessibilidade guarda uma maior correlação com esses valores. Partindo-se do princípio que o valor da terra reflete, de alguma forma, a acessibilidade aos transportes (ver Aoki et al., 1994), as medidas que guardarem as maiores correlações poderiam ser as que melhor representam a acessibilidade.

Os resultados da avaliação da correlação entre as classificações (rankings) são mostrados na Tabela 5.1. Alguns resultados apresentam alta correlação, como as duas medidas de Davidson (acessibilidade e isolamento), para ambos os tipos de redes analisados. Estas duas medidas são também altamente correlacionadas com a medida separação média entre zonas. Estes altos valores podiam, de certa maneira, ser esperados, devido ao fato de que a medida de atividade adotada para as zonas foi a população. Se tivesse sido adotada a densidade de empregos, por exemplo, os resultados provavelmente seriam diferentes, mas talvez não o bastante para justificar o uso das medidas de Davidson, que exigem um esforço considerável na fase de coleta de dados. Ao se comparar as medidas mais sofisticadas com aquelas mais simples, os valores encontrados para o índice de correlação tornam-se muito baixos. Em geral, as medidas mais simples apresentam baixa correlação entre si, o que pode significar que elas representam diferentes aspectos da acessibilidade, cada um deles importante sob um ponto de vista.

\begin{tabular}{|c|c|c|c|c|c|c|c|c|c|c|}
\hline & $\begin{array}{l}\text { Dist } \\
\text { Ctr }\end{array}$ & $\begin{array}{l}\text { Dist } \\
\text { Bus }\end{array}$ & $\begin{array}{l}\text { Bus/ } \\
\text { Ruas }\end{array}$ & $\begin{array}{c}\text { Não } \\
\text { Pav/Tot }\end{array}$ & $\begin{array}{c}\text { DstMédia } \\
\text { RedTot }\end{array}$ & $\begin{array}{l}\text { DstMédia } \\
\text { RedBus }\end{array}$ & $\begin{array}{c}\text { Grav } \\
\text { RedTot }\end{array}$ & $\begin{array}{c}\text { Grav } \\
\text { RedBus }\end{array}$ & $\begin{array}{c}\text { Isol } \\
\text { RedTot }\end{array}$ & $\begin{array}{c}\text { Isol } \\
\text { RedBus }\end{array}$ \\
\hline DistCtr & 1,00 & & & & & & & & & \\
\hline DistBus & 0,40 & 1,00 & & & & & & & & \\
\hline Bus/Ruas & 0,38 & 0,48 & 1,00 & & & & & & & \\
\hline $\begin{array}{c}\text { Não } \\
\text { Pav/Tot }\end{array}$ & 0,69 & 0,39 & 0,40 & 1,00 & & & & & & \\
\hline $\begin{array}{c}\text { DstMédia } \\
\text { RedTot }\end{array}$ & 0,74 & 0,42 & 0,45 & 0,87 & 1,00 & & & & & \\
\hline $\begin{array}{c}\text { DstMédia } \\
\text { RedBus }\end{array}$ & 0,66 & 0,41 & 0,44 & 0,79 & 0,83 & 1,00 & & & & \\
\hline $\begin{array}{c}\text { Grav } \\
\text { RedTot }\end{array}$ & 0,70 & 0,41 & 0,42 & 0,96 & 0,88 & 0,79 & 1,00 & & & \\
\hline $\begin{array}{c}\text { Grav } \\
\text { RedBus }\end{array}$ & 0,65 & 0,42 & 0,45 & 0,80 & 0,80 & 0,92 & 0,82 & 1,00 & & \\
\hline IsolRedTot & 0,71 & 0,41 & 0,42 & 0,96 & 0,88 & 0,8 & 0,98 & 0,82 & 1,00 & \\
\hline IsolRedBus & 0,62 & 0,42 & 0,45 & 0,80 & 0,80 & 0,92 & 0,82 & 0,98 & 0,82 & 1,00 \\
\hline
\end{tabular}

Tabela 5.1 - Coeficientes de correlação de rank de Kendall para as classificações de acessibilidade. 
Para a comparação com os valores da terra, a cidade foi dividida em 200 zonas, de acordo com a divisão dos loteamentos originais da cidade, e foi levantado o preço de 258 terrenos. Enquanto algumas dessas zonas tiveram mais de um terreno pesquisado, para outras não foi possível obter um único registro sequer. Para os casos em que mais de um valor foi levantado em uma mesma zona, foi considerado aqui o valor médio por zona. Além disso, como os lotes pesquisados nem sempre possuíam as mesmas dimensões, adotou-se o valor médio por metro quadrado, de forma a uniformizar os dados. No total, foram registrados valores em 62 das 200 zonas, e os resultados foram inseridos na base de dados do SIG utilizado. A localização dessas 62 zonas é mostrada na Figura 5.14, em que um mapa temático mostra os valores levantados em três classes. Pode-se observar que, quanto mais próximas as zonas estão do centro da cidade, maiores os preços dos terrenos levantados. Isto parece ser uma primeira indicação de que existe de fato uma correlação entre acessibilidade aos transportes e valor da terra.

A variação dos preços da terra em função dos valores de acessibilidade pode ser também analisada através de gráficos, nos quais se pode identificar tendências. Na Figura 5.15 foram plotados todos os resultados das medidas de acessibilidade e os correspondentes preços nas zonas. Pode-se observar uma clara tendência de maiores preços para maiores valores de acessibilidade em todos os casos. Além disso, em alguns deles, como isolamento e separação média entre zonas a tendência observada parece seguir claramente uma função exponencial. Os coeficientes de correlação entre o logaritmo dos valores dos terrenos e cada um dos resultados das medidas de acessibilidade são apresentados na Tabela 5.2.

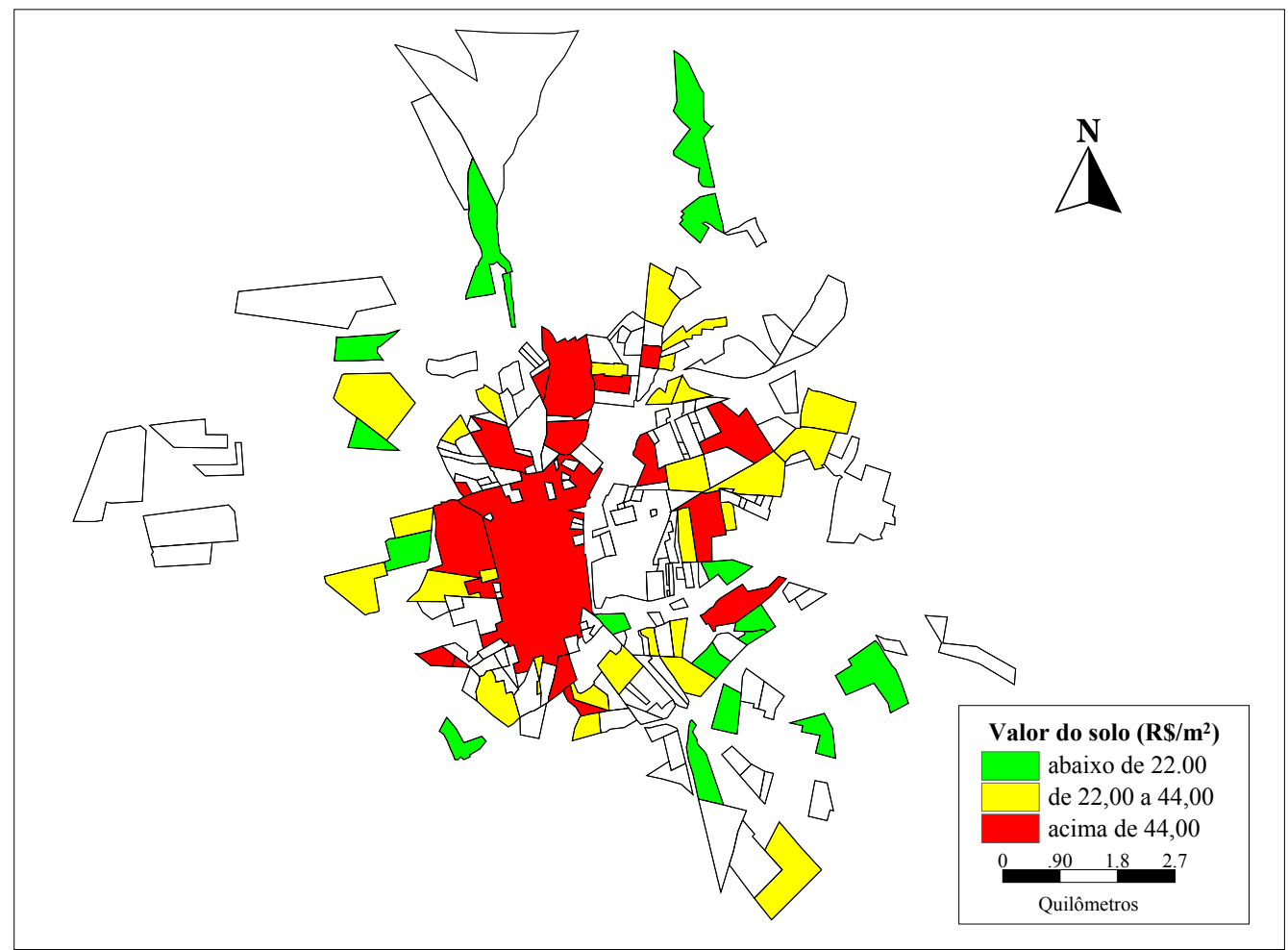

Figura 5.14 - Mapa temático com os valores da terra em 62 zonas de Araraquara. 
Valor do solo $\left(\mathrm{R} \$ / \mathrm{m}^{2}\right)$

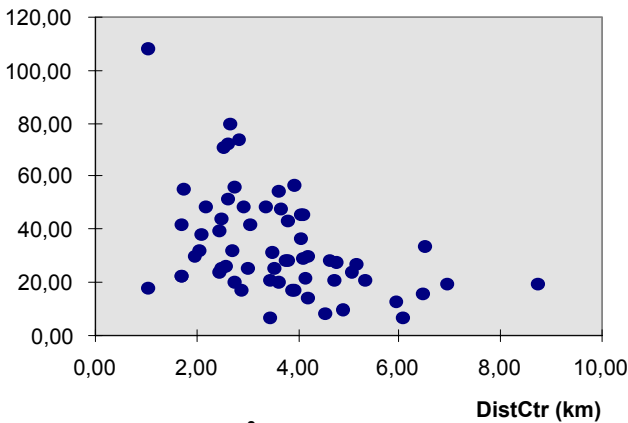

Valor do solo $\left(\mathbf{R} \$ / \mathrm{m}^{2}\right)$

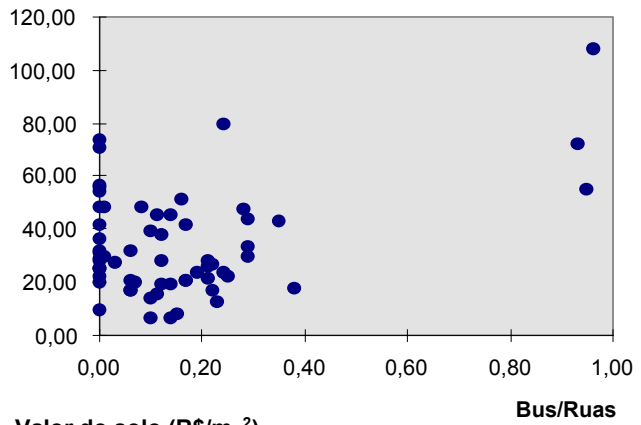

Valor do solo $\left(\mathrm{R} \$ / \mathrm{m}^{2}\right)$

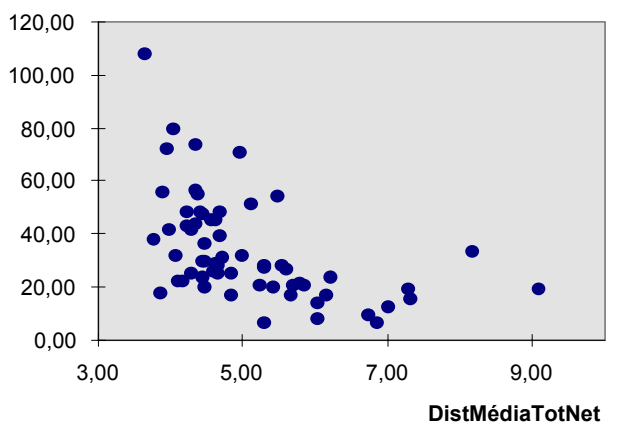

Valor do solo $\left(\mathbf{R} \$ / \mathrm{m}^{2}\right)$

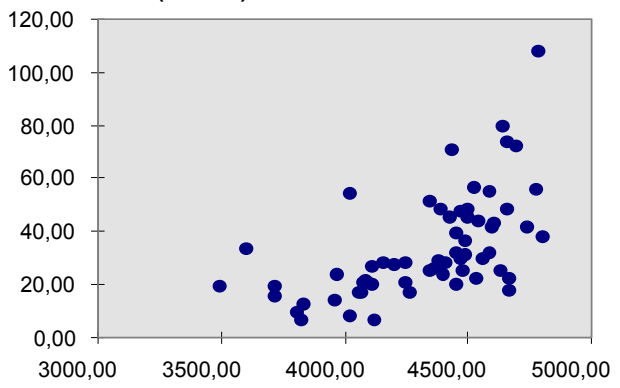

GravRedTot

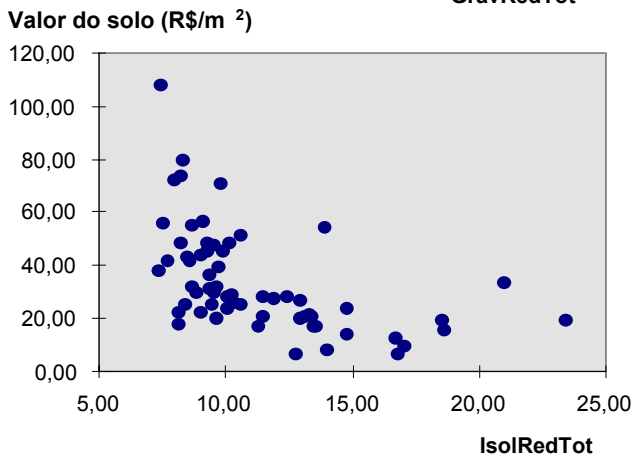

Valor do solo $\left(\mathrm{R} \$ / \mathrm{m}^{2}\right)$

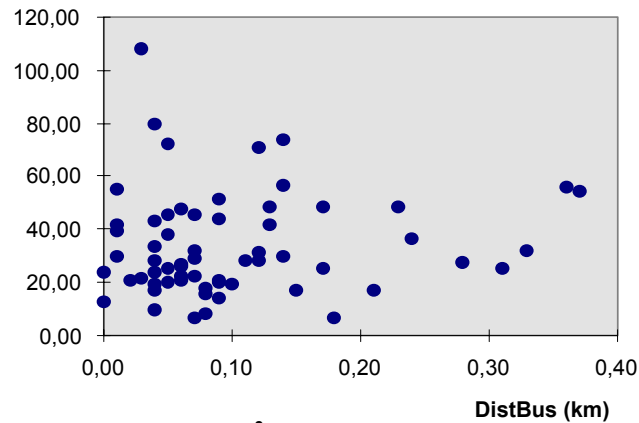

Valor do solo $\left(\mathrm{R} \$ / \mathrm{m}^{2}\right)$

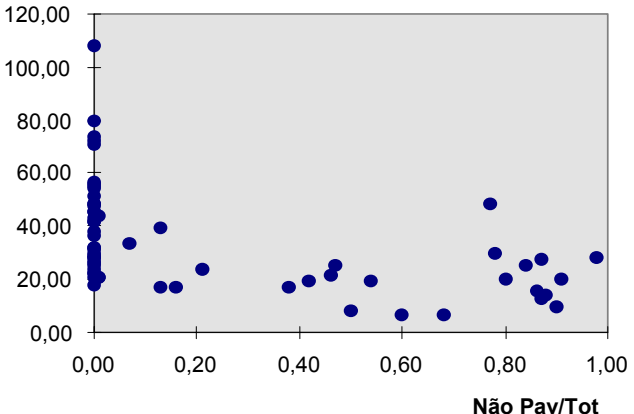

Valor do solo $\left(\mathbf{R} \$ / \mathrm{m}^{2}\right)$

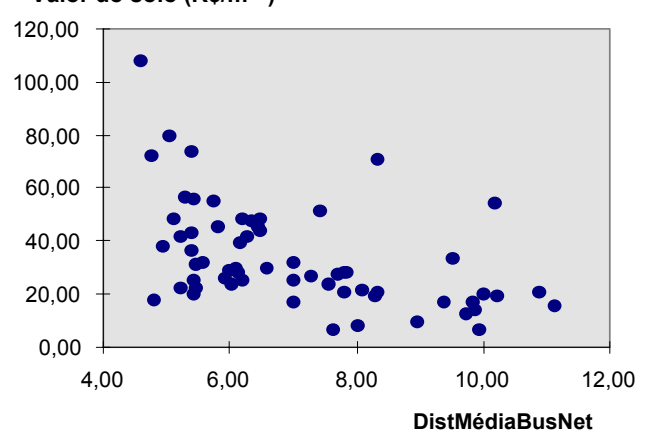

Valor do solo $\left(\mathbf{R} \$ / \mathrm{m}^{2}\right)$
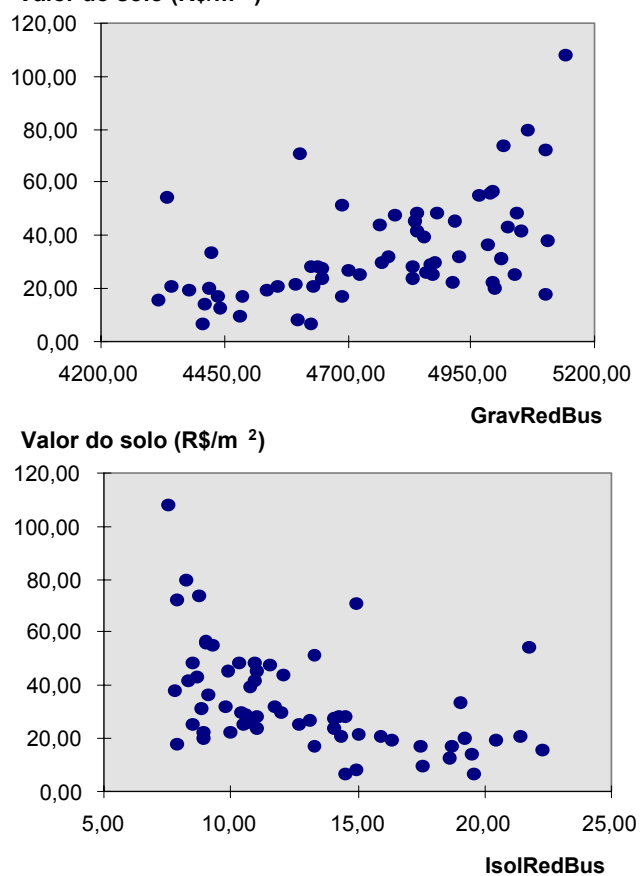

Figura 5.15 - Acessibilidade aos transportes e valor do solo em 62 zonas de Araraquara. 


\begin{tabular}{cccccccccc}
\hline $\begin{array}{c}\text { Dist } \\
\text { Ctr }\end{array}$ & DistBus & $\begin{array}{c}\text { Bus/ } \\
\text { Ruas }\end{array}$ & $\begin{array}{c}\text { Não Pav/ } \\
\text { Tot }\end{array}$ & $\begin{array}{c}\text { DstMédia } \\
\text { RedTot }\end{array}$ & $\begin{array}{c}\text { DstMédia } \\
\text { RedBus }\end{array}$ & $\begin{array}{c}\text { Grav } \\
\text { RedTot }\end{array}$ & $\begin{array}{c}\text { Grav } \\
\text { RedBus }\end{array}$ & $\begin{array}{c}\text { Isol } \\
\text { RedTot }\end{array}$ & $\begin{array}{c}\text { Isol } \\
\text { RedBus }\end{array}$ \\
\hline-0.45 & 0.12 & 0.28 & -0.56 & -0.56 & -0.55 & 0.64 & 0.58 & -0.58 & -0.55 \\
\hline
\end{tabular}

Tabela 5.2 - Coeficientes de correlação entre valores do solo e acessibilidade aos transportes estimada de dez diferentes maneiras.

Pode-se observar na Tabela 5.2 que os coeficientes de correlação variam consideravelmente. Há valores muito próximos, mas também alguns bastante distantes. $\mathrm{O}$ significado do sinal pode variar de acordo com a medida, pois em alguns casos, como para a medida do tipo gravitacional, o sinal negativo indica que quanto maior a medida de acessibilidade, maior o valor da terra. Por outro lado, o sinal positivo do isolamento aponta que quanto menor o seu valor, maior será o preço dos terrenos. Uma análise dos números mostra que a medida do tipo gravitacional apresenta o maior coeficiente de correlação. A similaridade entre os coeficientes encontrados para as medidas do tipo gravitacional e isolamento já era esperada, pois a última medida é derivada da primeira, embora elas sejam diferentes.

É também interessante observar que o coeficiente de correlação encontrado com a medida distância média entre zonas é muito próximo dos valores encontrados para as medidas do tipo gravitacional e isolamento. Esta é uma observação importante, pois pode significar que não há necessidade de se trabalhar com medidas mais sofisticadas, se uma medida mais simples pode conduzir a resultados semelhantes. Esta possibilidade deve ser investigada com atenção, como já se propôs em Raia Jr. et al. (1997). Algumas das outras medidas propostas apresentaram coeficientes de correlação muito baixos, como se pode observar na Tabela 5.2. A medida distância às rotas de ônibus não só apresentou um baixo coeficiente de correlação, mas até mesmo o seu sinal estava incorreto.

\subsection{COMENTÁRIOS FINAIS}

A primeira observação que se pode fazer relativa a esse capítulo é que a acessibilidade aos transportes ainda é um tema relevante e atual de pesquisa na área de planejamento de transportes. As possibilidades que se abriram com o uso dos SIG são, em parte, responsáveis pela nova "onda" de estudos sobre o assunto, que parece estar apenas começando. As vantagens do uso dos SIG para se estimar a acessibilidade vão desde a simples adoção das ferramentas que já acompanham os software, até a possibilidade de conexão com modelos externos, de forma a explorar, do SIG, os seus recursos gráficos para visualização de resultados (como sugerido por Geertman \& Van Eck, 1995). Isto não significa, no entanto, que se deveria abandonar medidas mais simples para avaliação da acessibilidade. Estas ainda podem, ao contrário, cumprir um importante papel no processo de planejamento, com ou sem o uso dos SIG, como ficou evidente nas medidas extraídas da literatura de geografia médica aqui comentadas.

Agora que tanto software como hardware não são mais tão caros como eram no passado, o seu potencial se coloca disponível também para países em desenvolvimento. A avaliação da acessibilidade é um dos aspectos do processo de planejamento de transportes que pode ser explorado de forma mais intensa nestes países com o apoio dos SIG. Existe ainda 
uma série de obstáculos para que isso se concretize, e o maior ainda é, provavelmente, a escassez de dados (e pior ainda, a sua acurácia). No entanto, mesmo com todas as dificuldades para se obter dados em um país em desenvolvimento, estudos simples não são tão difíceis de se realizar, como já se pôde aqui demonstrar.

As dez diferentes formas de medição da acessibilidade aplicadas na cidade de Araraquara forneceram resultados coerentes, mesmo com a dificuldade computacional que poderia surgir devido ao grande número de zonas (200). Quatro dos índices aqui aplicados são bastante simples e tentam capturar aspectos da cidade que usualmente não são considerados em países desenvolvidos. Alguns deles refletem a oferta de itens específicos de infraestrutura, o que pode indicar o nível de acessibilidade da zona. Esses são os casos da porcentagem do comprimento de vias pavimentadas em relação à extensão total de vias e da oferta de transporte público. Outros três índices, extraídos de uma ampla revisão da literatura, foram também aplicados na cidade de Araraquara, gerando seis conjuntos de resultados. Nenhuma das medidas, no entanto, apresenta alto grau de sofisticação, uma vez que esta aplicação é apenas uma primeira tentativa para se verificar a correlação entre os níveis de acessibilidade e o valor da terra urbana, como mencionado em Silva et al. (1998). Destas avaliações deverá sair um índice a ser incluído em um modelo de avaliação de imóveis em massa que, por sua vez, deverá aprimorar a estratégia de tributação originalmente proposta pelo autor. 


\section{CONSIDERAÇÕES FINAIS}

O autor reuniu, neste texto, a parte de sua obra que trata do uso dos Sistemas de Informações Geográficas (SIG) para o planejamento de transportes, com vistas à sua introdução como ferramenta de uso efetivo no Brasil. Foi apresentado inicialmente, no capítulo 2, uma revisão a respeito da evolução do tema no país, cuja introdução se deu no início desta década. Este curto espaço de tempo que se passou entre os primeiros trabalhos e o presente momento possibilitou um acompanhamento quase que integral do avanço do assunto, permitindo uma avaliação bastante acurada do quadro atual das pesquisas, dos principais grupos de pesquisa que atuam na área e das tendências de curto e médio prazo no país. Percebe-se, no entanto, por esta revisão, que os primeiros trabalhos do autor com a ferramenta eram trabalhos que se poderia chamar de independentes, pois tratavam de diferentes fases do planejamento de transportes, sem vínculo uns com os outros. Não que isto chegasse a ser um problema, uma vez que era desejável que a ferramenta fosse testada com diferentes problemas, mas o autor tinha outras pesquisas, às quais deseja dar continuidade.

Assim, em 1995, este quadro começou a mudar, quando o autor utilizou-se de alguns recursos de um SIG-T em seu projeto mais amplo de pesquisa. Para facilitar a compreensão de como isto se deu, foram apresentadas, no capítulo 3, as bases da pesquisa original do autor, que trata da avaliação e busca de alternativas para reduzir os custos urbanos. O ponto central desta pesquisa foi uma proposta de tributação da propriedade urbana, na qual o valor do imposto é calculado a partir dos custos adicionais de transportes e de infra-estrutura decorrentes dos vazios urbanos. Esta proposta foi apresentada de forma resumida no capítulo 3 , juntamente com os modelos que a acompanham e com uma descrição sucinta das principais atividades que foram desenvolvidas em um projeto de pesquisa conduzido no período de 1995 a 1997. A este projeto de pesquisa, em que se aplicou a metodologia proposta à cidade de Araraquara, foram incorporadas os recursos do SIG, ainda que de forma incipiente.

A utilização efetiva dos recursos do SIG para planejamento de transportes na pesquisa original do autor aconteceu em outro projeto, descrito no capítulo 4. Neste, os modelos propostos para a estratégia de tributação passaram a funcionar diretamente no ambiente de um Sistema de Informações Geográficas para transportes. Essa inovação permitiu a criação de inúmeros cenários a serem considerados como a cidade de referência para a estratégia de tributação, mas não resolveu algumas falhas que tinham sido constatadas nessa forma alternativa de taxação. O principal problema é que não parece sensato deixar de levar em consideração o preço de mercado das propriedades ao se calcular o valor do imposto. Assim, encontra-se em fase inicial um novo projeto de pesquisa, em que se pretende estimar o 
valor de propriedades urbanas a partir de diversos elementos que influenciam na sua formação. Pretende-se incluir, como variável nos modelos de avaliação de imóveis em massa, a acessibilidade aos transportes.

Os primeiros passos nesse sentido já foram dados, com uma investigação das principais medidas de acessibilidade encontradas na literatura internacional e posterior aplicação de algumas dessas medidas na cidade de Araraquara. Essas atividades foram apresentadas no capítulo 5, onde se pode perceber o uso intenso de um Sistema de Informações Geográficas para transportes nas aplicações realizadas. O capítulo se encerra com uma comparação dos resultados das diversas medidas empregadas, na tentativa de se identificar qual delas melhor serviria como indicador de acessibilidade a ser empregado em modelos de avaliação de imóveis em massa para as cidades médias brasileiras.

\subsection{PROJETOS PARA O FUTURO}

O conjunto de experiências reunidas ao longo dos últimos anos e parcialmente relatadas nesse texto levou à proposição de novos projetos, que deverão ser desenvolvidos (alguns deles já iniciados) no futuro próximo. Eles são apresentados a seguir, de forma resumida, sendo que os três primeiros são decorrência direta dos projetos aqui relatados. Os demais, embora todos ligados aos SIG-T, não guardam uma relação tão direta com o projeto maior do autor, mas nem por isso são menos importantes.

\subsubsection{Introdução da Acessibilidade em Modelos de Avaliação de Imóveis}

O primeiro trabalho a ser desenvolvido na seqüência, com o título Combinando Redes Neurais Artificiais e Sistemas de Informações Geográficas na introdução da acessibilidade em modelos de avaliação de imóveis, já está em fase adiantada. Este trabalho vem sendo conduzido, como projeto de Doutoramento orientado pelo autor, pela Bacharel em Estatística e Mestre em Engenharia Elétrica Nair Cristina Margarido Brondino, que recebe para isto bolsa de estudos concedida pela FAPESP.

Foi a partir do projeto em que se demonstrou a viabilidade da combinação dos modelos para estimativa dos custos de transportes e infra-estrutura com um SIG-T, que ficou claro que somente o uso dos mesmos não bastava para o cálculo de tributos. É preciso levar em consideração, para esse cálculo, o valor de mercado da propriedade. As possibilidades de utilização dos SIG para estimar o valor da terra urbana são indiscutíveis, seja pelo acesso aos dados nele armazenados, seja pela possibilidade de uso de resultados de análises conduzidas com suas ferramentas. Nessa segunda categoria se incluem as diversas formas de mensuração da acessibilidade, aspecto muitas vezes não considerado nos modelos de avaliação de imóveis.

Assim, a pesquisa aqui proposta é um prosseguimento dos estudos anteriores, permitindo a estimativa de valor de mercado da terra. Estas estimativas devem complementar a estratégia original de tributação, que já se beneficiou da combinação dos modelos originais com um SIG-T, fazendo uso também de outra ferramenta com grande potencial para este fim: 
as Redes Neurais Artificiais. Além da perspectiva de conduzir a boas estimativas do valor de mercado da terra, as Redes Neurais Artificiais devem permitir a inclusão da acessibilidade nos modelos de avaliação e a posterior verificação da sua influência na valorização da propriedade urbana, objetivos desse projeto.

Este projeto teve início com a adaptação de um cadastro de imóveis para cálculo de imposto territorial utilizando um SIG, como pode ser visto em Brondino \& Silva (1996). Em seguida, procurou-se comparar algumas estratégias de avaliação de imóveis para fins de tributação, valendo-se para isso de um SIG (Brondino \& Silva, 1997). O passo seguinte foi uma proposta de inclusão de características espaciais das propriedades em uma estratégia de avaliação imobiliária, já se buscando alguma forma de medida de acessibilidade (Brondino et al., 1997). Mais recentemente, foi desenvolvido um trabalho sobre a atualização de Plantas Genéricas de Valores, usadas para tributação imobiliária (Brondino \& Silva, 1998a), além de um primeiro estudo sobre a influência da acessibilidade na valorização imobiliária utilizando redes neurais (Brondino et al., 1998). O mais recente trabalho relativo a este projeto foi apresentado na $4^{a}$ International Conference on Design and Decision Support Systems in Architecture and Urban Planning, realizada na Holanda, em julho de 1998, onde foi apresentada uma comparação entre três métodos de avaliação de imóveis em massa, um dos quais baseado na técnica de rede neurais artificiais (Brondino \& Silva, 1998b).

\subsubsection{Evolucão Urbana e Acessibilidade - O Caso das Cidades Médias Brasileiras}

O objetivo desse projeto financiado pela FAPESP e conduzido, dentro do programa de Mestrado em Transportes, pelo Engenheiro Civil Renato da Silva Lima, é avaliar de que forma uma evolução desordenada tem alterado os padrões de acessibilidade intraurbana nas cidades médias brasileiras. $\mathrm{O}$ que se pretende com a pesquisa é criar, a partir da medida de acessibilidade, um instrumento auxiliar no processo de planejamento urbano. Para isso, é preciso que se saiba a sua influência na evolução das cidades. A grande dificuldade é que a acessibilidade é um índice de difícil comparação no tempo e no espaço. No entanto, a metodologia proposta por Allen et al. (1993) permite a comparação da acessibilidade para regiões diferentes. A partir do mesmo conceito, é possível estudar agora a variação da acessibilidade não apenas espacialmente, mas também em momentos distintos do tempo, analisando, por exemplo, os índices de acessibilidade em intervalos até anuais. Adicionalmente, deverá ser analisado um outro índice que considere aspectos de demanda, através de um sistema de classificação (ranking).

De posse desses índices, serão analisados os padrões de acessibilidade em duas cidades médias, Araraquara e São Carlos, em diferentes instantes no tempo. Os resultados das primeiras aplicações já foram obtidos, como se pode ver na Figura 6.1, em que aparece a distribuição percentual de acessibilidade de Allen et al. (1993) nas diversas épocas da história de São Carlos. Neste gráfico nota-se como a distância média entre todos os pontos vem aumentando com o passar dos anos. É interessante observar que o cálculo da acessibilidade foi realizado em uma escala muito diferente das aplicações do capítulo 5. Ao invés de se trabalhar com zonas, resolveu-se testar a capacidade do software para resolver matrizes muito maiores, como aquelas que se originam do cálculo das distâncias mínimas entre interseções. Neste caso, esta experiência gerou matrizes com mais de 4000 linhas e colunas, que o software conseguiu resolver a contento. 
A partir daí pode-se calcular a medida global de acessibilidade, que nada mais é que a média das distâncias médias. Os diferentes cenários deverão ser comparados, tentando-se extrair, dessa análise, a influência da evolução desordenada das duas cidades sobre os níveis de acessibilidade intra-urbana. Todo o cálculo das acessibilidades, bem como a análise do processo evolução urbana $x$ acessibilidade deverá ser desenvolvido em um Sistema de Informações Geográficas. Para mais detalhes, pode-se ver o projeto na íntegra em Lima \& Silva (1997).

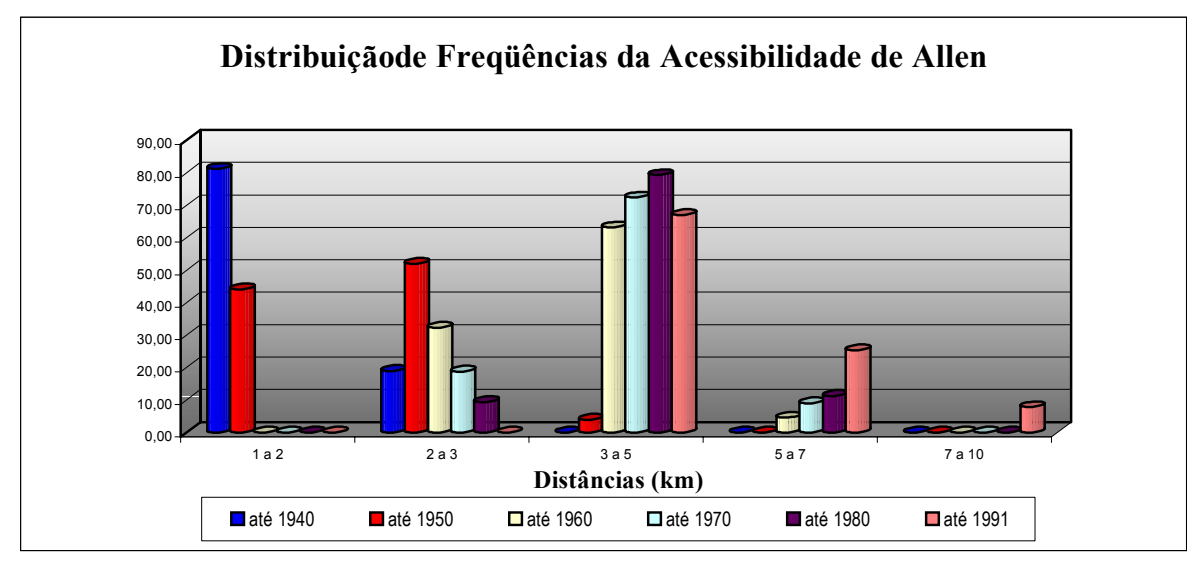

Figura 6.1 - Distribuição de freqüências da acessibilidade em São Carlos.

\subsubsection{Acessibilidade, Mobilidade e Desigualdade Social}

Esse projeto está sendo desenvolvido, dentro do programa de Doutorado em Transportes, pelo Engenheiro Mecânico e Mestre em Transportes Archimedes Azevedo Raia Jr. A sua motivação vem do fato de que cidades brasileiras, nas últimas décadas, passaram por processos de crescimento intensos, sofrendo a reconstrução física e a adaptação do sistema viário para atender, prioritariamente, às necessidades do modo automóvel. Uma das conseqüências disso foi que os grupos de baixa renda foram induzidos a morar em regiões cada vez mais periféricas, tendo que percorrer diariamente longas jornadas ao trabalho, o que inviabiliza o deslocamento através de modos não motorizados (a pé ou bicicleta). Assim, o trabalhador de renda mais baixa passou a ser dependente do transporte motorizado, o que significa, para quem nem sempre tem acesso ao automóvel, depender do transporte coletivo. Por outro lado, os crescentes custos do transporte público não foram acompanhados pela proporcional elevação dos salários, fazendo com que esses grupos sociais tivessem de reduzir suas viagens, em alguns casos, até mesmo com objetivos de trabalho.

Nas análises convencionais de planejamento de transportes, se determinada região da cidade tem disponível a oferta de transporte público, em geral, a população ali residente é considerada atendida em suas necessidades de transportes. Na prática, isso nem sempre é verdade, uma vez que vem ocorrendo uma diminuição no uso do transporte coletivo. Uma avaliação da acessibilidade, medida com alguns índices convencionais, de populações com diferentes níveis de renda deixou claro que as medidas convencionais de acessibilidade não são capazes de identificar, por exemplo, quando grupos de baixa renda estão sendo excluídos do sistema público de transporte, muitas vezes não pela falta de oferta, mas pela incapacidade de pagar a tarifa (Silva et al., 1998). A partir dessas constatações, o objetivo 
deste projeto é construir um indicador de acessibilidade que leve em consideração não só a disponibilidade de transporte, mas que incorpore também restrições na mobilidade, como a incapacidade dos usuários de financiar o próprio deslocamento. Com esse tipo de indicador, as análises de planejamento de transportes poderão assumir um caráter mais eqüitativo na distribuição de novos investimentos públicos em transportes.

\subsubsection{Um Estudo Comparativo de Programas de SIG-T}

Este é um projeto ainda em fase inicial, para o qual a Engenheira Civil Adriana Rose está recebendo bolsa de Mestrado da CAPES. Considerando que o sucesso de qualquer projeto depende do uso e escolha da ferramenta adequada e que os SIG-T estão no mercado em larga escala, disponíveis com vários tipos de configurações e funcionalidades, o objetivo dessa pesquisa é comparar três programas de SIG aplicados ao planejamento de transportes, quanto às suas características funcionais e desempenho. Os programas Ufosnet, Transcad e ArcView terão os seguintes itens avaliados: tempo de processamento, sistema de gerência de dados, capacidade e condições de armazenamento de dados, facilidades de operação, recursos para customização, comunicação com outros sistemas, etc. A escolha desses três programas foi baseada no fato de que todos apresentam ferramentas específicas para soluções de problemas de transportes, além de não exigirem configurações de hardware muito robustas. $\mathrm{O}$ trabalho deverá ajudar aos usuários na escolha do software mais adequado à determinada aplicação, pois é de suma importância o conhecimento mais aprofundado do desempenho de cada programa perante os problemas a serem solucionados.

\subsubsection{Desenvolvimento de Material Didático para a Introdução de um SIG-T em Cursos de Engenharia Civil}

Este é um projeto de longo prazo, que se iniciou em 1995, e que vem sendo adaptado e ampliado de acordo com as necessidades e recursos de cada momento. A sua semente foi lançada no primeiro curso sobre SIG-T ministrado para a pós-graduação pelo autor, em 1994, na EESC-USP. Naquela ocasião, constatou-se que a documentação que acompanhava o software utilizado no curso era totalmente inadequada para iniciantes. Esta constatação, que é comum a vários programas comerciais, levou o autor a trabalhar no desenvolvimento de um material didático, a princípio, somente para o curso de pósgraduação. O autor encontrou, para esta atividade, um parceiro na Universidade de Eindhoven, na Holanda, que vivenciava exatamente as mesmas dificuldades em seu curso. Esta atividade conjunta apresentou alguns resultados (Silva \& Waerden, 1997a e 1997b, Waerden \& Silva, 1997), que estimularam o autor a prosseguir com a iniciativa. Assim, e face às condições disponíveis em dado momento na EESC-USP, o autor começou a trabalhar no atual projeto, que encontra-se atualmente em desenvolvimento e já tem resultados concretos (Silva et al., 1997).

O projeto recebe atualmente apoio da FAPESP, que concede bolsa de Iniciação Científica para o estudante de Engenharia Civil Jônatas José de Oliveira Melo. O trabalho conta ainda com a participação dos Engenheiros Renato da Silva Lima, Adriana Rose e da 
Bacharel em Estatística Nair Cristina Margarido Brondino, que embora estejam envolvidos com outros projetos, têm colaborado com essa iniciativa. Um resumo das principais etapas já desenvolvidas foi apresentado em Silva et al. (1997b), e já se trabalha no próximo passo, que será a disponibilização de tudo o que foi elaborado na Internet. Isto deverá realmente ampliar o acesso a este material, permitindo que outros cursos de Engenharia Civil no Brasil o utilizem, a exemplo do que já ocorre na EESC-USP desde 1997.

\subsubsection{Avaliação de Desempenho de Algoritmos de um Programa Comercial para Roteirização de Veículos}

Este projeto de pesquisa tem como objetivo a avaliação dos algoritmos do programa denominado Delivery, que não chega a ser um SIG-T, embora tenha algumas de suas características. O software, desenvolvido por uma empresa privada, se propõe a ser uma ferramenta de apoio à decisão na escolha da rotina operacional de coleta e/ou distribuição física de produtos, através da criação e simulação de roteiros alternativos. Possibilita, desta forma, analisar a viabilidade de implantação da rotina operacional. O programa, composto por uma base cartográfica com todas as cidades do Brasil e por um banco de dados integrado a esta base cartográfica (o que faz com que se assemelhe a um SIG), permite inclusive que o usuário defina restrições e janelas de tempo. Ao final do processamento, o usuário visualiza os resultados em mapas e sob a forma de relatórios.

A proposta para este projeto de pesquisa, que está sendo conduzido pela Engenheira de Produção Cláudia Pelizaro, em programa de Mestrado financiado pela FAPESP, é testar o software para validação do algoritmo utilizado e, se necessário, sugerir melhorias no algoritmo. Não se trata de uma avaliação do programa em si, mas dos resultados que ele gera. A importância deste projeto está no fato de não existir nenhuma ferramenta computacional de apoio à decisão na roteirização de distribuição de produtos físicos no mercado brasileiro, viável quanto à facilidade de manipulação por parte dos usuários e, principalmente, no aspecto econômico. É importante dizer que esta ferramenta pode proporcionar, tanto às pequenas como às grandes empresas, um forte potencial de redução de custos, já que a distribuição física costuma ser a atividade mais importante em termos de custo para a maioria das empresas, podendo representar parcela substancial do custo logístico. Uma vez concluído este projeto, será possível a comparação deste produto nacional com alguns SIG-T, na sua maioria norte-americanos, de forma a identificar as vantagens e desvantagens das diferentes opções, em termos de custos e benefícios. Espera-se que os resultados dessa comparação possam, inclusive, estimular o fabricante nacional a introduzir melhorias, se necessárias, em seu produto.

\subsubsection{Um Sistema de Apoio à Decisão para Implantação e Uso de Infra-estrutura Pontual em Cidades Médias Brasileiras}

O Engenheiro Civil Renato da Silva Lima, que deverá concluir o projeto descrito no item 6.1.2 até o final de 1998, submeteu pedido de bolsa de Doutoramento à FAPESP para o desenvolvimento desta pesquisa. O pedido encontra-se ainda em fase de 
julgamento, mas o projeto já está delineado, como se descreve a seguir. O seu objetivo é desenvolver um SAD - Sistema de Apoio à Decisão - para otimizar a distribuição de infraestrutura pontual (escolas, postos de saúde, etc.) em cidades médias brasileiras. Esta iniciativa é um avanço em relação ao trabalho de Dutra (1998), que buscou, com ferramentas de um SIG-T, reduzir as distâncias de deslocamento para as escolas de São Carlos, a partir de uma melhor distribuição dos alunos. A pesquisa aqui proposta também se vale da experiência de diagnóstico da distribuição espacial dos usuários do sistema de saúde da mesma cidade, conduzida por Silva \& Silva (1998) e é, de certa forma, um prosseguimento do trabalho iniciado por Penteado (1995), sob orientação do autor (ver também Silva \& Penteado, 1995).

A partir de uma análise cuidadosa dos conceitos de SAD encontrados na literatura internacional, deverão ser analisados os critérios utilizados para definir a localização e tipo de infra-estrutura, bem como a sua real distribuição, em três cidades médias de diferentes países: uma brasileira (São Carlos, no interior paulista), uma norte-americana (Madison, no estado de Wisconsin, EUA) e uma européia (Eindhoven, na Holanda). Essas cidades foram escolhidas porque possuem aproximadamente a mesma população (cerca de 180.000 habitantes) e também pela facilidade para obtenção de dados junto às Universidades nelas situadas, uma vez que este autor desenvolveu parte de suas atividades para obtenção do título de doutor na Universidade de Wisconsin, Madison (bolsista sanduíche) e realizou estágio de pós-doutorado na Universidade de Eindhoven, Holanda.

Com os resultados obtidos, pretende-se desenvolver uma metodologia para implantação e uso de infra-estrutura pontual adequada à realidade das cidades médias brasileiras, incorporando os aspectos positivos das experiências analisadas. Os estudos devem ser baseados em dados censitários das cidades em questão e deverão ser desenvolvidos em um Sistema de Informações Geográficas, procurando-se adequar, em cada caso, os conceitos às características específicas das cidades brasileiras. Espera-se que o resultado final desse trabalho possa servir como ferramenta do planejamento, podendo ser utilizado por prefeituras ou outros órgãos de planejamento no Brasil, com o propósito de reduzir custos de implantação sem reduzir a acessibilidade aos serviços de educação e saúde.

\subsubsection{Sistema Informatizado de Consulta para um Sistema de Transporte Público}

Esse projeto de pesquisa, cuja proposta é a elaboração de um sistema informatizado de consulta às rotas do sistema de transporte coletivo da cidade de São Carlos, utilizando um SIG-T, teve início com o trabalho de Marques (1998). O seu objetivo é que, conhecidos apenas os pontos de origem e destino, o software informe diretamente ao usuário qual a melhor rota existente para realizar a viagem e se são necessárias transferências no trajeto. Como dados de saída, também devem ser fornecidos ao usuário o custo da viagem e o tempo de espera.

A idéia de se realizar um sistema de consulta para usuários de transporte público através de um Sistema de Informações Geográficas não é nova. Nas primeiras tentativas realizadas no Brasil, no entanto, foram observadas várias dificuldades em desenvolver algoritmos e programas para solucionar problemas de caminho mínimo. No trabalho de Marques (1998) não houve esse tipo de dificuldade, pois o SIG-T utilizado possui uma rotina que resolve, de forma rápida, o problema de caminho mínimo. O problema que 
existe em Marques (1998) é que o sistema de consulta não é automático, o que torna difícil a sua utilização por uma pessoa que não esteja habituada com o software.

A automação do sistema de consulta é o objetivo do atual projeto, financiado pelo CNPq, através de bolsa de Iniciação Científica concedida ao aluno de Engenharia Civil Raphael Wambier Fagundes. Uma vez atingido este objetivo, o próximo passo será a investigação dos procedimentos necessários para se introduzir este tipo de sistema de consulta na Internet, sem perder com isso os recursos disponíveis no SIG-T (acesso aos mapas e demais ferramentas do sistema original). Neste trabalho também será feita uma atualização dos dados referentes ao sistema viário e às linhas de ônibus, uma vez que a cidade de São Carlos vem sofrendo mudanças no sistema viário com relação ao sentido de várias ruas e avenidas, o que afeta diretamente as rotas de transporte público.

\subsection{CONCLUSÕES}

Com base no quadro traçado no capítulo 2 e no trabalho apresentado no restante do texto, é possível antever um quadro promissor para a introdução do SIG-T como ferramenta para o planejamento de transportes no Brasil. A estratégia de desenvolver aplicações no ambiente acadêmico para posterior uso pelos técnicos de prefeituras e empresas parece ter sido importante nesse processo. A quantidade de problemas que surgiram nos primeiros anos de trabalho com a ferramenta certamente teria desestimulado os administradores que desejassem soluções imediatas já nas primeiras experiências. Nesse sentido, até mesmo passos elementares tiveram que ser dados, como a avaliação dos problemas que ocorriam na transferência de dados de programas de desenho auxiliado por computador para os SIG (ver Viviani et al., 1995). Hoje, no atual estágio de desenvolvimento dos programas de SIG-T, problemas dessa natureza já são muito mais raros.

As aplicações práticas realizadas, não só pelo autor, mas pelos principais grupos de pesquisa envolvidos com o tema no Brasil, mostram, de forma inequívoca, o enorme potencial dos Sistemas de Informações Geográficas (SIG) para o planejamento de transportes. Tanto assim que, cada vez mais, esta ferramenta passa a ser utilizada em novos projetos, agora não mais como objeto da pesquisa, mas como uma ferramenta de suporte. Apesar dessa tendência, é importante que as Universidades não abandonem a tarefa de implementar e testar novas aplicações, principalmente aquelas de maior complexidade.

O grande desafio agora consiste em efetivamente transferir a tecnologia dos SIG-T às condições de recursos financeiros e humanos encontradas no país. Esta tem sido uma das preocupações do autor nos últimos anos, e parte dos seus projetos para o futuro está ligada a este tema, como se pôde ver aqui. Reforçando a última sentença do parágrafo anterior, muitos dos projetos ainda se referem a aplicações da ferramenta na busca de soluções para problemas de planejamento urbano e de transportes, principalmente de cidades brasileiras pequenas e médias. De forma prioritária, permanece a preocupação do autor com a implantação de alternativas de planejamento urbano e de transportes para reduzir os custos das cidades, seja através de estratégias de tributação que induzam os usuários a proceder de forma menos perniciosa para o conjunto da sociedade, seja através de medidas de alocação de atividades que permitam otimizar o uso dos escassos recursos de infra-estrutura. 


\section{REFERÊNCIAS BIBLIOGRÁFICAS}

Abebe, Y. \& Holdstock, D. (1993) Applicability of GIS technology for transport planning and development in developing countries: a case study for sub-sahara Africa. In: ANNUAL MEETING OF THE INSTITUTE OF TRANSPORTATION ENGINEERS, The Hague, The Netherlands, 1993. Compendium of Technical Papers. Washington, D.C., ITE. p. 342-6.

Alencar, V.C. \& Aquino, M.S. (1994) Um Sistema de Informações Geográficas para o planejamento de rotas de ônibus. In: GIS BRASIL, 1, Curitiba, 1994. Anais. Curitiba, Editora Sagres. p. 1-9.

Almeida, M.F.B. \& Sanches, S.P. (1997) Roteirização de veículos para transporte de alunos da zona rural com auxílio de um SIG. In: CONGRESSO DE PESQUISA E ENSINO EM TRANSPORTES, 11, Rio de Janeiro, 1997. Anais. Rio de Janeiro, Associação Nacional de Pesquisa e Ensino em Transportes, Dissertações em andamento, p. 45-8.

Akinyemi, E.O. (1998). Enhancement of people's mobility and accessibility through traffic management in developing cities, apresentado na $8^{\text {th }}$ World Conference on Transport Research, Antuérpia - Bélgica, 1998. Book of Abstracts. Antuérpia, Universeit Antwerpen, p. 267.

Allen, W. B.; Liu, D.; Singer, S. (1993) Accessibility measures of U.S. Metropolitan areas. Transportation Research. Part B, Methodological, 27(6): 439-50.

Alves, D.S. (1990) Sistemas de Informação Geográfica. In: SIMPÓSIO BRASILEIRO DE GEOPROCESSAMENTO, 1, São Paulo, 1997. Anais. São Paulo, EDUSP. p. 66-78.

Andrade, R.C.A. \& Mendes, A.P.D. (1995) Plano multimodal de transportes para o estado de Minas Gerais: uma abordagem ao sistema informatizado de planejamento de transportes. In: CONGRESSO NACIONAL DE TRANSPORTES PÚBLICOS, 10, São Paulo, 1995. Comunicações Técnicas. São Paulo, Associação Nacional de Transportes Públicos-ANTP. p. 361-8.

ANTP - Associação Nacional de Transportes Públicos. (1994) Boletim Estatístico. N ${ }^{\text {os }} 43$ a 47. São Paulo.

Antenucci, J.C. et al. (1991) Geographic Information Systems: a guide to the technology. New York, Van Nostrand Reinhold.

Aoki, Y.; Osaragi, T.; Ishizaka, K. (1994) An interpolating model for land-price data with transportation costs and urban activities. Environment and Planning. B, 21(1): 53-66. 
Arentze, T.A.; Borgers, A.W.J.; Timmermans, H.J.P. (1994a) Multistop-based measurements of accessibility in a GIS environment. International Journal of Geographical Information Systems, 8(4): 343-56.

Arentze, T.A.; Borgers, A.W.J.; Timmermans, H.J.P. (1994b) Geographical Information Systems in the context of multipurpose travel: a new approach. Geographical Systems, 1(4): 87-102.

Arruda, J.B.F. (1995) Evaluation of Urban Transport Projects in Developing Countries: An Accessibility Approach. Tese de Doutorado, Institute for Transport Studies, University of Leeds, United Kingdom.

Arruda, J.B.F. (1997) Determinação do impacto de projetos de transportes na acessibilidade do trabalhador às principais zonas de emprego urbano. In: CONGRESSO DE PESQUISA E ENSINO EM TRANSPORTES, 11, Rio de Janeiro, 1997. Anais. Rio de Janeiro, Associação Nacional de Pesquisa e Ensino em Transportes, v.II, p. 975-84.

Barra, A. \& Kawamoto, E. (1997) Uso de um SIG-T para determinação de itinerários de linhas de ônibus urbanos com base na matriz O/D. In: CONGRESSO DE PESQUISA E ENSINO EM TRANSPORTES, 11, Rio de Janeiro, 1997. Anais. Rio de Janeiro, Associação Nacional de Pesquisa e Ensino em Transportes, Dissertações em andamento, p. 61-4.

Barros Jr., L.A.T. (1994) Um modelo para avaliação do custo do transporte coletivo por onibus nas cidades médias e pequenas. Dissertação de Mestrado, Escola de Engenharia de São Carlos, Universidade de São Paulo.

Bartoli, S.P.; Fortes, J.A.A.S; Andrade, N.P. (1996) Sistema de Informação Geográfica (SIG) como instrumento para avaliação da acessibilidade locacional de paradas de ônibus. In: CONGRESSO DE PESQUISA E ENSINO EM TRANSPORTES, 10, Brasília, 1996. Anais. Rio de Janeiro, Associação Nacional de Pesquisa e Ensino em Transportes, v.I, p. 245-56.

Ben-Akiva, M. \& Lerman, S.R. (1978) Disaggregate travel and mobility-choice models and measures of accessibility. In: Hensher, D. \& Stopher, P.R. (eds) Behavioural Travel Modelling, London, Croom Helm. p. 654-79.

Black, J. \& Conroy, M. (1977) Accessibility measures and the social evaluation of urban structure. Environment and Planning A, 9(9): 1013-31.

Borges, J.M.M. (1975) Custos de transporte e valor dos terrenos urbanos. Dissertação de Mestrado. Faculdade de Economia e Administração, Universidade de São Paulo.

Bravo, F. \& Cerda, J. (1995) Tecnologia SIG aplicada a sistemas de transporte. In: CONGRESO CHILENO DE INGENIERIA DE TRANSPORTE, 7, Santiago, 1995. Actas. p. 547-62.

Brondino, N.C.M. \& Silva, A.N.R. (1996) Adaptação de um cadastro de imóveis para cálculo de imposto territorial utilizando um SIG. In: CONGRESSO BRASILEIRO DE CADASTRO TÉCNICO MULTIFINALITÁRIO, 2, Florianópolis, 1996. Anais. Tomo III, p. $122-30$.

Brondino, N.C.M. \& Silva, A.N.R. (1997) Comparando estratégias de avaliação de imóveis para fins de tributação com o auxílio de um SIG. In: GIS BRASIL, 3, Curitiba, 1997. Anais. (em CD-ROM) Curitiba, Editora Sagres. 
Brondino, N.C.M.; Silva, A.N.R.; Matsuo, E.T. (1997) Inclusão de características espaciais das propriedades em uma estratégia de avaliação imobiliária. In: SIMPÓSIO BRASILEIRO DE GEOPROCESSAMENTO, 4, São Paulo, 1997. Anais. São Paulo, Instituto de Desenvolvimento de Eventos em Tecnologia da Informação - IDETI. p. 48897.

Brondino, N.C.M.; Silva, A.N.R.; Carvalho, A.P.L.F. (1998) Estudo da influência da acessibilidade na valorização imobiliária utilizando Redes Neurais. Apresentado no Encontro dos Pesquisadores de Redes Neurais, Lógica Fuzzy e Algoritmo Genético. Em São Carlos, no Instituto de Ciências Matemáticas de São Carlos.

Brondino, N.C.M. \& Silva, A.N.R. (1998a) Atualização de plantas genéricas de valores: novo levantamento cadastral ou amostra de valores de mercado? In: GIS BRASIL, 4, Curitiba, 1998. Anais. (em CD-ROM) Curitiba, Editora Sagres, 1998.

Brondino, N.C.M. \& Silva, A.N.R. (1998b) A comparison of land valuation methods supported by GIS. In: INTERNATIONAL CONFERENCE ON DESIGN AND DECISION SUPPORT SYSTEMS IN ARCHITECTURE AND URBAN PLANNING, 4, Maastricht - Holanda, 1998. Proceedings. (em CD-ROM). Eindhoven, Eindhoven University of Technology.

Buzay, G.D \& Durán, D. (1997) Enseñar e investigar com Sistemas de Información Geográfica (S.I.G.). Buenos Aires, Troquel.

Caliari, C.C.L.; Araújo, A.A.; Gomes, F.A.N. (1996) Identificação de atributos de grafos em imagens de mapas viários (para problemas de roteamento). In: GIS BRASIL, II, Curitiba, 1996. Anais. Curitiba, Editora Sagres. p. 388-91.

Calijuri, M.L \& Röhm, S.A. (1994) Sistemas de Informações Geográficas. Viçosa, Universidade Federal de Viçosa.

Caliper. (1990) TransCAD - Transportation GIS Software - Reference Manual Version 2.0. Newton, MA, Caliper Corporation.

Caliper. (1992) TransCAD - Transportation GIS Software - Manual Supplement Version 2.1. Newton, MA, Caliper Corporation.

Caliper. (1996a) TransCAD User's Guide - Version 3.0 for Windows. Newton, MA, Caliper Corporation.

Caliper. (1996b) Travel Demand Modeling with TransCAD 3.0. Newton, MA, Caliper Corporation.

Câmara, G.; Casanova, M.A.; Hemerly, A.S.; Magalhães, G.C.; Medeiros, C.M.B. (1996) Anatomia de Sistemas de Informação Geográfica. Campinas, Instituto de Computação, UNICAMP.

Campos, V.B.G. \& Januário, M.H. (1996) Determinação de níveis de acessibilidade do transporte público. In: CONGRESO LATINOAMERICANO DE TRANSPORTE PÚBLICO Y URBANO, 8, Curitiba, 1996. Memorias. (Em disquetes) ANTP/Urbanização de Curitiba S.A. - URBS.

Ceccato, V.A.; Foresti, C.; Kurkdijan, M.L.N.O. (1993) Proposta metodológica para avaliação da qualidade de vida urbana a partir de dados convencionais e de sensoriamento remoto, Sistema de Informação Geográfica (SIG) e de um banco de dados. In: 
SIMPÓSIO BRASILEIRO DE SENSORIAMENTO REMOTO, 7, Curitiba, 1993. Anais. São José dos Campos, Instituto Nacional de Pesquisas Espaciais - INPE. v. I, p. 32-9.

Costa, S.M.F. \& Silva, E.A. (1993) Urbanização da área metropolitana de Belo Horizonte: o monitoramento do crescimento urbano através do Sistema de Informação Geográfica SGI-INPE. In: SIMPÓSIO BRASILEIRO DE SENSORIAMENTO REMOTO, 7, Curitiba, 1993. Anais. São José dos Campos, Instituto Nacional de Pesquisas Espaciais INPE. v. I, p. 41-47.

Custos \& Fretes. (1994) Indicadores Operacionais. n.31,33,35 a 38. São Paulo, Editora TM.

D'Alge, J.C.L. \& Goodchild, M.F. (1993) Digitalização e simplificação de linhas. In: IV CONFERÊNCIA LATINOAMERICANA SOBRE SISTEMAS DE INFORMAÇÃO GEOGRÁFICA, 4, e SIMPÓSIO BRASILEIRO DE GEOPROCESSAMENTO, 2, São Paulo, 1993. Anais. São Paulo. p. 17-25.

Dantas, A.S.; Taco, P.W.G.; Yamashita, Y. (1996) Sistemas de Informação Geográfica em transportes: o estudo do estado da arte. In: CONGRESSO DE PESQUISA E ENSINO EM TRANSPORTES, 10, Brasília, 1996. Anais. Rio de Janeiro, Associação Nacional de Pesquisa e Ensino em Transportes, v.I, p. 209-22.

Dantas, A.S.; Abreu, V.C.; Bartoli, S.P.; Silveira, L.S.C.; Yamashita, Y. (1997) Decisões no planejamento de transportes: uma abordagem hierárquica e georeferenciada In: CONGRESSO DE PESQUISA E ENSINO EM TRANSPORTES, 11, Rio de Janeiro, 1997. Anais. Rio de Janeiro, Associação Nacional de Pesquisa e Ensino em Transportes, v.I, p. 230-42.

Dantas, A.S.; Taco, P.W.G.; Bartoli, S.P.;Yamashita, Y. (1997) Aplicações dos Sistemas de Informações Geográficas em transportes sob o enfoque da análise espacial In: SIMPÓSIO BRASILEIRO DE GEOPROCESSAMENTO, 4, São Paulo, 1997. Anais. São Paulo, Instituto de Desenvolvimento de Eventos em Tecnologia da Informação - IDETI. p. 46977.

Dalvi, M. Q. (1978) Behavioural modelling, accessibility, mobility and need: concepts and measurement. In: Hensher, D. \& Stopher, P.R. (eds) Behavioural Travel Modelling, London, Croom Helm. p. 639-53.

Dalvi, M.Q. \& Martin, K.M. (1976) The measurement of accessibility: some preliminary results. Transportation, 5(1): 17-42.

Davidson, K.B. (1977) Accessibility in transport/land-use modelling and assessment. Environment and Planning A, 9(12): 1401-16.

Davidson, K.B. (1995) Accessibility and isolation in transport network evaluation. Artigo apresentado na $7^{\text {th }}$ World Conference on Transport Research, Sydney - Australia. Book of Abstracts. Sydney, The University of New South Wales, p. 10.8.

Davis, R.E.; Foote, F.S.; Kelly, J.W. (1972) Tratado de topografia. Aguilar, Madrid.

Davis Jr., C.A. (1997) Aumentando a eficiência da solução de problemas de caminho mínimo em SIG. In: GIS BRASIL, 3, Curitiba, 1997. Anais. (em CD-ROM) Curitiba, Editora Sagres.

Deluqui, K.K. \& Aguiar, E.M. (1996) Utilização de um SIG para a roteirização de veículos de coleta domiciliar de resíduos sólidos. In: CONGRESSO DE PESQUISA E ENSINO 
EM TRANSPORTES, 10, Brasília, 1996. Anais. Rio de Janeiro, Associação Nacional de Pesquisa e Ensino em Transportes, Dissertações em andamento, p. 25-8.

Denno, N.A. (1993) Network development for four step traffic models using GIS and TIGER files. In: ANNUAL MEETING OF THE INSTITUTE OF TRANSPORTATION ENGINEERS, The Hague, The Netherlands, 1993. Compendium of Technical Papers. Washington, D.C., ITE. p. 347-51.

Di Pierro, L.F. (1982) Estrutura urbana e consumo energético. Dissertação de Mestrado, Escola Politécnica, Universidade de São Paulo.

Dimitriou, H.T. (1990) The urban transport planning process: its evolution and application to Third World cities. In: Dimitriou, H.T. (ed.) Transport planning for Third World cities. London, Routledge. p. 144-83

Duarte, A.M. \& Gabbay, A. (1995) Avaliação em massa: modelos genéricos de valores integrados a um Sistema de Informação Geográfica - SIG. In: CONGRESSO BRASILEIRO DE ENGENHARIA DE PERÍCIAS E AVALIAÇÕES, VIII. Anais. Florianópolis, IBAPE. p. 237-240.

Dutra, N.G.S. (1998) Planejando uma rede escolar municipal para reduzir custos de deslocamentos. Dissertação de Mestrado, Escola de Engenharia de São Carlos, Universidade de São Paulo.

Dutra, N.G.S. \& Silva, A.N.R. (1997). Avaliando uma reforma no sistema educacional sob a ótica dos transportes. In: CONGRESSO DE PESQUISA E ENSINO EM TRANSPORTES, 11, Rio de Janeiro, 1997. Anais. Rio de Janeiro, Associação Nacional de Pesquisa e Ensino em Transportes, v.I, p. 92-100.

Ferguson, E.; Ross, C.; Meyer, M. (1992) PC Software for Urban Transportation Planning. Journal of the American Planning Association, Chicago, 58(02): 238-43.

Ferrari, R. (1997) Viagem ao SIG: planejamento estratégico, viabilização, implantação e gerenciamento de Sistemas de Informação Geográfica. Curitiba, Sagres Editora.

Ferraz, A.C.P. (1989) A qualidade do serviço de transporte coletivo em cidades médias sob a ótica dos usuários. In: ENCONTRO NACIONAL DA ANPET, 2, São Paulo, 1989. Anais. São Paulo, Associação de Ensino e Pesquisa em Transportes. v.1, p. 111-26.

Ferraz, A.C.P. (1990) Sobre a eficiência e a eficácia do transporte público nas cidades médias. Tese de Livre Docência, Escola de Engenharia de São Carlos, Universidade de São Paulo.

Ferraz, A.C.P. \& Felex, J.B. (1988) Um modelo para avaliação da influência do porte da cidade no custo do transporte coletivo. In: ENCONTRO NACIONAL DA ANPET, 2, São Paulo, 1988. Anais. Associação Nacional de Pesquisa e Ensino em Transportes. São Paulo. v.1, p. 231-7.

Ferraz, A.C.P.; Silva, A.N. R.; Felex, J.B. (1991) Custo do transporte público x tamanho e forma das cidades. Revista dos Transportes Públicos, (52): 17-21.

Ferreira, F.E.; Sá, L.A.C.M.; Loch, C.; Mayerle S.F. (1994) Metodologia para o planejamento da rede transportes de coletivos urbanos por ônibus. In: CONGRESSO NACIONAL DA ANPET, 8, Recife, 1994. Anais. São Paulo, Associação Nacional de Pesquisa e Ensino em Transportes. v. I, p. 529-39. 
FIBGE - Fundação Instituto Brasileiro de Geografia e Estatística. (1992) Censo demográfico de 1991: resultados preliminares. Rio de Janeiro.

Fouchier, V. (1997) Urban Density and Mobility: What do we know? What can we do? The case of Paris'region. Artigo apresentado no Second Symposium on Urban Planning and Environment, Gröningen - Holanda. 15p.

Françoso, M.T.; Viadana, M.I.C.F.; Teixeira, A.L.A. (1992) Utilização de Sistemas de Informação Geográfica na análise e planejamento das cidades. Revista de Administração Municipal, Rio de Janeiro, 39(205): 36-47.

Françoso, M.T.; Freitas, M.A.R.R.; Mello, H.M.C.F. (1993) Sensoriamento remoto como fonte de dados para Sistemas de Informação Geográfica aplicados ao transporte e urbanismo. In: SIMPÓSIO BRASILEIRO DE SENSORIAMENTO REMOTO, 7, Curitiba, 1993. Anais. São José dos Campos, Instituto Nacional de Pesquisas Espaciais INPE. v. I, p. 62-67.

Geertman, S.C.M. \& Van Eck, J.R.R. (1995) GIS and models of accessibility potential: an application in planning. International Journal of Geographical Information Systems, 9(1): 67-80.

GEIPOT - Empresa Brasileira de Planejamento de Transportes. (1980) Estudo de transportes urbanos da Região Metropolitana de Belém-TRANSCOL, tomo 1. Brasília.

GEIPOT - Empresa Brasileira de Planejamento de Transportes. (1985) Estudo da demanda de transportes urbanos: Diagnóstico 1981. Prognóstico 1985-1990. Brasília.

Geleski, L.F.P. \& Aguiar, E.M. (1996) Roteirização e programação de veículos de coleta e transporte de resíduos de serviço de saúde com o auxílio de um SIG. In: CONGRESSO DE PESQUISA E ENSINO EM TRANSPORTES, 10, Brasília, 1996. Anais. Rio de Janeiro, Associação Nacional de Pesquisa e Ensino em Transportes, Dissertações em andamento, p. 69-72.

Gerrard, R.A. \& Church, R.L. (1994) Analyzing tradeoffs between zonal constraints and accessibility in facility location. Computers \& operations research and their application to problems of world concern: an international journal, 21(1): 79-99.

Graciolli, O.D.; Novaes, A.G.; Cursi, J.E.S. (1997). A GIS approach to the problem of collecting health service refuse. In: CONGRESSO DE PESQUISA E ENSINO EM TRANSPORTES, 11, Rio de Janeiro, 1997. Anais. Rio de Janeiro, Associação Nacional de Pesquisa e Ensino em Transportes, v.I, p. 81-91.

Handy, S.L. (1992) Regional versus local accessibility: neo-traditional development and its implications for nonwork travel. Built Environment, 18(4): 253-67.

Handy, S.L. (1993) Regional versus local accessibility: implications for nonwork travel. Transportation Research Record, (1400): 58-66.

Hansen, W.G. (1959) How accessibility shapes land use. Journal of the American Institute of Planners, 25: 73-76.

Hanson, S. \& Schwab, M. (1987) Accessibility and intraurban travel. Environment and Planning A, 19(6): 735-748.

Hoggart, K. (1973) Transportation accessibility: some references concerning applications, definitions, importance and index construction. Monticello, Council of Planning Librarians: Exchange Bibliography 482, 42p. 
Huxhold, W.E. (1991) An introduction to urban Geographic Information Systems. New York, Oxford.

Ihlanfeldt, K.R. (1993) Intra-urban job accessibility and hispanic youth employment rates. Journal of Urban Economics, 33(2): 254-71.

Ingram, D.R. (1971) The concept of accessibility: a search for an operational form. Regional Studies, 5(2): 101-7.

Innes, J.E. \& Simpson, D.M. (1993) Implementing GIS for planning. Journal of the American Planning Association, Chicago, 59(02): 230-6.

Januario, M.H. (1995) Procedimento para Determinação de Índices de Accessibilidade de Transporte e Tratamento Cartográfico dos Mesmos. Dissertação de Mestrado. Instituto Militar de Engenharia.

Jones, S.R. (1981) Accessibility measures: a literature review. Transport and Road Research Laboratory Report 967. Berkshire, Crowthorne. 38p.

Kaffum, J. \& Taylor, M. (1998) Integration of Geographic Information Systems and models for transportation planning and analysis, apresentado na $8^{\text {th }}$ World Conference on Transport Research, Antuérpia - Bélgica, 1998. Book of Abstracts. Antuérpia, Universeit Antwerpen, p. 186.

Kagan, H.; Rossetto, C.F.; Custódio, P.S.; Martins, W.C. (1992) Uso de Sistemas de Informações Geográficas no Planejamento de Transportes. In: CONGRESSO NACIONAL DA ANPET, 6, Rio de Janeiro, 1992. Anais. São Paulo, Associação Nacional de Pesquisa e Ensino em Transportes. v. II, p. 894-909.

Kirchner, F.F. (1994) O Sistema Geográfico de Informações e o Cadastro Técnico Multifinalitário. In: CONGRESSO BRASILEIRO DE CADASTRO TÉCNICO MULTIFINALITÁRIO, 1, Florianópolis, 1994. Anais.

Klosterman, R.E. \& Lew, A.A. (1992) TIGER products for planning. Journal of the American Planning Association, Chicago, 58(03): 379-85.

Koenig, J.G. (1980) Indicators of urban accessibility: theory and application. Transportation, 9(2): 145-72.

Korte, G.B. (1997) The GIS Book. 4.ed. Santa Fe, Onword.

Lewis, S. (1990) Use of Geographical Information Systems in transportation modeling. ITE Journal, Washington, D.C., 61(3): 34-8.

Lima, R.S. \& Silva, A.N.R. (1997) Evolução urbana e acessibilidade - O caso das cidades médias brasileiras. In: CONGRESSO DE PESQUISA E ENSINO EM TRANSPORTES, 11, Rio de Janeiro, 1997. Anais. Rio de Janeiro, Associação Nacional de Pesquisa e Ensino em Transportes. Dissertações em andamento, p. 143-7.

Linneker, B.J. \& Spence, N.A. (1992) Accessibility measures compared in an analysis of the impact of the M25 London Orbital Motorway on Britain. Environment and planning. Part A, 24(8): 1137-54.

Logie, M. (1992) Network management using GIS. In: ANNUAL MEETING OF THE INSTITUTE OF TRANSPORTATION ENGINEERS, Washington, D.C., 1992. Compendium of Technical Papers. Washington, D.C., ITE. p. 437-41. 
Loureiro, C.F.G. \& Ralston, B. (1996) SIG como plataforma para modelos de análise de redes de transporte. In: CONGRESSO DE PESQUISA E ENSINO EM TRANSPORTES, 10, Brasília, 1996. Anais. Rio de Janeiro, Associação Nacional de Pesquisa e Ensino em Transportes, v.I, p. 235-44.

Love, D. \& Lindquist, P. (1995) The geographical accessibility of hospitals to the aged: a Geographic Information Systems analysis within Illinois. Health Services Research, 29(6): 629-52.

Mackiewicz, A. \& Ratajczak, W. (1996) Towards a new definition of topological accessibility. Transportation research: an international journal. Part B, Methodological, 30(1): 47-79.

Marques, H.N. (1998) Um sistema de informações para usuários de transporte coletivo em cidades de porte médio. Dissertação de Mestrado, Escola de Engenharia de São Carlos, Universidade de São Paulo.

Marques, H.N. \& Silva, A.N.R. (1997). Um sistema de informações para usuários de transporte coletivo em cidades de porte médio. In: CONGRESSO DE PESQUISA E ENSINO EM TRANSPORTES, 11, Rio de Janeiro, 1997. Anais. Rio de Janeiro, Associação Nacional de Pesquisa e Ensino em Transportes, v.I, p. 138-46.

Martin, D. \& Williams, H.C.W.L. (1992) Market-area analysis and accessibility to primary health-care centres. Environment and Planning A, 24(7): 1009-19.

Martins, W.C. \& Iversson, G. (1993) Criação de uma base de dados georeferenciada para estudos de planejamento regional no Brasil. In: CONGRESSO NACIONAL DA ANPET, 7, São Paulo, 1993. Anais. São Paulo, Associação Nacional de Pesquisa e Ensino em Transportes. v. II, p. 617-25.

Martins, W.C.; Rosseto, C.F.; Iverson, G.B.; Adorni, M.F. (1995) Sistema computacional de controle operacional de transporte coletivo para a cidade de São Paulo. In: CONGRESSO NACIONAL DE TRANSPORTES PÚBLICOS, 10, São Paulo, 1995. Comunicações Técnicas. São Paulo, Associação Nacional de Transportes Públicos - ANTP. p. 422-8.

Martins, W.C.; Cunha, C.B.; Iversson, G.; Pontes, C. (1997) Metodologia para otimização de frota e redução de custos operacionais para serviços de ônibus fretados de transporte de funcionários. In: CONGRESSO NACIONAL DE TRANSPORTES PÚBLICOS, 11, Belo Horizonte - MG, 1997. Comunicações Técnicas. (Em disquetes) São Paulo, Associação Nacional de Transportes Públicos - ANTP.

Mascaró, J.L. (1979) Estudo dos custos de infra-estrutura em cidades de porte médio. Universidade de São Paulo, Faculdade de Arquitetura e Urbanismo. 5 v.

McCormack, E. \& Nyerges, T. (1997) What transportation modeling needs from a GIS: a conceptual framework. Transportation Planning and Technology, 21: 5-23.

Meirelles, A.A.C. (1997) O uso de SIG's no planejamento e gestão do transporte coletivo e trânsito de Belo Horizonte. In: CONGRESSO NACIONAL DE TRANSPORTES PÚBLICOS, 11, Belo Horizonte - MG, 1997. Comunicações Técnicas. (Em disquetes) São Paulo, Associação Nacional de Transportes Públicos - ANTP.

Miller, Harvey J. (1991) Modelling accessibility using space-time prism concepts within Geographical Information Systems. International Journal of Geographical Information Systems, 5(3): 287-301. 
Mitchel, A. (1997) Zeroing in. Redlands, California, Environmental Systems Research Institute.

Morlok, E.K. (1978) Introduction to transportation engineering and planning. New York, McGraw-Hill.

Morris, J.M.; Dumble, P.L.; Wigan M.R. (1979) Accessibility indicators for transport planning. Transportation Research. Part A, Policy and practice, 13(2): 91-109.

Næss, P.; Sandberg, S.L.; Røe, P.G. (1996) Energy Use for Transportation in 22 Nordic Towns. Scandinavian Housing \& Planning Research. 13: 79-97.

Nassi, C.D.; Santos, M.P.S.; Bodmer, M.; Orrico Filho; R.D.; Gava. R.M. (1994) Adaptação gráfica de uma base cartográfica de um município voltada para os problemas de transporte público. In: CONGRESSO NACIONAL DA ANPET, 8, Recife, 1994. Anais. São Paulo, Associação Nacional de Pesquisa e Ensino em Transportes. v. I, p. 541-50.

Nassi, C.D.; Santos, M.P.S.; Bodmer, M.; Orrico Filho; R.D.; Moraes, A.C.P.; Lins, F.J.P.; Moreira, D.C.; Gava. R.M. (1994) Aplicações da computação gráfica no setor de transportes. In: CONGRESO LATINOAMERICANO DE TRANSPORTE PÚBLICO Y URBANO, 7, Buenos Aires - Argentina, 1994. Memorias. Buenos Aires, Ministerio de Economia y Obras y Servicios Públicos/CNTA/Municipalidad de la Ciudad de Buenos Aires. p. 343-55.

Nassi, C.D.; Santos, M.P.S.; Bodmer, M.; Orrico Filho; R.D.; Campos, F.C.; Guedes, E.P.; Silva, A.J.B.F; Gava. R.M. (1995) Planejamento e operação de transporte público urbano feito através de uma ferramenta de tratamento de imagens e de banco de dados convencionais. In: CONGRESSO NACIONAL DE TRANSPORTES PÚBLICOS, 10, São Paulo, 1995. Comunicações Técnicas. São Paulo, Associação Nacional de Transportes Públicos-ANTP. p. 395-402.

Nassi, C.D.; Santos, M.P.S. et al. (1996) A experiência brasileira no uso de Sistemas de Informação Geográfica aplicados ao sistema de transporte público urbano: O Caso do município do Rio de Janeiro. In: CONGRESO LATINOAMERICANO DE TRANSPORTE PÚBLICO Y URBANO, 8, Curitiba, 1996. Memorias. (Em disquetes) ANTP/Urbanização de Curitiba S.A. - URBS.

Newman, Peter W. G. \& Kenworthy, Jeffrey R. (1989) Cities and automobile dependence: An international sourcebook. Aldershot, England, Gower.

Newman, P.; Kenworthy, J.; Vintila, P. (1995) Can we overcome automobile dependence? Physical planning in an age of urban cynicism. Cities. 12(1): 53-65.

Nicolini, J.L. (1998) Transportation in new urban areas: the case of Puerto Madero in Buenos Aires, apresentado na $8^{\text {th }}$ World Conference on Transport Research, Antuérpia Bélgica, 1998. Book of Abstracts. Antuérpia, Universeit Antwerpen, p. 263.

Nilda, C. \& Abriani, A.D. (1994) Sistemas de Información Geográfica en la planificación del transporte. In: CONGRESO LATINOAMERICANO DE TRANSPORTE PÚBLICO Y URBANO, 7, Buenos Aires - Argentina, 1994. Memorias. Buenos Aires, Ministerio de Economia y Obras y Servicios Públicos/CNTA/Municipalidad de la Ciudad de Buenos Aires. p. 311-22.

Niemeier, D.A. \& Beard, M.K. (1993) GIS and transportation planning: a case study. Computers, Environment, and Urban Systems. p. 31-43. 
Nigriello, A. (1977) O valor do solo e sua relação com a acessibilidade. Dissertação de Mestrado, Faculdade de Economia e Administração, Universidade Federal do Rio de Janeiro.

Novaes, A.G. \& Rosseto, C.F. (1993) Localização de depósitos numa rede logística com o auxílio de GIS. In: CONGRESSO NACIONAL DA ANPET, 7, São Paulo, 1993. Anais. São Paulo, Associação Nacional de Pesquisa e Ensino em Transportes. v. II, p. 605-16.

Novaes, A.G. (1995) Aproximações em redes logísticas com o auxílio de SIG. In: CONGRESSO DE PESQUISA E ENSINO EM TRANSPORTES, 9, São Carlos, 1995. Anais. São Paulo, Associação Nacional de Ensino e Pesquisa em Transportes. v. III, p. 1161-72.

Oda, S. (1995) Caracterização de uma rede municipal de estradas não-pavimentadas. Dissertação de Mestrado, Escola de Engenharia de São Carlos, Universidade de São Paulo.

Oliveira, M.G.S. \& Ribeiro, P.C.M. (1997) Aplicações de Sistemas de Informações Geográficas em coordenação semafórica. In: CONGRESSO DE PESQUISA E ENSINO EM TRANSPORTES, 11, Rio de Janeiro, 1997. Anais. Rio de Janeiro, Associação Nacional de Pesquisa e Ensino em Transportes, v.I, p. 113-25.

Oppong, J.R. \& Hodgson, M.J. (1994) Spatial accessibility to health care facilities in Suhum District, Ghana. Professional Geographer, 46(2): 199-209.

Ortiz, R.V.O. \& Nassi, C.D. (1998) Los Sistemas de Información Geográfica en Transporte. $\mathrm{Su}$ uso en Rio de Janeiro y Caracas. In: CONGRESO LATINOAMERICANO DEL TRANSPORTE PUBLICO Y URBANO, 9, Guadalajara, Jalisco - México, 1998. Memorias (em CD-ROM). Guadalajara, CLATPU.

Ortúzar, J.D. \& Willumsen, L.G. (1994) Modelling Transport. Chichester, England, John Wiley \& Sons.

Paiva, J.A.C. (1997) School bus routing. In: SIMPÓSIO BRASILEIRO DE GEOPROCESSAMENTO, 4, São Paulo, 1997. Anais. São Paulo, Instituto de Desenvolvimento de Eventos em Tecnologia da Informação - IDETI. p. 228-41.

Pirie, G.H. (1979) Measuring accessibility: a review and proposal. Environment and Planning A, 11(3): 299-312.

Pooler, J.A. (1995) The use of spatial separation in the measurement of transportation accessibility. Transportation Research. Part A, Policy and practice, 29(6): 421-8.

Paredes, E.A. (1994) Sistema de Informação Geográfica (SIG) - Princípios e Aplicações (Geoprocessamento). São Paulo, Érica.

Pantigoso, J.F. (1998) Uso dos Sistemas de Informação Geográfica para a integração de gerência de pavimentos urbanos com as atividades das concessionárias de serviços públicos. Dissertação de Mestrado, Escola de Engenharia de São Carlos, Universidade de São Paulo.

Penteado, S.R. (1994) Uma proposta para determinação de prioridades em transportes e infra-estrutura de pequenos municípios - $O$ caso de Jaguariúna - SP. Dissertação de Mestrado, Escola de Engenharia de São Carlos, Universidade de São Paulo.

Pinto, A.B. \& Lindau, L.A. (1997). Cadastros de linhas de ônibus utilizando Sistemas de Informação Geográfica e GPS. In: CONGRESSO DE PESQUISA E ENSINO EM 
TRANSPORTES, 11, Rio de Janeiro, 1997. Anais. Rio de Janeiro, Associação Nacional de Pesquisa e Ensino em Transportes, v.I, p. 126-37.

Pimentel, F.L \& Salgado, A.C. (1994) Uma visão sobre SIG. In: CONGRESSO NACIONAL DA ANPET, 8, Recife, 1994. Anais. São Paulo, Associação Nacional de Pesquisa e Ensino em Transportes. v. I, p. 517-28.

Putman, S.H. (1983) Integrated urban models. London, Pion.

Raia Jr., A.A. \& Silva, A.N.R. (1995) Uma avaliação do modelo META para cálculo de custos de transportes. In: CONGRESSO DE PESQUISA E ENSINO EM TRANSPORTES, 9, São Carlos, 1995. Anais. São Paulo, Associação Nacional de Ensino e Pesquisa em Transportes. v. I, p. 272-83.

Raia Jr., A.A. (1995) Uma avaliação do modelo META para cálculo dos custos de transportes e seu uso na tributação de terrenos urbanos ociosos. Dissertação de Mestrado, Escola de Engenharia de São Carlos, Universidade de São Paulo.

Raia Jr., A.A. \& Silva, A.N.R. (1996a) Relação acessibilidade-preço de terrenos com o uso de um SIG. In: CONGRESSO TÉCNICO-CIENTÍFICO DE ENGENHARIA CIVIL, Florianópolis, 1996. Anais. Departamento de Engenharia Civil - UFSC, v.III, p. 338-48.

Raia Jr., A.A. \& Silva, A.N.R. (1996b) Utilizando um SIG para avaliar níveis de acessibilidade em uma cidade média. In: CONGRESSO BRASILEIRO DE CADASTRO TÉCNICO MULTIFINALITÁRIO, 2, Florianópolis, 1996. Anais. Tomo III, p. 193-204.

Raia Jr., A.A. \& Silva, A.N.R. (1997) A influência do adensamento das cidades nos custos do transporte público urbano. In: CONGRESSO NACIONAL DE TRANSPORTES PÚBLICOS, 11, Belo Horizonte - MG, 1997. Comunicações Técnicas. (Em disquetes) São Paulo, Associação Nacional de Transportes Públicos - ANTP.

Raia Jr., A.A.; Silva, A.N.R.; Lima, R.S. (1996) Acessibilidade e valor de terrenos urbanos $O$ caso da cidade de Araraquara. In: CONGRESO LATINOAMERICANO DE TRANSPORTE PÚBLICO Y URBANO, 8, Curitiba, 1996. Memorias. (Em disquetes) ANTP/Urbanização de Curitiba S.A. - URBS.

Raia Jr., A.A.; Silva, A.N.R.; Brondino, N.C.M. (1997a) Comparação entre medidas de acessibilidade para aplicação em cidades brasileiras de porte médio. In: CONGRESSO DE PESQUISA E ENSINO EM TRANSPORTES, 11, Rio de Janeiro, 1997. Anais. Rio de Janeiro, Associação Nacional de Pesquisa e Ensino em Transportes. v.II, p. 997-1008.

Raia Jr., A.A.; Silva, A.N.R.; Milhin, M. (1997b) Impactos provocados pelo espalhamento urbano no custo das redes públicas de transportes e infra-estrutura utilizando Sistemas de Informações Geográficas In: SIMPÓSIO BRASILEIRO DE GEOPROCESSAMENTO, 4, São Paulo, 1997. Anais. São Paulo, Instituto de Desenvolvimento de Eventos em Tecnologia da Informação - IDETI. p. 522-32.

Regional Plan Association. (1976) Where transit works: urban densities for public transportation. Regional Plan News 99. New York. 23p.

Richardson, A.J. \& Young, W. (1982) A measure of linked-trip accessibility. Transportation Planning and Technology, 7(2): 73-82.

Rocha, E.A. (1996) Reavaliação das áreas de distribuição de jornais: uma solução utilizando geoprocessamento. In: GIS BRASIL, II, Curitiba, 1996. Anais. Curitiba, Editora Sagres. p. 401-10. 
Rodrigues, M. (1990) Introdução ao Geoprocessamento. In: SIMPÓSIO BRASILEIRO DE GEOPROCESSAMENTO, 1, São Paulo - SP, 1990. São Paulo, Escola Politécnica da Universidade de São Paulo. p. 1-26.

Roehl, W.S.; Fesenmaier, J.; Fesenmaier, D.R. (1995) Highway accessibility and regional tourist expenditures. Journal of Travel Research, 31(3): 58-63.

Rosa, R. \& Brito, J.L.S. (1996) Introdução ao Geoprocessamento: Sistema de Informação Geográfica. Uberlândia, Universidade Federal de Uberlândia.

Rosseto, C.F. \& Cunha, C.B. (1997) A aplicação do geoprocessamento na roteirização de veículos. In: GIS BRASIL, 1, Curitiba, 1997. Anais. Curitiba, Editora Sagres. p. 35-44.

Rosseto, C.F.; Rosseto, M.F.A.; Guimarães, P.C.; Martins, W.C. (1997) Sistema Autobus Sistema integrado de informações de apoio à gestão de transportes coletivos. In: CONGRESSO NACIONAL DE TRANSPORTES PÚBLICOS, 11, Belo Horizonte - MG, 1997. Comunicações Técnicas. (Em disquetes) São Paulo, Associação Nacional de Transportes Públicos - ANTP.

Salles Filho, L.H. (1996) O Uso de Indicadores de Accessibilidade na Avaliação de Redes Estruturais de Transporte Urbano. Tese de Doutorado, PET-COPPE, Universidade Federal do Rio de Janeiro.

Salles Filho, L.H. (1997). Indicadores de acessibilidade: alguns aprimoramentos análiticos e seu uso na avaliação de redes estruturais de transporte urbano. In: CONGRESSO DE PESQUISA E ENSINO EM TRANSPORTES, 11, Rio de Janeiro, 1997. Anais. Rio de Janeiro, Associação Nacional de Pesquisa e Ensino em Transportes, v.II, p. 985-96.

Salles Filho, L.H. (1998) The accessibility matrix - A new approach for evaluating urban transportation networks, apresentado na $8^{\text {th }}$ World Conference on Transport Research, Antuérpia - Bélgica, 1998. Book of Abstracts. Antuérpia, Universeit Antwerpen, p. 201.

Sanches, S.P. (1988) Contribuição à análise operacional de redes de transporte coletivo em cidades de porte médio. Tese de Doutorado, Escola de Engenharia de São Carlos Universidade de São Paulo.

Sanches, S.P. (1996) Acessibilidade: um indicador de desempenho dos sistemas de transporte nas cidades. In: CONGRESSO DE PESQUISA E ENSINO EM TRANSPORTES, 10, Brasília, 1996. Anais. Rio de Janeiro, Associação Nacional de Pesquisa e Ensino em Transportes, v.I, p. 199-208.

Sanches, S.P. (1997) Definição de zonas de tráfego, a partir de setores censitários, usando um SIG. In: CONGRESSO DE PESQUISA E ENSINO EM TRANSPORTES, 11, Rio de Janeiro, 1997. Anais. Rio de Janeiro, Associação Nacional de Pesquisa e Ensino em Transportes, v.I, p. 103-12.

Santos, E.E. \& Aguiar, E.M. (1996a) Elaboração de rotas para caminhões numa cidade de porte médio. In: CONGRESSO DE PESQUISA E ENSINO EM TRANSPORTES, 10, Brasília, 1996. Anais. Rio de Janeiro, Associação Nacional de Pesquisa e Ensino em Transportes, Dissertações em andamento, p. 37-40.

Santos, R.M. \& Aguiar, E.M. (1996b) Localização de usinas de lixo para grupos de cidades formados através da utilização de ferramentas logísticas e restrições de fatores ambientais. In: CONGRESSO DE PESQUISA E ENSINO EM TRANSPORTES, 10, Brasília, 1996. Anais. Rio de Janeiro, Associação Nacional de Pesquisa e Ensino em Transportes, Dissertações em andamento, p. 65-8. 
Schneider, F. F. (1994) Cadastro Técnico Multifinalitário e o sistema tributário. In: CONGRESSO BRASILEIRO DE CADASTRO TÉCNICO MULTIFINALITÁRIO, 1, Florianópolis, 1994.

Shimble, A. (1953) Structural parameters of communication networks. Bulletin of Mathematical Biophysics. 15, 501-7.

Silva, A.N.R. (1990) Densidades urbanas econômicas: a influência do transporte público. Dissertação de Mestrado, Escola de Engenharia de São Carlos, Universidade de São Paulo.

Silva, A.N.R. (1992) Visita técnica ao Wisconsin DoT - Department of Transportation. Gravação em vídeo (VHS). 60 minutos.

Silva, A.N.R. (1993) O custo do solo urbano ocioso e uma nova sistemática de tributação da propriedade. Tese de Doutorado, Escola de Engenharia de São Carlos, Universidade de São Paulo.

Silva, A.N.R. \& Ferraz, A.C.P. (1991) Densidades urbanas x custo dos serviços públicos e análise do caso de São Carlos. Revista de Administração Municipal, Rio de Janeiro, 38(199): 57-65.

Silva, A.N.R. \& Ferraz, A.C.P. (1993) Uma nova sistemática de tributação da propriedade urbana. Revista de Administração Municipal, Rio de Janeiro, 40(208): 51-61.

Silva, A.N.R. \& Kawamoto, E. (1995) Using GIS to improve urban public transportation - A case study in a developing country. Artigo apresentado na $7^{\text {th }}$ World Conference on Transport Research, Sydney - Australia. Book of Abstracts. Sydney, The University of New South Wales, p. 5.4.

Silva, A.N.R.; Lima, R.S.; Melo, J.J.O. (1997a) Introduzindo os Sistemas de Informações Geográficas no ensino de Engenharia de Transportes. In: CONGRESSO DE PESQUISA E ENSINO EM TRANSPORTES, 11, Rio de Janeiro, 1997. Anais. Rio de Janeiro, Associação Nacional de Pesquisa e Ensino em Transportes, v.II, p. 685-91.

Silva, A.N.R.; Lima, R.S.; Raia Jr., A.A. (1995) Utilizando um Sistema de Informação Geográfica para estimar viagens em uma cidade de porte médio. In: CONGRESSO DE PESQUISA E ENSINO EM TRANSPORTES, 9, São Carlos, 1995. Anais. São Paulo, Associação Nacional de Ensino e Pesquisa em Transportes. v.III, p. 1173-83.

Silva, A.N.R.; Lima, R.S.; Raia Jr., A.A. (1996a) Obtenção de dados básicos para planejamento de transportes em cidades médias com o auxílio de um SIG. In: GIS BRASIL, II, Curitiba, 1996. Anais. Curitiba, Editora Sagres. p. 392-400.

Silva, A.N.R.; Lima, R.S.; Raia Jr., A.A.; Waerden, P. van der. (1998) Urban transportation accessibility and social inequity in a developing country. Aceito para a $8^{\text {th }}$ CODATU World Conference of the Co-Operation for the Continuing Development of Urban and Suburban Transportation, a ser realizada de 21 a 25 de setembro de 1998, na Cidade do Cabo - África do Sul.

Silva, A.N.R.; Lotti, C.P.; Margarido, S.A; Pampolha, V.M.P. (1996b) Quem não tem TIGER... Fator GIS, 4(14): 18-19.

Silva, A.N.R. \& Marques, H.N. (1998) Um Sistema de Informações Geográficas a serviço dos usuários de transporte público urbano. In: CONGRESO LATINOAMERICANO DEL TRANSPORTE PUBLICO Y URBANO, 9, Guadalajara, Jalisco - México, 1998. Memorias (em CD-ROM). Guadalajara, CLATPU, 1998. 
Silva, A.N.R.; Mendes Filho, J.T.; Raia Jr., A.A. (1995) Using GIS to evaluate the impacts of urban growth on the transit system of a Brazilian medium-sized city. In: INTERNATIONAL CONFERENCE ON COMPUTERS IN URBAN PLANNING AND URBAN MANAGEMENT, 4, Melbourne - Australia. Proceedings. Melbourne, The University of Melbourne/CSIRO/Australian Housing and Urban Research Institute. p. 25566.

Silva, A.N.R.; Melo, J.J.O.; Brondino, N.C.M. (1997a) Uma Introdução ao Planejamento de Transportes com Sistemas de Informação Geográfica. São Carlos, Escola de Engenharia de São Carlos - Universidade de São Paulo.

Silva, A.N.R. \& Motta, S.H.S. (1995) Avaliação do desempenho de um sistema de transporte público urbano com o auxílio de um software para Sistemas de Informação Geográfica. In: CONGRESSO DE PESQUISA E ENSINO EM TRANSPORTES, 9, São Carlos, 1995. Anais. São Paulo, Associação Nacional de Ensino e Pesquisa em Transportes. v.III, p. 1154-60.

Silva, A.N.R. \& Penteado, S.R. (1995) Planejamento da oferta de redes de infra-estrutura em pequenos municípios. Revista de Administração Municipal, Rio de Janeiro, 42(217): 2945.

Silva, A.N.R. \& Silva, A.L.M. (1997) Caracterização espacial da população rastreada. In: Panico, S.R.G. (ed.) Subsídios para políticas municipais de saúde. São Carlos, NIPE Núcleo Interdisciplinar de Pesquisa e Ensino.

Silva, A.N.R.; Vargas, E.N.Z.; Ito, L.E.; Cubas, S.I.B. (1994) O cadastro dos terrenos ociosos e a sua importância para uma tributação mais justa da propriedade urbana. In: CONGRESSO BRASILEIRO DE CADASTRO TÉCNICO MULTIFINALITÁRIO, 1, Florianópolis, 1994. Anais. Florianópolis. Tomo III, p. 118-126.

Silva, A.N.R.; Vargas, E.N.Z.; Ito, L.E.; Cubas, S.I.B. (1994) O uso de Sistemas de Informação Geográfica no planejamento e reestruturação de sistemas de transporte público urbano. In: CONGRESO LATINOAMERICANO DE TRANSPORTE PÚBLICO Y URBANO, 7, Buenos Aires - Argentina, 1994. Memorias. Buenos Aires, Ministerio de Economia y Obras y Servicios Públicos/CNTA/Municipalidad de la Ciudad de Buenos Aires. p. 333-42.

Silva, A.N.R. \& Waerden, P. van der. (1997a) First Steps with a Geographic Information System for Transportation. Ribeirão Preto, São Francisco Ed.

Silva, A.N.R. \& Waerden, P. van der. (1997b) Supporting education in transportation planning with a GIS-T student-friendly training tool. In: GIS BRASIL, 3, Curitiba, 1997. Anais. (em CD-ROM) Curitiba, Editora Sagres.

Silva, A.N.R. \& Waerden, P. van der. (1997c) Combining Simplified Models and GIS to Estimate Urban Costs in Developing Countries. In: INTERNATIONAL CONFERENCE ON COMPUTERS IN URBAN PLANNING AND URBAN MANAGEMENT, 5, Mumbai - India. Proceedings Mumbai, Narosa Publishing House I. p. 85-96.

Silva, A.N.R.; Waerden, P. van der; Timmermans, H. (1998) Measuring intra-urban accessibility in developing countries, apresentado na $8^{\text {th }}$ World Conference on Transport Research, Antuérpia - Bélgica, 1998. Book of Abstracts. Universeit Antwerpen, p. 265.

Silva, H.A. \& Grubman, S. (1996) A aplicação de geoprocessamento na distribuição de jornais In: GIS BRASIL, II, Curitiba, 1996. Anais. Curitiba, Editora Sagres. p. 373-5. 
Silva, M.P.; Almeida, C.L.T.; Rubira, J.A.C.; Braglia, J.M. (1997d) O processo de implantação de um Sistema de Informações Geográficas no planejamento do transporte integrado ao Metrô/SP. In: GIS BRASIL, 3, Curitiba, 1997. Anais. (em CD-ROM) Curitiba, Editora Sagres.

Siegfried, R.H; Vaidya, N.; Avila, S.J.; Mccasland, W.; Levine, S. (1992) Incident management using Geographic Information Systems. In: ANNUAL MEETING OF THE INSTITUTE OF TRANSPORTATION ENGINEERS, WASHINGTON, D.C., 1992. Compendium of Technical Papers. Washington, D.C., ITE. p. 433-43.

Simkowitz, H.J. (1989) GIS: Technology for Transportation. Civil Engineering. p. 72-5.

Simkowitz, H.J. (1990) Integrating Geographic Information System Technology and Transport Models. Transportation Research Record. 1271. p. 44-7.

Sinay, M.C.F. \& Lima Jr., P.C.R. (1998) SIG na avaliação dos impactos ambientais de projetos de transporte público. In: CONGRESO LATINOAMERICANO DEL TRANSPORTE PUBLICO Y URBANO, 9, Guadalajara, Jalisco - México, 1998. Memorias (em CD-ROM). Guadalajara, CLATPU, 1998.

Siqueira, C.A.B. \& Cassundé, M.I.V. (1994) O geoprocessamento como instrumento de gestão de transporte coletivo na EMTU/Recife. In: CONGRESSO NACIONAL DA ANPET, 8, Recife, 1994. Anais. São Paulo, Associação Nacional de Pesquisa e Ensino em Transportes. v.I, p. 551-6.

Smeed, R.J. (1967) The road capacity of city centers. Highway Research Record, 169, Washington D.C. p. 22-9.

Stokes, R.W. \& Marucci, G. (1995) GIS for Transportation: Current practices, problems and prospects. ITE Journal, Washington, D.C., 66(3): 28-37.

Sosslau, A.B. et al. (1978) Quick-response urban travel estimation techniques and transferable parameters-User's guide. Transportation Research Board, Washington, D.C., NCHRP Report 187.

Spring, G.S. (1992) Using GIS for traffic control inventory management. In: ANNUAL MEETING OF THE INSTITUTE OF TRANSPORTATION ENGINEERS, Washington, D.C., 1992. Compendium of Technical Papers. Washington, D.C., ITE. p. 430-2.

Sung, J. (1992) Transit route level planning and analysis using Geographic Information Systems as a decision support tool. Dissertação de Mestrado em Engenharia Civil e Ambiental, University of Wisconsin-Madison, USA.

Taco, P.W.G.; Yamashita, Y; Souza, N.M. (1996) Definição de setores agregados homogêneos (SAH) usando sensoriamento remoto para a análise de zonas de tráfego. In: CONGRESSO DE PESQUISA E ENSINO EM TRANSPORTES, 10, Brasília, 1996. Anais. Rio de Janeiro, Associação Nacional de Pesquisa e Ensino em Transportes, v.I, p. 223-34.

Taco, P.W.G.; Yamashita, Y.; Souza, N.M.; Dantas, A.S. (1997). Modelo de geração de viagens com aplicação do sensoreamento remoto e dos Sistemas de Informação Geográfica. In: CONGRESSO DE PESQUISA E ENSINO EM TRANSPORTES, 11, Rio de Janeiro, 1997. Anais. Rio de Janeiro, Associação Nacional de Pesquisa e Ensino em Transportes, v.I, p. 253-64. 
Tagore, M.R. \& Sikdar, P.K. (1995) A new accessibility measure accounting mobility parameters. Artigo apresentado na $7^{\text {th }}$ World Conference on Transport Research, Sydney Australia. Book of Abstracts. Sydney, The University of New South Wales, p. 10.7.

Teixeira, A.L.A; Moretti, E.; Christofoletti, A. (1992) Introdução aos Sistemas de Informação Geográfica. Rio Claro, Edição do autor.

Tesima, R.S. \& Lapolli, E.M. (1996) Localização de pontos de parada de ônibus. In: GIS BRASIL, II, Curitiba, 1996. Anais. Curitiba, Editora Sagres. p. 869-79.

Vial, E. (1991) Un caso de implementación de SIG aplicado a la planificación urbana: la National Capital Planning Comission in Washington D.C. In: CONFERENCIA LATINOAMERICANA SOBRE SISTEMAS DE INFORMACIÓN GEOGRÁFICO, 3, Pontificia Universidad Católica de Chile. Proceedings. Viña del Mar, Chile. v. 1, p. 31426.

Vickerman, R.W. (1974) Accessibility, attraction, and potential: a review of some concepts and their use in determining mobility. Environment and Planning A, 6(6): 675-91.

Viviani, E. (1998) A utilização de um Sistema de Informação Geográfica como auxílio à gerência de manutenção de estradas rurais não-pavimentadas. Tese de Doutorado, Escola de Engenharia de São Carlos, Universidade de São Paulo.

Viviani, E.; Silva, A.N.R; Zainaghi, G. (1995) Análise do processo de conversão de dados entre os softwares AutoCAD e TransCAD. In: CONGRESSO BRASILEIRO DE CARTOGRAFIA, 17, Salvador, 1995. Volume V, Anais. Rio de Janeiro, Sociedade Brasileira de Cartografia.

Viviani, E.; Silva, A.N.R.; Sória, M.H.A. (1998) Maintenance management of rural roads in a developing country, apresentado na $8^{\text {th }}$ World Conference on Transport Research, Antuérpia - Bélgica, 1998. Book of Abstracts. Universeit Antwerpen, p. 271.

Viviani, E.; Sória; M.H.A.; Silva, A.N.R. (1994) Gerenciamento de vias não pavimentadas e a utilização de Sistemas de Informação Geográfica. In: CONGRESSO BRASILEIRO DE CADASTRO TÉCNICO MULTIFINALITÁRIO, 1, Florianópolis, 1994. Anais. Florianópolis. Tomo II, p. 118-126.

Viviani, E. \& Sória, M.H.A. (1995) Aplicação de um SIG no desenvolvimento de sistema de gerência de vias não-pavimentadas. In: CONGRESSO DE PESQUISA E ENSINO EM TRANSPORTES, 9, São Carlos, 1995. Anais. São Paulo, Associação Nacional de Ensino e Pesquisa em Transportes. v.III, p. 1148-53.

Vonderohe, A.P.; Travis, L.; Smith, R. (1991) Implementation of Geographic Information Systems (GIS) in State DOTs. National Cooperative Highways Research Program. 180: $1-32$.

Wachs, M. \& Koenig, J.G. (1978) Behavioural modelling, accessibility, mobility and travel need. In: Hensher, D. \& Stopher, P.R. (eds) Behavioural Travel Modelling, Croom Helm, London. p. 698-710.

Waerden, P. van der \& Timmermans, H. (1995) Transportation planning and the use of TransCAD. Artigo apresentado no Workshop sobre GIS-T realizado no IX Congresso de Pesquisa e Ensino em Transportes, São Carlos.

Waerden, P. van der. \& Silva, A.N.R. (1997) Evaluation of a Student-Friendly GIS Training Tool, apresentado no $3^{\text {rd }}$ International Symposium on GIS in Higher Education, Chantilly, 
Virginia - USA, promovido pelo NCGIA - National Center for Geographic Information and Analysis e pela Towson State University. Resumo em http://www.ncgia.ucsb.edu/gishe/program_files/ncgia.html.

Weibull, J.W. (1980) On the numerical measurement of accessibility. Environment and Planning A, 12(1): 53-67.

Wright, P.H. \& Ashford, N.J. (1989) Transportation engineering: planning and design. 3.ed. New York, John Wiley \& Sons.

Zuppo, C.A.; Davis Jr., C.A.; Meirelles, A.A.C. (1996) Geoprocessamento no sistema de transporte e trânsito de Belo Horizonte. In: GIS BRASIL, II, Curitiba, 1996. Anais. Curitiba, Editora Sagres. p. 376-87. 